UNIVERSIDADE DE SÃO PAULO

ESCOLA DE EDUCAÇÃO FÍSICA E ESPORTE

CONTROLE DE MOVIMENTOS RÁPIDOS E PRECISOS

DIRECIONADOS A ALVOS ESPACIAIS

Victor Hugo Alves Okazaki

SÃO PAULO

2009 


\title{
CONTROLE DE MOVIMENTOS RÁPIDOS E PRECISOS DIRECIONADOS A ALVOS ESPACIAIS
}

\section{VICTOR HUGO ALVES OKAZAKI}

\author{
Tese apresentada à Escola de \\ Educação Física e Esporte da \\ Universidade de São Paulo, como \\ requisito parcial para obtenção do \\ grau de Doutor em Educação Física.
}





\section{AGRADECIMENTOS}

Agradeço a Deus pela força e entendimento concedidos para realizar esta tese...

Agradeço minha família NELSON, ALMIRA, FÁBIO, CARLOS e CAROL, pelo amor, apoio e incentivo incondicionais... AMO VCS...!!!

Agradeço meus amigos: Hurzo, Wesley \& Auzira, Meira \& Mari, Nog \& Amalia, Suco, San \& Si, Markitos, Soninha \& Alcemir, Tan-Tan, Deni, Mariah, Kakau, Jemima, Tia Bruna, Mazzuco, KZ, BA, Jeffer, Gersinho, R.Lopes, P.Caçola, Naná, Paulinho \& Estela, Spider, Quel, Mirian, Juliana-Jones, Ozéias, Marta, Mota, Qzia, Scaff, Luizinho, Edgard, Mayra, Will, Willow \& Diamante Negro... a todos, e muitos outros não aqui mencionados, meus sinceros agradecimentos...

Agradeço pelo apoio, pela parceria e pelas longas horas de trabalho em conjunto com os membros do laboratório Sistemas Motores Humanos - USP: Andrea, Babo, Cândida, Carla, Elke, João, Juliana, Leandro, Raymundo e Tatiana...

Agradeço ao prof. Dr. Luis A. Teixeira por me acolher para o doutorado e para trabalhar em seu laboratório sempre com grande incentivo, apoio, dedicação e zelo...

Agradeço aos professores. Dr. André L.F. Rodacki, Dr. Iverson Ladewig, Dr. Ricardo Coelho e prof. Roberto Cavagnari, por sempre me incentivarem em minha formação...

Agradeço aos meus professores de graduação (UFPR), especialização (UFPR \& Dom Bosco), mestrado (UFPR) e doutorado (USP) pela contribuição em minha formação...

Agradeço ao professor Dr. Marcos Duarte por ceder o sistema Qualysis de cinemática para o realizar deste estudo e aos professores Dr. Luis Mochizuki e Dr. Carlos Ugrinowitsch pelo apoio e incentivo durante meu doutoramento...

Agradeço a CNPQ pela bolsa de estudo e a FAPESP pela bolsa para aquisição de sistema de cinemetria durante o período de realização desta tese...

E, mais uma vez, agradeço a Deus.... 
DEDICATÓRIA

Dedico este trabalho a JESUS CRISTO que deu sua vida como grande gesto de amor por todos nós!

A Ele toda a honra, a glória, o domínio, o Louvor, a adoração, a majestade e o poder para todo o sempre. 


\section{EPÍGRAFE}

"Respondeu-Ihe JESUS:

Não te disse $E U$ que, se creres, verás a glória de DEUS?"

João 11.40 
SUMÁRIO

Página

LISTA DE TABELAS ...................................................................... iv

LISTA DE FIGURAS.............................................................. vii

LISTA DE SIGLAS, ABREVIAÇÕES E SÍMBOLOS................................ viii

LISTA DE EQUAÇÕES................................................................ $\mathrm{x}$

LISTA DE ANEXOS.........................................................................

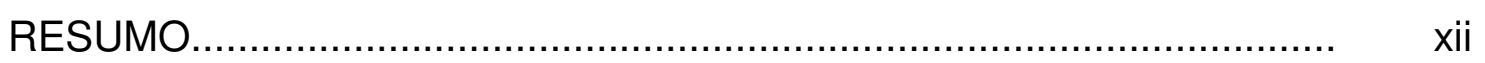

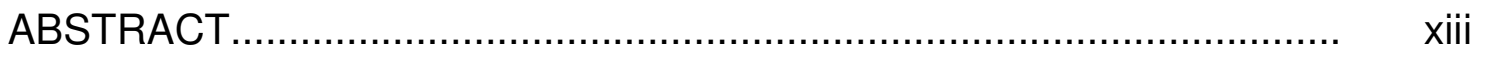

1 INTRODUÇÃO

1.1 Controle de movimentos rápidos e precisos............................................ 1

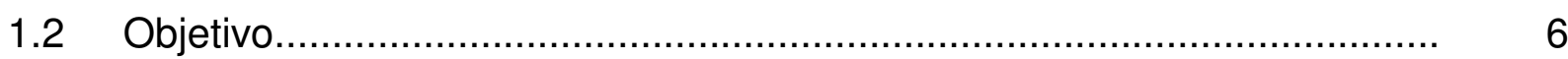

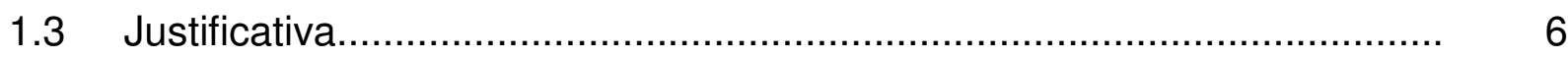

2 REVISÃO DA LITERATURA.............................................................. 7

2.1 Modelos de controle de movimentos rápidos e precisos........................... 7

2.1.1 Modelo da variabilidade do impulso......................................................... 7

2.1.2 Modelo da variabilidade do impulso simétrico.......................................... 12

2.1.3 Modelo estocástico de sub-movimentos otimizados................................. 17

2.1.4 Modelo de deslizamento da desaceleração.............................................. 23

2.1.5 Modelo da teoria cinemática............................................................ 27

2.1.6 Modelo da capacidade limitada de processar informações....................... 31

2.2 Movimentos rápidos e precisos dirigidos a alvos espaciais...................... 38

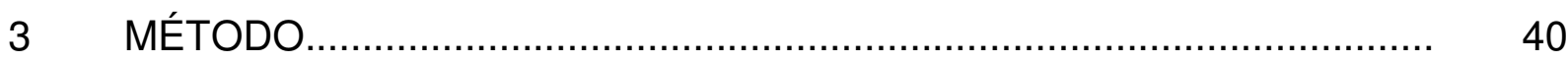

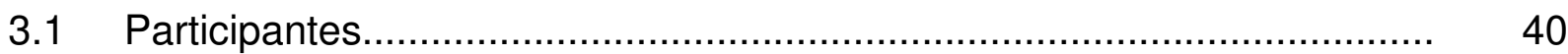

3.2 Instrumentos e tarefas............................................................... 40

3.3 Procedimentos experimentais.......................................................... 43 
3.4 Variáveis de estudo................................................................ 44

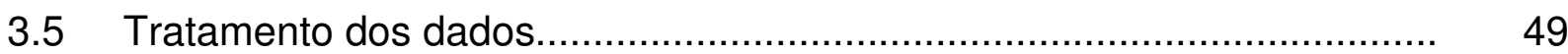

3.6 Análise estatística..................................................................... 50

4 EXPERIMENTO I: EFEITO DA DISTÂNCIA ..................................... 51

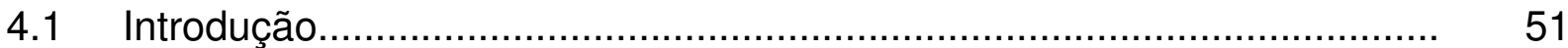

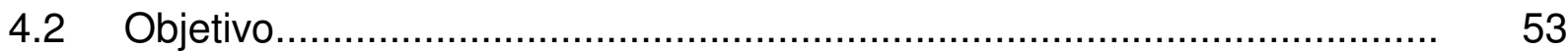

4.3 Hipóteses................................................................................ 54

4.4 Procedimentos particulares do método......................................... 55

4.5 Resultados........................................................................... 56

4.5.1 Variáveis lineares de resultado (disco) e de desempenho (manopla)....... 56

4.5.2 Variáveis angulares de desempenho (articulações)............................... 59

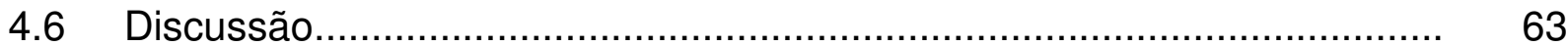

4.6.1 Variáveis lineares de resultado (disco) e de desempenho (manopla)....... 63

4.6.2 Variáveis angulares de desempenho (articulações) .............................. 69

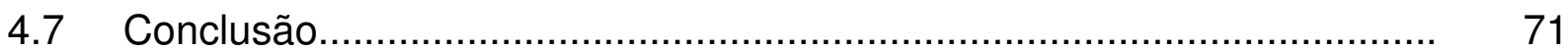

5 EXPERIMENTO II: EFEITO DA VELOCIDADE................................... 72

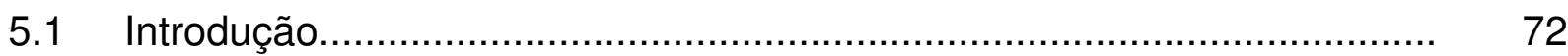

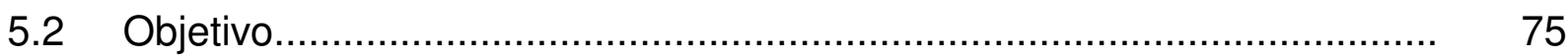

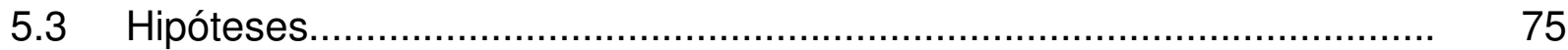

5.4 Procedimentos particulares do método................................................ 76

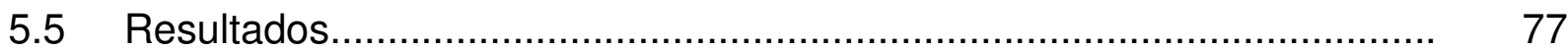

5.5.1 Variáveis lineares de resultado (disco) e de desempenho (manopla)....... 77

5.5.2 Variáveis angulares de desempenho (articulações)............................. 82

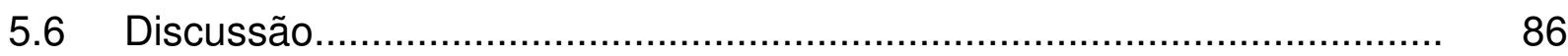

5.6.1 Variáveis lineares de resultado (disco) e de desempenho (manopla)....... 86

5.6.2 Variáveis angulares de desempenho (articulações)............................... 90

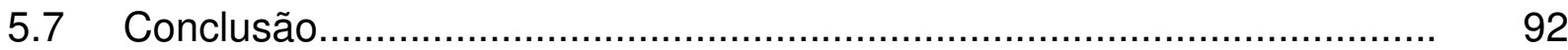

6 EXPERIMENTO III: EFEITO DO TAMANHO DO DISCO $\ldots \ldots \ldots \ldots \ldots \ldots \ldots \ldots . . . . . . . . . . . . .93$

6.1 Introdução............................................................................. 93

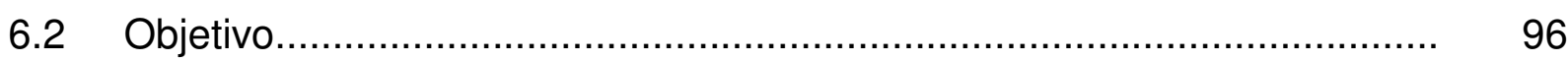

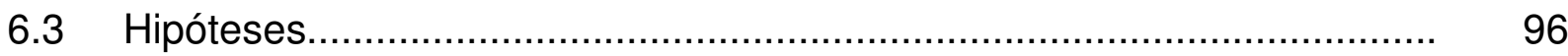


6.4 Procedimentos particulares do método........................................ 97

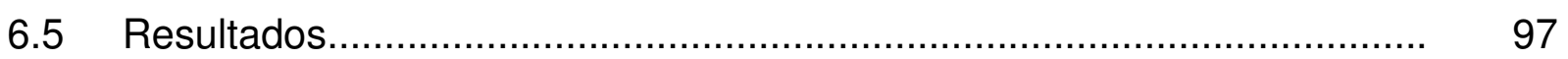

6.5.1 Variáveis lineares de resultado (disco) e de desempenho (manopla)....... 97

6.5.2 Variáveis angulares de desempenho (articulações).............................. 101

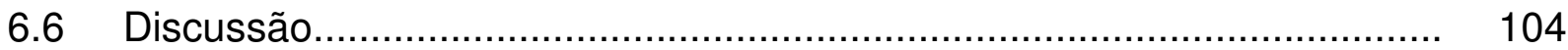

6.6.1 Variáveis lineares de resultado (disco) e de desempenho (manopla)....... 104

6.6.2 Variáveis angulares de desempenho (articulações)............................ 107



7 EXPERIMENTO IV: EFEITO DO TAMANHO DO ALVO......................... 109

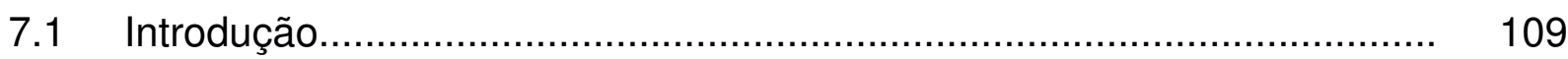

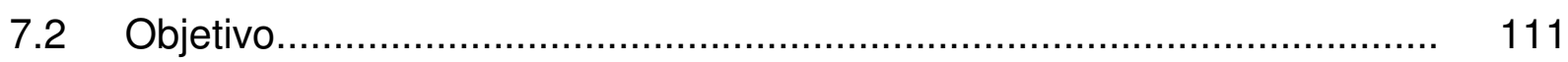



7.4 Procedimentos particulares do método................................................ 112

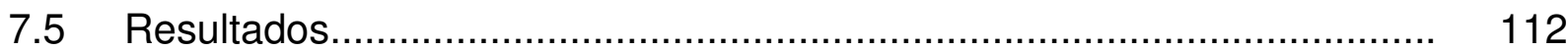

7.5.1 Variáveis lineares de resultado (disco) e de desempenho (manopla)....... 112

7.5.2 Variáveis angulares de desempenho (articulações).............................. 116

7.6 Discussão......................................................................... 119

7.6.1 Variáveis lineares de resultado (disco) e de desempenho (manopla)....... 119

7.6.2 Variáveis angulares de desempenho (articulações)............................... 121

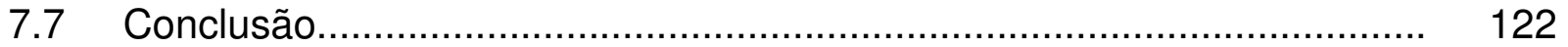

8 EXPERIMENTO V: EFEITO DA MASSA DA MANOPLA $\ldots \ldots \ldots \ldots \ldots \ldots \ldots \ldots \ldots \ldots \ldots \ldots \ldots$

8.1 Introdução............................................................................ 123

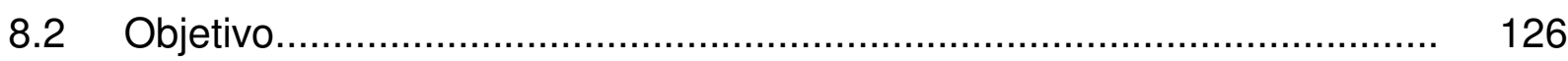

8.3 Hipóteses....................................................................... 126

8.4 Procedimentos particulares do método.............................................. 126

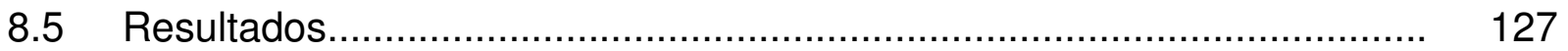

8.5.1 Variáveis lineares de resultado (disco) e de desempenho (manopla)....... 127

8.5.2 Variáveis angulares de desempenho (articulações)................................ 129

8.6 Discussão........................................................................... 132

8.6.1 Variáveis lineares de resultado (disco) e de desempenho (manopla)....... 132

8.6.2 Variáveis angulares de desempenho (articulações).............................. 134 


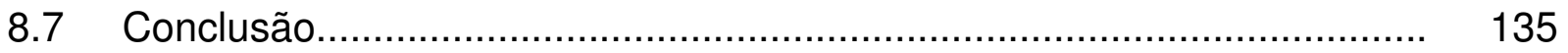

9 EXPERIMENTO VI: EFEITO DA MASSA DO DISCO.............................. 136

9.1 Introdução................................................................................. 136

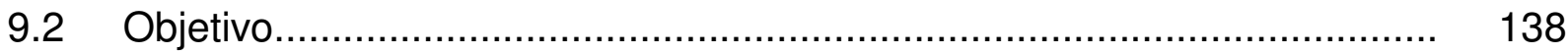

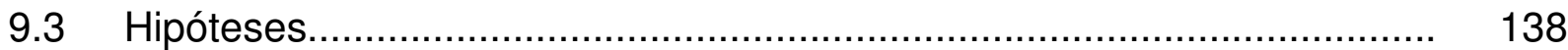

9.4 Procedimentos particulares do método.............................................. 139

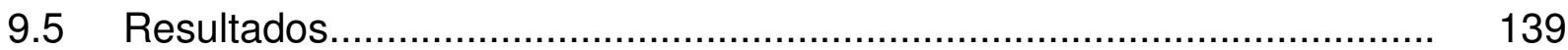

9.5.1 Variáveis lineares de resultado (disco) e de desempenho (manopla)...... 139

9.5.2 Variáveis angulares de desempenho (articulações)................................ 141

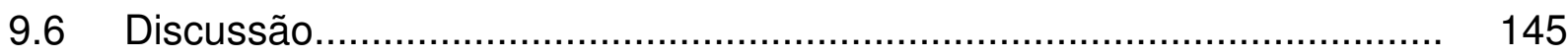

9.6.1 Variáveis lineares de resultado (disco) e de desempenho (manopla)...... 145

9.6.2 Variáveis angulares de desempenho (articulações)................................ 147

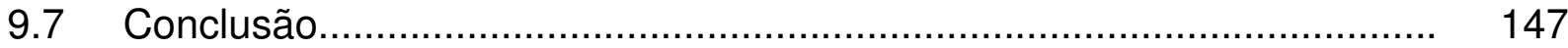



10.1 Estratégias de controle motor para regulação velocidade-precisão.......... 149

10.2 Análises de regressão linear: relação velocidade-precisão...................... 155

10.3 Desempenho das articulações no movimento.......................................... 157

11 CONCLUSÃO GERAL \& RECOMENDAÇÕES...................................... 160

11.1 Conclusão Geral............................................................................. 160

11.2 Recomendações................................................................... 161



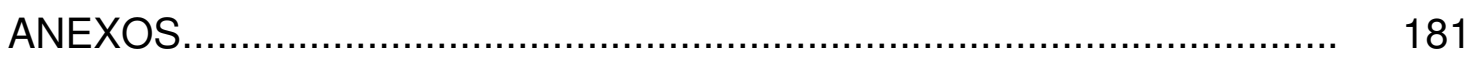




\section{LISTA DE TABELAS}

Página

TABELA 1 - Suporte empírico para a lei de Fitts........................................... 33

TABELA 2 - Formulações matemáticas para o ID........................................ 37

TABELA 3 - Síntese das variáveis independentes e variáveis de controle nos seis experimentos........................................................... 46

TABELA 4 - Índices de dificuldade calculados para os experimentos............ 48

TABELA 5 - Média, DP (entre parênteses), $F$ e $p$ para as variáveis de resultado (disco) e de desempenho (manopla), em função da distância manopla-disco.

TABELA 6 - Valores da regressão linear do tempo de movimento, do tempo para contato e do tempo após contato, em função dos índices de dificuldade (ID' e ID')

TABELA 7 - Média, DP (entre parênteses), $F$ e $p$ para as variáveis angulares espaciais de desempenho (articulações), em função da distância manopla-disco

TABELA 8 - Média, DP (entre parênteses), $F$ e $p$ para as variáveis angulares temporais de desempenho (articulações), em função da distância manopla-disco.

TABELA 9 - Média, DP (entre parênteses), $F$ e $p$ para as variáveis espaciais de resposta (disco) e de desempenho (manopla), em função da velocidade de movimento

TABELA 10 - Média, DP (entre parênteses), $F$ e $p$ para as variáveis temporais de resposta (disco) e de desempenho (manopla), em função da velocidade de movimento

TABELA 11 - Valores da regressão linear das variáveis de velocidade em função do erro e da variabilidade. 
TABELA 12 - Média, DP (entre parênteses), $F$ e $p$ para as variáveis angulares espaciais de desempenho (articulações), em função da velocidade de movimento

TABELA 13 - Média, DP (entre parênteses), $F$ e $p$ para as variáveis angulares temporais de desempenho (articulações), em função da velocidade de movimento...

TABELA 14 - Média, DP (entre parênteses), $F$ e $p$ para as variáveis de resposta (disco) e de desempenho (manopla), em função do tamanho do disco.

TABELA 15 - Valores da regressão linear do tempo de movimento, tempo para o contato e tempo após o contato, em função dos índices de dificuldade (ID' e ID').

TABELA 16 - Média, DP (entre parênteses), $F$ e $p$ para as variáveis angulares espaciais de desempenho (articulações), em função do tamanho do disco.

TABELA 17 - Média, DP (entre parênteses), $F$ e $p$ para as variáveis angulares temporais de desempenho (articulações), em função do tamanho do disco.

TABELA 18 - Média, DP (entre parênteses), $F$ e $p$ para as variáveis de resposta (disco) e de desempenho (manopla), em função do tamanho do alvo.

TABELA 19 - Valores da regressão linear do tempo de movimento, tempo para o contato e tempo após o contato, em função dos índices de dificuldade (ID' e ID').

TABELA 20 - Média, DP (entre parênteses), $F$ e $p$ para as variáveis angulares espaciais de desempenho (articulações), em função do tamanho do alvo.

TABELA 21 - Média, DP (entre parênteses), $F$ e $p$ para as variáveis angulares temporais de desempenho (articulações), em função do tamanho do alvo. 
TABELA 22 - Média, DP (entre parênteses), $F$ e $p$ para as variáveis de resposta (disco) e de desempenho (manopla), em função massa da manopla

TABELA 23 - Média, DP (entre parênteses), $F$ e $p$ para as variáveis angulares espaciais de desempenho (articulações), em função da massa da manopla

TABELA 24 - Média, DP (entre parênteses), $F$ e $p$ para as variáveis angulares temporais de desempenho (articulações), em função da massa da manopla.

TABELA 25 - Média, DP (entre parênteses), $F$ e $p$ para as variáveis de resposta (disco) e de desempenho (manopla), em função da massa do disco.

TABELA 26 - Média, DP (entre parênteses), $F$ e $p$ para as variáveis angulares espaciais de desempenho (articulações), em função da massa do disco

TABELA 27 - Média, DP (entre parênteses), $F$ e $p$ para as variáveis angulares espaciais de desempenho (articulações), em função da massa do disco 


\section{LISTA DE FIGURAS}

Página

FIGURA 1 - Representação esquemática da tarefa experimental, indicando os componentes do equipamento (manopla, disco e alvo), posicionamento inicial do participante e as dimensões da mesa e a posição da filmadora..................................................

FIGURA 2 - Modelo biomecânico a partir de vista superior da execução da tarefa experimental, representando os pontos anatômicos (ombros esquerdo e direito, cotovelo, punho e mão-manopla), ângulos articulares $(\theta 1-\theta 3)$ e erro de deslocamento do disco (a).

FIGURA 3 - Representação esquemática para o cálculo dos índices de dificuldade

FIGURA 4 - Tempo de movimento (TM), tempo para o contato $\left(T_{c}\right)$ e tempo após o contato $\left(T_{\mathrm{a}}\right)$, em função dos índices de dificuldade (ID' e ID')

FIGURA 5 - Tempo de movimento (TM), tempo para o contato $\left(T_{c}\right)$ e tempo após o contato $\left(T_{\mathrm{a}}\right)$, em função dos índices de dificuldade (ID' e ID').

FIGURA 6 - Tempo de movimento (TM), tempo para o contato $\left(T_{c}\right)$ e tempo após o contato $\left(T_{a}\right)$, em função dos índices de dificuldade (ID' e ID'). 


\section{LISTA DE SIGLAS, ABREVIAÇÕES E SÍMBOLOS}
A Aceleração
A' Distância do centro do disco até a borda do alvo virtual
A" Distância do centro da manopla até a borda do alvo virtual
$A_{m d}$ Distância do centro da manopla até o centro do disco
B Comprimento do canal de transmissão de informação
C Capacidade de informação efetiva
D Distância de movimento
$D_{d a} \quad$ Distância do centro do disco até o centro do alvo remoto
$D_{e} \quad$ Distância de movimento efetiva

DM Distância da borda da manopla até o centro do disco

DP Desvio padrão

$\mathrm{DP}_{\mathrm{f}} \quad$ Desvio padrão do parâmetro de força

$\mathrm{DP}_{\mathrm{i}} \quad$ Desvio padrão do impulso da aceleração

$D_{t} \quad$ Atraso temporal de correção

$\mathrm{D}_{1} \quad$ Diâmetro do disco

F Coeficiente da análise de variâncias com medidas repetidas estatística

F Força

F Força de aceleração aplicada no movimento

G Coeficiente para o ganho do dispositivo

I Impulso da aceleração

ID Índice de dificuldade

ID' Índice de dificuldade determinado através do ângulo da margem de acerto

ID" I Índice de dificuldade determinado através do tamanho do alvo virtual

$\mathrm{ID}_{\mathrm{e}} \quad$ Índice de dificuldade efetivo

m Massa 
$p \quad$ Coeficiente de significância (alfa) utilizado nas análises estatísticas

$S \quad$ Potência do sinal

$r \quad$ Raio do disco

R Potência do ruído

$R \quad$ Coeficiente de relação/associação da análise de regressão linear

$R^{2} \quad$ Coeficiente de determinação da análise de regressão linear

T Tamanho do alvo

$\mathrm{T}_{\mathrm{a}} \quad$ Tempo após contato manopla-disco

$\mathrm{T}_{\mathrm{c}} \quad$ Tempo para contato manopla-disco

$\mathrm{T}_{\mathrm{e}} \quad$ Tamanho do alvo efetivo

$\mathrm{T}_{\mathrm{t}} \quad$ Tempo para o cursor atingir o alvo

$\mathrm{T}_{\mathrm{v}} \quad$ Tamanho do alvo virtual necessário para direcionar o disco ao alvo remoto

T 1 Tamanho da projeção de a" sobre o disco para direcioná-lo ao alvo remoto

$\mathrm{T}_{2} \quad$ Tamanho do alvo remoto

TM Tempo de movimento

V Média de velocidade do alvo

$W_{e} \quad$ Erro/alvo efetivo, ou erro subjetivo (desvio padrão do erro espacial)

$a_{\mathrm{n}} \quad$ Parâmetro escalar da magnitude da desaceleração

$\alpha_{p} \quad$ Parâmetro escalar da magnitude da aceleração positiva

$\alpha^{\prime} \quad$ Ângulo para determinação dos IDs (ou, $\left.\beta^{\prime} / 2\right)$

a" $\quad$ Ângulo para determinação dos IDs (ou, $\beta " / 2$ )

$\beta^{\prime} \quad$ Ângulo da margem de acerto do disco em relação ao alvo remoto

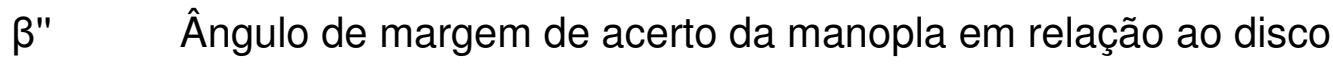

$\mathrm{T}_{\mathrm{n}} \quad$ Tempo para a maior magnitude da desaceleração

$\mathrm{T}_{\mathrm{p}} \quad$ Tempo para a maior magnitude da aceleração positiva

$\omega \quad$ Tempo virtual 


\section{LISTA DE EQUAÇÕES}

Página

\begin{tabular}{|c|c|}
\hline EQUAÇÃO 1 & $-\quad \beta^{\prime}=2 \times \alpha^{\prime}$ \\
\hline EQUAÇÃO 2 & $-\alpha^{\prime}=\operatorname{ATan}\left[\left(T_{2} / 2\right) / D_{d a}\right]$ \\
\hline EQUAÇÃO 3 & $-T_{v}=2 \times T_{1} \ldots \ldots \ldots \ldots \ldots \ldots \ldots \ldots \ldots \ldots \ldots \ldots$ \\
\hline EQUAÇÃO 4 & $-T_{1}=\operatorname{Sen} \alpha^{\prime}{ }_{x} r$ \\
\hline EQUAÇÃO 5 & $-A_{m d}=A^{\prime}+A^{\prime \prime}$ \\
\hline EQUAÇÃO 6 & $-\quad A^{\prime}=$ Raiz $\left[(r)^{2}-\left(T_{1}\right)^{2}\right]$ \\
\hline EQUAÇÃO 7 & - $\alpha^{\prime \prime}=A \operatorname{Tan}\left(T_{1} / A^{\prime \prime}\right)$ \\
\hline EQUAÇÃO 8 & - $\beta^{\prime \prime}=2 \times \alpha^{\prime \prime}$ \\
\hline EQUAÇÃO 9 & $-\quad I D^{\prime}=\log _{2}\left[\cot \left(\beta^{\prime \prime} / 2\right)\right]$ \\
\hline EQUAÇÃO 10 & $\left.-\quad I D=\log _{2}[(2 \times D) / T]\right)$ \\
\hline QUAÇÃO 11 & - $\quad I D^{\prime \prime}=\log _{2}\left[\left(2_{x} A^{\prime \prime}\right) / T_{v}\right]$ \\
\hline
\end{tabular}




\section{LISTA DE ANEXOS}

Página

ANEXO I - Termo de consentimento. 


\title{
RESUMO
}

\section{CONTROLE DE MOVIMENTOS RÁPIDOS E PRECISOS DIRECIONADOS A ALVOS}

\author{
Autor: VICTOR HUGO ALVES OKAZAKI \\ Orientador: PROF.DR. LUIS AUGUSTO TEIXEIRA
}

\begin{abstract}
Neste estudo foi analisado o efeito de distância, velocidade, tamanhos do disco e do alvo, e massas do disco e da manopla, sobre o desempenho motor em movimentos requisitando rapidez e precisão. Para tanto, foram analisadas as características cinemáticas da tarefa de projetar um disco a um alvo com movimento de contato balístico, empunhando uma manopla. Os movimentos foram desempenhados sobre uma base plana e filmados com câmera optoeletrônica de alta freqüência. O estudo foi conduzido em seis experimentos com um grupo único de participantes. Os resultados indicaram que os modelos de controle motor que têm sido empregados para analisar a relação velocidade-precisão em tarefas mais simples não foram apropriados para explicar o comportamento da tarefa utilizada. $O$ controle motor na tarefa demonstrou ser dinâmico e flexível, frente às diferentes restrições de movimento. As seguintes estratégias de controle foram sugeridas na explicação dos resultados: sincronização da maior velocidade e do instante de contato manopla-disco, manutenção na proporção entre as fases aceleração-desaceleração, maior inércia e menor impacto para aumentar a estabilidade de movimento, e o controle da velocidade e da precisão em dimensões independentes. A análise das ações articulares demonstrou as particularidades das estratégias utilizadas pelo sistema no movimento em função das variáveis manipuladas. Em conjunto, esta seqüência de experimentos permitiu uma compreensão mais ampla das estratégias de controle motor empregadas em movimentos com alta demanda de velocidade e de precisão.
\end{abstract}

Palavras-chave: movimentos rápidos e precisos, relação velocidade-precisão, lei de Fitts, restrição espacial, restrição temporal, estratégias de controle motor. 


\title{
ABSTRACT \\ CONTROL OF RAPID AND ACCURATE MOVEMENTS AIMED TO SPATIAL TARGETS
}

\author{
Author: VICTOR HUGO ALVES OKAZAKI \\ Adviser: PROF.DR. LUIS AUGUSTO TEIXEIRA
}

In this study it was analyzed the effect of distance, velocity, disc and target width, disc and manipulandum mass, over motor control of a rapid and accurate movement. For such, it was analyzed the kinematic characteristics of the task of launching a disc to a target using a ballistic movement, performed with a manipulandum. Movements were performed on a flat surface and filmed with a high frequency optoelectronic camera. The study was conducted through six experiments with a single group of participants. Analysis of results indicated that models of motor control that has been used to analyze speed-accuracy tradeoff in simpler tasks were not appropriate to explain the observed behavior in the task used. Motor control in the task showed to be dynamic and flexible, regarding the several constraints manipulated. The follow strategies of control were suggested to explain the results: synchronization of the peak velocity and the instant of disc-manipulandum contact, maintenance of the proportion between the acceleration-deceleration phases, greater inertia and minor impact to increase movement stability, and control of velocity and accuracy of independent dimensions. The prediction of Analysis of joint actions showed the particularities of the strategies used by the system on movement as a function of the manipulated variables. Together, this study sequence of experiments allowed for a deeper comprehension of the control strategies used in the control of rapid and accurate movements.

Keywords: $\quad$ speed and accurate movements, speed-accuracy trade-off, Fitts' law, spatial constraint, temporal constraint, strategies of motor control. 
1.1 Controle de movimentos rápidos e precisos direcionados a alvos

Movimentos manuais balísticos desempenhados para atingir alvos espaciais estão sujeitos a uma relação inversamente proporcional entre a manutenção na precisão e a geração de velocidade. Assim, quanto maior a demanda na precisão em uma dada tarefa motora maior o tempo de movimento para sua realização. Essa relação foi modelada matematicamente por Fitts (1954), ao ser demonstrado que o tempo de movimento é uma função linear do logaritmo do dobro da distância de movimento (D) dividido pelo tamanho (T) do alvo (TM = a + b $\log _{2}[2 x$ D / T]; no qual 'a' e 'b' são constantes empíricas). Fitts (1954) formulou esta relação a partir de movimentos cíclicos de toques alternados, de transporte de pinos e de transporte de argolas. Todavia, experimentos posteriores demonstraram que o modelo matemático também se aplica em diferentes tipos de tarefas, tais como: toques sucessivos (Fitts \& Petersen, 1964; Mackenzie et al., 1987; Marteniuk et al., 1987), transferência de objetos (Raouf \& Tsui, 1978), arremessos de dardo (Kerr \& Langol, 1977), utilizando mouse de computador (Accot \& Zhai, 2003; Okazaki et al., 2008b; Pereira \& Okazaki, 2008); também com diferentes grupos musculares, como: extensão de cotovelo (Kerr \& Langolf, 1977; Khan et al., 1999), flexão de cotovelo (Corcos et al., 1988), rotação de punho (Meyer et al., 1988; Write \& Meyer, 1983), movimento dos pés (Hoffman, 1991), movimento da cabeça (Andres \& Hartung, 1989; Jagacinski \& Mok, 1985); e, com diferentes populações, como: crianças (Jones, 1991; Salmoni, 1983; Smits-Engelsman et al., 2006), adolescentes (Salmoni, 1983; Sugden, 1980; Wallace et al., 1978), adultos (Adam et al., 1997; Guiard, 1997; Okazaki et al., 2008b), idosos (Goggin \& Meeuwsen, 1992; Welford et al., 1969). Conseqüentemente, este fenômeno foi considerado um dos mais consistentes e estudados em comportamento motor (Bootsma et al., 2004; Sparrow \& Sparrow, 1991; Teixeira, 2006). Diversos modelos tentaram explicar a origem desta relação inversa velocidade-precisão através de diferentes mecanismos de controle, tais como uso do feedback, geração de ruído, capacidade limitada de processar informações, 
modulação das fases de aceleração-desaceleração e organização das sinergias agonistas-antagonistas no movimento.

Os pesquisadores que basearam sua explicação da relação inversa velocidade-precisão através da informação de feedback apontam que o aumento da velocidade permite menor tempo para a utilização do feedback (Beggs \& Howart, 1972a, 1972b; Crossman \& Goodeve, 1963/1983; Woodworth, 1899). Todavia, movimentos nos quais não há tempo para a utilização do feedback, outra fonte de erro também contribui para a redução da precisão, com o aumento na velocidade de movimento: a geração de ruído neural (Meyer et al., 1982, 1988; Schmidt et al., 1978, 1979). Este ruído pode ser gerado em três diferentes níveis do sistema: processamento da informação (níveis superiores de comando), transmissão da informação para o sistema efetor e no sistema efetor durante o desempenho do movimento (Schmidt et al., 1978, 1979). No que diz respeito ao processamento de informações, foi proposto que a capacidade limitada de processar informações também poderia regular esta relação inversa entre velocidade e precisão. Quanto maior a demanda na precisão, através de maiores informações para especificar os parâmetros de controle, maior é o tempo necessário para processar as informações para controlar o movimento (Fitts, 1954; Fitts \& Petersen, 1964). A relação inversa velocidade-precisão também foi explicada pela proporção entre fase de aceleração e de desaceleração no movimento (Teixeira, 2000; Zelaznik, 1993). Ou seja, quando a velocidade é priorizada no movimento, maior fase de aceleração ocorre para potencializar a geração de velocidade. Ao passo que, para manter a precisão aumenta-se a fase de desaceleração do movimento. Entretanto, esta relação inversa velocidade-precisão também foi sugerida como uma característica inata do sistema (Van Galen \& Shomaker, 1992), que emerge em função das respostas da musculatura agonista e antagonista que atuam no movimento (Plamondon, 1995a, 1995b; Plamondon \& Alimi, 1997). Estes modelos auxiliaram na compreensão geral de algumas estratégias de controle na geração da velocidade e na manutenção da precisão dos movimentos. Contudo, a maioria dos estudos utilizados para fundamentar estes modelos não analisou tarefas motoras complexas, deixando ainda diversas lacunas não contempladas no paradigma da relação velocidade-precisão. 
Em se tratando de tarefas motoras complexas, existe uma série de tarefas que também impõem restrições simultaneamente de precisão e de velocidade, nas quais se espera que ocorra uma relação inversamente proporcional entre esses fatores. Dentre essas habilidades podem ser citadas as tarefas de martelar um prego, de golpear uma bola com bastão ou raquete a fim de projetá-la em alguma direção, ou ainda a tarefa de chutar uma bola. Algumas diferenças entre essas tarefas motoras complexas e as tarefas motoras estudadas sob o paradigma de Fitts (1954), entretanto, impedem a generalização do modelo elaborado para o universo de habilidades motoras balísticas com alvo espacial (Elliott et al., 2001; Meyer et al., 1988; Teixeira, 1997, 2000). Em primeiro lugar, movimentos discretos ou de toques alternados em dois alvos, como no paradigma de Fitts, produzem movimentos relativamente suaves com picos de velocidade ocorrendo numa porção intermediária do movimento, ou até mesmo em porções anteriores quando a demanda de precisão é elevada (Mackenzie et al., 1987; Milner \& ljaz, 1990). Ao passo que, tarefas balísticas complexas, normalmente, exigem uma sincronização entre o tempo do maior valor de velocidade e o instante de contato com o alvo, para maximizar a velocidade produzida no movimento (Anderson \& Sidaway, 1994; Okazaki et al., 2006b; Southard, 1998). Uma vez que a maior variabilidade espacial de resposta foi associada ao aumento na velocidade do movimento (Meyer et al., 1982; 1988; Schmidt et al., 1978, 1979), temos características antagônicas ocorrendo justamente no período crítico de performance, as quais devem ser ajustadas pelo sistema para cumprir o objetivo da tarefa. Todavia, poucos estudos procuraram analisar as estratégias de controle na geração de velocidade e na manutenção da precisão em tarefas dessa natureza. Ademais, ainda não são conhecidos efeitos de restrições espaciais (tamanhos de distância e de alvo) e temporais (velocidade de movimento) sobre as estratégias de controle utilizadas em tarefas motoras complexas.

Segundo, em diversas tarefas motoras complexas há um alvo primário que é contatado/atingido para ser projetado em direção a um alvo secundário remoto objetivado (Anderson \& Sidaway, 1994; Elliott et al., 1989; Teixeira, 1999). Por exemplo, uma bola (alvo primário) chutada em direção a um gol (alvo secundário/remoto). A bola deve ser projetada a partir do contato com uma área restrita a fim de produzir o deslocamento desejado em direção ao gol. Tal 
característica faz com que haja uma área virtual sobre a área total do alvo primário, correspondente á tolerância de erro espacial ao redor do ponto de contato que conduz à maior precisão de movimento. Por conseguinte, há duas fontes de restrição espacial da precisão que atuam concomitantemente, a restrição no tamanho do alvo primário e no tamanho do alvo remoto secundário. Resultados preliminares têm indicado que, em tarefas complexas, o alvo remoto corresponde a fonte de restrição determinante sobre as estratégias de controle no movimento. Teixeira (1999) demonstrou que o menor tamanho da bola não modificou a velocidade linear do pé no chute do futebol. Apenas quando o tamanho do gol foi reduzido houve redução na velocidade do chute. O arremesso no basquetebol também não apresentou modificações com a manipulação no tamanho da bola (Okazaki \& Rodacki, 2005), entretanto, demonstrou modificações nos parâmetros de controle (velocidade e amplitude angulares) com o aumento na distância que diminui a área virtual de passagem da cesta quando o ângulo de lançamento é mantido constante (Rodacki et al., 2005). Tarefas simples de tocar em dois alvos sucessivos também demonstraram que o segundo alvo é a fonte de restrição (no tempo de movimento e de reação) determinante sobre o movimento (Short et al., 1996; Sidaway, 1991). Contudo, Teixeira (1999) não procurou analisar as estratégias do controle e da coordenação adotadas no desempenho do chute, em função da manipulação da precisão (tamanho da bola e do gol). Por outro lado, Okazaki e Rodacki (2005) não se preocuparam em quantificar a precisão no arremesso. Short e colaboradores (1996) e Sidaway e colaboradores (1991) utilizaram tarefas motoras simples de contatar alvos espaciais, além de não analisarem as estratégias de controle no movimento. Desta forma, à escassez de informações e de estudos, com tarefas motoras complexas, torna ainda pouco compreendido o efeito das restrições impostas pela precisão sobre as estratégias de controle na geração de velocidade e na manutenção da precisão do movimento.

E terceiro, considerando que as forças ambientais que atuam no sistema podem ter grande influência sobre o movimento (Pfann et al., 2002; Sherwood et al., 1988; Southard, 1998), torna-se necessário analisar o efeito da inércia e do impacto sobre as estratégias de controle no paradigma da relação inversa velocidadeprecisão (Smeets et al., 1995; Smits-Engelsman et al., 2002). A força de inércia e a 
força de impacto podem ser originadas de velocidades mais altas de movimento, de segmentos corporais mais pesados ou do aumento no peso pelo uso de implementos para contato (raquete, taco, manopla, etc.). Tem sido sugerido que o aumento na inércia auxilia na estabilização do movimento (Khan et al., 1999), enquanto o maior impacto pode ser explorado como mecanismo passivo para desacelerar o movimento (Adam et al., 1997; Biegstraaten et al., 2003; Guiard, 1997). Todavia, como a maior variabilidade espacial de resposta está associada ao aumento na geração de força (Schmidt et al., 1978, 1979), proporcionada em situações com maiores inércia (Khan et al., 1999) e impacto (Adam et al., 1997; Biegstraaten et al., 2003), temos características opostas ocorrendo concomitantemente, as quais devem ser ajustadas pelo sistema. Dessa forma, torna-se importante conhecer o efeito das forças de inércia e das forças de impacto sobre as estratégias de controle no movimento. Além disso, poucos estudos têm explorada a análise do desempenho das articulações que participam no movimento.

Uma estratégia que também pode auxiliar no entendimento da relação velocidade-precisão é a analise do desempenho em cada articulação que participa no movimento. Por exemplo, apesar de o aumento na velocidade ter sido associado à maior a variabilidade de resposta (Schmidt et al., 1978, 1979), ao analisar individualmente as articulações, o sistema demonstra uma flexibilidade na qual a variabilidade das articulações é compensada ao longo da cadeia cinemática. Esta estratégia ocorre para a manutenção da precisão de forma que diferentes combinações articulares garantam a mesma precisão de resposta (Doorenbosch et al., 1997; Henlsen et al., 2000; Stelmach \& Diggles, 1982). Contudo, poucos estudos analisaram a contribuição das ações articulares no paradigma da relação inversa entre velocidade-precisão. Como a resposta do movimento é produto da organização das ações inter-articulares que participam do movimento, a análise do desempenho das articulações pode trazer informações importantes sobre as estratégias de controle utilizadas para a regulação velocidade-precisão.

Neste ínterim, o modelo experimental utilizado no presente estudo analisou o efeito de variáveis espaciais (distância e tamanho dos alvos primário e secundário), temporais (tempo/velocidade de movimento) e cinéticas (impacto e inércia), sobre as estratégias de controle na geração de velocidade e na manutenção 
da precisão em uma tarefa motora complexa. Para tanto, foram analisadas as variáveis cinemáticas de resposta e de desempenho de uma tarefa motora complexa selecionada especialmente para atender os objetivos do estudo. A tarefa motora complexa consistiu de um movimento manual planar, requisitando grandes velocidade e precisão, no qual uma manopla era utilizada para contatar um disco que deveria ser projetado em direção a um alvo remoto.

\subsection{Objetivo}

O presente estudo objetivou analisar o efeito de (a) distância de movimento, (b) velocidade de movimento, (c) tamanho do disco, (d) tamanho do alvo remoto, (e) massa da manopla e (f) massa do disco, sobre as variáveis cinemáticas de resposta e de desempenho na tarefa de contatar um disco para direcioná-lo a um alvo remoto, com um movimento planar rápido e preciso, utilizando uma manopla.

$1.3 \quad$ Justificativa

O conhecimento atual sobre movimentos rápidos (ações balísticas) e precisos está praticamente restrito às tarefas de contato suave entre alvos espaciais planares imóveis dos estudos conduzidos dentro do paradigma de Fitts. Como nesta seqüência de estudos foi realizada uma análise abrangente de diferentes fatores associados ao controle motor em movimentos expressivamente mais rápidos do que daqueles empregados no paradigma de Fitts, a série de estudos aqui proposta tem 0 potencial de gerar conhecimento sobre uma forma de movimento escassamente avaliado no âmbito científico. Como foi avaliado o efeito de diferentes fatores sobre o controle motor nesta ação, o presente projeto pode também proporcionou uma compreensão mais ampla das variáveis influenciando movimentos muito rápidos em direção a um alvo espacial. 
Esta seção objetiva discutir a relação de troca velocidade-precisão em movimentos rápidos e precisos dirigidos a alvos. Os principais modelos teóricos que não utilizaram o controle via feedback para explicar a origem desta troca velocidadeprecisão foram abordados. Os construtos teóricos, as sustentações empíricas, e as limitações de cada modelo foram apresentados para vislumbrar a presente discussão científica no que tange o paradigma da relação inversa velocidade-precisão. Posteriormente, foram abordadas as particularidades da tarefa de movimento rápido e preciso direcionada a alvos espaciais que foi utilizada nos experimentos desta tese.

2.1 Modelos de controle de movimentos rápidos e precisos

\subsubsection{Modelo da variabilidade do impulso}

Um dos principais objetivos em qualquer domínio da pesquisa é o estabelecimento de relações entre variáveis dependentes e independentes. No comportamento motor, a investigação da distância, do tempo e da precisão do movimento tem produzido a formulação de modelos e leis capazes de explicar a relação destas variáveis. Dentro do paradigma da relação inversa velocidadeprecisão, Schmidt e colaboradores $(1978,1979)$ foram os primeiros pesquisadores a elaborar um modelo de controle para explicar a origem desta relação em movimentos no qual não há a possibilidade da correção via processos de feedback. Esta explicação foi baseada no ruído da resposta do sistema, ou seja, na variabilidade intra-individual. Três fatores inerentes ao sistema seriam as possíveis fontes desta variabilidade: seleção no programa motor, seleção nos parâmetros de controle e a variabilidade do sistema efetor.

A primeira fonte de variabilidade está na seleção do programa, no qual erros são produzidos através da seleção de um programa inapropriado para a situação ambiental. A segunda fonte de variabilidade ocorre na seleção dos parâmetros de controle do programa. Ou seja, a determinação inapropriada de variáveis absolutas de força, de tempo, de velocidade ou de amplitude no 
movimento. A terceira fonte de variabilidade é adicionada subseqüentemente à seleção dos parâmetros de controle. Tal variabilidade pode ser considerada como randômica (ruído), no sentido que é desassociada a caminho dos vários grupos musculares. Por exemplo, um grupo muscular pode ter um componente positivo no sinal de ruído, enquanto outro grupo pode ter um sinal negativo, e a relação poderia ser revertida na próxima execução do movimento. Em aspectos fisiológicos, o ruído pode existir em termos de como a informação neural para o motoneurônio na medula é transformada nas ativações de um certo número de unidades motoras, as quais determinam a quantidade de força produzida (Burke \& Edgerton, 1975). Desta forma, o modelo da variabilidade do impulso foi baseado nos princípios do programa motor generalizado (Schmidt, 1975) para explicar movimentos rápidos, no qual não há tempo para o processamento de feedback (períodos menores que 200 ms) (Schmidt et al., 1978, 1979).

O programa motor generalizado foi considerado como uma representação abstrata que especifica as características gerais de uma classe de movimentos (Keele, 1968; Schmidt, 1975). As forças relativas em contrações envolvidas num movimento, assim como o tempo relativo de suas aplicações, são aspectos invariáveis do movimento governados através de um mesmo programa motor (Schmidt et al., 1979). As forças e os intervalos de tempo são modulados através da especificação de um parâmetro escalar para cada aspecto que modulam os padrões de contração muscular. Assim, os movimentos resultam de uma série de impulsos, ou seja, forças ou torques que atuam em uma ou mais articulações por um período de tempo (Rosenbaum \& Krist, 1996; Schmidt et al., 1978). Impulso foi definido como a integral da força através do tempo, ou uma função força-tempo em forma de seno (Schmidt et al., 1978, 1979). Lembrando que, o impulso foi analisado por Schmidt e colaboradores através da área representada abaixo da função aceleração-tempo. Como a força é igual ao produto massa vezes aceleração, quando a massa é constante, o perfil no comportamento da aceleração é estereotipado ao da força.

O impulso, segundo o modelo, seria controlado como uma unidade. Por conseguinte, quando o parâmetro de força é alterado, todas as porções da função de força são graduadas proporcionalmente de acordo com a alteração. Os impulsos são linearmente graduados através de dois parâmetros independentes, um parâmetro de 
força e outro de duração. Conseqüentemente, mudanças na distância e no tempo do movimento são realizadas através da graduação na intensidade (magnitude) e na duração do impulso de forma similar à graduação da amplitude e da duração da função seno. A magnitude determina a altura do impulso e sua duração o comprimento. Os pressupostos na escolha dos parâmetros de força e de tempo têm sido chamados de re-escalonamento da força e re-escalonamento do tempo, respectivamente (Meyer et al., 1982).

O pressuposto do re-escalonamento da força aponta que a amplitude do perfil da aceleração-tempo é proporcional à amplitude (distância) do movimento. Assim, aumentar duas vezes a amplitude do movimento demanda produzir o dobro de velocidade para cada instante de movimento. Por conseguinte, a altura do impulso também deve ser duas vezes maior em cada instante de tempo na função forçatempo. Por outro lado, o pressuposto do re-escalonamento do tempo estabelece que, quando a duração do movimento muda, ocorre alteração no perfil aceleração-tempo de forma proporcional, mantendo o mesmo tempo relativo dos eventos no perfil da aceleração. A média de velocidade deve ser proporcional ao impulso, ou seja, a área abaixo da função força-tempo. Desta forma, quando o movimento é realizado na metade do tempo, a velocidade deve ser dobrada. $\mathrm{O}$ impulso, então, deve aumentar em razão quadrada para dobrar a área da função força-tempo.

Estes pressupostos de re-escalonamento da força e do tempo tiveram suporte em experimentos que analisaram a produção de força isométrica e a duração do impulso (Schmidt et al., 1978). Os parâmetros de força e de tempo em cada impulso foram analisados como variáveis estocásticas, ou seja, o desvio padrão de cada um foi proporcional à sua respectiva média (Schmidt et al., 1979). Assim, a variabilidade das forças musculares geradas no desempenho de um movimento em direção a um alvo aumentou proporcionalmente com a força absoluta produzida. Ademais, a variabilidade no tempo de duração do impulso foi proporcional com o aumento no tempo de movimento. Suporte para pressupostos do modelo de variabilidade do impulso foi obtido pela duração no sinal da EMG que foi graduada em função do tempo de movimento (Wallace, 1981). Através destes pressupostos, o modelo demonstrou como a variabilidade de um impulso afeta a variabilidade espacial e temporal da trajetória do movimento (Rosenbaum \& Krist, 1996). 
O modelo também prediz como os erros variáveis no espaço (alvo efetivo) e o tempo se relacionaram com a média da amplitude e duração dos movimentos, desempenhados em condições constantes. Como a variabilidade das forças musculares produzidas aumenta proporcionalmente com a força absoluta, maiores força e variabilidade de força são associadas a movimentos mais rápidos (menor tempo de duração) e que cobrem maiores distâncias (maior amplitude de movimento). Desta forma, a variabilidade de resposta foi linearmente relacionada com a razão da amplitude de movimento pelo tempo de movimento. Esta relação pode ser expressa através da equação: $W_{e}=a+b(D / T M)$, no qual $W_{e}$ é o desvio padrão dos pontos finais do movimento (também chamado de alvo efetivo), D é a média da distância do movimento, TM é a média do tempo de movimento, e 'a' e 'b' são constantes empíricas. Esta relação inversa linear entre velocidade-precisão tem sido replicada por outros estudos que analisaram o movimento de digitação (Zelaznik et al., 1981), rotações de punho (Wright \& Meyer, 1983) e movimentos sacádicos dos olhos (Plata et al., 1985).

O modelo da variabilidade de impulso falha em sustentar seus pressupostos, no que diz respeito ao paradigma do movimento de precisão simples utilizado originalmente para estruturar o modelo (Schmidt et al., 1985). Em estudo subseqüente, Schmidt e colaboradores (1985) proporcionaram apenas suporte parcial para o modelo da variabilidade de impulso sem encontrar uma relação linear entre a velocidade e precisão do movimento. Newell (1980) também falhou em confirmar a relação linear velocidade-precisão. Enquanto a generalidade da variabilidade espacial e temporal foi linearmente relacionada ao tempo e à distância do movimento, respectivamente; demonstrações repetidas no efeito da velocidade falharam em confirmar as predições do modelo. Foi demonstrado que a precisão espacial tende a diminuir com o aumento da velocidade de movimentos (Newell, 1980). Outras três limitações são relatadas por Meyer, Smith, Wright (1982) no modelo da variabilidade do impulso: simplificação demasiada da dinâmica do movimento, aplicações matemáticas erradas nas leis da física, e violações na teoria da probabilidade.

A simplificação demasiada na dinâmica do movimento diz respeito à limitação do modelo em abranger a fase de desaceleração do movimento. Ou seja, 
não há suporte matemático para descrever como a desaceleração influencia a precisão e a velocidade do movimento como um todo. Alguns estudos têm demonstrado que em certos movimentos a fase de desaceleração corresponde a grande parte do movimento, revelando a importância de considerar este aspecto na análise do controle do movimento (Carlton, 1980; Langolf et al., 1976; Zelaznik, 1993). Segundo Meyer, Smith e Wright (1982), esta fase de desaceleração é fonte de uma oposição na ação da musculatura antagonista em relação à agonista, e ao impacto do braço com a região ao redor do alvo. Outro problema foi verificado no perfil da curva força-tempo em forma de uma onda quadrada. Pois, o perfil da curva força-tempo tende a se aproximar mais a uma onda em forma de seno do que em forma de uma onda quadrada. Apesar de o modelo considerar informalmente a possibilidade de uma função em forma de seno, não há explicação quantitativa para este problema.

Aplicações precipitadas da física também foram apontadas como problemas na formulação do modelo de variabilidade do impulso. Por exemplo, foi considerado que a amplitude de um movimento é diretamente proporcional ao impulso da aceleração, pelo fato da máxima velocidade do movimento aumentar diretamente com a magnitude do impulso para a aceleração. Tal tratamento não é fisicamente válido de forma geral. Supondo as condições do modelo no qual a força de aceleração é aplicada para uma proporção de $\mathrm{K}$ x i do tempo total de um movimento e que o membro continua a viajar em queda livre desde então até o impacto. Então a distância do movimento seria diretamente proporcional ao impulso para a aceleração (aceleração do impulso) se e apenas se o tempo de movimento fosse constante. Isto pelo fato de que a equação deve assegurar a segunda lei de Newton no movimento: $\mathrm{D}=\mathrm{K}_{\times} \mathrm{i} \times(2-\mathrm{Ki}) \times \mathrm{F}_{\times} \mathrm{TM}^{2 / 2 \mathrm{~m}}$; no qual $\mathrm{D}$ é a distância movida, F é a força de aceleração aplicada ao membro, $m$ é a massa do membro, e TM é o tempo de movimento. Como o impulso da aceleração aqui seria $i=K \times i \times F \times T M, a$ única forma de obter uma relação proporcional entre a distância do movimento e o impulso da aceleração é ter o tempo de movimento permanecendo constante com i e D variando com F. Se, ao invés, o parâmetro de força não for proporcional; D seria proporcional ao quadrado de i. Então, em efeito, o modelo de variabilidade do 
impulso violaria um dos princípios básicos da física do movimento (Meyer et al., 1982).

De algumas formas o modelo da variabilidade do impulso também falhou em satisfazer alguns princípios da teoria da probabilidade. Por exemplo, segundo o modelo, para que um movimento seja desempenhado na metade do tempo, a força deve ser aumentada quatro vezes. Como a força é diretamente proporcional à variabilidade da força, a variabilidade da força também aumentaria numa magnitude de quatro vezes. Entretanto, o impulso para a aceleração pode ser expresso por: i = $K_{x} i_{x} F_{x}$ TM. Então, baseado na teoria da probabilidade simples, o desvio padrão de i seria $D P_{i}=K_{x} i_{x} T M_{x} D P_{F}$, assumindo temporariamente que $D P_{F}$ é o desvio padrão do parâmetro de força e que $\mathrm{K}_{\mathrm{x}}$ i e o TM são ambos constantes. Isto significa que o desvio padrão somente seria dobrado quando o TM fosse a igual a sua metade, enquanto $\mathrm{F}$ e $\mathrm{DP}_{\mathrm{F}}$ são conseqüentemente quadruplicados. Assim, ao invés de ser encontrada uma dispersão dos pontos finais variando com o inverso do quadrado do tempo $\left(\mathrm{W}_{\mathrm{e}} \sim 1 / \mathrm{TM}^{2}\right)$, esta dispersão dos pontos finais obedeceria apenas uma relação inversa $\left(\mathrm{W}_{\mathrm{e}} \sim 1 / \mathrm{TM}\right)$.

Apesar das limitações do modelo de variabilidade de impulso proposto por Schmidt e colaboradores $(1978,1979)$, grande contribuição foi proporcionada para o entendimento dos parâmetros de alguns princípios que atuam no controle da velocidade e da precisão dos movimentos. Os pressuposto do presente modelo proporcionaram a base para o desenvolvimento do modelo de variabilidade do impulso simétrico (Meyer et al., 1982) e do modelo estocástico de sub-movimentos otimizados (Meyer et al., 1988).

\subsubsection{Modelo da variabilidade do impulso simétrico}

Em função das limitações encontradas no modelo de Schmidt e colaboradores (1978, 1979), Meyer et al. (1982) propuseram o modelo da variabilidade do impulso simétrico. Este novo modelo foi baseado no modelo anterior da variabilidade do impulso, considerando o controle por meio dos programas motores generalizados e, conseqüentemente, assumindo os pressupostos do reescalonamento da força e do re-escalonamento do tempo. Ou seja, Meyer, Smith e 
Wright (1982), sugeriram que o sistema motor tem dois mecanismos distintos para controlar um movimento de precisão: um associado com um parâmetro de força e outro associado com um parâmetro de tempo. Estes dois parâmetros foram analisados através de uma função força-tempo que representam o impulso de força gerado no movimento. Meyer, Smith e Wright (1982) também assumiram que a média da força e do tempo movimento são parâmetros de variáveis randômicas nos quais seus desvios padrão aumentam proporcionalmente com suas médias (Schmidt et al., 1978). Por conseguinte, quando é feita uma série de tentativas para desempenhar um mesmo movimento, são produzidas amostras randômicas de uma série de curvas força-tempo, nas quais os parâmetros são aumentados ou diminuídos através das dimensões na força ou no tempo.

Um aspecto que diferencia os dois modelos de variabilidade do impulso, entretanto, é a maior flexibilidade no perfil da função força-tempo no modelo da variabilidade do impulso simétrico. O modelo da variabilidade do impulso simétrico não assume o mesmo perfil de curva para uma série de tentativas de um movimento como foi feito no modelo de Schmidt e colaboradores (1978, 1979). Ao contrário, considera um conjunto variável nos perfis de curva nos quais as propriedades dinâmicas do movimento (aceleração e desaceleração) foram mais apropriadamente analisadas. Todavia, alguns pressupostos qualitativos na função força-tempo devem ser atendidos para que seja assegurada a relação linear de troca velocidadeprecisão.

O modelo da variabilidade do impulso simétrico aponta que a força gerada no início, no meio e no final do intervalo no tempo de movimento seja zero. Isto permite que o movimento seja caracterizado por uma fase inicial de aceleração e outra final de desaceleração. A força aplicada na primeira fase do movimento deve ser oposta à força aplicada na segunda fase do movimento. Ou seja, se a aceleração inicial do movimento tiver em sentido positivo, a aceleração final deverá estar em sentido negativo. Estas fases de aceleração e de desaceleração devem necessariamente ter perfis equivalentes. Ou seja, a segunda metade de cada função força-tempo também deverá ser uma imagem espelho invertida da primeira metade. Não deve haver descontinuidade na função força-tempo, ou seja, a função não poderá ser interrompida subitamente. Pois, ambos, aceleração e desaceleração 
fazem parte integral na resultante da variabilidade do modelo. Diferente do modelo de Schmidt et al. (1978), no qual apenas a variabilidade do impulso na fase de aceleração representava a variabilidade final de resposta.

Segundo o modelo da variabilidade do impulso simétrico, a função forçatempo é expressa como o produto de um parâmetro de força multiplicado por uma função do tempo. O parâmetro de força pode ser manipulado para aumentar ou diminuir a magnitude da função força-tempo, enquanto o parâmetro tempo permanece constante. Assim, é permitido que a força total de um movimento, e conseqüentemente a distância total percorrida, seja ajustada mesmo quando o tempo total do movimento permanece constante. Contudo, o modelo não entende os parâmetros de força e de tempo como estatisticamente independentes, mas considera que estes parâmetros não devem ter uma correlação perfeita entre si (ou seja, $R<1)$. A interação dos parâmetros de força e tempo seria responsável pela variabilidade da resposta quando um movimento é desempenhado várias vezes. Devido às interações variadas entre estes parâmetros, uma relação de troca entre velocidade e precisão deveria ocorrer como resultado desejado da média no parâmetro de força e de tempo ajustados através da função de peso para alcançar um tempo e uma distância de movimentos desejados (Meyer et al., 1982).

A função de peso seria utilizada para ajustar a função força-tempo quando mudanças na distância ou tempo de movimento fosse desejadas. Por exemplo, quando o tempo de movimento fosse diminuído pela metade, a amplitude do impulso deveria ser elevada em quatro vezes, assim como no modelo da variabilidade do impulso de Schmidt e colaboradores (1978, 1979). Contudo, o modelo da variabilidade do impulso simétrico indica que este aumento na amplitude do impulso deve ser ajustado em cada instante de tempo no movimento pela função de peso. Caso este ajuste não seja realizado, ocorre uma relação distância-precisão ao invés de uma relação velocidade-precisão (cf. Meyer et al., 1982). No entanto, não existe suporte empírico ou forma direta para confirmar a existência da função de peso analisando as funções força-tempo. A função de peso é confundida com o parâmetro de força sobre condições atuais de movimento; pois, ambos a força e a função de peso modulariam a magnitude da função da força multiplicativamente. Todavia, a existência da função de peso foi justificada pela eficiência na programação do 
movimento e no fato de que a função seria um pressuposto para considerar a troca linear velocidade-precisão no modelo.

Meyer, Smith e Wright (1982) foram os primeiros pesquisadores a tentar abordar aspectos biomecânicos e fisiológicos para entender o controle de movimentos no paradigma da velocidade-precisão. Através da teoria do ponto de equilíbrio estes autores procuraram suporte para seu modelo da variabilidade do impulso simétrico. De acordo com a teoria do ponto de equilíbrio os músculos agonistas e antagonistas podem ser entendidos como molas nas quais as tensões opostas (forças) controlam o movimento. É assumido que mover a massa de um determinado segmento envolve o ajuste na rigidez e/ou nos comprimentos de descanso da musculatura para atingir um novo ponto de equilíbrio, nos quais as tensões e o equilíbrio de cada um é exato. Suporte para esta teoria foi obtido no estudo de Polit e Bizzi (1979), no qual foi analisado o movimento do braço de macacos direcionado a um alvo com a aplicação de perturbação no movimento e com a retirada da informação visual e cinestésica. Foi verificado que os macacos alcançaram o alvo desejado com precisão apesar da aplicação da perturbação. Tais resultados sugerem que alcançar um alvo depende somente da rigidez final e do comprimento de descanso final da musculatura agonista e antagonista. Se estes parâmetros são programados antes do início do movimento, então uma perturbação subseqüente breve durante o curso do movimento pode impedir sua progressão temporariamente. Todavia, esta perturbação não deveria alterar seu ponto de terminação, pois a tensão relativa dos músculos (e assim as tensões finais opostas que elas geram) não seria influenciada através da perturbação. Suporte para a teoria do ponto de equilíbrio também foi verificado em estudos com seres humanos (Schmidt \& McGown, 1980). Os movimentos rápidos de precisão seriam regulados através de um componente tônico e um componente fásico. O componente fásico supostamente atua no ajuste da rigidez na musculatura rapidamente no início do movimento, acelerando o membro em direção ao alvo desejado e mantendo o membro na terminação local alcançada através da ação do componente fásico. Meyer, Smith e Wright (1982) assumiram que a terminação local do membro é mantida através do componente tônico que é fortemente correlacionado com o que permitiria ser alcançado pelo componente fásico sobre condições normais, apesar de 
pequenas oscilações sobre sua localização podem acontecer pelo fato de que o componente fásico induzir um resíduo (ressonância tipo mola).

Apesar do embasamento teórico na biomecânica e fisiologia, Schmidt (1980) contestou os modelos da variabilidade do impulso através da mesma teoria utilizada por Meyer, Smith e Wright para apoiar seu modelo, a teoria do ponto de equilíbrio. Segundo Schmidt (1980) há mais suporte para a teoria do ponto de equilíbrio do que para o modelo da variabilidade do impulso simétrico. Para este autor, estes dois modelos não são congruentes em sua essência, pois a introdução de perturbação num movimento de precisão com uma força externa inesperada não mudaria apenas a dinâmica do movimento, mas também a distância total movida. Como Schmidt e McGown (1980), assim como Polit e Bizzi (1979) falharam em encontrar este erro na distância movida, isto sugere que os modelos da variabilidade do impulso sejam incorretos. Outras limitações apresentadas na forma da curva, no re-escalonamento da força e do tempo, nos tipos de tarefas analisadas (unidimensionais) e na desconsideração do impacto em alguns movimentos, contribuíram para aumentar a fragilidade do modelo.

Zelaznik, Schmidt e Gielen (1986) demonstraram que o pressuposto da forma constante é severamente violado em movimentos de toques com ponteira. $O$ tempo para o pico da aceleração, assim como para o pico da desaceleração, na terminação do movimento, permaneceu virtualmente constante, ou seja, estes picos ocorreram no mesmo instante absoluto e não relativo do tempo (Zelaznik et al., 1986). A relação entre a média força gerada e sua respectiva variabilidade (desvio padrão) também foi comprometida quando a taxa da força atingiu limites próximos ao máximo (Sherwood \& Schmidt, 1980). Carlton e Newell (1993) obtiveram evidência de que o tempo para o pico da força (altura do impulso) é o maior determinante na variabilidade do impulso (variabilidade na altura do impulso), contrariando o princípio do re-escalonamento da força. Outros estudos apontam para violações no pressuposto do re-escalonamento do tempo, ou seja, fornecem evidência de que a variabilidade-temporal (desvio-padrão do tempo) e o tempo de movimento são proporcionais. Rosenbaum e Patashnik (1980) demonstraram que a relação entre o desvio padrão no tempo de movimento e a duração do tempo de movimento aproxima-se mais a uma função de raiz quadrada. Gielen, Oosten e Van Pull Ter 
Gunne (1985) observaram que em movimentos rápidos de mãos direcionados a alvos o tempo do pico da aceleração foi fixo no tempo absoluto, e que a duração da atividade na EMG não foi graduada com o tempo alvo. Zelaznik, Schmidt e Gielen (1986) verificaram uma relação linear entre $W_{e}$ e D / TM, entretanto, o tempo para 0 pico da aceleração não foi relacionado ao tempo de movimento, mas ao invés disso foi fixo através dos diferentes valores do tempo. Assim, não é claro se os pressupostos de re-escalonamento da força e do tempo são estabelecidos como os modelos da variabilidade do impulso predizem.

Meyer, Smith e Wright (1982) também apontaram limitações em seu modelo quanto à simplicidade da tarefa analisada. Ou seja, seus achados foram baseados em movimentos simples unidimensionais e com curto período de tempo de execução. Assim, movimentos mais complexos (em duas ou três dimensões), ou movimentos no qual seja possível a utilização de feedback, podem não ser explicados de forma adequada pelo modelo da variabilidade do impulso simétrico. Este modelo também não foi desenvolvido para considerar o efeito do impacto do membro (implemento) na região alvo no final do movimento. O impacto com a área alvo poderia contribuir significantemente na desaceleração final do movimento, possivelmente, até mesmo modificando a relação de troca velocidade-precisão. Todavia, apesar das limitações apresentadas, Meyer, Smith e Wright (1982) utilizaram os conceitos do modelo de variabilidade do impulso para criar um modelo que fosse capaz de explicar movimentos sem feedback para regular o controle do movimento.

\subsubsection{Modelo estocástico de sub-movimentos otimizados}

O modelo estocástico de sub-movimentos otimizados foi desenvolvido por Meyer, Abrams, Kornblum e Smith (1988) a partir do modelo de variabilidade de impulso simétrico (Meyer et al., 1982). Este novo modelo foi capaz de explicar a relação de troca velocidade-precisão utilizando os princípios do ruído inerente ao sistema e da regulação do controle via processo de feedback. Assim como nos modelos precedentes (variabilidade do impulso e variabilidade do impulso simétrico), foi considerada a existência do ruído neuromotor. Contudo, o presente modelo não 
se preocupou em descrever os mecanismos que o causam o ruído. Foi assumido que os movimentos de alta velocidade são mediados por impulsos de força associados com parâmetros de amplitude e parâmetros de tempo que governam a magnitude e duração dos impulsos, respectivamente. Desta forma, os pressupostos de reescalonamento da força e de re-escalonamento do tempo também foram considerados, assumindo estes parâmetros como fenômenos estocásticos.

O movimento, segundo o modelo, seria regulado através de um ou dois sub-movimentos que tentam minimizar a média do tempo total de movimento. $\mathrm{O}$ processo de pré-programação alcançaria esta minimização através de um ajuste ótimo das magnitudes e da duração do ruído das forças de impulso neuromotor utilizadas para gerar os sub-movimentos. O sub-movimento inicial ou primário seria realizado para terminar no centro do alvo. Se o sub-movimento primário termina na região alvo, então nenhum sub-movimento secundário ocorre. Entretanto, o final do sub-movimento primário pode errar o alvo por causa das perturbações causadas através do ruído neuromotor. Se um erro ocorrer, então um sub-movimento secundário, preparado através da visão ou de outro estímulo de feedback, seria desempenhado para a correção do erro. $O$ pressuposto de dois sub-movimentos otimizados teve suporte de alguns resultados de Langolf et al.(1976) e de Carlton (1979). Eles demonstraram uma larga preponderância de tentativas com apenas um ou dois sub-movimentos no total de movimentos dos sujeitos em direção a um alvo. A ausência de ordens mais altas de sub-movimentos (um terceiro sub-movimento) parece fazer sentido dado que um sub-movimento pode tipicamente percorrer $90 \%$ da distância da posição inicial para o centro do alvo (Carlton, 1979; Vince, 1948). Com este deslocamento inicial e com esta usual combinação distância-tamanho selecionado para a restrição dos movimentos da tarefa, a combinação de dois submovimentos deveria quase sempre ser suficiente para alcançar a região alvo sucessivamente. Também, quando três ou mais sub-movimentos ocorressem (Crossman \& Goodeve, 1963/1983; Jagacinski et al., 1980a, 1980b), a presente abordagem teórica poderia ainda ser apropriada pelo fato de que o modelo poderia assimilar no interior de seu sub-movimento secundário a contribuição de submovimentos de ordens mais altas. 
O modelo assume que o erro espacial (pontos finais) dos sub-movimentos possui uma distribuição normal ao redor do alvo, em função do ruído neuromotor. Suporte empírico para este pressuposto tem sido verificado em outros estudos (Crossman \& Goodeve, 1963/1983; Fitts, 1954; Fitts \& Peterson, 1964; Wallace \& Newell, 1983). O ruído neuromotor também afetaria o desvio padrão dos pontos finais do sub-movimento primário e secundário. O desvio padrão do erro espacial (pontos finais) dos sub-movimentos primários e secundários são assumidos serem proporcionais às suas velocidades médias. Entretanto, pelo fato de erros serem desencorajados em tarefas de movimentos com restrição espacial, o desvio padrão do sub-movimento secundário deve ser suficientemente pequeno para que uma grande proporção do sub-movimento secundário termine dentro da região alvo. $\mathrm{O}$ desejado desvio padrão do sub-movimento secundário é alcançado através do ajuste da média da duração do sub-movimento secundário para ter um valor que depende de distância remanescente para atingir o alvo, do tamanho do alvo, e do nível de precisão necessário. De forma geral, o modelo prediz que o desvio padrão dos pontos finais do movimento ao redor do alvo aumenta linearmente com a média da velocidade do movimento.

Outro pressuposto importante para o modelo estocástico de submovimentos otimizados diz respeito à minimização dos tempos de movimento. Segundo o modelo, o sub-movimento primário e secundário possuem velocidades médias programadas para minimizar a média do tempo total através de um compromisso ideal entre a média de duração dos tempos dos sub-movimentos. Realizando sub-movimentos primários que têm velocidades mais altas deveriam aumentar a freqüência e a magnitude com a qual a região alvo não é atingida, sendo assim necessários os sub-movimentos secundários. $O$ aumento da freqüência e da magnitude do sub-movimento secundário deveria produzir aumentos na média do tempo total, mesmo que os sub-movimentos primários associados possuíssem pequenas durações. Por outro lado, realizar um sub-movimento primário que tem velocidades muito baixas deveria diminuir a freqüência e a magnitude do submovimento secundário, pois os pontos finais seriam mais próximos do alvo. Contudo, nesta situação, o tempo total de movimento seria aumentado como resultado das durações do sub-movimento primário. Desta forma, minimizando o tempo de 
movimento médio, o sub-movimento primário não deveria ser muito rápido ou muito lento, e correspondentemente, o sub-movimento secundário não deveria ser muito freqüente ou pouco freqüente. Os tempos dos sub-movimentos primários e secundários dependeriam da razão entre a distância e o tamanho do alvo (D / T). Em geral, grande razão $D / T$ requere a duração de ambos o sub-movimento primário e secundário para ser relativamente longa mesmo com a otimização do submovimento. A minimização assumida da média do tempo total de movimento satisfaz as demandas da tarefa usualmente impostas em movimentos de restrição espacial.

Meyer e colaboradores (1988) também explicaram como entendem o processamento preparatório da informação para a produção de movimento. No submovimento primário, a informação incluiria parâmetros da distância e do tamanho dos alvos em processo de preparação antes do início do sub-movimento primário. No sub-movimento secundário, informações subseqüentes são adquiridas considerando os processos do sub-movimento primário do início ao fim. O movimento secundário pode ser preparado com base na localização do alvo e feedback visual ou cinestésico no que diz respeito às características dinâmicas (por exemplo: velocidade e aceleração) do sub-movimento primário. O processo que prepara o sub-movimento secundário pode também usar processos antecipatórios através da cópia da eferência de um sub-movimento. Feedback e controle antecipatório seriam processados em tempo real na produção do movimento, de forma que essencialmente nenhum atraso é conseqüência entre o final de um sub-movimento primário e o início do subseqüente sub-movimento secundário. $O$ modelo estocástico de sub-movimentos otimizados fez predições quantitativas de movimentos rápidos com restrição espacial. Tais predições dizem respeito ao tempo médio total de movimento, duração média do sub-movimento primário e secundário, variabilidade espacial (desvio padrão) do ponto final do sub-movimento primário, freqüência relativa do sub-movimento secundário, e erros da freqüência relativa (alvos que não foram acertados). Para cada uma destas variáveis dependentes, uma predição pode ser realizada como uma função da distância e do tamanho do alvo.

Segundo o modelo, movimentos rápidos com restrição espacial apresentam o tempo médio de movimento total (TM), do sub-movimento primário e do sub-movimento secundário, aproximados à equação: $T M=a+b$ Raiz $(D / T)$, no 
qual 'a' e 'b' são constantes empíricas positivas, $D$ é a distância e T é o tamanho do alvo. A função de raiz quadrada (raiz de D / T) e logarítmica de troca (log de D / T) são próximas uma da outra $(R=0,97)$, exceto para valores pequenos e grandes de $D$ / $\mathrm{T}$, no qual a grande curvatura logarítmica de troca produz maiores desvios (Meyer et al., 1988). Contudo, existem algumas circunstâncias na qual o tempo pode ser uma relação linear de D / T. Quando o movimento é realizado apenas com um submovimento primário, omitindo sub-movimento secundário e outros de ordens mais altas, o tempo de movimento segue os resultados observados em movimentos de restrição temporal (Schmidt et al., 1978, 1979; Wright \& Meyer, 1983).

O erro espacial (ponto final) dos sub-movimentos primários deve ter um desvio padrão que aumenta linearmente com a média de velocidade do submovimento primário. A freqüência relativa dos sub-movimentos secundários aumenta continuamente com o aumento de $\mathrm{D} / \mathrm{T}$. Isto segue porque a freqüência de submovimentos secundários aumenta quando a probabilidade dos sub-movimentos primários atingirem o alvo diminui, e esta última diminui quando $D$ / T aumenta. Quando mais de um sub-movimento é realizado, com o aumento de $D / T$, é permitido que a média total de tempo de movimento permaneça relativamente pequena apesar da grande restrição espacial. Para alcançar grande precisão através apenas do sub-movimento primário seriam necessárias grandes durações dos submovimentos primários, dado o efeito do ruído neuromotor.

A taxa, ou seja, a freqüência relativa das tentativas que não atingem um alvo, do erro também aumenta em função do $D$ / T. Pelo fato de existir supostamente apenas dois sub-movimentos por movimento, um erro somente ocorrerá se o submovimento primário e secundário terminarem fora da região alvo. Existem apenas duas chances para atingir a região alvo em cada tentativa. Uma destas envolve o sub-movimento primário, e a outra envolve o sub-movimento secundário. Assim que o D / T aumenta, a probabilidade de que um sub-movimento secundário errar o alvo é assumido permanecer a mesma, mas a probabilidade de que um sub-movimento primário errar o alvo aumenta. Então a chance total de uma resposta correta diminui, e a taxa de erro aumenta. A taxa de aumento no erro com $D / T$ será menor que a taxa de aumento nos erros através de sub-movimentos primários por causa da contribuição de sub-movimentos secundários corretivos. Testes detalhados das 
predições sobre a taxa de erro não têm sido verificados na literatura passada em movimentos rápidos de restrição espacial.

Foi verificado que a média do tempo total, a média de duração do submovimento primário, o desvio padrão dos pontos finais do sub-movimento primário, a freqüência relativa do sub-movimento secundário, a média de duração do submovimento secundário, e a taxa de erro, todos aumentaram com a dificuldade do alvo (D / T) como o modelo prediz. De forma geral, o sucesso do modelo de submovimentos estocásticos foi atribuído ao compromisso ideal próximo entre a duração dos sub-movimentos primários e secundários capaz de compensar o ruído inerente no sistema que produz a variabilidade de movimento. Apesar do modelo estocástico de sub-movimentos otimizados ser considerada uma das melhores explicações no que diz respeito ao controle de movimentos balísticos direcionados a alvos, limitações também foram verificadas no modelo.

Sub-movimentos de ordens mais altas têm sido verificados em estudos que envolvem grande restrição espacial na tarefa (Carlton, 1980; Crosman \& Goodeve, 1963/1983; Jagacinski et al., 1980b; Meyer et al., 1982), contrariando o modelo proposto. Os pontos finais dos sub-movimentos (erros espaciais) não parecem sempre apresentar uma distribuição simétrica ao redor da região alvo. Por exemplo, no estudo de Fitts (1954, experimento 1) mais toques antes do alvo foram realizados em comparação aos toques depois do alvo, sugerindo uma tendência sistemática realizada pelos sub-movimentos curtos. Outra limitação foi encontrada na predição da duração do sub-movimento. Annett et al. (1958) demonstrou que as durações dos sub-movimentos primários foram independentes da distância e do tamanho do alvo, ao invés de ser diretamente relacionada à sua razão (D / T). Meyer et al. (1988) também questionam se a execução do movimento em seus experimentos ocorreu realmente de forma ótima. Como os sub-movimentos secundários ocorreram com menor freqüência que o predito para os alvos fáceis e mais freqüentemente que os alvos preditos com maior dificuldade, foi sugerida uma performance mais conservadora do que ótima na programação dos sub-movimentos. Em alguns casos o sub-movimento primário contribuiu entre $60 \%$ e $75 \%$ da média total do tempo de movimento, enquanto o modelo de sub-movimentos estocásticos previu que a razão deveria ser entre 50\% e 55\%. Em algumas situações, os 
resultados subestimam a verdadeira probabilidade de eventos prováveis e superestimou a verdadeira probabilidade de eventos improváveis. Tal comportamento também não corroborou exatamente o teorema de Bayes, uma regra normativa que combina a probabilidade prévia com os dados amostrados para estimar as probabilidades posteriores imparciais. Estas limitações apresentadas no modelo estocástico de sub-movimentos otimizados foram resultaram em outras pesquisas que originaram outros modelos que também tentaram explicar 0 paradigma da relação inversa velocidade-precisão.

\subsubsection{Modelo do deslizamento da desaceleração}

Em função das limitações verificadas nos pressupostos dos modelos anteriores, Zelaznik (1993) propôs o modelo do tempo de acionamento/deslizamento da desaceleração para explicar a relação inversa velocidade-precisão. Neste modelo, durante o movimento haveria um controle independente das forças de aceleração positivas e negativas para alcançar determinadas demandas de distância e de tempo na tarefa. Especificamente, se o tempo de movimento objetivado diminuísse, o atraso relativo no início das forças de aceleração negativa seria aumentado. Em outras palavras, existe um processo temporal que determinaria o início das forças de aceleração negativa, ou seja, um acionador (trigger). Quando o tempo diminuísse, o tempo relativo do início das forças de aceleração negativas seria aumento. $O$ controle deste processo acionador para o início das forças negativas foi denominado como deslizamento. Desta forma, o controle do movimento seria modulado através do deslizamento do início das forças aceleração negativa em relação ao início das forças de aceleração positiva.

De acordo com o modelo de deslizamento da desaceleração, o movimento seria controlado por dois conjuntos de impulsos, um para a aceleração positiva e outra para a aceleração negativa (desaceleração). Os impulsos compõem a soma das forças musculares que atuariam através do segmento movido. Cada impulso de aceleração foi caracterizado por uma função exponencial. Para acelerações positivas a função tem a seguinte forma: $a_{p}(T M)=\alpha_{p} T M_{x} \exp \left(-T M / T_{p}\right)$. O parâmetro $\alpha_{p}$ é um parâmetro escalar da magnitude da aceleração. $O$ parâmetro $T_{p}$ determina 0 
tempo para a maior magnitude da aceleração positiva. Para a aceleração negativa a descrição cinemática tem a mesma forma geral, apesar da equação da aceleração se tornar: $a_{n}(T M)=a_{n}(\omega-T M) \exp \left(-(\omega-T M) / T_{n}\right)$. Quando $\omega$ é igual a TM, a aceleração é igual a zero. O parâmetro $\omega$ foi chamado de tempo virtual, porque em situações de movimentos manuais de precisão a mensuração do tempo de movimento ocorre antes que o sujeito retorne a velocidade horizontal zero. Assim, a porção da força de aceleração negativa gerada através das forças musculares ocorreria através do impacto com o alvo. Este tempo virtual foi definido como o tempo no qual o movimento teria alcançado a velocidade zero dado que o movimento foi parado apenas por forças passivas e forças de atividade muscular. A quantificação do tempo virtual menos o tempo de movimento foi denominada de deslizamento porque ela representa 0 atraso das forças de desaceleração da musculatura antagonista. Situações na qual o deslizamento é igual a zero o movimento terminaria coincidindo com as forças musculares retornando o membro para velocidade e aceleração zero (por exemplo: modelos de Meyer et al., 1982). O padrão da aceleração foi determinado através da soma das funções de aceleração positivas e negativas, então: $a(T M)=a_{p} \exp \left(-T M / T_{n}\right)-a_{n}(\omega-T M) \exp (-(\omega-T M) /$ $\left.T_{n}\right)$.

Suporte para as predições do modelo foi verificado em experimento com simulação de dados no qual o modelo capturou de forma satisfatória as magnitudes dos picos da aceleração positiva e negativa (Zelaznik, 1993). Pode haver variabilidade no perfil da aceleração-tempo que produziria variabilidade no ponto final do movimento. Tal variabilidade poderia ser derivada de variabilidade no tempo (respectivamente, $T_{p}$ e $T_{n}$ ) e/ou na magnitude do maior valor da aceleração positiva e negativa (respectivamente, $\alpha_{p}$ e $\alpha_{n}$ ). Também haveria variabilidade no tempo virtual (w). A variabilidade na duração da aceleração positiva seria resultado da variabilidade de todos os parâmetros do modelo. Todavia, os modelos anteriores eram fundamentados na teoria dos programas motores generalizados, apontando que a duração do impulso para a aceleração positiva e negativa seria escalada com o tempo, pois o sistema nervoso central faria uma temporização na duração da atividade muscular agonista e antagonista (Wallace, 1981). Esta temporização seria graduada proporcionalmente ao tempo de movimento. No modelo de deslizamento 
da desaceleração, a duração da aceleração positiva seria determinada através de valores da magnitude e do tempo do pico na aceleração (respectivamente para $\alpha_{p}$ e $\left.T_{p}\right)$. A duração da aceleração negativa seria determinada primeiramente através dos valores da magnitude do pico da aceleração $\left(\alpha_{p}\right)$, do tempo virtual $(\omega)$ e do tempo para o pico da aceleração $\left(\mathrm{T}_{\mathrm{p}}\right)$. Além do mais, a duração da aceleração positiva seria também determinada através de quando as forças de aceleração negativa são iniciadas através da atividade eletromiográfica da musculatura antagonista. De forma geral, o modelo seria consistente com um sistema massa-mola (teoria do ponto de equilíbrio) com um acionador de desaceleração que determina o tempo de movimento.

Em se tratando da relação de troca linear velocidade-precisão, existiriam duas formas do modelo de deslizamento produzir esta relação linear. A primeira assume que a relação entre o desvio padrão do tempo virtual e o tempo de movimento seja uma função de raiz quadrada do tempo de movimento. Suporte para esta proposição do modelo foi na relação linear encontrada nos modelos anteriores da variabilidade do impulso (Meyer et al., 1982, 1988; Schmidt et al., 1978, 1979) e, confirmada, através de simulação de dados (Zelaznik, 1993). Zelaznik (1993) realizou uma através de simulação de dados para manipular a relação entre o tempo e a variabilidade do tempo de movimento, controlando o perfil da onda (quadrada e seno) para três níveis de distância e cinco de tempo de movimento. Foi verificado que o aumento da distância diminuiu o erro do alvo efetivo. Entretanto, o efeito do tempo no erro do alvo efetivo foi dependente do desvio padrão do tempo. Quando houve uma relação proporcional entre o tempo e o desvio padrão do tempo, não houve efeito do tempo sobre o erro do alvo efetivo. Por outro lado, com uma relação raiz quadrada, a troca linear velocidade-precisão foi produzida. Desta forma, não foi necessariamente o perfil cinemático do movimento, mas sim a relação entre o tempo e a variabilidade do tempo que determinou a relação velocidade-precisão. Estes resultados contrariam a proposição de Meyer, Smith e Wright (1982) que apontam apenas uma função especial, quase em forma de seno, para produzir uma relação de troca linear entre velocidade-precisão. Também foi demonstrado que o aumento na variabilidade da magnitude no pico da aceleração apresentou um acréscimo na variabilidade do erro. Contudo, não houve efeito do aumento na variabilidade da magnitude do impulso 
sobre o efeito do tempo de movimento no erro do alvo efetivo. Os resultados destas simulações sugerem que o efeito da distância e o efeito do tempo na relação de troca velocidade-precisão são resultado de diferentes processos. Nos dois modelos de variabilidade do impulso, a variabilidade do impulso produziu o erro no alvo efetivo, sem considerar se a variabilidade foi produzida através da altura do impulso ou da duração do impulso. Schmidt e colaboradores (1979) apontaram que a mudança no tempo provocou alterações na amplitude e na duração do impulso de forma particular que produziram mudanças na variabilidade do impulso que regulam a relação velocidade-precisão. $O$ fato do aumento na variabilidade da magnitude do impulso não produzir aumento no erro em valores pequenos do tempo de movimento, nos experimentos simulados, deixaram dúvidas sobre as suposições propostas nos modelos anteriores da variabilidade do impulso.

A segunda forma do modelo de deslizamento produzir uma troca linear diz respeito à natureza da relação entre o tempo de movimento virtual e o tempo de movimento. Se o tempo de movimento virtual não for uma proporção constante do tempo de movimento objetivado, mas ao invés aumentar proporcionalmente com a diminuição do tempo de movimento, então a relação entre o desvio padrão e a média do tempo de movimento seria aproximadamente uma função de raiz-quadrada. Assim, também ocorreria a troca linear velocidade-precisão. Esta segunda proposição do modelo teve suporte empírico através de um experimento cinemático analisando o movimento da mão em direção a um alvo. Zelaznik (1993) demonstrou uma forte correlação entre o erro e a velocidade do movimento ( $D / T M ; R=0,98$ ) em experimento em que foram manipuladas três distâncias $(5,20$ e $30 \mathrm{~cm})$ e cinco tempos de movimento $(150,175,200,225$ e $250 \mathrm{~ms})$. Os resultados indicaram que não houve efeito do tempo e da distância sobre a magnitude do impulso para a aceleração positiva nem efeito da distância sobre o tempo virtual (Zelaznik, 1986, 1993). O tempo para o pico da aceleração $\left(T_{p}\right)$ e para o a aceleração negativa também não tiveram efeito do tempo de movimento. Entretanto, houve aumento da magnitude do pico da aceleração negativa e do tempo virtual, em função do acréscimo de tempo de movimento. A razão do tempo virtual pelo tempo de movimento $(\omega / T)$ demonstrou que o tamanho relativo do tempo virtual aumentou com a diminuição do tempo de movimento. Esta é uma condição necessária para que 
o modelo do deslizamento produza uma relação linear de troca velocidade-precisão. Contudo, de acordo com o pressuposto do re-escalonamento do tempo nos modelos de variabilidade do impulso, o tempo virtual deveria ser proporcional ao tempo de movimento.

Estas evidências fornecem suporte para a hipótese de um modelo que considera distintas predições, sobre a cinemática, que foram desconsideradas em estudos anteriores. O modelo também leva em consideração a atividade eletromiográfica de movimentos rápidos, considerando que (a) a atividade muscular agonista deveria ser menos afetada através da manipulação da distância, tempo e estratégia antagonista de atividade muscular; e que (b) o acionamento relativo da atividade eletromiográfica antagonista deveria ser maior à medida que o tempo de movimento é diminuído, onde relativo acionamento da atividade é definido como o tempo entre o acionamento do desligamento da atividade agonista e o acionamento da atividade antagonista, relativamente para toda a duração do movimento. Contudo, pouco é conhecido sobre o tempo de acionamento da aceleração negativa. A maioria dos estudos em controle motor foi baseada em eletromiografia concêntrica na ativação da musculatura agonista (cf. Gottlieb et al., 1985; Wadman et al., 1979). Outra limitação do modelo foi que este necessita de um grande número de tentativas (maior que 20) para cada condição de distância e tempo de movimento. Esta limitação dificulta avaliar as predições do modelo de deslizamento com os dados reportados na literatura. Em algumas situações as predições do modelo sobre o pico da aceleração positiva e negativa foram subestimadas em suas magnitudes. Como nos modelos anteriores, o modelo do deslizamento da aceleração também se limitou a analisar um movimento unidimensional. Por conseguinte, faltam mais trabalhos empíricos para dar suporte às proposições do modelo, principalmente que explorem outras habilidades bi e tri-dimensionais para dar maior poder de generalização para o modelo.

\subsubsection{Modelo da teoria cinemática}

A teoria cinemática de Plamondon (1992, 1993, 1995a, 1995b; Plamondon \& Alimi, 1997) foi proposta para explicar a relação de troca velocidade-precisão em 
função das restrições inerentes que emergem diretamente da resposta do impulso delta-lognormal no sistema neuromuscular global envolvido na sinergia. A propriedade intrínseca desta resposta de impulso, combinada com a condição perceptivo-motora que deve ser encontrada em algum nível sensório-motor, seria suficiente para garantir o efeito da produção de qualquer movimento rápido. A teoria cinemática utiliza uma sinergia, envolvida na produção de um movimento destinado a um alvo, composta por dois sistemas paralelos com vários componentes de um conjunto neural e de redes musculares envolvidas nas ações neuromusculares agonistas e antagonistas que resultam num movimento específico. Utilizando tal modelo, seria possível proporcionar uma descrição analítica da resposta da sinergia, quando poucas hipóteses básicas fossem respeitadas.

Primeiro, a representação espacial deve ser selecionada para esta resposta. Para tal, foi assumido que a resposta da sinergia pode ser descrita no domínio da velocidade. Pois, o perfil da velocidade de movimentos rápidos e precisos teria uma forma global assimétrica em forma de sino que seria invariável através de uma grande extensão de movimentos com diferentes tamanhos e velocidades (Abend et al., 1982; Atkeson \& Hollerback, 1985; Morasso, 1981; Nagasaki, 1989; Soechting \& Laquaniti, 1981; Uno et al., 1989). Esta invariância sugere que a velocidade poderia representar uma regra chave no controle do movimento (Plamondon \& Alimi, 1997). Segundo, para a descrição bem aprendida e bem praticada dos movimentos, foi assumido que numa tarefa específica cada subsistema trabalharia de forma linear ao redor de algumas condições estáveis. Apesar do feedback proprioceptivo e das várias formas de interação e acoplamento entre estes dois sistemas, foi assumido que o efeito global nesses mecanismos podem ser verificados basicamente no final do processo através da subtração de duas respostas: resposta dos sistemas neuromusculares agonistas e antagonistas, pesados através da respectiva amplitude de comando de ativação.

Segundo a teoria cinemática cada componente dos sistemas neuromusculares presentes na sinergia interagem em série com seu vizinho mais próximo e em paralelo de forma hierárquica com os componentes mais distantes. Desta forma, baseado no tempo de atraso introduzido em um sistema através de diferentes componentes que tem reagido a um comando específico, a teoria 
conseguiria explicar estes dois casos extremos. No modelo puramente paralelo o tempo total de atraso caracterizando o sistema, agonista ou antagonista, seria limitado através de uma distribuição do tempo de atraso máximo dos diferentes componentes. Ao passo que, no sistema puramente seqüencial, o tempo total do atraso seria a soma dos tempos de atraso individual de cada componente. Considerando um modelo misto, o tempo de atraso associado com cada componente levado individualmente afeta o tempo total do atraso do sistema global de uma forma mais complexa para refletir ambos o acoplamento paralelo e seqüencial entre os componentes.

Realizando uma analogia com as predições do teorema central do limite, foi predito que a resposta do impulso de um sistema neuromuscular seria convergida numa curva normal logarítmica (Plamondon 1991, 1993, 1995a), desde que a resposta do impulso individual de cada componente encontre algumas das mais variadas condições (real, normalizada, não-negativa, condições não-negativas com um terceiro momento finito e dispersão graduada). Esta diferença dos dois logaritmos normais foi denominada como variação normal logarítmica, ou delta-lognormal, ou ainda lei Delta-A (Plamondon, 1993, 1995a). A lei Delta-A tem sido considerada a equação mais poderosa para reproduzir os perfis de velocidade completos de movimentos simples (Alimi \& Plamondon, 1993a, 1993b, 1994; Plamondon et al., 1993; Plamondon, 1995a).

A lei Delta-A prediz que, em movimentos de deslocamento com diferentes amplitudes e mesmo tempo de duração, o maior valor de velocidade aumenta quase que proporcionalmente com a distância coberta, o tempo para o maior valor de velocidade é constante e os diferentes perfis de velocidade se sobrepõem depois que o deslocamento é re-escalonado (normalizado). Estas inferências têm suporte de outros autores (Gielen et al., 1985). Em movimentos com distância constante e diferentes velocidades, a lei Delta-A prediz que o maior valor de velocidade aumenta nos movimentos mais rápidos e que o tempo para o maior valor de velocidade diminui com o aumento da velocidade média. Estas predições são consistentes com os resultados de diversos autores (Corcos et al., 1990; Gielen et al., 1985; Lestienne, 1979; Nagasaki, 1989). Além disso, os perfis de velocidade nesta classe de movimentos seriam aproximadamente sobrepostos depois do apropriado re- 
escalamento da amplitude e do tempo (Corcos et al., 1990; Gielen et al., 1985; Mustard \& Lee, 1987). Finalmente, para movimentos realizados o mais rapidamente possível para uma zona alvo, a lei Delta-A prediz que o maior valor de velocidade aumenta com o tempo de movimento, e que o tempo para o maior valor de aumenta com o acréscimo da velocidade máxima. Estas predições podem ser confirmadas pelos resultados de outros autores (Brown \& Cook, 1981; Gielen et al., 1985; Mustard \& Lee, 1987). Também é predito que a o maior valor de velocidade com o deslocamento, como observado através de muitos pesquisadores (Jeannerod, 1984; Milner, 1986; Schmidt et al., 1978, 1979).

A teoria cinemática também fez predições consistentes nas durações do tempo de movimento através da lei quadrática. Apesar de a simples curva normal logarítmica alcançar um valor nulo depois de um valor infinito de tempo (Plamondon, 1991), a subtração de dois logarítmicos normais podem resultar em um ou dois zeros cruzando o perfil da velocidade (Plamondon, 1993, 1995b). Esta teoria também demonstrou grande poder em predizer o perfil da velocidade verificado em movimentos balísticos de precisão. Contudo, assim como os modelos anteriores que tentaram explicar a origem da relação de troca velocidade-precisão, limitações também são verificadas no modelo de Plamondon. Ao contrário do que o modelo assume, o feedback parece ter importante papel no controle e na relação velocidadeprecisão (Chua \& Elliott, 1997; Hancock \& Verwey, 1997). Também não é sabido se o modelo assegura movimentos com utilização do feedback (Chua \& Elliott, 1997; Desmurget et al., 1997). Assim, o modelo torna-se instável, pois com aplicação de perturbação o alvo não seria alcançado, uma vez que o modelo não considera o uso do feedback no movimento (De Jong \& Van Galen, 1997). Ademais, assumir o perfil invariável da velocidade não parece estar correto, pois através de perturbação (alvo some ou é movido) o movimento pode ser corrigido sem alterar o perfil da velocidade (Desmurget et al., 1997). O modelo também é determinístico e não considera nenhum ruído neuro-motor (Bootsma \& Mottet, 1997; Goodman, 1997). Assumir que a troca velocidade-precisão é uma restrição inerente e emergente parece não ser apropriada, uma vez que em tarefas como a utilizada por Fitts (1954) as restrições impostas são externas e não internas (Bootsma \& Mottet, 1997). O modelo também deveria ser testado em movimentos mais complexos (Herrmann \& Soechting, 1997) e 
deveria considerar a interação do torque inercial não-linear, a redundância articular (Desmurget et al., 1997) e o impacto para frear o movimento (Hancock \& Verwey, 1997), rigidez e viscosidade (De Jong \& Van Galen, 1997).

O significado dos parâmetros do sistema também pareceu comprometido, pois as propriedades neurais e biomecânicas foram colocadas juntas no modelo (Bootsma \& Mottet, 1997). Alguns termos e explicações também não foram claros no texto, como "comportamento assintótico de grande número de sistemas lineares ligados, do qual a lei delta-lognormal pode ser derivada" (Goodman, 1997). A validade e testabilidade da arquitetura interna do modelo é questionável, pois mudanças nos dados poderiam ser atribuídas às mudanças nos padrões das sinergias (Carlton \& Liu, 1997). Foi contestada a necessidade de um grande número de sistemas lineares e a explicação neural destes sistemas, pois no modelo VITE (Bullock \& Grossberg, 1988) um sistema rudimentar não linear conseguiria explicar como as sinergias contraem sincronizadamente em diferentes velocidades para explicar a troca velocidade-precisão (Grossberg, 1997). A teoria utilizada para explicar a lei quadrática não pareceu ser apropriada em sua aplicação, pois pareceram ser independentes (Heuer, 1997). A origem e a justificativa para alguns pressupostos do modelo não foram claras, como a proporcionalidade entre as respostas das sinergias na lei delta-lognormal que parece não ocorrer em termos matemáticos (Holly, 1997). Não é claro como os alguns parâmetros do modelo foram relacionados aos parâmetros de controle tais como a rigidez e viscosidade (De Jong \& Van Galen, 1997). Através de simulação de dados foi demonstrado que as definições do tempo e precisão utilizadas por Plamondon e Alimi (1997) foram inapropriadas e poderiam violar os pressupostos originais da teoria (Holly, 1997).

\subsubsection{Modelo da capacidade de transmissão da informação}

Utilizando a teoria da informação (Miller, 1953; Pierce, 1961; Shannon, 1948; Shannon \& Weaver, 1949), Fitts (1954) levantou a hipótese de que a capacidade de transmissão da informação fixa do sistema motor possibilita um caminho para analisar a relação entre a distância (D), o tamanho do alvo (T) e o tempo de movimento (TM). Por conseguinte, a dificuldade da tarefa poderia ser 
mensurada em bits utilizando uma informação métrica e que, considerando uma tarefa de movimento, a informação seria transmitida através de um canal de comunicação estocástico de ruído que modela o comportamento do sistema motor humano. Para tanto, foi utilizada uma adaptação do teorema 17 de Shannon (1948), que expressa a capacidade de informação efetiva $C$ (em bitts/segundo), de um canal com comprimento de banda $B(e m H z)$, como: $C=B \log _{2}((S+N) / N)$, no qual $N$ é a potência do ruído e $S$ é a potência do sinal. Fitts afirmou que, em taxa máxima de transmissão da informação, o sistema motor humano se comporta de acordo com uma relação logarítmica através da identificação de 1/TM com $B, 2 \times D \operatorname{com} S+N$, e A com $\mathrm{N}$ para obter a relação de troca velocidade-precisão proposta na equação: TM $=a+b \log _{2}(2 \times D / T)$, no qual 'a' e 'b' são constantes empíricas.

Fitts proporcionou suporte para sua hipótese através de três experimentos com: (i) tarefa de toques repetitivos com uma ponteira, (ii) tarefa de transferência de discos e (iii) tarefa de transferência de pinos. Através da manipulação da distância entre os alvos e do tamanho dos alvos, nestes três experimentos, foi demonstrado que o tempo de movimento poderia ser predito. O tempo de movimento aumentou proporcionalmente com o acréscimo no índice de dificuldade (ID), através do aumento na distância do movimento ou da diminuição do tamanho do alvo. Assim, quanto maior a precisão necessária para completar a tarefa, menor a velocidade do movimento, estabelecendo a relação de troca velocidade-precisão. Devido ao grande suporte empírico a formulação de Fitts ganhou status de lei, sendo confirmada, totalmente ou parcialmente, para uma variedade de movimentos, membros e grupos musculares, condições experimentais e manipulação de dispositivos, sujeitos, e uma grande faixa de índices de dificuldade (tabela 1; Plamondon \& Alimi, 1997). Entretanto, apesar da consistência verificada experimentalmente ao longo do tempo para predizer o tempo de movimento através da distância do movimento e do tamanho do alvo, limitações foram encontradas na explicação para a relação de troca velocidade-precisão. 
TABELA 1 - Suporte empírico para a lei de Fitts (adaptado de Plamondon \& Alimi, 1997).

\begin{tabular}{|c|c|c|}
\hline & Estudos & Autores \\
\hline 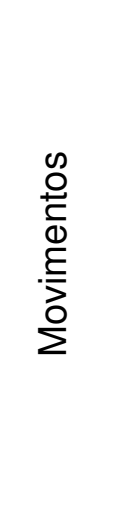 & $\begin{array}{l}\text { (a) Serial ou contínuo } \\
\text { (b) Discreto } \\
\text { (c) Toques } \\
\text { (d) Transferência de objetos } \\
\text { (e) Lançamento de dardo } \\
\text { (f) Três dimensões } \\
\text { (g) Rotação } \\
\text { (h) Apontar e largar/arrastar }\end{array}$ & $\begin{array}{l}\text { (a) Fitts (1954); Kvalseth (1975) } \\
\text { (b) Carlton (1979; 1980); Fitts \& Peterson (1964). } \\
\text { (c) Fitts (1954); Fitts \& Peterson (1964); } \\
\text { Kantowitz \& Elvers (1988); Megaw (1975); } \\
\text { (d) Fitts (1954); Raouf \& Tsui (1978) } \\
\text { (e) Kerr \& Langolf (1977) } \\
\text { (f) MacKenzie et al. (1987) } \\
\text { (g) Knight \& Dagnall (1967); Meyer et al. (1982, 1988) } \\
\text { (h) Gillan et al. (1990) }\end{array}$ \\
\hline 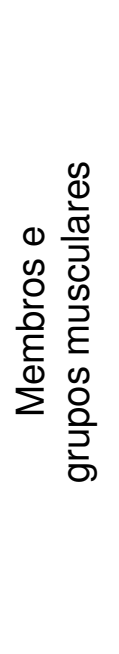 & $\begin{array}{l}\text { (a) Flexão e rotação de punho } \\
\text { (b) Movimentos dos pés } \\
\text { (c) Movimento da cabeça } \\
\text { (d) Manipulação dos dedos } \\
\text { (e) Extensão do braço } \\
\text { (f) Flexão rápida do cotovelo } \\
\text { (g) Fala } \\
\text { (h) Movimento das mãos } \\
\text { (i) Foi sugerido que a lei } \\
\text { deveria assegurar qualquer } \\
\text { habilidade motora }\end{array}$ & $\begin{array}{l}\text { (a) Crossman \& Goodeve (1963/1983); } \\
\text { Meyer et al. (1988); Wright \& Meyer (1983) } \\
\text { (b) Drury (1975); Hoffmann (1991b) } \\
\text { (c) Andres \& Hartung (1989); Jagacinski \& Monk (1985) } \\
\text { (d) Hoffmann \& Sheikh (1991); Langolf et al. (1976) } \\
\text { (e) Kerr \& Langolf (1977) } \\
\text { (f) Corcos et al. (1988) } \\
\text { (g) Jafari \& Kondraske (1988) } \\
\text { (h) Beggs \& Howarth (1972a, 1972b); Howarth et al. (1971) } \\
\text { (i) Glencross \& Barrett (1989); MacKenzie (1992) }\end{array}$ \\
\hline 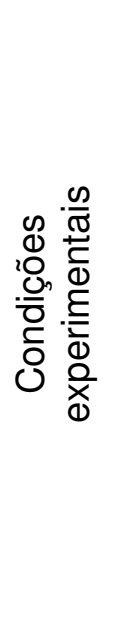 & $\begin{array}{l}\text { (a) Movimentos microscópicos } \\
\text { (b) Movimentos aquáticos } \\
\text { (c) Vôo com aeronave } \\
\text { (d) Feedback visual controlado } \\
\text { (e) Anestesia por gás } \\
\text { (f) Preferência manual } \\
\text { (g) Alvos móveis } \\
\text { (h) Atraso de informação } \\
\text { (i) Dinâmicas não usuais }\end{array}$ & $\begin{array}{l}\text { (a) Hancock et al. (1973); Langolf \& Hancock (1975) } \\
\text { (b) Kerr (1973; 1978) } \\
\text { (c) Hartzell et al. (1982) } \\
\text { (d) Bootsma et al. (2002); Carlton (1981a, 1981b); Crossman (1960); } \\
\text { Glencross \& Barrett (1989); Keele \& Posner (1968); Meyer et al. } \\
\text { (1988); Prablanc et al. (1979); Wallace \& Newell (1983); Zelaznik et } \\
\text { al. (1981) } \\
\text { (e) Fowler et al. (1982) } \\
\text { (f) Flowers (1975) } \\
\text { (g) Hoffmann (1991); Jagacinski et al. (1980a; 1980b) } \\
\text { (h) Ferrell (1965); Hoffmann (1992); Sheridan \& Ferrell (1963) } \\
\text { (i) Newman \& Bussolari (1990) }\end{array}$ \\
\hline
\end{tabular}


TABELA 1 - Continuação.

\section{Estudos}

(a) Ponteira de mão

(b) Rotação de mão

(c) Joystick

(d) Mouse de computador

(e) Teclado de computador

(f) Pedal

(g) Tele-operador

(h) Controle pela cabeça

(i) Mesa digitalizadora

(j) TrackBall

(k) Touchpad

(l) Eyetracker

(m) Sistema tele-robótico

(n) Touch Tablet

(o) Luva de Realidade Virtual

(a) Adolescentes e crianças

(b) Idosos

(c) Deficientes mentais

(d) Mal de Parkinson

(e) Paralisia cerebral

(f) Efeito de drogas

(g) Macacos

(h) Diferentes idades e sexo

(a) Menos de $1 \mathrm{bit} / \mathrm{seg}$.

으 (a) Fitts (1954); Kvalseth (1978)

(b) Crossman \& Goodeve (1963/1983)

(c) Card et al. (1978); Epps (1986); Hartzell et al. (1982); Jagacinski et al. (1980a)

(d) Boritz et al. (1991); Card et al. (1978); Epps (1986); Johnsgard (1994); Okazaki et al. (2008b); Pereira \& Okazaki (2008)

(e) Card et al. (1978); Drury \& Hoffmann (1992)

(f) Drury (1975)

(g) Draper et al. (1990); Drascic et al. (1989); Repperger \& Remis (1990); Shinhar (1986)

(h) Lin et al. (1992); Radwin et al. (1990); Spitz (1990)

(i) Spitz (1990); van Galen \& Schomaker (1992)

(j) Arnault \& Greenstein (1987); Epps (1986)

(k) Epps (1986)

(I) Ware \& Mikaelian (1987)

(m) Cannon \& Leifer (1990)

(n) Arnault \& Greenstein (1987)

(o) Johnsgard (1994)

(a) Jones (1991); Salmoni (1983); Salmoni \& Mcllwain (1979); Sugden (1980); Wallace et al. (1978)

(b) Goggin \& Meeuwsen, 1992; Welford et al. (1969)

(c) Wade et al. (1978)

(d) Flowers (1976)

(e) Bravo et al. (1990)

(f) Kvalseth (1977)

(g) Brooks (1979)

(h) Brogmus (1991)

(a) Hartzell et al. (1982)

(b) Kvalseth (1981)

(c) MacKenzie (1992)

\section{Autores}


Uma das maiores hipóteses da teoria da informação de Fitts é que o sistema motor humano se comporta como um canal de comunicação estocástico. Esta perspectiva teórica tem sido criticada por Crossman \& Goodeve (1963/1983), pois há uma grande dificuldade empírica de estabelecer a existência do postulado ruído ou de uma incerteza inicial. Além disso, Mackenzie (1989) demonstrou que a lei de Fitts seria derivada da equação 39 de Goldman (Goldman, 1953), a qual é uma aproximação do teorema de Shannon, ao invés do original teorema 17 de Shanonn (1948), dado na equação: $C=B \log _{2}(S / N)$. Um aumento na curvatura da relação entre o tempo de movimento e o índice de dificuldade, fora da linha de regressão, também tem sido observado para baixos índices de dificuldade (Buck, 1986; Crossman, 1957; Crossman \& Goodeve, 1963/1983; Drury, 1975; Klapp, 1975; Langolf et al., 1976; Meyer et al., 1988; Wallace et al., 1978; Welford, 1960). No experimento de toques recíprocos de Fitts, a constante empírica 'a' se torna negativa quando o tempo de movimento é apresentado em função do índice de dificuldade, assim como isso também traz para zero o número de informação por resposta. Ademais, a melhor linha de regressão dos dados de tempo de movimento em função do índice de dificuldade não é uma linha reta, mas uma curva levemente para cima (Knight \& Dargnall, 1967).

Outra limitação foi encontrada na contribuição relativa do tamanho do alvo e da distância na equação para predição do tempo de movimento. Em contraste aos pressupostos da lei de Fitts, tem sido sugerido que a amplitude e o tamanho do alvo não possuem força igual na determinação do tempo de movimento (Meyer et al., 1988; Sheridan, 1979; Welford et al., 1969). A desproporcionalidade aumentada no tempo de movimento causado através de reduções no tamanho do alvo, comparado aos aumentos similares na amplitude do alvo, tem sido reportada diretamente (Buck, 1986; Jagacinski et al., 1980a; Jagacinski \& Monk, 1985; Keele, 1973; Meyer et al., 1988; Welford et al., 1969), ou indiretamente de análises da taxa do erro, a qual foi encontrado aumentar com a diminuição do tamanho do alvo independentemente da distância de movimento (Card et al., 1978; Wade et al., 1978). Também deve ser notado que não foram todos os estudos que proporcionaram suporte para a lei de Fitts. Grande parte deles apresentou violação, novas formulações, ou novas explicações para esta lei. 
Várias discrepâncias entre os dados experimentais de Fitts e sua formulação teórica foram verificadas por alguns autores que mudaram a formulação do índice de dificuldade (tabela 2). Mackenzie $(1989,1992)$ demonstrou que a formulação de Fitts foi levemente diferente do teorema fundamental 17 de Shannon e propôs uma equação corrigida. Welford e colaboradores (1969) sugeriram uma equação que levasse em consideração o efeito independente da amplitude e do tamanho do alvo sobre a predição do tempo de movimento. Gan e Hoffmann (1988) propuseram uma equação para pequenos índices de dificuldade para predizer o tempo de movimento apenas através da amplitude do movimento. Welford (1968) também verificou que os sujeitos utilizavam apenas a metade mais próxima da área alvo e não toda sua extensão, ou seja, a restrição imposta pela precisão continha um viés, que foi corrigido por uma equação que levasse em consideração este viés. A partir desta perspectiva, Schmidt e colaboradores $(1978,1979)$ propõem o conceito de alvo efetivo $\left(\mathrm{W}_{\mathrm{e}}\right)$, ou alvo subjetivo (para Meyer et al., 1988), ou seja, um valor que especifique o alvo ou ponto final realmente alcançado na tarefa desempenhada. Avançando ainda mais, Soukoreff e Mackenzie (2004) propuseram um índice de dificuldade efetivo $\left(\mathrm{ID}_{\mathrm{e}}\right)$. Este índice de dificuldade específico seria alcançado através de um alvo efetivo $\left(T_{e}\right)$, em conjunto com uma distância efetiva $\left(D_{e}\right)$. Jagacinski e colaboradores (1980b) propuseram um índice de dificuldade que considerava o efeito da velocidade de movimento do alvo. Hoffmann (1991a) também propôs dois modelos para explicar o efeito da velocidade de um alvo em movimento. Foi acrescentado o efeito do atraso na informação entre o controle do movimento e o feedback da resposta do sistema efetor, demonstrando um bom ajuste para os resultados experimentais de Jagacinski e colaboradores (1980b). Johnsgard (1994) sugeriu que fosse considerado um efeito do ganho do dispositivo (G) utilizado na realização da tarefa. Desta forma, o índice de dificuldade foi reformulado para diversas condições específicas para melhorar o ajuste entre os dados para predizer o tempo de movimento. 
TABELA 2 - Formulações matemáticas para o ID (adaptado de Plamondon \& Alimi, 1997).

\begin{tabular}{|c|c|c|}
\hline Autor & Equação & Notas \\
\hline Shannon (1949) & $T M=a+b \log _{2}(D / T+1)$ & $\begin{array}{l}\text { D é a amplitude de movimento e T é } \\
\text { o tamanho do alvo. }\end{array}$ \\
\hline Crossman $(1957,1960)$ & $T M=a+b \log _{2}(D / T)$ & a e b são constantes de ajuste. \\
\hline Welford (1968) & $T M=a+b \log _{2}(D / T+0.5)$ & a e b são constantes de ajuste. \\
\hline Welford et al. (1969) & $T M=a+b_{A} \log _{2}(D)+b_{T} \log _{2}(1 / T)$ & a e b são constantes de ajuste. \\
\hline Jagacinski et al. (1980b) & $T M=c+d D+e(V+1)(1 / T-1)$ & $\begin{array}{l}\text { V é a media de velocidade do alvo } \\
\text { em movimento e c, } d \text {, e são } \\
\text { constantes de ajuste. }\end{array}$ \\
\hline Jagacinski et al. (1980b) & $T M=p+q \log _{2}\left\{2\left[D+V / T\left(T M+T_{t}\right)\right]\right\}$ & $\begin{array}{l}T_{\mathrm{t}} \text { é uma constante, correspondente } \\
\text { ao comprimento do tempo que o } \\
\text { cursor tinha para exceder o alvo } \\
\text { para capturá-lo, e p, q ou } x, y, z \\
\text { são constantes de ajuste. }\end{array}$ \\
\hline Jagacinski et al. (1980b) & $T M=x+y \log _{2}(2 D / T)+z \log _{2}\left[V /\left(T / T_{t}\right)+1\right]$ & $\begin{array}{l}\mathrm{T}_{\mathrm{t}} \text { é uma constante, correspondente } \\
\text { ao comprimento do tempo que o } \\
\text { cursor tinha para exceder o alvo } \\
\text { para capturá-lo e p, q ou } x, y, z \\
\text { são constantes de ajuste. }\end{array}$ \\
\hline Hoffman (1991a) & $\begin{array}{c}T M=1 / d \ln \{[D+V / d] /[T / 2-V / d]\} \\
\& \\
T M=a+b \log _{2}(D+V / d)-\operatorname{clog}_{2}(T / 2-V / d)\end{array}$ & a, b, c, d são constantes de ajuste. \\
\hline Hoffman (1992) & $T M=-a+b\left(c+D_{t}\right) \log _{2}(2 A / W)$ & $\begin{array}{l}D_{t} \text { é um atraso; a, b, c constantes de } \\
\text { ajuste. }\end{array}$ \\
\hline MacKenzie $(1989 ; 1992)$ & $T M=a+b \log _{2}(D / T+1)$ & \\
\hline Gan \& Hoffmann (1988) & $T M=a+b \operatorname{raiz}(D)$ & D é a distância do movimento. \\
\hline Johnsgard (1994) & $T M=a+b \log _{2}[(D / T) / G+1]$ & G é o efeito do ganho positivo. \\
\hline Kvalseth (1980) & $T M=a(D / T)^{b}$ & \\
\hline Soukoreff \& Mackenzie (2004) & $\begin{array}{c}T M=a+b \log _{2}\left(D / T_{e}+1\right) \\
\& \\
T M=a+b \log _{2}\left(D_{e} / T_{e}+1\right)\end{array}$ & $\begin{array}{l}T_{e} \text { é o alvo efetivo, } D_{e} \text { é a distância } \\
\text { efetiva. }\end{array}$ \\
\hline
\end{tabular}


As demais limitações no modelo da capacidade de transmissão da informação são comuns aos modelos anteriores. Ou seja, utilizou tarefas motoras simples, não foram analisados efeitos de inércia e de impacto, as tarefas analisadas não permitem a manipulação conjunta de outras variáveis como fontes de restrição no movimento (tamanho da distância, tamanho dos alvos, velocidade de movimento, inércia e impacto), etc. No entanto, apesar das limitações à formulação proposta por Fitts (1954), a relação velocidade-precisão tem sido considerada ser um dos fenômenos mais consistentes em comportamento motor (Bootsma et al., 2004; Plamondon \& Alimi, 1997; Teixeira, 2006). A partir da formulação, diversos pesquisadores procuraram explicações e novas formulações matemáticas capazes de predizer o desempenho humano dentro do paradigma da relação inversa velocidade-precisão (Elliott et al., 2001; Plamondon \& Alimi, 1997).

2.2 Movimentos rápidos e precisos dirigidos a alvos espaciais

O paradigma da relação de troca velocidade-precisão é um dos fenômenos mais investigados na área do comportamento motor. Diversos modelos tentaram explicar a origem desta relação de troca e entender a relação de variáveis como o tempo de movimento, dispersão dos pontos finais, velocidade, tamanho do alvo e distância entre os alvos. Todavia, diversas limitações foram verificadas nestes modelos, algumas destas em comum: simplicidade da tarefa (unidimensional, uniarticular, movimentos de toques em alvos espaciais, movimentos de rotação, etc.), não foram analisados os efeitos da inércia e do impacto, foi manipulado apenas a precisão (tamanho do alvo e distância entre os alvos) ou apenas o tempo de movimento (velocidade do movimento) num mesmo estudo, em geral não foram analisadas as respostas e o desempenho do movimento para entender as estratégias de controle e coordenação, entre outras limitações particulares aos modelos. Em função disto, ainda existe grande lacuna a ser preenchida no entendimento desta relação de inversa velocidade-precisão. Para atacar esta questão, o presente estudo utilizou um movimento complexo (balístico, em duas dimensões, multi-aticular) de impacto direcionado a alvos espaciais que permitiu analisar o efeito de algumas variáveis que não foram exploradas nos modelos anteriores (tamanho de alvo 
primário e secundário, impacto e inércia). Além de analisar uma classe de movimento que possui particularidades ainda não exploradas, como: movimento sem possibilidade de utilização do feedback, movimento complexo multi-articular, movimento de contato de um alvo (estático) dirigido a outro alvo remoto, o pico de velocidade tende a ser sincronizado com o instante de impacto (ao invés de ocorrer nas porções mediais do tempo de movimento) e a geração de velocidade ocorrendo predominantemente num eixo perpendicular ao eixo da precisão (erro espacial).

A partir da manipulação das variáveis de distância (manopla-disco), velocidade, precisão (tamanho do disco e do alvo remoto), inércia (peso da manopla) e impacto (peso do disco), este estudo realizou uma análise mais abrangente dos fatores associados ao controle das tarefas motoras mais complexas. Este conjunto de experimentos tem potencial para contribuir no entendimento desta classe de tarefas, assim como auxiliar no entendimento do controle motor utilizado na geração de velocidade e na manutenção da precisão em movimentos que necessitam de grande velocidade e precisão concomitantemente. 
Seis experimentos foram conduzidos para investigar as estratégias de controle motor utilizadas para a geração de velocidade e para a manutenção da precisão no movimento. Para tanto, foi utilizada a tarefa de contatar com máxima potência, com uma manopla, um disco em direção a um alvo remoto. Foram manipuladas as seguintes variáveis nos experimentos: (I) distância de movimento, (II) velocidade de movimento, (III) tamanho do disco, (IV) tamanho do alvo, (V) massa da manopla, e (VI) massa do disco.

\subsection{Participantes}

Dezesseis participantes foram utilizados nos seis experimentos. Foram selecionados participantes destros do sexo masculino com idades entre 18-23 anos, com estatura entre 1,70-1,80 m. Todos os participantes foram informados dos procedimentos do estudo e assinaram um termo de consentimento de participação livre e esclarecido (Anexo I). Os procedimentos do experimento foram aprovados pelo Comitê de Ética e Pesquisa da Escola de Educação Física e Esporte - USP.

\subsection{Instrumentos e tarefa}

A tarefa consistiu em golpear um disco tridimensional em posição fixa com uma manopla de base circular, procurando projetar o disco em direção a um alvo espacial. O movimento era desempenhado com o cotovelo inicialmente flexionado, mão próxima ao peito segurando a manopla. Por meio de movimentos simultâneos de extensão do cotovelo e flexão horizontal do ombro, o sujeito golpeava o disco, projetando-o na direção do alvo com máxima velocidade e precisão (figura 1).

Como superfície para deslizamento da manopla e do disco, foi empregada uma base de madeira medindo 1,80 $\mathrm{m}$ de largura por 0,90 $\mathrm{m}$ de comprimento. Essa base foi sustentada por quatro pernas $(0,70 \mathrm{~m}$ de altura), conferindo à estrutura 0 formato de uma mesa. As laterais e a parede do fundo foram delimitadas por uma parede vertical de $10 \mathrm{~cm}$ de altura, as quais foram forradas com espuma. $O$ sujeito foi 
instruído a ficar em uma posição confortável, com o tronco ereto apoiado anteriormente em um suporte acoplado à mesa e posteriormente pelo encosto da cadeira. Definindo a posição de início do movimento, houve um apoio semicircular no tabuleiro do lado em que o sujeito se posicionava para realizar o movimento. Este apoio foi utilizado para não permitir um movimento para trás (contra-movimento) antes de iniciar o movimento da manopla em direção ao disco. A distância entre a borda mais próxima da manopla e o tronco do sujeito foi de $8 \mathrm{~cm}$. Houve cinco possibilidades de posição inicial do disco variando entre $20-40 \mathrm{~cm}$, com intervalos de $4 \mathrm{~cm}$ entre elas, para permitir o desempenho de movimentos com diferentes distâncias. A medida da distância entre manopla e disco foi a partir da borda mais próxima destes.

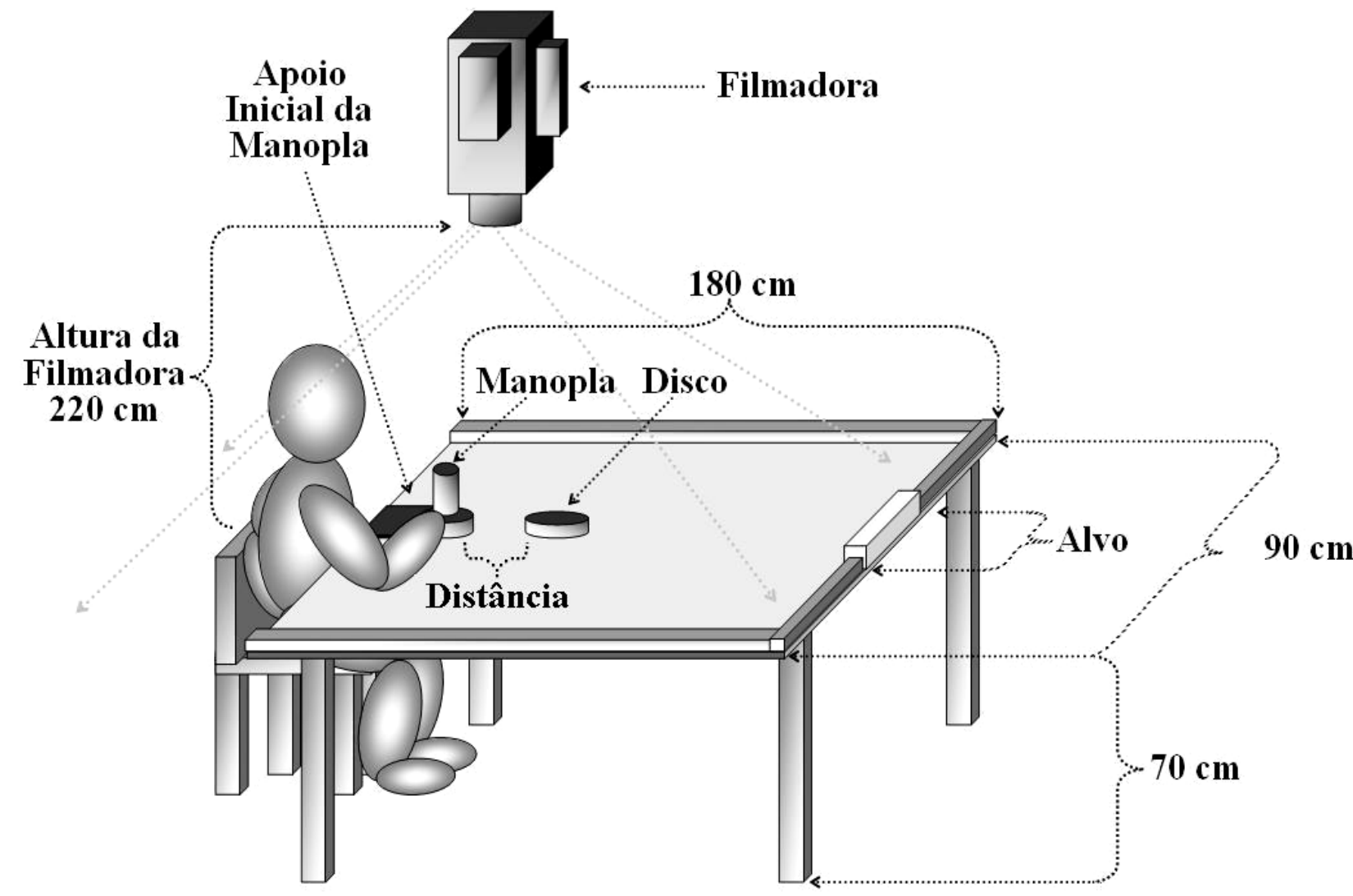

FIGURA 1- Representação esquemática da tarefa experimental, indicando os componentes do equipamento (manopla, disco e alvo), posicionamento inicial do participante e as dimensões da mesa e a posição da filmadora. 
A manopla consistiu de uma base metálica circular tridimensional de 7,5 $\mathrm{cm}$ de diâmetro com uma haste vertical para empunhadura de $15 \mathrm{~cm}$ de altura por $1,5 \mathrm{~cm}$ de diâmetro. Foram utilizadas cinco manoplas com diferentes massas. As manoplas tiveram variação de massa entre $200 \mathrm{~g}$ e $600 \mathrm{~g}$, com diferença de $100 \mathrm{~g}$ entre massas adjacentes. Foram empregados cinco discos, com o menor deles possuindo diâmetro igual a $3,5 \mathrm{~cm}$ e o maior igual a $7,5 \mathrm{~cm}$. Os demais discos adjacentes diferiram em $1 \mathrm{~cm}$ de diâmetro. $O$ disco com 7,5 cm possuiu massas variando de $100 \mathrm{~g}$ a $500 \mathrm{~g}$, com diferença de $100 \mathrm{~g}$ entre massas adjacentes. Isto permitiu manipular a força de impacto entre a manopla e o disco. O alvo foi constituído por uma porção da parede vertical, indicada pelo experimentador por meio de marcadores móveis, dispostas do lado oposto da mesa em que se encontrava o sujeito. Variações de $1 \mathrm{~cm}$ foram utilizadas entre alvos adjacentes para delimitar a largura do alvo, definido entre 2 e $10 \mathrm{~cm}$ (tabela 3).

O registro dos movimentos para posterior análise cinemática foi realizado por um sistema optoeletrônico. Para tal, uma câmera filmadora da marca Qualysis (v.2.57) foi colocada ortogonalmente 2,20 m acima da base de suporte onde foi desempenhado o movimento para posterior análise planar (Figura 1). Marcadores passivos refletivos, constituídos por meia esfera de isopor (15 $\mathrm{mm}$ de raio), revestida com fita refletiva $(3 \mathrm{M})$, foram afixados no sujeito, no disco e na manopla. Os marcadores foram rastreados automaticamente pelo sistema optoeletrônico, com aquisição de dados na freqüência de $240 \mathrm{~Hz}$.

Os marcadores refletivos foram colocados (1) no ombro esquerdo (acrômio esquerdo), (2) no ombro direito (acrômio direito), (3) no cotovelo direito (parte superior central de uma linha traçada entre os dois epicôndilo do úmero), (4) no punho direito (processo estilóide do rádio), (5) na parte superior central da haste da manopla e (6) na parte superior central do disco. A junção entre os pontos adjacentes relativos às articulações e manopla constituiu os segmentos do tronco (12), do braço (2-3), do antebraço (3-4) e da mão (4-5). O ângulo formado entre os segmentos adjacentes determinou o ângulo relativo do ombro (tronco-braço), do cotovelo (braço-antebraço) e do punho (antebraço-mão). O rastreamento dos marcadores da manopla e do disco permitiu a determinação do erro angular do disco e do instante de contato da manopla com o disco. O erro angular do disco foi 
determinado através do ângulo absoluto do segmento de reta formado pelos pontos da manopla e do disco na posição final do movimento, em relação a uma linha horizontal imaginária (figura 2).

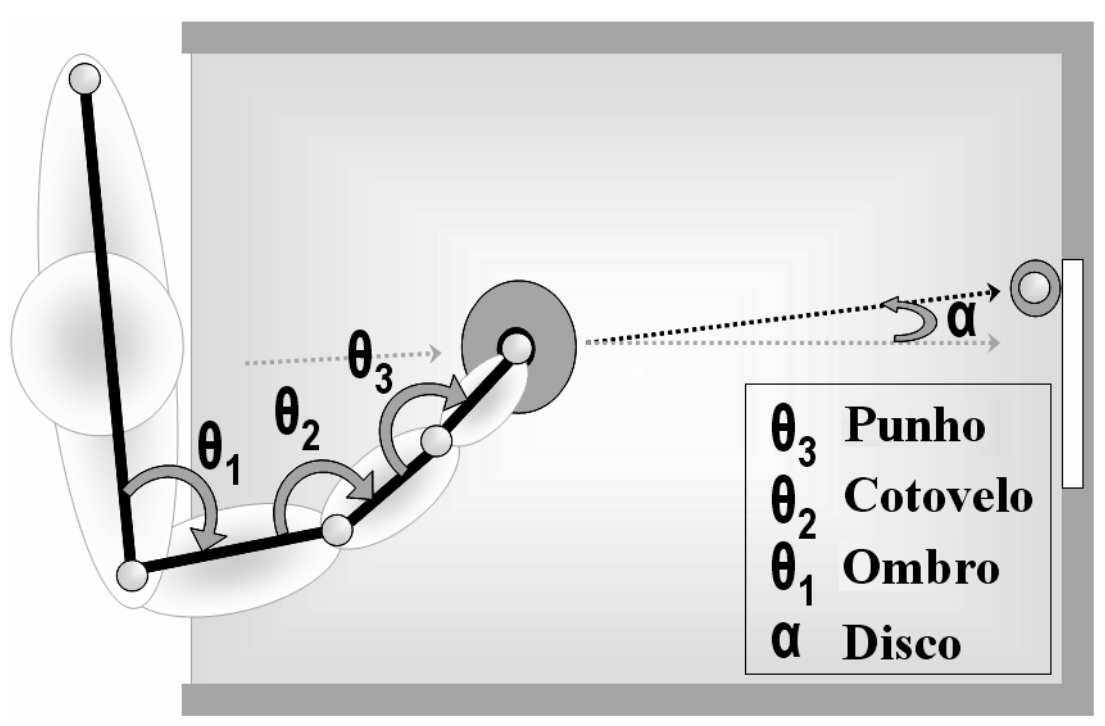

FIGURA 2- Modelo biomecânico a partir de vista superior da execução da tarefa experimental, representando os pontos anatômicos (ombros esquerdo e direito, cotovelo, punho e mão-manopla), ângulos articulares $(\theta 1-\theta 3) \mathrm{e}$ erro de deslocamento do disco ( $\alpha$ ).

\subsection{Procedimentos experimentais}

Inicialmente os sujeitos eram informados dos procedimentos experimentais e assinaram um termo de consentimento de participação livre e esclarecido. Posteriormente, marcadores eram afixados em regiões específicas para determinar o modelo biomecânico do estudo. Em seguida, os sujeitos participavam de uma sessão de adaptação e de aquecimento, praticando os movimentos específicos da tarefa nas condições experimentais. Os sujeitos eram instruídos a realizar os movimentos com maior velocidade e precisão possíveis, sempre tentando atingir o alvo com o disco. Inicialmente, o foco visual era direcionado ao alvo para a percepção da posição relativa entre o disco e o alvo. Posteriormente, o foco visual era dirigido até o disco, sobre o local onde o disco deveria ser golpeado com a 
manopla. Após um sinal sonoro indicando que o movimento poderia ser iniciado, o sujeito realizava a tarefa em momento determinado por ele mesmo.

Para cada condição experimental, os participantes desempenhavam cinco tentativas de familiarização (que foram descartadas) seguidas de 10 tentativas, cujos resultados eram registrados para subseqüente análise. Assim, as cinco condições experimentais totalizaram 50 tentativas em cada sessão experimental. A fim de prevenir fadiga, era adotado um intervalo de repouso de $2 \mathrm{~min}$. entre os blocos de tentativas para cada condição experimental. $O$ intervalo entre as tentativas foi de aproximadamente $8 \mathrm{~s}$. A seqüência das tentativas e a ordem de realização dos experimentos foram randomizadas para as condições experimentais por meio do procedimento do quadrado de Williams adaptado (Thomas et al., 2007), exceto no Experimento 2 (no qual foi manipulada a velocidade de movimento). Os procedimentos aqui descritos foram comuns entre os experimentos, exceto quando indicado de forma diferente na descrição específica.

\subsection{Variáveis do estudo}

As variáveis dependentes analisadas foram de resultado (cinemática do disco) e de desempenho (cinemática do modelo biomecânico e da manopla) do movimento. As variáveis de resultado do movimento foram a precisão (média do erro angular absoluto) e a variabilidade (desvio padrão do erro angular absoluto). O desempenho do movimento foi analisado por meio de variáveis espaciais e temporais angulares (articulações: ombro, cotovelo e punho) e lineares (manopla). As variáveis de desempenho analisadas foram: amplitude linear e angular de deslocamento (diferença entre o maior e o menor valor); ângulo articular no contato manopla-disco (deslocamento no instante de contato da manopla com o disco); maior valor de velocidade e de aceleração (linear e angular); velocidade e aceleração no instante de contato manopla-disco (linear e angular); tempo absoluto dos maiores valores de velocidade e de aceleração lineares e angulares; tempo total de movimento (até o instante em que a manopla terminou seu deslocamento); tempo absoluto de movimento até o contato manopla-disco; tempo absoluto após o contato manopladisco (tempo total menos tempo de movimento até o contato manopla-disco); e a 
diferença entre o tempo absoluto de contato manopla-disco e o tempo absoluto em que ocorreu o maior valor de velocidade; e o tempo relativo das fases de aceleração e de desaceleração no movimento. Estas variáveis dependentes foram utilizadas nos seis experimentos. Cada um dos experimentos possuiu uma variável independente particular: distância de movimento, velocidade de movimento, tamanho do disco, tamanho do alvo, massa da manopla e massa do disco, respectivamente para os experimentos I a VI (tabela 3).

TABELA 3 - Síntese das variáveis independentes e variáveis de controle nos seis experimentos.

\begin{tabular}{|c|c|c|c|c|c|c|c|c|}
\hline \multirow[b]{2}{*}{ Exp. } & \multirow[b]{2}{*}{$\begin{array}{c}\text { Variável } \\
\text { Manipulada }\end{array}$} & \multirow[b]{2}{*}{$\begin{array}{c}\text { Amplitude } \\
(\mathrm{cm})\end{array}$} & \multirow[b]{2}{*}{$\begin{array}{l}\text { Velocidade } \\
\text { (níveis) }\end{array}$} & \multicolumn{3}{|c|}{ Tamanho (cm) } & \multicolumn{2}{|c|}{ Massa (g) } \\
\hline & & & & Disco & Alvo & Manopla & Disco & Manopla \\
\hline 1 & Distância & $\begin{array}{c}16,20 \\
24,28,32\end{array}$ & Máxima & 7,5 & 10 & 7,5 & 100 & 200 \\
\hline II & Velocidade & 32 & $\begin{array}{c}\text { Mínimo ao } \\
\text { Máximo } \\
\text { em } 5 \\
\text { Níveis }\end{array}$ & 7,5 & 10 & 7,5 & 100 & 200 \\
\hline III & $\begin{array}{l}\text { Tamanho } \\
\text { do disco }\end{array}$ & 32 & Máxima & $\begin{array}{l}3,5 \\
4,5 \\
5,5 \\
6,5 \\
7,5\end{array}$ & 10 & 7,5 & 100 & 200 \\
\hline IV & $\begin{array}{l}\text { Tamanho } \\
\text { do alvo }\end{array}$ & 32 & Máxima & 7,5 & $\begin{array}{c}2,4 \\
6,8 \\
10\end{array}$ & 7,5 & 100 & 200 \\
\hline V & $\begin{array}{l}\text { Massa da } \\
\text { Manopla } \\
\text { (Inércia) }\end{array}$ & 32 & Máxima & 7,5 & 10 & 7,5 & $\begin{array}{l}100 \\
200 \\
300 \\
400 \\
500\end{array}$ & 200 \\
\hline VI & $\begin{array}{l}\text { Massa do } \\
\text { disco } \\
\text { (Impacto) }\end{array}$ & 32 & Máxima & 7,5 & 10 & 7,5 & 100 & $\begin{array}{l}200 \\
300 \\
400 \\
500 \\
600\end{array}$ \\
\hline
\end{tabular}


Índices de dificuldade foram calculados a partir da relação entre tamanho do disco, tamanho do alvo remoto e distância manopla-disco. Considerando a distância do centro do disco até o centro do alvo remoto $\left(D_{\mathrm{da}}\right)$ e o tamanho do alvo remoto $\left(T_{2}\right)$, foi possível determinar uma margem angular $\left(\beta^{\prime}\right)$, que o disco pode percorrer para atingir o alvo remoto. A margem angular de acerto $\left(\beta^{\prime}\right)$ é igual ao dobro do ângulo $\alpha^{\prime}$, calculado através da equação (figura 3 - Painel $A$ ):

$$
\begin{aligned}
& \beta^{\prime}=2 \times \alpha^{\prime} & \text { (equação 1) } \\
\text { no qual: } & \alpha^{\prime}=A \operatorname{Tan}\left[\left(T_{2} / 2\right) / D_{d a}\right] & \text { (equação 2). }
\end{aligned}
$$

O ângulo $\alpha^{\prime}$ também delimitou uma margem de acerto angular ( $\left.\beta "\right)$, na qual a manopla deve contatar o disco (perpendicularmente), para que o disco atinja o alvo remoto. Esta margem de acerto da posição inicial da manopla, em relação à região na qual o disco pode ser contatado para que atinja o alvo remoto (alvo virtual: $T_{v}$ ), foi calculada em função de $\alpha^{\prime}$, do raio do disco $(r)$ e da distância entre o centro da manopla e o centro do disco $\left(A_{m d}\right)$ :

$$
\begin{array}{lll} 
& T_{v}=2 \times T_{1} & \text { (equação 3), } \\
\text { no qual: } & T_{1}=\operatorname{Sen} \alpha^{\prime}{ }_{x} r & \text { (equação 4) }
\end{array}
$$

(figura 3 - Painel B). Posteriormente, foi calculada a distância entre o centro do disco e a distância alvo ( $\left.A^{\prime}\right)$ que foi utilizada para calcular a margem de acerto angular manopla-disco (figura $3-$ Painel $C$ ):

$$
\begin{array}{lll} 
& A_{m d}=A^{\prime}+A^{\prime \prime} & \text { (equação 5), } \\
\text { no qual: } & A^{\prime}=\text { Raiz }\left[(r)^{2}-\left(T_{1}\right)^{2}\right] & \text { (equação 6). }
\end{array}
$$

Após, foi calculada a margem de acerto angular manopla-disco ( $\beta ")$ :

$$
\begin{array}{lll} 
& \alpha^{\prime \prime}=A \operatorname{Tan}\left(T_{1} / A^{\prime \prime}\right) & \text { (equação 7), } \\
\text { no qual: } & \beta^{\prime \prime}=2 \times \alpha^{\prime \prime} & \text { (equação 8). }
\end{array}
$$

Enfim, o índice de dificuldade (ID') pôde ser representado pela cotangente do ângulo da margem de acerto angular (para maiores detalhes consulte: Sidaway et al., 1988) manopla-disco:

$$
\left.\left.I^{\prime}=\log _{2} \text { [cot ( } \beta^{\prime \prime} / 2\right)\right]
$$$$
\text { (equação 9). }
$$

Outra forma para calcular o índice de dificuldade foi utilizada o tamanho do alvo virtual, ou seja, a margem de acerto delimitada pela região na qual o disco pode ser contatado para que atinja o alvo remoto $\left(T_{v}\right)$, como se fosse o alvo a ser 
contatado na tarefa de Fitts. A partir desta medida do tamanho do alvo virtual foi utilizada a equação já conhecida na lei de Fitts (1954):

$\left.\mathrm{ID}=\log _{2}[(2 \times \mathrm{D}) / \mathrm{T}]\right)$,

no qual a distância entre os alvos foi igual à $A$ " e o tamanho do alvo igual à $T_{v}$, assim foi formulada a seguinte equação:

ID" $=\log _{2}\left[\left(2 \times A^{\prime \prime}\right) / T_{v}\right]$

(equação 11).

Estas duas propostas de ID, adaptadas para a tarefa de contatar uma manopla num disco para lançar o disco em direção a um alvo remoto, foram utilizadas no estudo para possibilitar um parâmetro de comparação com outros estudos realizados. Os índices de dificuldade e as variáveis utilizadas para calcular estes índices encontram-se expressos na tabela 4.

\section{PATNEL A}

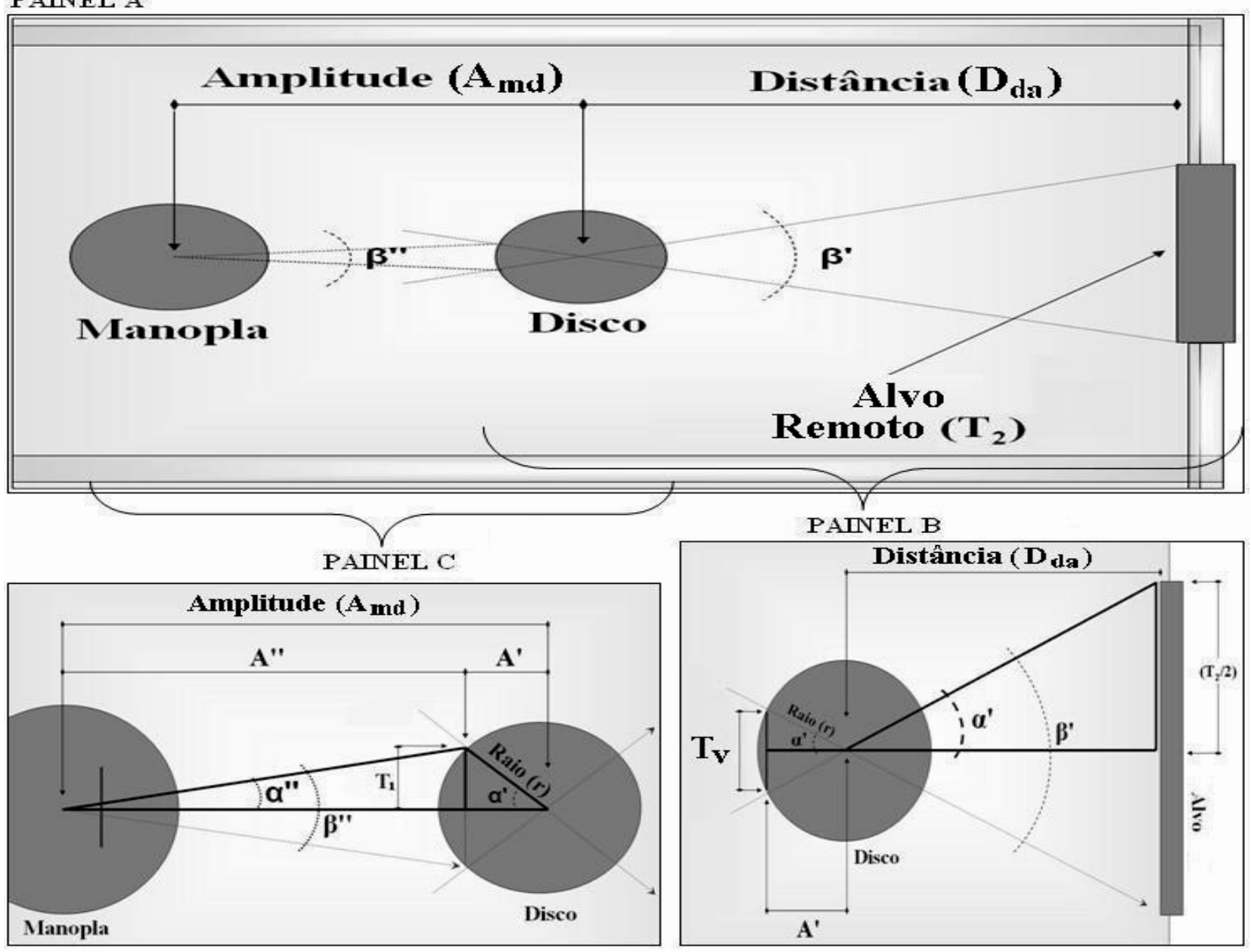

FIGURA 3 - Representação esquemática para o cálculo dos índices de dificuldade. 
TABELA 4 - Índices de dificuldade calculados para os experimentos.

\begin{tabular}{|c|c|c|c|c|c|c|c|c|c|c|c|}
\hline \multirow{2}{*}{\multicolumn{2}{|c|}{ Experimento }} & \multicolumn{3}{|c|}{$\begin{array}{l}\text { Alvos } \\
(\mathrm{cm})\end{array}$} & \multicolumn{3}{|c|}{$\begin{array}{l}\text { Distâncias } \\
\text { (cm) }\end{array}$} & \multicolumn{2}{|c|}{$\begin{array}{c}\text { Margem de } \\
\text { acerto }(\stackrel{\circ}{)})\end{array}$} & \multicolumn{2}{|c|}{$\begin{array}{c}\text { ID } \\
\text { (bits/s) }\end{array}$} \\
\hline & & \multirow{2}{*}{$\begin{array}{l}\mathrm{D}_{1} \\
7,5\end{array}$} & \multirow{2}{*}{$\frac{T_{v}}{0,25}$} & \multirow{2}{*}{$\frac{T_{2}}{10}$} & \multirow{2}{*}{$\frac{\mathrm{DM}}{16}$} & \multirow{2}{*}{$\frac{A^{\prime}}{3,75}$} & \multirow{2}{*}{$\frac{A^{\prime \prime}}{19,75}$} & \multirow{2}{*}{$\frac{\beta^{\prime}}{3,92}$} & \multirow{2}{*}{$\frac{\beta^{\prime \prime}}{1,49}$} & \multirow{2}{*}{$\begin{array}{c}I^{\prime} \\
6,27\end{array}$} & \multirow{2}{*}{$\frac{I^{\prime \prime}}{6,96}$} \\
\hline I & Distância & & & & & & & & & & \\
\hline I & Distância & 7,5 & 0,26 & 10 & 20 & 3,75 & 23,75 & 4,03 & 1,27 & 6,49 & 7,24 \\
\hline I & Distância & 7,5 & 0,27 & 10 & 24 & 3,75 & 27,75 & 4,15 & 1,12 & 6,67 & 7,47 \\
\hline I & Distância & 7,5 & 0,28 & 10 & 28 & 3,75 & 31,75 & 4,27 & 1,01 & 6,83 & 7,65 \\
\hline 1 & Distância & 7,5 & 0,29 & 10 & 32 & 3,75 & 35,75 & 4,41 & 0,92 & 6,95 & 7,79 \\
\hline II & Velocidade & 7,5 & 0,29 & 10 & 32 & 3,75 & 35,75 & 4,41 & 0,92 & 6,95 & 7,79 \\
\hline III & Disco & 7,5 & 0,29 & 10 & 32 & 3,75 & 35,75 & 4,41 & 0,92 & 6,95 & 7,79 \\
\hline III & Disco & 6,5 & 0,25 & 10 & 32 & 3,25 & 35,75 & 4,37 & 0,79 & 7,17 & 8,01 \\
\hline III & Disco & 5,5 & 0,21 & 10 & 32 & 2,75 & 35,75 & 4,34 & 0,67 & 7,42 & 8,26 \\
\hline III & Disco & 4,5 & 0,17 & 10 & 32 & 2,25 & 35,75 & 4,31 & 0,54 & 7,72 & 8,56 \\
\hline III & Disco & 3,5 & 0,13 & 10 & 32 & 1,75 & 35,75 & 4,27 & 0,42 & 8,10 & 8,94 \\
\hline IV & Alvo & 7,5 & 0,29 & 10 & 32 & 3,75 & 35,75 & 4,41 & 0,92 & 6,95 & 7,79 \\
\hline IV & Alvo & 7,5 & 0,23 & 8 & 32 & 3,75 & 35,75 & 3,52 & 0,74 & 7,28 & 8,12 \\
\hline IV & Alvo & 7,5 & 0,17 & 6 & 32 & 3,75 & 35,75 & 2,64 & 0,55 & 7,69 & 8,53 \\
\hline IV & Alvo & 7,5 & 0,12 & 4 & 32 & 3,75 & 35,75 & 1,76 & 0,37 & 8,28 & 9,12 \\
\hline IV & Alvo & 7,5 & 0,06 & 2 & 32 & 3,75 & 35,75 & 0,88 & 0,18 & 9,27 & 10,12 \\
\hline V & Inércia & 7,5 & 0,29 & 10 & 32 & 3,75 & 35,75 & 4,41 & 0,92 & 6,95 & 7,79 \\
\hline VI & Impacto & 7,5 & 0,29 & 10 & 32 & 3,75 & 35,75 & 4,41 & 0,92 & 6,95 & 7,79 \\
\hline
\end{tabular}

Legenda: $\mathrm{D}_{1}$, diâmetro do disco; $\mathrm{T}_{\mathrm{v}}$, tamanho do alvo virtual; $\mathrm{T}_{2}$, tamanho do alvo; $\mathrm{DM}$, distância da borda da manopla até a borda do disco; $A^{\prime}$, distância do centro do disco até a linha que delimita o alvo virtual; $A^{\prime \prime}$, distância do alvo virtual até o centro da manopla; $\beta^{\prime}$, margem angular de acerto do disco em relação ao alvo; $\beta$ ", margem angular de acerto da manopla em relação ao disco; ID', índice de dificuldade calculado a partir da margem de acerto $\left(\beta^{\prime}\right)$; ID", índice de dificuldade calculado a partir do tamanho do alvo virtual $\left(\mathrm{T}_{1}\right)$. 
A posição linear espacial dos marcadores foi utilizada para determinar os ângulos das articulações do ombro, do cotovelo e do punho. Estas variáveis de posição (linear e angular) foram filtradas para o cálculo posterior das variáveis de velocidade e de aceleração (Giakas \& Baltzopoulos, 1997b; Okazaki et al., 2007a). Para atenuar os ruídos na análise cinemática, foi aplicado um filtro recursivo do tipo Buterworth passa-baixa de $4^{\text {a }}$ ordem (Giakas \& Baltzopoulos, 1997a; Okazaki et al., 2007a, 2007b). A freqüência de corte para a filtragem dos marcadores rastreados foi determinada por meio de análise residual (Okazaki et al., 2007c; Winter, 1990) e por meio de um teste do rastreamento dos marcadores. A análise residual indicou a freqüência de corte para o filtro através do resíduo do sinal filtrado em diversas freqüências, em relação ao sinal bruto rastreado. As freqüências de corte que apontaram menor perda do sinal e maior atenuação do ruído foram identificadas por este método (entre 7 e $10 \mathrm{~Hz}$ ) e utilizadas nos experimentos. O teste de rastreamento foi realizado com os marcadores parados (marcadores de calibração instantânea) para verificar o erro associado ao processo de identificação da posição dos marcadores pelo sistema. As freqüências de corte que eliminam os erros (variações) no rastreamento dos marcadores parados também foram utilizadas para confirmar a freqüência de corte do filtro (acima de $20 \mathrm{~Hz}$ ).

A calibração do espaço planar, ou seja, a conversão dos valores virtuais (pixels) para valores reais (metros), foi realizada por meio de quatro marcadores formando um quadrado $(0,8 \mathrm{~m} \times 0,8 \mathrm{~m})$, colocados sobre a área do movimento. $\mathrm{O}$ ângulo de inclinação da linha formada entre a posição inicial da manopla e do disco também foi utilizado para corrigir a inclinação do sistema de coordenadas cartesiano proporcionado pela análise cinemática.

O início do movimento foi determinado no instante em que a manopla alcançou velocidade linear no eixo $x$ igual a $5 \mathrm{~mm} / \mathrm{s}$. O final do movimento foi determinado no instante em que a velocidade linear da manopla no eixo $x$, após 0 contato com o disco, atingiu velocidade de $5 \mathrm{~mm} / \mathrm{s}$ no eixo $x$. $O$ instante de contato da manopla com o disco foi determinado no instante em que o disco atingiu velocidade de $5 \mathrm{~mm} / \mathrm{s}$ no eixo $\mathrm{x}$. 
Os dados foram analisados por meio de estatística descritiva, inferencial e associativa. Para a estatística descritiva os dados foram representados através de medianas, médias, e desvios padrão. A mediana foi utilizada como medida representativa das 10 tentativas para cada condição experimental nos dados individuais dos sujeitos. A média e o desvio padrão foram utilizados, respectivamente, para agrupar os dados individuais dos sujeitos em cada condição experimental e representar sua variabilidade. Os testes de Kolmogorov-Smirnov e Bartlett foram utilizados para analisar a normalidade e a homocedasticidade dos dados, respectivamente. A estatística inferencial foi utilizada para comparação entre as diferentes condições experimentais por meio de análise de variância unifatorial com medidas repetidas. A identificação das diferenças entre os cinco níveis de análise foi realizada, posteriormente, através do teste de Tukey. A estatística associativa foi utilizada por meio de uma análise de regressão linear simples, no Experimento II, para entender a relação entre as seguintes variáveis: (a) velocidade média $\times$ precisão/variabilidade (média e desvio padrão do erro angular absoluto, respectivamente); (b) velocidade no instante de contato manopla-disco $x$ precisão/variabilidade; e (c) maior valor de velocidade $\times$ precisão/variabilidade. Nos experimentos I, III e IV, a análise de regressão linear simples foi utilizada para verificar a relação entre os índices de dificuldade propostos (ID' e ID") e as variáveis temporais de tempo de movimento, tempo para contato, e tempo após contato. $\mathrm{O}$ nível mínimo de significância adotado nos procedimentos estatísticos para as análises foi estabelecido em $5 \%$. 
4.1 Introdução

Movimentos rápidos direcionados a alvos espaciais, sob a restrição do aumento na distância ou da diminuição do tamanho do alvo, tendem a apresentar uma relação inversa entre velocidade e precisão no movimento (Fitts, 1954; Fitts \& Petersen, 1964; Meyer et al., 1982, 1988). Esta relação entre as variáveis de tamanho do alvo (T) e de distância (D) do movimento foi expressa matematicamente por Fitts (1954), definindo um índice de dificuldade (ID $=\log _{2}$ [ $\left.2 \times \mathrm{D} / \mathrm{T}\right]$ ), sendo linearmente relacionado ao tempo de movimento (TM). Assim, quanto menor o tamanho do alvo ou maior a distância movida, maior é a restrição imposta sobre o movimento, resultando em movimentos com maior duração.

Diversos resultados de pesquisa têm corroborado a predição do tempo de movimento em função do ID, em tarefas discretas (Carlton, 1979; Glencross \& Barrett, 1989; Smits-Engelsman et al., 2006), cíclicas (Guiard, 1997; Mottet et al., 2001; Salmoni, 1983), lançamentos (Kerr \& Langolf, 1977), movimentos de extensão de braço (Kerr \& Langolf, 1977), movimentos de flexão do braço (Corcos et al., 1988), movimentos unidimensionais (Fitts, 1954; Fitts \& Petersen, 1964; Okazaki et al., 2008b), movimentos bidimensionais (Jax et al., 2007; Yao et al., 2007), movimentos tridimensionais (Mackenzie et al., 1987; Murata \& Iwase, 2001); de tal forma que esta formulação matemática tem sido um dos fenômenos mais consistentes nos estudos do comportamento motor (Bootsma et al., 2004; Elliott et al., 2004; Teixeira, 2006). Contudo, a formulação proposta por Fitts parte do pressuposto de que a amplitude de movimento e o tamanho do alvo são restrições de mesma natureza na regulação do movimento. Alguns estudos já demonstraram que o tamanho do alvo ou a distância movida possuem efeitos independentes sobre o tempo do movimento (Annett et al., 1958; Goggin \& Meeuwsen, 1992; Meyer et al., 1988). Por conseguinte, estes processos de regulação no movimento podem ser provenientes de fontes e estratégias de controle distintas (Thompson et al., 2007). Por exemplo, acrescentar restrição ao movimento através do aumento na distância resulta em maior tempo de movimento, que permite a geração de maior velocidade 
através do aumento na fase de aceleração no movimento (Bootsma et al., 2004; Mackenzie et al., 1987; Milner, 1986; Teixeira, 2000). Ao passo que, a diminuição no tamanho do alvo resulta em maior tempo de movimento, mas com redução na velocidade e com aumento na duração da fase de desaceleração no movimento (Adam, 1992; Adam et al., 1995; Langolf et al., 1976). Assim, o aumento na distância apresenta uma restrição da tarefa mais associada à geração de velocidade no movimento, enquanto a diminuição no tamanho do alvo apresenta uma restrição no sistema associada ao controle de manutenção da precisão (Thompson et al., 2007). Desta forma, deve-se considerar o efeito isolado destas restrições de distância e de tamanho do alvo na regulação do movimento.

Devido à importância da variável distância como fonte de restrição espacial na regulação do movimento, diversos estudos analisaram o efeito desta variável sobre o controle de movimentos rápidos e precisos (Crossman \& Goodeve, 1963/1983; Fitts, 1954; Meyer et al., 1982, 1988; Schmidt et al., 1978). Schmidt e colaboradores $(1978,1979)$ demonstraram que para aumentar a distância de movimento, mantendo o tempo constante, é necessário empregar maior força para aumentar a velocidade de movimento. Uma vez que a maior variabilidade espacial de resposta está associada ao aumento na geração de força, relacionada ao aumento da velocidade, tem-se o detrimento na precisão quando a velocidade de movimento é aumentada (Meyer et al., 1982; 1988; Schmidt et al., 1978, 1979). Contudo, nas tarefas normalmente utilizadas para analisar os modelos de controle motor, o maior valor da velocidade tende a ocorrer na porção medial do movimento (Plamondon \& Alimi, 1997). Assim, pode haver tempo para o sistema desacelerar o movimento antes do instante de contato, garantindo menor variabilidade e maior precisão no movimento (Teixeira, 2000). Por outro lado, em movimentos mais complexos, tal como rebater (Caljouw et al., 2005; Putnan, 1993) ou lançar no beisebol (Chodhary \& Challis, 2001; Southard, 1998, 2002), arremessar no basquetebol (Okazaki \& Rodacki, 2005; Okazaki et al., 2006a, 2006b, 2006c), ou chutar no futebol (Anderson \& Sidaway, 1994; Putnan, 1991; Teixeira, 1999), o maior valor de velocidade tende a convergir para o instante mais próximo ao contato com o alvo primário para maximizar sua velocidade de projeção em direção ao alvo remoto secundário. Uma vez que a maior variabilidade espacial de resposta está associada ao aumento na 
velocidade do movimento (Meyer et al., 1982; 1988; Schmidt et al., 1978, 1979), temos características antagônicas ocorrendo justamente no período crítico de performance (contato com disco), as quais deverão ser balanceadas pelo sistema para cumprir o objetivo da tarefa. Dessa forma, um aspecto importante a ser conhecido sobre tarefas motoras dessa natureza é o efeito da distância sobre as estratégias de controle na geração da velocidade e na regulação da precisão no movimento.

Uma estratégia que também pode auxiliar no entendimento da regulação de troca entre velocidade e precisão é a analise do desempenho em cada articulação que participa no movimento. Por exemplo, apesar de o aumento na velocidade ter sido associado à maior a variabilidade de resposta (Schmidt et al., 1978, 1979), ao analisar individualmente as articulações, o sistema demonstra uma flexibilidade na qual a variabilidade das articulações é compensada ao longo da cadeia cinemática. Esta estratégia ocorre para a manutenção da precisão de forma que diferentes combinações articulares garantam a mesma precisão de resposta (Doorenbosch et al., 1997; Helsen et al., 2000; Stelmach \& Diggles, 1982). Contudo, poucos estudos analisaram a contribuição das ações articulares no paradigma da relação inversa entre velocidade-precisão. Como a resposta do movimento é produto da organização das ações inter-articulares que participam do movimento, a análise do desempenho das articulações pode trazer informações importantes sobre as estratégias de controle utilizadas para a regulação velocidade-precisão.

Considerando os pontos discutidos anteriormente, no presente experimento foi analisado o efeito da distância para entender as estratégias de controle por meio das variáveis cinemáticas lineares de resposta e angulares de desempenho no movimento.

\subsection{Objetivo}

Analisar o efeito da distância de movimento (distância manopla-disco), na tarefa de contatar um disco com uma manopla em direção a um alvo remoto, sobre as variáveis cinemáticas de resposta e de desempenho no movimento. 
4.3 Hipóteses

H1 Maior distância de movimento induz maior geração de velocidade em detrimento de precisão e de consistência do movimento (maior variabilidade).

H2 O tempo do maior valor de velocidade é sincronizado com o instante em que ocorre o contato manopla-disco.

H3 Maior distância de movimento resulta em maior índice de dificuldade que está diretamente relacionado ao tempo de movimento, tempo para contato e tempo após contato manopla-disco.

H4 Maior distância de movimento resulta no aumento da maior velocidade e da maior aceleração nas articulações do ombro, do cotovelo e do punho.

H5 Maior distância de movimento possibilita maior fase de aceleração nas articulações do ombro, do cotovelo e do punho.

\subsection{Procedimentos particulares do método}

Foi analisada a tarefa de contatar um disco com uma manopla em direção a um alvo remoto, realizada com máxima velocidade e maior precisão possíveis. Análises cinemáticas do resultado (variáveis lineares do disco) e do desempenho (variáveis angulares das articulações e lineares da manopla) foram realizadas para entender as estratégias de controle motor na geração de velocidade e na manutenção da precisão do movimento.

As distâncias manopla-disco foram manipuladas em cinco condições com 16, 20, 24, 28 e $32 \mathrm{~cm}$. Foi utilizada uma manopla circular de 7,5 cm de diâmetro e massa de $200 \mathrm{~g}$ para contatar um disco de $7,5 \mathrm{~cm}$ de diâmetro com massa de $100 \mathrm{~g}$. Este disco era direcionado a um alvo remoto com tamanho de $10 \mathrm{~cm}$. As demais características do arranjo experimental foram descritas na sessão de métodos. 


\subsection{Resultados}

4.5.1 Variáveis lineares de resultado (disco) e de desempenho (manopla)

A tabela 5 apresentou a estatística descritiva (média e desvio padrão) e inferencial (análise de variância com medidas repetidas) das variáveis lineares espaciais e temporais de reposta (disco) e de desempenho (manopla), em função da distância de movimento (distância manopla-disco). A manipulação da distância de movimento não teve efeito sobre a precisão e a variabilidade de resposta. Entretanto, o aumento na distância de movimento foi realizado através de maiores amplitudes total de movimento da manopla no eixo $\mathrm{x}$, com diferença entre todas as condições, apenas com exceção na comparação entre as amplitudes 24 e $28 \mathrm{~cm}$. Estes aumentos na distância de movimento e na amplitude total de movimento da manopla resultaram em maiores velocidade linear da manopla no movimento e no instante de contato manopla-disco, com diferença entre todas as condições de amplitude para ambas as variáveis. Menor aceleração ocorreu na distância $16 \mathrm{~cm}$ em comparação com as distâncias 28 e $32 \mathrm{~cm}$. Contudo, apesar do aumento na velocidade e aceleração, em função do acréscimo na distância de movimento, durante o instante de contato manopla-disco a aceleração diminuiu, com diferença entre todas as condições de distância. Na maior distância de movimento $(32 \mathrm{~cm})$, o contato entre a manopla e o disco ocorreu quando o movimento foi desacelerado, ao invés de acelerado como nas outras condições de distância $(16-28 \mathrm{~cm})$. No instante de contato manopla disco, foi verificada menor aceleração com o aumento na distância de movimento entre todas as condições.

O tempo de movimento aumentou em função do acréscimo na distância de movimento. Foram verificadas diferenças no tempo de movimento entre a condição $32 \mathrm{~cm}$ em comparação a 16, 20 e $24 \mathrm{~cm}$; e entre a condição $28 \mathrm{~cm}$ em comparação a 16 e $20 \mathrm{~cm}$. O tempo para contato também aumentou em função da maior distância de movimento, com diferença entre a distância $32 \mathrm{~cm}$ e as demais $(16-28 \mathrm{~cm})$; e entre a distância de $28 \mathrm{~cm}$ em comparação às distâncias 16 e $20 \mathrm{~cm}$. O tempo após contato manopla-disco também aumentou em função do acréscimo na distância de movimento, com diferença entre as condições de menor e maior distância (16 cm e 
$32 \mathrm{~cm}$, respectivamente). Houve um atraso no instante em que a maior velocidade ocorreu em função do acréscimo na distância de movimento. No qual, o tempo da maior velocidade apresentou diferença entre a distância $32 \mathrm{~cm}$ em comparação com as distâncias 16, 20, 24 e $28 \mathrm{~cm}$; e entre a distância $28 \mathrm{~cm}$ em comparação com a distância $16 \mathrm{~cm}$. O instante em que a maior aceleração ocorreu também foi atrasado com o aumento na distância de movimento. Foram verificadas diferenças no tempo da maior aceleração na distância $32 \mathrm{~cm}$ em comparação às distâncias 16, 20, $24 \mathrm{e}$ $28 \mathrm{~cm}$; e na distância $28 \mathrm{~cm}$ em comparação às distâncias 16 e $20 \mathrm{~cm}$. A diferença entre os tempos para contato manopla-disco e da maior velocidade diminuiu em função do acréscimo na distância de movimento, apresentando diferença entre todas as condições de distância. O aumento na distância manopla-disco proporcionou maior fase de aceleração (tempo relativo; \%), e menor fase de desaceleração, na distância 32 cm em comparação às distâncias 16, 20 e 24 cm. 
TABELA 5 - Média, DP (entre parênteses), $F$ e $p$ para as variáveis de resultado (disco) e de desempenho (manopla), em função da distância manopladisco.

\begin{tabular}{|c|c|c|c|c|c|c|c|}
\hline \multirow[b]{2}{*}{ Variáveis } & \multicolumn{5}{|c|}{ Distância manopla-disco (cm) } & \multicolumn{2}{|c|}{ Estatística } \\
\hline & 16 & 20 & 24 & 28 & 32 & $F_{1,15}$ & $p$ \\
\hline Erro angular absoluto $(\stackrel{\circ}{)})$ & $\begin{array}{l}2,23 \\
(1,04)\end{array}$ & $\begin{array}{l}2,17 \\
(0,94)\end{array}$ & $\begin{array}{l}2,14 \\
(1,07)\end{array}$ & $\begin{array}{l}2,31 \\
(0,98)\end{array}$ & $\begin{array}{l}2,93 \\
(1,44)\end{array}$ & 1,69 & 0,163 \\
\hline Variabilidade $(\stackrel{\circ}{)})$ & $\begin{array}{l}1,71 \\
(0,68)\end{array}$ & $\begin{array}{l}1,97 \\
(0,82)\end{array}$ & $\begin{array}{l}1,78 \\
(0,57)\end{array}$ & $\begin{array}{l}2,21 \\
(1,03)\end{array}$ & $\begin{array}{l}2,15 \\
(0,87)\end{array}$ & 1,91 & 0,120 \\
\hline Amplitude de mov. (m) & $\begin{array}{c}0,52 \\
(0,07)^{2345}\end{array}$ & $\begin{array}{c}0,54 \\
(0,05)^{1345}\end{array}$ & $\begin{array}{c}0,57 \\
(0,05)^{125}\end{array}$ & $\begin{array}{c}0,59 \\
(0,04)^{125}\end{array}$ & $\begin{array}{c}0,61 \\
(0,05)^{1234}\end{array}$ & 51,57 & 0,0001 \\
\hline Maior velocidade $(\mathrm{m} / \mathrm{s})$ & $\begin{array}{c}4,45 \\
(0,47)^{2345}\end{array}$ & $\begin{array}{c}4,74 \\
(0,36)^{1345}\end{array}$ & $\begin{array}{c}4,93 \\
(0,40)^{1245}\end{array}$ & $\begin{array}{c}5,14 \\
(0,35)^{1235}\end{array}$ & $\begin{array}{c}5,36 \\
(0,39)^{1234}\end{array}$ & 67,12 & 0,0001 \\
\hline Veloc. no contato (m/s) & $\begin{array}{c}4,03 \\
(0,30)^{2345}\end{array}$ & $\begin{array}{c}4,55 \\
(0,29)^{1345}\end{array}$ & $\begin{array}{c}4,86 \\
(0,35)^{1245}\end{array}$ & $\begin{array}{c}5,11 \\
(0,34)^{1235}\end{array}$ & $\begin{array}{c}5,32 \\
(0,43)^{1234}\end{array}$ & 190,20 & 0,0001 \\
\hline Maior aceleração $\left(\mathrm{m} / \mathrm{s}^{2}\right)$ & $\begin{array}{l}61,80 \\
(7,78)^{45}\end{array}$ & $\begin{array}{c}65,05 \\
(8,28)\end{array}$ & $\begin{array}{c}65,40 \\
(9,30)\end{array}$ & $\begin{array}{l}67,98 \\
(9,52)^{1}\end{array}$ & $\begin{array}{l}68,19 \\
(7,79)^{1}\end{array}$ & 7,98 & 0,0001 \\
\hline Acel. no contato $\left(\mathrm{m} / \mathrm{s}^{2}\right)$ & $\begin{array}{c}31,80 \\
(10,40)^{2345}\end{array}$ & $\begin{array}{c}25,03 \\
(9,54)^{1345}\end{array}$ & $\begin{array}{c}15,04 \\
(8,09)^{1245}\end{array}$ & $\begin{array}{c}3,65 \\
(10,07)^{1235}\end{array}$ & $\begin{array}{c}-7,03 \\
(11,51)^{1234}\end{array}$ & 202,97 & 0,0001 \\
\hline Tempo de movimento (s) & $\begin{array}{l}0,175 \\
(0,034)^{45}\end{array}$ & $\begin{array}{l}0,176 \\
(0,027)^{45}\end{array}$ & $\begin{array}{l}0,190 \\
(0,031)^{5}\end{array}$ & $\begin{array}{l}0,199 \\
(0,041)^{12}\end{array}$ & $\begin{array}{c}0,213 \\
(0,036)^{123}\end{array}$ & 9,73 & 0,0001 \\
\hline Tempo para contato (s) & $\begin{array}{c}0,066 \\
(0,010)^{345}\end{array}$ & $\begin{array}{c}0,077 \\
(0,011)^{345}\end{array}$ & $\begin{array}{l}0,092 \\
(0,018)^{5}\end{array}$ & $\begin{array}{c}0,103 \\
(0,019)^{125}\end{array}$ & $\begin{array}{c}0,124 \\
(0,027)^{1234}\end{array}$ & 44,63 & 0,0001 \\
\hline Tempo após contato (s) & $\begin{array}{l}0,109 \\
(0,028)^{5}\end{array}$ & $\begin{array}{l}0,097 \\
(0,019)\end{array}$ & $\begin{array}{l}0,095 \\
(0,018)\end{array}$ & $\begin{array}{l}0,096 \\
(0,033)\end{array}$ & $\begin{array}{l}0,088 \\
(0,025)^{1}\end{array}$ & 3,47 & 0,013 \\
\hline Tempo da maior veloc. (s) & $\begin{array}{l}0,089 \\
(0,016)\end{array}$ & $\begin{array}{l}0,091 \\
(0,013)^{5}\end{array}$ & $\begin{array}{l}0,100 \\
(0,018)^{5}\end{array}$ & $\begin{array}{c}0,104 \\
(0,021)^{15}\end{array}$ & $\begin{array}{c}0,121 \\
(0,028)^{1234}\end{array}$ & 13,02 & 0,0001 \\
\hline Tempo da maior acel. (s) & $\begin{array}{l}0,032 \\
(0,010)^{45}\end{array}$ & $\begin{array}{c}0,038 \\
(0,013)^{45}\end{array}$ & $\begin{array}{l}0,046 \\
(0,020)^{5}\end{array}$ & $\begin{array}{c}0,053 \\
(0,021)^{12}\end{array}$ & $\begin{array}{c}0,069 \\
(0,030)^{1234}\end{array}$ & 16,26 & 0,0001 \\
\hline $\begin{array}{l}\text { Tempo para contato menos } \\
\text { tempo da maior veloc. (s) }\end{array}$ & $\begin{array}{l}-0,023 \\
(0,010)^{2345}\end{array}$ & $\begin{array}{c}-0,014 \\
(0,005)^{1345}\end{array}$ & $\begin{array}{l}-0,007 \\
(0,004)^{1245}\end{array}$ & $\begin{array}{l}-0,002 \\
(0,004)^{1235}\end{array}$ & $\begin{array}{c}0,003 \\
(0,005)^{1234}\end{array}$ & 114,06 & 0,0001 \\
\hline Fase de aceleração (\%) & $\begin{array}{l}51,33 \\
(4,32)^{5}\end{array}$ & $\begin{array}{l}52,13 \\
(5,29)^{5}\end{array}$ & $\begin{array}{l}52,55 \\
(4,43)^{5}\end{array}$ & $\begin{array}{c}52,82 \\
(7,12)\end{array}$ & $\begin{array}{l}56,83 \\
(7,53)^{123}\end{array}$ & 4,03 & 0,0058 \\
\hline Fase de desaceleração (\%) & $\begin{array}{c}48,67 \\
(4,32)^{5}\end{array}$ & $\begin{array}{c}47,87 \\
(5,29)^{5}\end{array}$ & $\begin{array}{c}47,45 \\
(4,43)^{5}\end{array}$ & $\begin{array}{c}47,18 \\
(7,12)\end{array}$ & $\begin{array}{l}43,17 \\
(7,53)^{123}\end{array}$ & 4,03 & 0,0058 \\
\hline
\end{tabular}

Diferente de ${ }^{1} 16 \mathrm{~cm},{ }^{2} 20 \mathrm{~cm},{ }^{3} 24 \mathrm{~cm},{ }^{4} 28 \mathrm{~cm} \mathrm{e}{ }^{5} 32 \mathrm{~cm}$. 
A tabela 6 apresentou a estatística associativa através da análise de regressão linear simples entre os índices de dificuldade e algumas as variáveis temporais do movimento. $A$ análise de regressão linear entre o tempo de movimento (TM) e o índice de dificuldade ID' e ID" apresentou $R^{2}=0,903$ e $R^{2}=0,890$, respectivamente. A análise entre o tempo para contato $\left(T_{c}\right)$ e o índice de dificuldade ID' e ID" apresentou, respectivamente, um $R^{2}=0,832$ e um $R^{2}=0,840$. A análise entre os índices de dificuldade ID' e ID" e o tempo após contato $\left(T_{a}\right)$ demonstrou, respectivamente, um coeficiente de $R^{2}=0,953$ e de $R^{2}=0,944$. Por conseguinte, as variáveis temporais do tempo de movimento, tempo para o contato e tempo após o contato puderam ser preditas pelos dois índices de dificuldade calculados para a tarefa experimental proposta. A figura 4 apresentou os valores e uma linha de tendência linear de ajuste para os índices de dificuldade em função das variáveis temporais selecionadas, em função da manipulação na distância de movimento.

Tabela 6 - Valores da regressão linear do tempo de movimento, do tempo para contato e do tempo após contato, em função dos índices de dificuldade (ID' e ID').

\begin{tabular}{lrrrrr}
\hline Variáveis & $R$ & $R^{2}$ & $F_{1,3}$ & $p$ & Equação da reta \\
\hline ID' x Tempo de movimento & 0,950 & 0,903 & 27,82 & 0,013 & $y=3,59 x+16,02$ \\
ID" x Tempo de movimento & 0,944 & 0,890 & 24,35 & 0,016 & $y=3,72 x+19,43$ \\
ID' x Tempo para contato & 0,912 & 0,832 & 14,83 & 0,031 & $y=9,80 x-32,52$ \\
ID" x Tempo para contato & 0,916 & 0,840 & 15,73 & 0,029 & $y=11,29 x-39,91$ \\
ID' x Tempo após contato & 0,976 & 0,953 & 60,82 & 0,004 & $y=5,56 x+11,67$ \\
ID" x Tempo após contato & 0,972 & 0,944 & 50,78 & 0,006 & $y=6,11 x+14,19$ \\
\hline
\end{tabular}




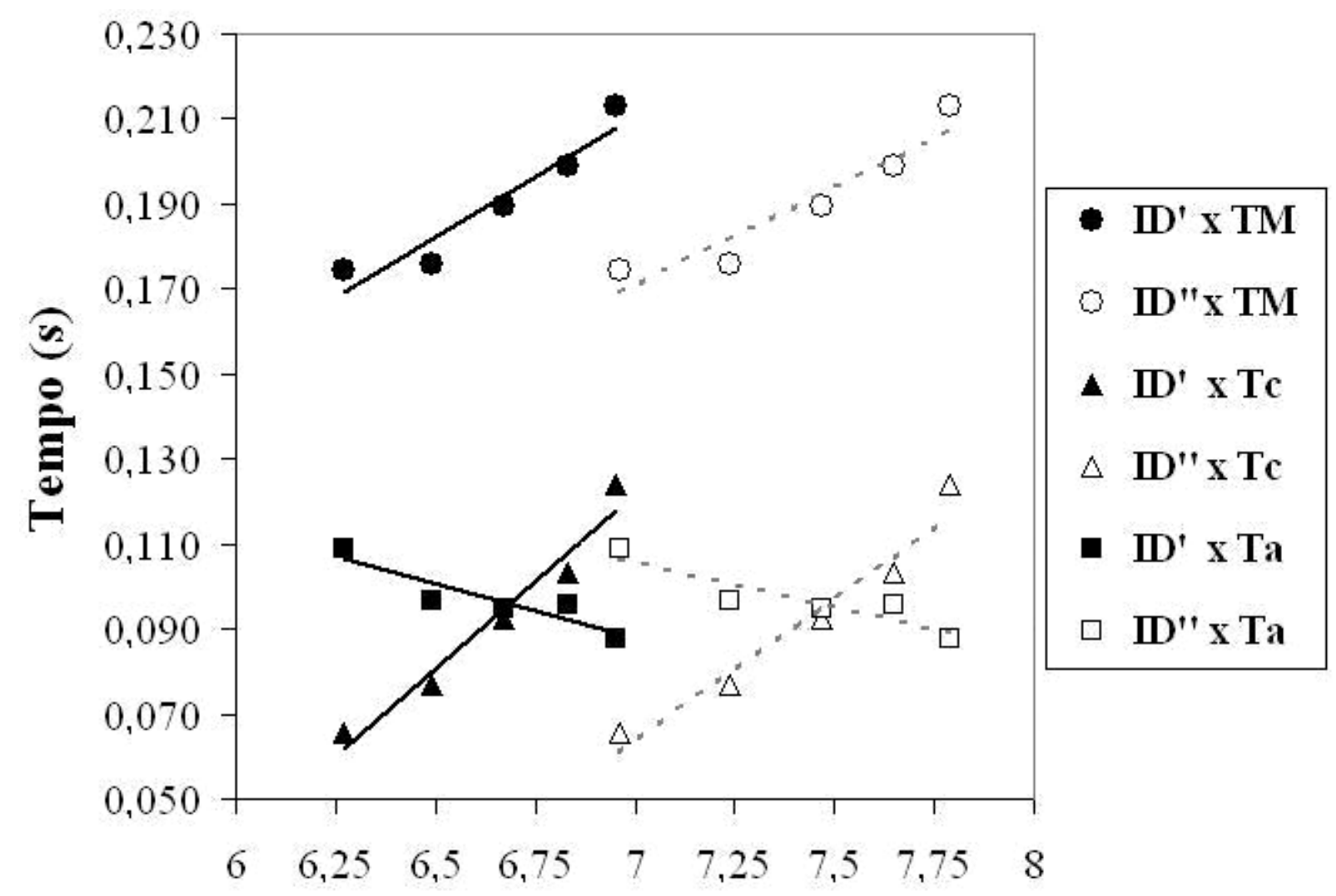

\section{ID (bits)}

FIGURA 4 - Tempo de movimento (TM), tempo para contato $\left(T_{c}\right)$ e tempo após contato ( $T_{a}$ ), em função dos índices de dificuldade (ID' e ID').

\subsubsection{Variáveis angulares de desempenho (articulações)}

A tabela 7 e a tabela 8 apresentaram, respectivamente, as variáveis espaciais e temporais da análise estatística (descritiva e inferencial), em função da distância de movimento. $O$ aumento na distância de movimento até o contato manopla-disco foi compensado por maiores ângulos no instante de contato do ombro, do cotovelo e do punho. No qual o ombro apresentou diferença no maior ângulo no instante de contato na distância $16 \mathrm{~cm}$ em comparação às distâncias 24 , 28 e $32 \mathrm{~cm}$, e entre a distância $20 \mathrm{~cm}$ e a $32 \mathrm{~cm}$. O cotovelo apresentou diferença entre todas as condições de distância e o punho entre as distâncias 16 e $32 \mathrm{~cm}$. Também foi verificada maior amplitude angular no cotovelo, em função do acréscimo na distância manopla-disco, com diferença na distância $16 \mathrm{~cm}$ em comparação às 
demais distâncias $(20,24,28$ e $32 \mathrm{~cm})$; na distância $20 \mathrm{~cm}$ em comparação às distâncias 28 e 32 cm; e na distância 24 cm em comparação à distância 28 e 32 cm.

O maior valor de velocidade no cotovelo também aumentou em função do acréscimo na distância de movimento. No qual, houve diferença entre a distância 16 cm comparadas às distâncias 24, 28 e $32 \mathrm{~cm}$; a distância $20 \mathrm{~cm}$ comparada às distâncias 16, 28 e 32 cm; e a distância 24 cm em comparação à distância 16 e 32 cm. O acréscimo na distância manopla-disco também aumentou a velocidade no instante de contato para a articulação do ombro, do cotovelo e do punho. No qual o ombro apresentou maior velocidade no contato manopla-disco na distância $16 \mathrm{~cm}$ em comparação à distância 24, 28 e 32 cm; na distância $20 \mathrm{~cm}$ em comparação à distância 28 e 32 cm; e com diferenças entre a distância $24 \mathrm{~cm}$ em comparação às distâncias 16 e $32 \mathrm{~cm}$. O cotovelo demonstrou aumento da velocidade no instante de contato manopla-disco entre todas as condições de distância. Menor velocidade no instante de contato manopla-disco foi verificada no punho para a distância $32 \mathrm{~cm}$ em comparação à distância 16 e 20 cm.

O maior valor de aceleração do ombro aumentou, em função no acréscimo da distância manopla-disco, no qual houve diferença na distância $16 \mathrm{~cm}$ em comparação à distância 28 e 32 cm; e na distância 20 cm em relação à distância 32 $\mathrm{cm}$. O acréscimo na distância até o contato manopla-disco também aumentou 0 maior valor de aceleração do cotovelo, no qual foi verificada diferença na distância 16 cm em comparação às distâncias 24, 28 e $32 \mathrm{~cm}$; na distância $20 \mathrm{~cm}$ em comparação à distância 28 e $32 \mathrm{~cm}$; e na distância $24 \mathrm{~cm}$ em relação às distâncias 16 e $32 \mathrm{~cm}$. Houve aumento na aceleração do cotovelo no instante de contato manopla-disco, em função da maior distância até o contato manopla-disco, entre todas as condições de distância. 
TABELA 7 - Média, DP (entre parênteses), $F$ e $p$ para as variáveis angulares espaciais de desempenho (articulações), em função da distância manopla-disco.

\begin{tabular}{|c|c|c|c|c|c|c|c|c|}
\hline \multirow[b]{2}{*}{ Variável } & \multirow[b]{2}{*}{ Artic. } & \multicolumn{5}{|c|}{ Distância manopla-disco (cm) } & \multicolumn{2}{|c|}{ Estatística } \\
\hline & & 16 & 20 & 24 & 28 & 32 & $F_{1,15}$ & $p$ \\
\hline \multirow{3}{*}{ 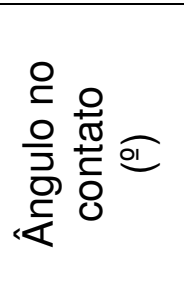 } & Ombro & $\begin{array}{l}124,49 \\
(8,57)^{345}\end{array}$ & $\begin{array}{c}126,40 \\
(7,00)^{5}\end{array}$ & $\begin{array}{c}127,50 \\
(6,62)^{1}\end{array}$ & $\begin{array}{c}127,59 \\
(7,89)^{1}\end{array}$ & $\begin{array}{c}129,41 \\
(6,30)^{12}\end{array}$ & 7,14 & 0,0001 \\
\hline & Cotovelo & $\begin{array}{c}95,21 \\
(9,04)^{2345}\end{array}$ & $\begin{array}{c}98,74 \\
(7,00)^{1345}\end{array}$ & $\begin{array}{l}102,27 \\
(7,96)^{1245}\end{array}$ & $\begin{array}{c}105,98 \\
(10,09)^{1235}\end{array}$ & $\begin{array}{l}108,76 \\
(8,35)^{1234}\end{array}$ & 41,45 & 0,0001 \\
\hline & Punho & $\begin{array}{c}175,35 \\
(12,80)^{5}\end{array}$ & $\begin{array}{c}176,26 \\
(9,22)\end{array}$ & $\begin{array}{c}179,02 \\
(9,84)\end{array}$ & $\begin{array}{c}179,27 \\
(9,93)\end{array}$ & $\begin{array}{c}180,31 \\
(10,51)^{1}\end{array}$ & 3,72 & 0,008 \\
\hline \multirow{3}{*}{ 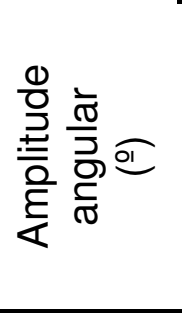 } & Ombro & $\begin{array}{c}15,74 \\
(4,63)\end{array}$ & $\begin{array}{c}16,23 \\
(4,09)\end{array}$ & $\begin{array}{c}17,08 \\
(4,43)\end{array}$ & $\begin{array}{c}17,66 \\
(3,31)\end{array}$ & $\begin{array}{c}17,13 \\
(3,22)\end{array}$ & 1,70 & 0,160 \\
\hline & Cotovelo & $\begin{array}{c}92,49 \\
(14,68)^{345}\end{array}$ & $\begin{array}{l}96,56 \\
(11,15)^{45}\end{array}$ & $\begin{array}{l}100,85 \\
(10,07)^{15}\end{array}$ & $\begin{array}{c}104,62 \\
(7,82)^{12}\end{array}$ & $\begin{array}{l}107,53 \\
(7,97)^{123}\end{array}$ & 22,48 & 0,0001 \\
\hline & Punho & $\begin{array}{c}16,81 \\
(7,32) \\
\end{array}$ & $\begin{array}{c}16,88 \\
(7,03)\end{array}$ & $\begin{array}{c}16,08 \\
(7,38)\end{array}$ & $\begin{array}{c}16,53 \\
(8,01)\end{array}$ & $\begin{array}{c}16,85 \\
(7,14) \\
\end{array}$ & 0,14 & 0,966 \\
\hline \multirow{3}{*}{ 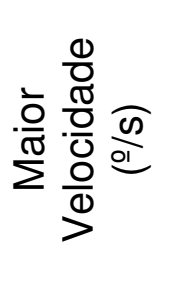 } & Ombro & $\begin{array}{c}142,97 \\
(30,25)\end{array}$ & $\begin{array}{c}147,77 \\
(25,74)\end{array}$ & $\begin{array}{c}153,78 \\
(24,05)\end{array}$ & $\begin{array}{c}159,26 \\
(28,22)\end{array}$ & $\begin{array}{c}158,88 \\
(24,83)\end{array}$ & 2,39 & 0,060 \\
\hline & Cotovelo & $\begin{array}{l}690,85 \\
(67,16)^{2345}\end{array}$ & $\begin{array}{l}725,30 \\
(45,31)^{145}\end{array}$ & $\begin{array}{l}745,67 \\
(47,13)^{15}\end{array}$ & $\begin{array}{l}768,70 \\
(40,89)^{12}\end{array}$ & $\begin{array}{l}787,81 \\
(50,00)^{123}\end{array}$ & 22,95 & 0,0001 \\
\hline & Punho & $\begin{array}{c}169,16 \\
(52,43)\end{array}$ & $\begin{array}{c}166,00 \\
(47,58)\end{array}$ & $\begin{array}{c}148,36 \\
(64,38)\end{array}$ & $\begin{array}{c}155,91 \\
(65,41)\end{array}$ & $\begin{array}{c}141,19 \\
(60,55)\end{array}$ & 2,40 & 0,059 \\
\hline \multirow{3}{*}{ 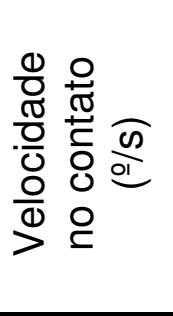 } & Ombro & $\begin{array}{c}81,48 \\
(42,30)^{345}\end{array}$ & $\begin{array}{l}95,78 \\
(34,37)^{45}\end{array}$ & $\begin{array}{l}108,85 \\
(26,28)^{15}\end{array}$ & $\begin{array}{l}125,10 \\
(22,83)^{12}\end{array}$ & $\begin{array}{l}127,44 \\
(22,47)^{12}\end{array}$ & 15,58 & 0,0001 \\
\hline & Cotovelo & $\begin{array}{l}591,59 \\
(50,54)^{2345}\end{array}$ & $\begin{array}{c}655,56 \\
(40,29)^{1345}\end{array}$ & $\begin{array}{l}700,83 \\
(38,28)^{1245}\end{array}$ & $\begin{array}{c}745,60 \\
(35,60)^{1235}\end{array}$ & $\begin{array}{l}772,92 \\
(46,18)^{1234}\end{array}$ & 147,53 & 0,0001 \\
\hline & Punho & $\begin{array}{c}123,30 \\
(65,92)^{5}\end{array}$ & $\begin{array}{c}128,16 \\
(67,32)^{5}\end{array}$ & $\begin{array}{c}105,76 \\
(77,76)\end{array}$ & $\begin{array}{c}97,44 \\
(88,56)\end{array}$ & $\begin{array}{l}83,85 \\
(78,51)^{12}\end{array}$ & 4,25 & 0,004 \\
\hline \multirow{3}{*}{ 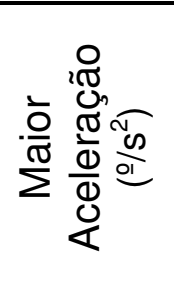 } & Ombro & $\begin{array}{c}2312,98 \\
(469,11)\end{array}$ & $\begin{array}{c}2428,28 \\
(426,49)^{5}\end{array}$ & $\begin{array}{c}2547,97 \\
(434,66)\end{array}$ & $\begin{array}{c}2667,78 \\
(583,57)^{1}\end{array}$ & $\begin{array}{c}2823,97 \\
(525,04)^{12}\end{array}$ & 7,70 & 0,0001 \\
\hline & Cotovelo & $\begin{array}{l}7174,91 \\
(573,46)^{345}\end{array}$ & $\begin{array}{c}7492,72 \\
(504,28)^{45}\end{array}$ & $\begin{array}{c}7740,63 \\
(693,88)^{15}\end{array}$ & $\begin{array}{c}8051,23 \\
(812,22)^{12}\end{array}$ & $\begin{array}{l}8192,79 \\
(726,09)^{123}\end{array}$ & 20,55 & 0,0001 \\
\hline & Punho & $\begin{array}{c}1835,95 \\
(724,76) \\
\end{array}$ & $\begin{array}{c}1929,76 \\
(821,25) \\
\end{array}$ & $\begin{array}{c}1653,66 \\
(649,00) \\
\end{array}$ & $\begin{array}{c}1983,35 \\
(698,11) \\
\end{array}$ & $\begin{array}{c}1818,19 \\
(572,54)\end{array}$ & 1,00 & 0,413 \\
\hline \multirow{3}{*}{ 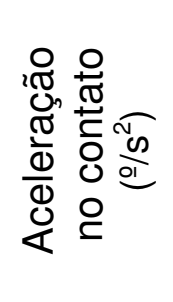 } & Ombro & $\begin{array}{c}2096,77 \\
(629,67)\end{array}$ & $\begin{array}{c}2187,67 \\
(572,38)\end{array}$ & $\begin{array}{c}2090,25 \\
(684,86)\end{array}$ & $\begin{array}{c}1987,30 \\
(699,60)\end{array}$ & $\begin{array}{c}1916,12 \\
(796,36)\end{array}$ & 1,25 & 0,298 \\
\hline & Cotovelo & $\begin{array}{c}5107,57 \\
(1316,65)^{2345}\end{array}$ & $\begin{array}{c}4565,23 \\
(1105,61)^{1345}\end{array}$ & $\begin{array}{c}3739,00 \\
(1198,23)^{1245}\end{array}$ & $\begin{array}{c}2833,61 \\
(1204,44)^{1235}\end{array}$ & $\begin{array}{c}2012,79 \\
(1503,59)^{1234}\end{array}$ & 87,14 & 0,0001 \\
\hline & Punho & $\begin{array}{c}-1155,06 \\
(1307,86)\end{array}$ & $\begin{array}{c}-987,30 \\
(1383,82)\end{array}$ & $\begin{array}{c}-1024,66 \\
(1221,97)\end{array}$ & $\begin{array}{c}-1311,39 \\
(1461,28)\end{array}$ & $\begin{array}{c}-1350,48 \\
(1328,07)\end{array}$ & 1,18 & 0,324 \\
\hline
\end{tabular}

Diferente de ${ }^{1} 16 \mathrm{~cm},{ }^{2} 20 \mathrm{~cm},{ }^{3} 24 \mathrm{~cm},{ }^{4} 28 \mathrm{~cm} \mathrm{e}{ }^{5} 32 \mathrm{~cm}$. 
TABELA 8 - Média, DP (entre parênteses), $F$ e $p$ para as variáveis angulares temporais de desempenho (articulações), em função da distância manopla-disco.

\begin{tabular}{|c|c|c|c|c|c|c|c|c|}
\hline \multirow[b]{2}{*}{ Variável } & \multirow[b]{2}{*}{ Artic. } & \multicolumn{5}{|c|}{ Distância manopla-disco (cm) } & \multicolumn{2}{|c|}{ Estatística } \\
\hline & & 16 & 20 & 24 & 28 & 32 & $F_{1,15}$ & $p$ \\
\hline \multirow{3}{*}{  } & Ombro & $\begin{array}{c}0,109 \\
(0,017)^{345}\end{array}$ & $\begin{array}{l}0,116 \\
(0,015)^{45}\end{array}$ & $\begin{array}{l}0,125 \\
(0,018)^{5}\end{array}$ & $\begin{array}{c}0,132 \\
(0,020)^{125}\end{array}$ & $\begin{array}{c}0,150 \\
(0,024)^{1234}\end{array}$ & 20,61 & 0,0001 \\
\hline & Cotovelo & $\begin{array}{l}0,099 \\
(0,016)\end{array}$ & $\begin{array}{l}0,103 \\
(0,015)^{45}\end{array}$ & $\begin{array}{l}0,112 \\
(0,019)^{5}\end{array}$ & $\begin{array}{l}0,117 \\
(0,020)^{12}\end{array}$ & $\begin{array}{c}0,133 \\
(0,028)^{123}\end{array}$ & 14,08 & 0,0001 \\
\hline & Punho & $\begin{array}{l}0,054 \\
(0,041)^{5}\end{array}$ & $\begin{array}{l}0,060 \\
(0,038)^{5}\end{array}$ & $\begin{array}{l}0,066 \\
(0,043)\end{array}$ & $\begin{array}{c}0,070 \\
(0,044)\end{array}$ & $\begin{array}{l}0,080 \\
(0,048)^{12}\end{array}$ & 5,96 & 0,0004 \\
\hline \multirow{3}{*}{ 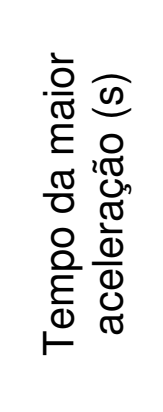 } & Ombro & $\begin{array}{l}0,062 \\
(0,024)^{5}\end{array}$ & $\begin{array}{c}0,074 \\
(0,035)\end{array}$ & $\begin{array}{l}0,076 \\
(0,032)\end{array}$ & $\begin{array}{r}0,077 \\
(0,018)\end{array}$ & $\begin{array}{l}0,094 \\
(0,022)\end{array}$ & 3,63 & 0,010 \\
\hline & Cotovelo & $\begin{array}{c}0,035 \\
(0,011)^{45}\end{array}$ & $\begin{array}{l}0,037 \\
(0,012)^{45}\end{array}$ & $\begin{array}{l}0,046 \\
(0,017)^{5}\end{array}$ & $\begin{array}{c}0,051 \\
(0,018)^{125}\end{array}$ & $\begin{array}{l}0,067 \\
(0,028)^{1234}\end{array}$ & 15,14 & 0,0001 \\
\hline & Punho & $\begin{array}{l}0,125 \\
(0,080)\end{array}$ & $\begin{array}{c}0,119 \\
(0,086)\end{array}$ & $\begin{array}{l}0,132 \\
(0,089)\end{array}$ & $\begin{array}{c}0,144 \\
(0,087)\end{array}$ & $\begin{array}{c}0,172 \\
(0,094)\end{array}$ & 1,99 & 0,106 \\
\hline \multirow{3}{*}{  } & Ombro & $\begin{array}{c}62,93 \\
(5,57)^{5}\end{array}$ & $\begin{array}{c}66,29 \\
(6,57)\end{array}$ & $\begin{array}{c}66,43 \\
(4,58)\end{array}$ & $\begin{array}{c}67,62 \\
(8,36)\end{array}$ & $\begin{array}{c}70,91 \\
(5,39)^{1}\end{array}$ & 4,88 & 0,002 \\
\hline & Cotovelo & $\begin{array}{c}57,13 \\
(3,14)^{5}\end{array}$ & $\begin{array}{c}58,79 \\
(5,39)\end{array}$ & $\begin{array}{c}59,29 \\
(2,93)\end{array}$ & $\begin{array}{c}59,56 \\
(6,78)\end{array}$ & $\begin{array}{c}62,46 \\
(6,30)^{1}\end{array}$ & 3,02 & 0,025 \\
\hline & Punho & $\begin{array}{c}30,96 \\
(23,87)\end{array}$ & $\begin{array}{c}32,70 \\
(20,02)\end{array}$ & $\begin{array}{c}33,26 \\
(19,85)\end{array}$ & $\begin{array}{c}34,64 \\
(20,11)\end{array}$ & $\begin{array}{c}37,05 \\
(20,41)\end{array}$ & 1,22 & 0,311 \\
\hline \multirow{3}{*}{ 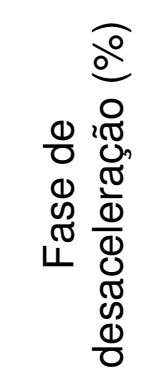 } & Ombro & $\begin{array}{c}37,07 \\
(5,57)^{5}\end{array}$ & $\begin{array}{c}33,71 \\
(6,57)\end{array}$ & $\begin{array}{c}33,57 \\
(4,58)\end{array}$ & $\begin{array}{c}32,38 \\
(8,36)\end{array}$ & $\begin{array}{c}29,09 \\
(5,39)^{1}\end{array}$ & 4,88 & 0,002 \\
\hline & Cotovelo & $\begin{array}{l}42,87 \\
(3,14)^{5}\end{array}$ & $\begin{array}{c}41,21 \\
(5,39)\end{array}$ & $\begin{array}{c}40,71 \\
(2,93)\end{array}$ & $\begin{array}{c}40,44 \\
(6,78)\end{array}$ & $\begin{array}{c}37,54 \\
(6,30)^{1}\end{array}$ & 3,02 & 0,025 \\
\hline & Punho & $\begin{array}{c}69,04 \\
(23,87)\end{array}$ & $\begin{array}{c}67,30 \\
(20,02)\end{array}$ & $\begin{array}{c}66,74 \\
(19,85)\end{array}$ & $\begin{array}{c}65,36 \\
(20,11)\end{array}$ & $\begin{array}{r}62,95 \\
(20,41)\end{array}$ & 1,22 & 0,311 \\
\hline
\end{tabular}

Diferente de ${ }^{1} 16 \mathrm{~cm},{ }^{2} 20 \mathrm{~cm},{ }^{3} 24 \mathrm{~cm},{ }^{4} 28 \mathrm{~cm} \mathrm{e}{ }^{5} 32 \mathrm{~cm}$. 
Com o aumento na distância de movimento houve um atraso no instante em que ocorreu a maior velocidade do ombro, do cotovelo e do punho. Este atraso no tempo da maior velocidade no ombro apresentou diferença entre a distância 28 $\mathrm{cm}$ em comparação às distâncias 16, 20 e $32 \mathrm{~cm}$; e entre a distância $32 \mathrm{~cm}$ em relação às distâncias 16, 20, 24 e $28 \mathrm{~cm}$. Para o cotovelo o atraso no tempo da maior velocidade foi maior na distância $28 \mathrm{~cm}$ em comparação à distância 16 e $20 \mathrm{~cm}$; e na distância $32 \mathrm{~cm}$ em relação às distâncias 16,20 e $24 \mathrm{~cm}$. O aumento no tempo da maior velocidade do punho ocorreu apenas na distância $32 \mathrm{~cm}$ em relação às distâncias 16 e $20 \mathrm{~cm}$. O instante em que a maior aceleração do ombro e cotovelo aconteceu foi atrasado, em função da maior distância até o contato manopla-disco. No qual, o tempo em que a maior aceleração do ombro foi maior na distância $32 \mathrm{~cm}$ em comparação à distância $16 \mathrm{~cm}$. $O$ cotovelo apresentou $O$ atraso no instante da maior aceleração da distância $32 \mathrm{~cm}$ em comparação à distância 16, 20, 24 e $28 \mathrm{~cm}$, e diferença entre a distância $28 \mathrm{~cm}$ em relação à distância 16,20 e $32 \mathrm{~cm}$. 0 acréscimo na distância até o contato manopla-disco proporcionou maior fase de aceleração (tempo relativo; \%), na articulação do ombro e do cotovelo, com diferença na distância $16 \mathrm{~cm}$ em comparação à distância $32 \mathrm{~cm}$.

\subsection{Discussão}

4.6.1 Variáveis lineares de resultado (disco) e de desempenho (manopla)

Os modelos que tentaram explicar a origem da relação inversa velocidadeprecisão apontam que o aumento na distância resulta em maior tempo de movimento (Fitts, 1954; Fitts \& Petersen, 1964; Plamondon \& Alimi, 1997). Esta estratégia permitiria menor velocidade (aceleração e/ou força) de movimento em níveis que garantiriam a manutenção da precisão (ou que a precisão não fosse comprometida quando esta fosse uma variável de controle no experimento; cf. Fitts, 1954). O aumento no tempo de movimento, no tempo para o contato e no tempo após o contato foi verificado no presente estudo, em função do acréscimo na distância de movimento (distância manopla-disco). Contudo, também houve aumento na amplitude total de movimento, na maior velocidade e na maior aceleração, com o 
acréscimo na distância de movimento. Segundo os modelos de variabilidade do impulso (Meyer et al., 1982; Newell et al., 1982; Schmidt et al,. 1978, 1979), de submovimentos otimizados (Meyer et al., 1988; Okazaki et al., 2006), de deslizamento da desaceleração (Zelaznik, 1993) e da teoria cinemática (Plamondon, 1993, 1995; Plamondon \& Alimi, 1997), o aumento na velocidade resultaria em maior variabilidade de resposta em função do ruído neural, da variabilidade dos parâmetros do movimento ou de uma característica que emerge através das sinergias agonistasantagonistas que atuam no sistema, respectivamente. Entretanto, mesmo com maiores velocidade e aceleração não foram verificadas menores precisão e variabilidade. Por conseguinte, foi refutada a hipótese $\mathrm{H} 1$ que sugeriu maior velocidade, menor precisão e maior variabilidade, em decorrência do aumento na distância de movimento. Desta forma, na tarefa de contatar um disco através de movimento de potência com uma manopla em direção a um alvo remoto, estratégias de controle velocidade-precisão ímpares foram utilizadas. Nas quais, mesmo com maiores velocidade e aceleração, houve a manutenção na precisão e na variabilidade do movimento. Alguns estudos que analisaram o controle de habilidades motoras complexas (multi-articulares e tridimensionais) detectaram estratégias de regulação velocidade-precisão diferentes das apresentadas nos modelos baseados em tarefas simples (uni-articulares, unidimensionais ou bidimensionais). Tais estratégias podem auxiliar na explicação da manutenção na precisão e na variabilidade, mesmo com o aumento da velocidade de movimento.

Tarefas que objetivam lançar um objeto em direção a um alvo, tais como no arremesso de beisebol (Chodhary \& Challis, 2001; Southard, 1998, 2002), no arremesso no basquetebol (Okazaki et al., 2006b, 2008; Rodacki et al., 2005) e no chute do futebol (Anderson \& Sidway, 1994; Putnan, 1991); ou que objetivam rebater um objeto utilizando algum implemento (Caljouw et al.,.2005), tal como uma raquete no tênis (Elliott et al., 1989); há uma regulação no tempo da maior velocidade, em função do instante crítico do desempenho (lançamento, contato, rebatida, etc.), como estratégia para manutenção da precisão. A justificativa para esta regulação no tempo da maior velocidade reside no fato de que no instante em que ocorre a maior velocidade a aceleração é nula. Baseado em estudos que analisaram a variabilidade de resposta na geração de força muscular, maior variabilidade é encontrada quando 
maior força é gerada (Newell \& Corcos, 1988; Schmidt et al., 1978, 1979; Slifkin \& Newell, 2000). Desconsiderando as propriedades não-lineares do sistema (características visco-elásticas, inércia, torque, etc), a massa do sistema pode ser considerada constante na tarefa experimental proposta. Assim, como a força é igual ao produto da massa e da aceleração $\left(F=m_{x} a\right)$, o perfil da função força-tempo é semelhante ao perfil da função aceleração-tempo no movimento. Desta forma, coincidir o tempo da maior velocidade e o instante crítico do desempenho (contato manopla-disco) poderia permitir maior precisão, em função da menor variabilidade de resposta decorrente da menor aceleração/força. Tal estratégia também possibilitaria maior geração de velocidade no movimento sem comprometer a precisão, desde que um controle apropriado no tempo da maior velocidade fosse realizado.

O presente estudo verificou que o tempo da maior velocidade também aumentou com o acréscimo no tempo de movimento, em função da maior distância manopla-disco. Esta regulação no tempo da maior velocidade permitiu que, à medida que a distância de movimento aumentou, houvesse maior aproximação entre 0 instante de contato-manopla disco e o instante da maior velocidade. Assim, o sistema pôde utilizar a estratégia de regular os tempos da maior velocidade para a manutenção da precisão e da variabilidade. Por conseguinte, foi aceita a hipótese $\mathrm{H} 2$ na qual o sistema utilizaria a estratégia de aproximar o instante de tempo do maior valor de velocidade e do tempo de contato manopla-disco como estratégia para a manutenção da precisão no movimento. Contudo, como a magnitude da aceleração no instante de contato manopla-disco foi maior nas condições de menor distância (por exemplo: na distância $16 \mathrm{~cm}$ foi igual a $31,80 \mathrm{~m} / \mathrm{s}^{2}$ e na distância $28 \mathrm{~cm}$ foi igual a $3,65 \mathrm{~m} / \mathrm{s}^{2}$ ), maior erro seria esperado em função da maior aceleração gerada. Desta forma, foi sugerida a participação de outros fatores para auxiliar o controle na manutenção da precisão do movimento, como: a independência na geração de velocidade e no controle da precisão, o tamanho do alvo virtual $\left(T_{v}\right)$, o impacto manopla-disco e a inércia no movimento.

A tarefa de direcionar um disco a um alvo remoto, com movimento rápido e preciso de contato utilizando uma manopla, possui características específicas e distintas da maioria das tarefas utilizadas no paradigma da relação inversa velocidade-precisão. Por exemplo, a tarefa de toques com ponteira utilizada por Fitts 
(1954), e em diversos outros experimentos subseqüentes (Crossman \& Goodeve, 1963/1983; Fitts \& Pettersen, 1964; Mackenzie et al., 1987; Meyer et al., 1988), o controle na geração de velocidade e a regulação da precisão ocorrem em uma única dimensão de movimento (entendendo o movimento espacialmente em um plano cartesiano). Por outro lado, na tarefa proposta no presente estudo, há uma dimensão na qual a geração de velocidade é predominante (eixo $\mathrm{x}$ : formado por uma linha traçada da manopla em direção ao disco) e outra na qual o controle da precisão atua restringindo o movimento (eixo y: no qual o desvio na trajetória da manopla neste eixo produz o erro na trajetória do disco). Por conseguinte, a geração de velocidade na direção manopla-disco não proporcionaria aumento do erro, mas apenas maior velocidade na direção perpendicular na qual ocorre o erro. Os resultados do presente experimento sugerem que esta especificidade no controle da geração de velocidade e na manutenção da precisão pode ter ocorrido. Contudo, as alterações verificadas nas variáveis temporais do movimento (tempo total, tempo para contato, tempo após contato, tempo da maior velocidade e tempo da maior aceleração) sugeriram que esta hipótese da especificidade na dimensão do movimento (geração de velocidade $\mathrm{x}$ controle da precisão) não pode ser o único fator considerado para explicar a manutenção na precisão e na variabilidade do movimento. Para melhor entendimento das estratégias de controle na geração de velocidade e manutenção da precisão, esta hipótese da especificidade na dimensão do movimento foi testada no experimento II.

Outro fator que também deve ser considerado é o tamanho do alvo virtual $\left(T_{v}\right)$, que delimita o ângulo da margem de acerto ( $\left.\beta^{\prime \prime}\right)$, ou também chamado de ângulo de aproximação (cf. Short et al., 1996; Sidaway, 1991; Sidaway et al., 1988). Apesar do tamanho do disco ter sido constante entre as condições (7,5 cm de diâmetro), 0 aumento na distância de movimento proporcionou duas restrições espaciais, a maior trajetória percorrida pela manopla para contatar o disco (distância manopla-disco) e a diminuição no ângulo de aproximação manopla-disco. Por conseguinte, nas condições com menor distância também houve maior ângulo de aproximação ( $\beta "$ = 1,49 na menor distância e $\beta^{\prime \prime}=0,92$ na maior distância), ou seja, um índice de dificuldade reduzido fornecendo menor restrição espacial no movimento (ID' de 6,27 até 6,95 bits/s e ID" de 6,96 até 7,79 bits/s, respectivamente da menor para a maior 
distância). Considerando este efeito do tamanho do alvo virtual e a estratégia de regulação do instante de maior velocidade, poderia ser aceito o fato de que nas condições de menor distância foram verificadas maiores magnitudes de acelerações, mas com a manutenção da precisão entre as diversas condições. Pois, mesmo que maior variabilidade de movimento fosse gerada em função da maior aceleração, houve maior ângulo de aproximação que diminuiu o efeito da variabilidade sobre o erro para estas condições de menor distância. Para tentar entender melhor este efeito do tamanho do ângulo de aproximação (estratégia de controle da precisão como fonte de restrição no movimento), a manipulação na dimensão do disco e do alvo remoto foi analisada no experimento III e IV, respectivamente. Porém, o aumento na aceleração para magnitudes tão discrepantes entre as condições também pode ter magnificado o efeito de outros fatores sobre o movimento, tais como o impacto manopla-disco e a inércia no movimento.

Alguns estudos têm sugerido que as forças resultantes do impacto também poderiam ser utilizadas como estratégia para auxiliar no controle do movimento (Adam et al., 1997; Biegstraaten et al., 2003; Guiard, 1997). Como o impacto auxilia de forma mecânica passiva na desaceleração do movimento, poderiam ser realizadas maiores fases de aceleração, com maior velocidade e menor fase de desaceleração. Tal estratégia permitiria maiores velocidade e precisão de movimento, e tem sido proposta em habilidades como o saque no tênis (Elliott et al., 1989), a rebatida de um objeto (Caljow et al., 2005), o arremesso (Teixeira, 2000) e a tarefa de Fitts (Adam et al., 1997; Teasdale \& Schmidt, 1991). Maiores acelerações geradas no movimento também venceriam a resistência inercial da manopla de forma mais abrupta, podendo ocasionar em maior instabilidade durante o movimento. Entretanto, os resultados do presente experimento demonstraram que, apesar da maior aceleração no instante de contato manopla-disco, sugerindo maior impacto nas condições de menor distância, o maior valor de aceleração gerado nas diferentes condições de distância foi muito próximo (entre 61,80 a 68,19 m/s ${ }^{2}$ ). Além disso, houve maior fase de aceleração na condição de maior distância de movimento, na qual foi verificada menor aceleração durante o instante de contato. Desta forma, o efeito do impacto e da inércia pareceram não ser a estratégia determinante utilizada pelo sistema para auxiliar na regulação da precisão no movimento. Por conseguinte, 
apesar de não desconsiderar o efeito do impacto e da inércia como fontes de restrição, a distância de movimento ainda pareceu ser o maior responsável pela restrição imposta sobre o movimento no presente experimento. Contudo, para tentar compreender o efeito do impacto e da inércia sobre as estratégias de controle na geração da velocidade e da manutenção na precisão, o experimento IV e $\mathrm{V}$, respectivamente, analisaram o efeito do impacto manopla-disco (manipulando a massa do disco) e da inércia (manipulando a massa da manopla). Outro aspecto que também merece importância na relação inversa velocidade-precisão é a relação entre o tempo de movimento e o índice de dificuldade, normalmente verificados nas tarefas que analisaram este paradigma e que foi expressa na lei de Fitts (1954).

Utilizando a teoria da informação (Miller, 1953; Pierce, 1961; Shannon, 1948; Shannon \& Weaver, 1949), Fitts (1954) levantou a hipótese de que a capacidade de transmissão da informação fixa do sistema motor possibilita um caminho para analisar a relação entre a distância (D), o tamanho do alvo (T) e o tempo de movimento (TM). Por conseguinte, a dificuldade da tarefa poderia ser mensurada em bits utilizando uma informação métrica e que, considerando uma tarefa de movimento, a informação seria transmitida através de um canal de comunicação estocástico de ruído que modela o comportamento do sistema motor humano. Para tanto, foi utilizada uma adaptação do teorema 17 de Shannon (1948), que expressou a capacidade de informação efetiva ( $C$, em bits/segundo), de um canal com comprimento de banda $\left(B\right.$, em Hz), como: $C=B \log _{2}([S+R] / R)$, no qual $R$ é a potência do ruído e $S$ é a potência do sinal. Fitts afirmou que, em taxa máxima de transmissão da informação, o sistema motor humano se comporta de acordo com uma relação logarítmica através da identificação de 1/TM com $B, 2 \times D \operatorname{com} S+R$, e T com R para obter a relação de troca velocidade-precisão proposta na equação: TM $=a+b \log _{2}\left(\left[\begin{array}{ll}2 & D\end{array}\right] / T\right)$, no qual 'a' e 'b' são constantes empíricas.

Suporte para esta proposição da relação entre o tempo de movimento e o índice de dificuldade, determinados pelas variáveis da distância de movimento e do tamanho do alvo, foi verificado em diversos estudos (Boritz et al., 1991; Card et al., 1978; Corcos et al., 1988; Epps, 1986; Fitts, 1954; Johnsgard, 1994; Kerr, 1973, 1978; Kerr \& Langolf, 1977; Okazaki et al., 2008). Por se tratar de um dos fenômenos mais consistentes na área do comportamento motor, no presente experimento, uma 
relação linear direta também era esperada entre os índices de dificuldade e as variáveis de tempo de movimento, de tempo para contato manopla-disco e de tempo após contato manopla-disco (hipótese H3). O presente experimento, manipulando a distância de movimento, permitiu o cálculo de dois índices de dificuldade (ID' e ID"). O ID' considerou o ângulo da margem de acerto, ao passo que o ID" utilizou o tamanho do alvo virtual $\left(T_{v}\right)$ e a distância manopla-disco, ambos para determinar o índice de dificuldade da tarefa experimental do estudo. Tanto o ID', quanto o ID", apresentaram uma relação linear capaz de predizer as variáveis temporais propostas. Contudo, a relação entre os índices de dificuldade e o tempo após contato manopla-disco foi inversa (ao contrário das demais variáveis que apresentaram uma relação direta). Ou seja, com o aumento no ID ocorreu uma diminuição no tempo após contato da manopla com o disco. Isto ocorreu em função do alvo ter sido contatado antes nas menores distâncias de movimento, possibilitando maior tempo após contato para desacelerar o movimento. Tais resultados refutam a hipótese H3 que previa uma relação direta entre os índices de dificuldade propostos (ID' e ID") e as variáveis temporais (tempo total, tempo para o contato e tempo após o contato).

\subsubsection{Variáveis angulares de desempenho (articulações)}

Uma estratégia que auxiliou no entendimento de como foi controlada a relação velocidade-precisão na regulação do movimento foi a analise da ação de cada articulação que participou no movimento. Apesar desta análise não ser verificada em estudos que investigaram o paradigma da relação inversa velocidadeprecisão, o presente estudo procurou entender o comportamento linear da manopla resultante da interação entre as variáveis angulares das articulações do ombro, do cotovelo e do punho.

O aumento na distância de movimento foi desempenhado através de maiores ângulos no ombro, no cotovelo e no punho, no instante de contato manopladisco. A articulação que mais contribuiu no acréscimo da distância manopla-disco foi o cotovelo através de uma maior amplitude angular. Esta maior amplitude, associada ao maior tempo de movimento, resultou em maior velocidade do cotovelo. Maior velocidade no instante de contato e maior aceleração, no ombro e no cotovelo, 
também foram verificadas com o aumento na distância de movimento. Entretanto, no instante de contato, houve uma diminuição da velocidade do punho e da aceleração do cotovelo, em função da maior distância de movimento. Estes resultados refutam a hipótese $\mathrm{H} 4$, que apontou maiores velocidade e aceleração nas articulações (ombro, cotovelo e punho) com o aumento na distância de movimento.

O aumento na distância de movimento atrasou os maiores valores de velocidade do ombro, do cotovelo e do punho. Também foi atrasado o tempo da maior aceleração no ombro e no cotovelo. Estes atrasos nas maiores velocidade e aceleração permitiram que, apesar das maiores velocidade no contato manopladisco, menor aceleração ocorresse, pelo menos no cotovelo no instante de contato manopla-disco. Ombro e cotovelo apresentaram maior aceleração, ou seja, maior força foi desempenhada por estas articulações, antes do contato com a manopla. Por sua vez, a maior velocidade no punho ocorreu antes do contato manopla-disco, que proporcionou menor velocidade no instante de contato. Maiores fase de aceleração também foram verificadas no ombro e no cotovelo ( $60 \%$ do tempo de movimento), em comparação à fase do punho ( 40\%m do movimento). Ao passo que o punho demonstrou maior fase de desaceleração ( 60\% do movimento), em comparação ao ombro e cotovelo ( $40 \%$ do movimento). O aumento na fase de aceleração linear da manopla, com o aumento na distância manopla-disco, foi desempenhado em função de maiores fases de aceleração do ombro e do cotovelo. Entretanto, o punho não demonstrou modificar a fase de aceleração do movimento com o acréscimo na distância manopla-disco. Estes resultados refutam a hipótese $\mathrm{H} 5$, que indicou o aumento na fase de aceleração das articulações, em função do aumento na distância de movimento. Tais resultados sugeriram uma contribuição diferenciada das articulações no controle da geração da velocidade e da manutenção da precisão no movimento. No qual, o ombro e o cotovelo possuem maior influência sobre a geração de velocidade e o punho sobre a regulação da precisão no movimento. Entretanto, sem desconsiderar a contribuição das articulações tanto na geração de velocidade como na regulação da precisão do movimento. Contudo, mais experimentos manipulando a geração de velocidade (Experimento II) e as restrições da precisão (Experimento III e IV) no movimento são necessários para testar tais suposições. 


\subsection{Conclusão}

O aumento na distância manopla-disco levou ao acréscimo na amplitude de movimento da manopla, além de maiores tempo de movimento, tempo para o contato e menor tempo após o contato. O maior tempo de movimento permitiu que maiores velocidades e acelerações (maior valor e no instante de contato manopladisco) fossem geradas no movimento. Entretanto, o acréscimo na distância de movimento não teve efeito sobre a precisão e a variabilidade. Foi sugerido que o sistema utilizou a estratégia de regular os tempos dos maiores valores de velocidade para que menor aceleração ocorresse no instante de contato manopla-disco. Também, houve menor restrição nas condições com menores distâncias, nas quais o índice de dificuldade foi diminuído em função da distância manopla-disco e do tamanho do ângulo da margem de acerto. Ademais, o aumento na aceleração sugere que tanto o impacto como a inércia de movimento pode ter contribuído para manutenção da precisão, mesmo com o aumento na geração de velocidade no movimento. O tempo de movimento, o tempo para contato e o tempo após contato manopla-disco apresentaram uma relação linear com os dois índices de dificuldade propostos. Com o aumento da distância manopla-disco, foram verificadas maior amplitude, velocidade e aceleração angular do cotovelo e maior aceleração angular do ombro. 
5.1 Introdução

A velocidade tem sido inversamente relacionada à precisão, de forma que quanto maior a demanda de precisão menor a velocidade de movimento apresentada (Fitts, 1954; Milner \& ljaz, 1990; Plamondon \& Alimi, 1997). Essa relação tem sido consistentemente demonstrada por meio do paradigma da restrição espacial (Crossman \& Goodeve, 1963/1983; Fitts, 1954; Fitts \& Peterson, 1954; Meyer et al., 1982, 1988) e do paradigma de restrição temporal (Schmidt et al., 1978, 1979; Write \& Meyer, 1983; Zelaznik, 1993). No paradigma da restrição espacial, a diminuição no tamanho do alvo (T) ou o aumento na distância de movimento (D) proporcionam maior restrição espacial que resultam em maiores tempos de movimento (TM, ou velocidade média). Esta restrição espacial expressada através do índice de dificuldade (ID $=\log _{2}[2 \times \mathrm{D} / \mathrm{T}]$; cf. Fitts, 1954) resulta numa relação inversa logarítmica entre velocidade e precisão (TM - ID). Diversos estudos corroboraram com esta relação inversa logarítmica entre a velocidade e a precisão (Crossman, 1956; Guiard, 1997; Mackenzie, 1989, 1992; Soukoreff \& Mackenzie, 2004). No paradigma da restrição temporal, a restrição espacial é constante (distância ou tamanho do alvo) enquanto é manipulado o tempo de movimento (velocidade média) e mensurada a dispersão dos pontos finais da resposta (precisão). O aumento da restrição temporal, ou aumento na velocidade de movimento, ocasiona em maior variabilidade de resposta (menor precisão), resultando numa relação linear velocidade-precisão (velocidade média $x$ desvio padrão do erro espacial; Schmidt et al., 1978, 1979; Tresilian \& Lonergan, 2002; Zelaznik et al., 1986). Contudo, esta relação inversa linear velocidade-precisão não demonstra ser um fenômeno tão consistente quanto à relação inversa logarítmica velocidade-precisão (Wright \& Meyer, 1983; Zelaznik, 1993), não sendo claras as situações em que ela ocorre.

Alguns modelos tentaram explicar esta relação inversa entre velocidade $e$ precisão como uma característica que emerge em resposta da sinergia agonistaantagonista da musculatura que atua no movimento (Plamondon, 1993, 1995a; Plamondon \& Alimi, 1997); como resultado do menor tempo disponível para utilização 
do feedback (Beggs \& Howarth, 1970, 1972a; Crossman \& Goodeve, 1963/1983); em função do aumento no ruído neural causado por diversos processos do sistema (Newell et al., 1982; Schmidt et al., 1978, 1979); ou como uma capacidade limitada do sistema em processar informações (Fitts, 1954; Fitts \& Pettersen, 1964). Apesar da contribuição destes modelos no entendimento das estratégias de controle na geração de velocidade e na manutenção na precisão, ainda há diversas limitações na aplicabilidade destes conceitos em habilidades motoras mais complexas. Como os experimentos que fundamentaram os modelos utilizaram apenas habilidades motoras simples (unidimensionais, rotação de apenas uma articulação, de mover uma ponteira em direção a um alvo, etc), a relação velocidade-precisão e as estratégias de controle que atuam sobre movimentos mais complexos ainda têm sido pouco analisadas e compreendidas (Elliott et al., 2004). Ademais, algumas habilidades motoras mais complexas não demonstraram obedecer estritamente esta relação inversa velocidade-precisão, como o chute no futebol (Teixeira, 1999), o arremesso estilo beisebol (Van Den Tillaar \& Ettema, 2006), o arremesso no basquetebol (Okazaki \& Rodacki, 2005; Okazaki et al., 2006c), ou a manutenção do equilíbrio postural (Danion et al., 1999). Desta forma, um importante aspecto a ser analisado no paradigma da relação velocidade-precisão é sua capacidade de generalização para habilidades motoras mais complexas como as do cotidiano e/ou esportivas.

As tarefas normalmente utilizadas para analisar o paradigma da relação inversa velocidade-precisão possuíram como característica comum a geração da velocidade e a restrição da precisão ocorrendo na mesma dimensão espacial. Nenhum estudo explorou tarefas na qual a geração de velocidade ocorre predominantemente numa dimensão e o controle da precisão em outra dimensão. Por exemplo, na tarefa de contatar um disco com uma manopla em direção a um alvo remoto, a geração de velocidade para contatar o disco ocorre predominantemente numa dimensão (eixo cartesiano $\mathrm{x}$ ), enquanto a restrição espacial da precisão associada à geração do erro no movimento ocorre em outra dimensão (eixo cartesiano y). Pois, nesta tarefa o sujeito deve gerar maior velocidade possível em direção ao disco a ser contatado pela manopla (eixo cartesiano $\mathrm{x}$ ), ao passo que deve evitar movimentos em direção perpendicular à direção do disco (eixo cartesiano $x)$ para que o disco possa atingir o alvo remoto. Esta característica das dimensões 
independentes no controle da velocidade e da precisão parece ser mais comum aos movimentos do cotidiano (lançamentos, arremessos, rebatidas, etc.) e poderiam explicar porque alguns movimentos podem ser velozes e acurados ao mesmo tempo. Contudo, esta hipótese de controle independente entre os componentes de geração de velocidade e a manutenção da precisão ainda não tem sido investigada.

Outra diferença entre as tarefas motoras simples, normalmente utilizadas para analisar o paradigma da relação velocidade-precisão, está no tempo em que ocorre o maior valor de velocidade no movimento. Nas tarefas de toques sucessivos em direção a um alvo (Fitts \& Petersen, 1964; Guiard, 1997), rotação de alguma articulação (Crosman \& Goodeve, 1963/1983; Meyer et al., 1988), transporte de pinos ou argolas (Fitts, 1954), etc.; o maior valor de velocidade ocorre nas porções medias do movimento, definindo fases proporcionais de aceleração e de desaceleração. Nas quais, quando maior velocidade é necessária há aumento na fase de aceleração, e quando maior precisão é requisitada há aumento na fase de desaceleração (Adam, 1992; Teixeira, 2000; Van Muelen \& Gooskens, 1990). Entretanto, em tarefas motoras mais complexas como o arremessar (Okazaki \& Rodacki, 2005; Okazaki et al., 2006, 2008a), chutar (Anderson \& Sidaway, 1994; Teixeira, 1999), rebater (Caljouw et al., 2005; Elliott et al., 1989), etc.; o maior valor de velocidade ocorre próximo ao instante crítico de performance (lançamento, contato, impacto, etc.). Em habilidades motoras dessa natureza outras estratégias além da manipulação das fases de aceleração e de desaceleração também são utilizadas para o controle na geração de velocidade e na manutenção da precisão do movimento.

Uma estratégia sugerida no controle da relação velocidade-precisão no movimento, em habilidades motoras mais complexas, é a regulação no tempo em que ocorre a maior velocidade e o instante crítico do desempenho (Okazaki \& Rodacki, 2005; Okazaki et al., 2006c; Teixeira, 1999, 2000). Pois, no instante em que ocorre a maior velocidade no movimento, a aceleração é nula. Como a aceleração (força) tem sido relacionada à produção de variabilidade no movimento (Schmidt et al., 1978, 1979), menor variabilidade seria verificada quando a velocidade estivesse próxima de seus valores máximos (Gielen et al., 1985). Desta forma, coincidir o instante em que ocorre a maior velocidade e o instante crítico do desempenho 
garante ao sistema maior consistência de movimento. Tal estratégia também possibilitaria maior geração de velocidade no movimento sem comprometer a precisão, desde que uma modulação apropriada no tempo da maior velocidade fosse realizada. Esta estratégia tem sido sugerida no arremesso do basquetebol (Okazaki \& Rodacki, 2005; Okazaki et al., 2006a, 2006b, 2006c), no chute do futebol (Teixeira, 1999), na rebatida do saque no tênis (Elliott et al., 1999). Porém, ainda não é sabido se esta estratégia de controle é comum para todas as habilidades motoras complexas, nem são conhecidos os efeitos da manipulação na velocidade de movimento sobre as estratégias de controle adotadas para a manutenção da precisão. Ademais, pouco é conhecido sobre a contribuição das ações articulares em habilidades motoras complexas, no paradigma da relação inversa velocidadeprecisão. Como a resposta do movimento é produto da organização das ações interarticulares que participam do movimento, a análise do desempenho das articulações também pode trazer informações importantes sobre as estratégias de controle utilizadas para a regulação velocidade-precisão.

Considerando os pontos discutidos anteriormente, no presente experimento foi analisado o efeito da velocidade de movimento para entender as estratégias de controle por meio das variáveis cinemáticas lineares de resposta e angulares de desempenho no movimento.

\section{$5.2 \quad$ Objetivo}

Analisar o efeito da velocidade de movimento, na tarefa de contatar um disco com uma manopla em direção a um alvo remoto, sobre as variáveis cinemáticas de resposta e de desempenho do movimento.

\subsection{Hipóteses}

H6 O aumento na velocidade de movimento, independente da dimensão (eixo x ou y) em que ele ocorre ou do parâmetro analisado (maior velocidade ou velocidade no instante de contato manopla-disco), resulta em menor precisão e maior variabilidade. 
H7 O erro e a variabilidade somente aumentam quando há maior geração de velocidade na dimensão em que ocorre o controle da precisão no movimento (eixo y).

H8 O tempo do maior valor de velocidade é sincronizado com o instante de contato manopla-disco.

H9 Maior velocidade linear da manopla ocorre através do aumento na fase de aceleração de movimento.

H10 Maior velocidade linear da manopla ocorre através do aumento na fase de aceleração do ombro e do cotovelo, e do aumento na fase de desaceleração do punho.

\subsection{Procedimentos particulares do método}

Foi analisada a tarefa de contatar um disco com uma manopla em direção a um alvo remoto, realizada com máxima velocidade e maior precisão possíveis. Análises cinemáticas do resultado (variáveis lineares do disco) e do desempenho (variáveis angulares das articulações e lineares da manopla) foram realizadas para entender as estratégias de controle motor na geração de velocidade e na manutenção da precisão do movimento.

Foi utilizada uma distância manopla-disco de $32 \mathrm{~cm}$ e uma manopla circular de $7,5 \mathrm{~cm}$ de diâmetro e massa de $200 \mathrm{~g}$. Esta manopla foi utilizada para contatar um disco de $7,5 \mathrm{~cm}$ de diâmetro com massa de $100 \mathrm{~g}$. O disco era direcionado a um alvo remoto com tamanho de $10 \mathrm{~cm}$. Os sujeitos foram instruídos a desempenhar cinco velocidades diferentes de forma gradativa (da menor velocidade até a velocidade máxima). No qual, a menor velocidade utilizada fazia apenas com que o disco tocasse levemente o alvo remoto. As tentativas na qual o disco não tocou o alvo remoto, por falta de velocidade/potência no movimento, foram desconsideradas da análise e repetidas em seguida. A maior velocidade foi solicitada com a maior potência possível, mas direcionando o disco ao alvo remoto. Desta 
forma, cinco níveis de velocidade foram desempenhados: (nível 1) 0-20\%, (nível 2) 21-40\%, (nível 3) 41-60\%, (nível 4) 61-80\% e (nível 5) 81-100\%. As demais características do arranjo experimental foram descritas na sessão de métodos.

\subsection{Resultados}

5.5.1 Variáveis lineares de resultado (disco) e de desempenho (manopla)

Neste experimento a velocidade de movimento foi manipulada subjetivamente em cinco níveis gradativos. Os valores de velocidade média confirmaram a distinção adequada de cada nível de velocidade $\left(F_{1,15}=157,46\right.$; $p<$ 0,0001 ), no qual houve diferença entre todos os níveis analisados (valores de $p<$ $0,05)$. Para distinguir os níveis de velocidade utilizados, os valores da velocidade média foram expressos no cabeçalho das tabelas (9, 10, 11, 12 e 13).

A tabela 9 apresentou a análise estática descritiva (média e desvio padrão) e inferencial (análise de variância com medidas repetidas) das variáveis lineares espaciais de reposta (disco) e de desempenho (manopla), em função da velocidade de movimento. Ao contrário do esperado, a velocidade não apresentou efeito sobre a precisão e a variabilidade de movimento. Houve aumento na amplitude total de movimento no eixo $x$ e no eixo y na maior velocidade $(2,93 \mathrm{~m} / \mathrm{s})$ em comparação às demais velocidades $(1,46,1,70,1,95$ e 2,27 m/s). O acréscimo na velocidade de movimento foi realizado através do aumento na maior velocidade, na velocidade no contato e na maior aceleração, com diferença entre todas as condições de velocidade desempenhadas nessas variáveis. Contudo, a aceleração do eixo $x$ no instante de contato manopla-disco diminuiu na condição de maior velocidade $(2,93 \mathrm{~m} / \mathrm{s})$ em comparação às velocidades 1,70, 1,95, 2,27 m/s. A maior velocidade do eixo y aumentou na velocidade 1,46 m/s em comparação à 1,95, 2,27 e $2,93 \mathrm{~m} / \mathrm{s}$; e na velocidade $1,70 \mathrm{~m} / \mathrm{s}$ em comparação à $2,93 \mathrm{~m} / \mathrm{s}$. A maior aceleração do eixo y aumentou na velocidade 1,46 m/s em comparação à 1,95, 2,27 e 2,93 m/s; na velocidade $1,70 \mathrm{~m} / \mathrm{s}$ em relação à 2,27 e $2,93 \mathrm{~m} / \mathrm{s}$; e na velocidade $1,95 \mathrm{~m} / \mathrm{s}$ em comparação à $2,93 \mathrm{~m} / \mathrm{s}$. $O$ acréscimo na velocidade também resultou no aumento da maior aceleração no eixo $\mathrm{y}$, com diferença na velocidade $2,93 \mathrm{~m} / \mathrm{s}$ em comparação à 
$1,46,1,70$ e $1,95 \mathrm{~m} / \mathrm{s}$; na velocidade $2,27 \mathrm{~m} / \mathrm{s}$ em relação à 1,46 e 1,70 m/s; e na velocidade 1,95 m/s em comparação à 1,46 e 2,93 m/s.

TABELA 9 - Média, DP (entre parênteses), $F$ e $p$ para as variáveis espaciais de resposta (disco) e de desempenho (manopla), em função da velocidade de movimento.

\begin{tabular}{|c|c|c|c|c|c|c|c|}
\hline \multirow[b]{2}{*}{ Variáveis espaciais } & \multicolumn{5}{|c|}{ Velocidade média eixo x (m/s) } & \multicolumn{2}{|c|}{ Estatística } \\
\hline & $\begin{array}{l}1,46 \\
(0,06)\end{array}$ & $\begin{array}{l}1,70 \\
(0,06)\end{array}$ & $\begin{array}{l}1,95 \\
(0,07)\end{array}$ & $\begin{array}{l}2,27 \\
(0,07)\end{array}$ & $\begin{array}{r}2,93 \\
(0,11)\end{array}$ & $F_{1,15}$ & $p$ \\
\hline Erro angular absoluto $(\stackrel{\circ}{)})$ & $\begin{array}{r}2,35 \\
(0,93)\end{array}$ & $\begin{array}{l}2,15 \\
(0,77)\end{array}$ & $\begin{array}{l}2,35 \\
(0,77)\end{array}$ & $\begin{array}{l}2,67 \\
(1,00)\end{array}$ & $\begin{array}{r}2,95 \\
(1,06)\end{array}$ & 1,78 & 0,142 \\
\hline Variabilidade $(\stackrel{\circ}{)})$ & $\begin{array}{l}1,79 \\
(0,43)\end{array}$ & $\begin{array}{l}1,83 \\
(0,68)\end{array}$ & $\begin{array}{l}1,91 \\
(0,40)\end{array}$ & $\begin{array}{l}2,00 \\
(0,61)\end{array}$ & $\begin{array}{l}2,10 \\
(0,82)\end{array}$ & 0,81 & 0,529 \\
\hline Amplitude linear eixo x (m) & $\begin{array}{l}0,576 \\
(0,056)^{5}\end{array}$ & $\begin{array}{l}0,582 \\
(0,057)^{5}\end{array}$ & $\begin{array}{l}0,583 \\
(0,056)^{5}\end{array}$ & $\begin{array}{l}0,588 \\
(0,053)^{5}\end{array}$ & $\begin{array}{c}0,611 \\
(0,052)^{1234}\end{array}$ & 14,70 & 0,0001 \\
\hline Amplitude linear eixo y (m) & $\begin{array}{l}0,041 \\
(0,016)^{5}\end{array}$ & $\begin{array}{l}0,044 \\
(0,019)^{5}\end{array}$ & $\begin{array}{l}0,046 \\
(0,017)^{5}\end{array}$ & $\begin{array}{l}0,049 \\
(0,020)^{5}\end{array}$ & $\begin{array}{c}0,059 \\
(0,025)^{1234}\end{array}$ & 8,70 & 0,0001 \\
\hline Maior veloc. eixo x (m/s) & $\begin{array}{c}3,37 \\
(0,24)^{2345}\end{array}$ & $\begin{array}{c}3,86 \\
(0,25)^{1345}\end{array}$ & $\begin{array}{c}4,33 \\
(0,32)^{1245}\end{array}$ & $\begin{array}{c}4,76 \\
(0,39)^{1235}\end{array}$ & $\begin{array}{c}5,30 \\
(0,45)^{1234}\end{array}$ & 248,60 & 0,0001 \\
\hline Veloc. contato eixo x (m/s) & $\begin{array}{c}3,29 \\
(0,26)^{2345}\end{array}$ & $\begin{array}{c}3,78 \\
(0,29)^{1345}\end{array}$ & $\begin{array}{c}4,24 \\
(0,36)^{1245}\end{array}$ & $\begin{array}{c}4,69 \\
(0,42)^{1235}\end{array}$ & $\begin{array}{c}5,25 \\
(0,47)^{1234}\end{array}$ & 260,42 & 0,0001 \\
\hline Maior acel. eixo $\times\left(\mathrm{m} / \mathrm{s}^{2}\right)$ & $\begin{array}{l}26,83 \\
(4,05)^{2345}\end{array}$ & $\begin{array}{c}35,87 \\
(4,50)^{1345}\end{array}$ & $\begin{array}{l}46,53 \\
(7,89)^{1245}\end{array}$ & $\begin{array}{l}56,55 \\
(8,34)^{1234}\end{array}$ & $\begin{array}{l}66,72 \\
(8,54)^{1234}\end{array}$ & 207,95 & 0,0001 \\
\hline $\begin{array}{l}\text { Acel. no contato eixo } x \\
\left(\mathrm{~m} / \mathrm{s}^{2}\right)\end{array}$ & $\begin{array}{c}-10,35 \\
(7,80)\end{array}$ & $\begin{array}{c}-11,40 \\
(8,48)^{5}\end{array}$ & $\begin{array}{c}-13,32 \\
(9,69)^{5}\end{array}$ & $\begin{array}{l}-12,45 \\
(10,46)^{5}\end{array}$ & $\begin{array}{c}-7,39 \\
(12,89)^{234}\end{array}$ & 6,15 & 0,0003 \\
\hline Maior veloc. eixo y (m/s) & $\begin{array}{c}0,36 \\
(0,16)^{345}\end{array}$ & $\begin{array}{l}0,46 \\
(0,17)^{5}\end{array}$ & $\begin{array}{l}0,50 \\
(0,18)^{1}\end{array}$ & $\begin{array}{l}0,54 \\
(0,21)^{1}\end{array}$ & $\begin{array}{l}0,58 \\
(0,25)^{12}\end{array}$ & 10,48 & 0,0001 \\
\hline Veloc. contato eixo y $(\mathrm{m} / \mathrm{s})$ & $\begin{array}{l}0,19 \\
(0,11)\end{array}$ & $\begin{array}{l}0,22 \\
(0,13)\end{array}$ & $\begin{array}{l}0,21 \\
(0,11)\end{array}$ & $\begin{array}{l}0,21 \\
(0,11)\end{array}$ & $\begin{array}{l}0,17 \\
(0,13)\end{array}$ & 0,82 & 0,513 \\
\hline Maior acel. eixo y $\left(\mathrm{m} / \mathrm{s}^{2}\right)$ & $\begin{array}{l}13,07 \\
(4,53)^{345}\end{array}$ & $\begin{array}{l}16,04 \\
(5,82)^{45}\end{array}$ & $\begin{array}{l}17,66 \\
(6,02)^{15}\end{array}$ & $\begin{array}{l}20,76 \\
(6,49)^{12}\end{array}$ & $\begin{array}{l}23,84 \\
(8,94)^{123}\end{array}$ & 20,33 & 0,0001 \\
\hline $\begin{array}{l}\text { Acel. no contato eixo y } \\
\left(\mathrm{m} / \mathrm{s}^{2}\right)\end{array}$ & $\begin{array}{l}-3,75 \\
(2,31)^{45}\end{array}$ & $\begin{array}{l}-4,77 \\
(2,41)^{45}\end{array}$ & $\begin{array}{l}-6,04 \\
(2,47)^{5}\end{array}$ & $\begin{array}{l}-8,15 \\
(3,00)^{12}\end{array}$ & $\begin{array}{c}-9,66 \\
(6,31)^{123}\end{array}$ & 9,64 & 0,0001 \\
\hline
\end{tabular}

Diferente de ${ }^{1} 1,46 \mathrm{~m} / \mathrm{s},{ }^{2} 1,70 \mathrm{~m} / \mathrm{s},{ }^{3} 1,95 \mathrm{~m} / \mathrm{s},{ }^{4} 2,27 \mathrm{~m} / \mathrm{s} \mathrm{e}^{5} 2,93 \mathrm{~m} / \mathrm{s}$. 
O aumento na velocidade diminuiu o tempo de movimento e o tempo para contato manopla-disco, com diferenças entre todos os níveis de velocidade nestas duas variáveis. Menor tempo após contato manopla-disco também foi verificado com o aumento na velocidade, com diferenças na velocidade $1,46 \mathrm{~m} / \mathrm{s}$ em comparação às demais $(1,70,1,95,2,27$ e 2,93 m/s); na velocidade $1,70 \mathrm{~m} / \mathrm{s}$ em relação à 1,46, 2,27 e $2,93 \mathrm{~m} / \mathrm{s}$; e na velocidade $1,95 \mathrm{~m} / \mathrm{s}$ em comparação à $1,46 \mathrm{~m} / \mathrm{s}, 2,27$ e $2,93 \mathrm{~m} / \mathrm{s}$. $O$ tempo da maior velocidade e da maior aceleração no eixo $\mathrm{x}$ foram antecipados, em função do aumento na velocidade, apresentando diferença entre todas as condições nestas duas variáveis. A diferença entre o tempo da maior velocidade e do tempo para contato manopla-disco diminuiu, em função do aumento na velocidade, com diferença na maior velocidade $(2,93 \mathrm{~m} / \mathrm{s})$ em comparação às demais $(1,46,1,70,1,95$ e $2,27 \mathrm{~m} / \mathrm{s}$ ). Apesar das modificações nas variáveis temporais absolutas, a manipulação da velocidade de movimento não teve efeito sobre o tempo relativo das fases de aceleração e de desaceleração. A análise estática descritiva (média e desvio padrão) e inferencial (análise de variância com medidas repetidas) das variáveis lineares temporais de reposta (disco) e de desempenho (manopla), em função da velocidade de movimento, foi apresentada na tabela 10 .

A análise de regressão linear do erro angular absoluto em função das velocidades médias do movimento (eixo $\mathrm{x}$ e y) demonstrou valores de $R>0,91$. A variabilidade (desvio padrão do erro angular absoluto) demonstrou associação com valores de $R>0,93$ para as variáveis de velocidade média (eixo $\mathrm{x}$ e y), maior velocidade (eixo $x$ e $y$ ) e velocidade no contato manopla-disco (eixo $x$ ). Por conseguinte, a precisão e a variabilidade foram capazes de serem preditas por diversos parâmetros da velocidade no movimento, tanto no eixo $x$ quanto no eixo $y$. Também, foi verificada uma associação entre a geração de velocidade entre 0 eixo $x$ e o eixo y nos valores de velocidade média e de maior velocidade (valores de $R>$ $0,97)$. As análises de regressão linear simples entre as variáveis de velocidade, em função das variáveis de erro e variabilidade, foram expressas na tabela 11. 
TABELA 10 - Média, desvio padrão (entre parênteses), $F$ e $p$ para as variáveis temporais de resposta (disco) e de desempenho (manopla), em função da velocidade de movimento.

\begin{tabular}{|c|c|c|c|c|c|c|c|}
\hline \multirow[b]{2}{*}{ Variáveis temporais } & \multicolumn{5}{|c|}{ Velocidade média eixo x (m/s) } & \multicolumn{2}{|c|}{ Estatística } \\
\hline & $\begin{array}{l}1,46 \\
(0,06)\end{array}$ & $\begin{array}{l}1,70 \\
(0,06)\end{array}$ & $\begin{array}{l}1,95 \\
(0,07)\end{array}$ & $\begin{array}{l}2,27 \\
(0,07)\end{array}$ & $\begin{array}{l}2,93 \\
(0,11)\end{array}$ & $F_{1,15}$ & $p$ \\
\hline Tempo de movimento (s) & $\begin{array}{c}0,403 \\
(0,071)^{2345}\end{array}$ & $\begin{array}{c}0,353 \\
(0,061)^{1345}\end{array}$ & $\begin{array}{c}0,306 \\
(0,054)^{1245}\end{array}$ & $\begin{array}{c}0,263 \\
(0,041)^{1235}\end{array}$ & $\begin{array}{c}0,212 \\
(0,032)^{1234}\end{array}$ & 124,67 & 0,0001 \\
\hline Tempo para contato (s) & $\begin{array}{c}0,228 \\
(0,039)^{2345}\end{array}$ & $\begin{array}{c}0,202 \\
(0,029)^{1345}\end{array}$ & $\begin{array}{c}0,177 \\
(0,030)^{1245}\end{array}$ & $\begin{array}{c}0,152 \\
(0,027)^{1235}\end{array}$ & $\begin{array}{c}0,117 \\
(0,017)^{1234}\end{array}$ & 106,76 & 0,0001 \\
\hline Tempo após contato (s) & $\begin{array}{c}0,172 \\
(0,066)^{2345}\end{array}$ & $\begin{array}{c}0,145 \\
(0,057)^{145}\end{array}$ & $\begin{array}{c}0,129 \\
(0,049)^{145}\end{array}$ & $\begin{array}{l}0,111 \\
(0,036)^{12}\end{array}$ & $\begin{array}{c}0,094 \\
(0,024)^{123}\end{array}$ & 25,59 & 0,0001 \\
\hline $\begin{array}{l}\text { Tempo da maior } \\
\text { velocidade no eixo x (s) }\end{array}$ & $\begin{array}{c}0,218 \\
(0,044)^{2345}\end{array}$ & $\begin{array}{c}0,194 \\
(0,033)^{1345}\end{array}$ & $\begin{array}{c}0,170 \\
(0,033)^{1245}\end{array}$ & $\begin{array}{c}0,146 \\
(0,030)^{1235}\end{array}$ & $\begin{array}{c}0,114 \\
(0,019)^{1234}\end{array}$ & 89,28 & 0,0001 \\
\hline $\begin{array}{l}\text { Tempo da maior } \\
\text { aceleração no eixo x (s) }\end{array}$ & $\begin{array}{c}0,160 \\
(0,051)^{2345}\end{array}$ & $\begin{array}{c}0,139 \\
(0,038)^{1345}\end{array}$ & $\begin{array}{c}0,118 \\
(0,035)^{1245}\end{array}$ & $\begin{array}{c}0,095 \\
(0,031)^{1235}\end{array}$ & $\begin{array}{c}0,059 \\
(0,020)^{1234}\end{array}$ & 59,44 & 0,0001 \\
\hline
\end{tabular}

$\begin{array}{llllllll}\text { Tempo para contato menos } & 0,009 & 0,008 & 0,007 & 0,007 & 0,003 & 12,96 & 0,0001 \\ \text { tempo da maior vel. eixo x (s) } & (0,008)^{5} & (0,006)^{5} & (0,007)^{5} & (0,005)^{5} & (0,005)^{1234} & 12,96 & \end{array}$

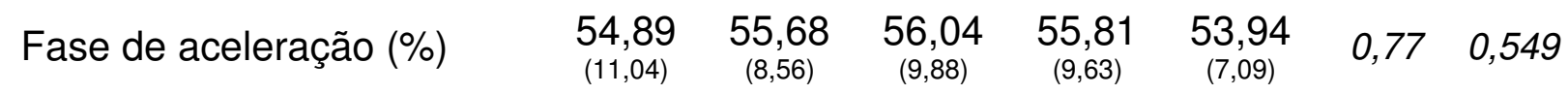




TABELA 11 - Valores da regressão linear das variáveis de velocidade em função do erro e da variabilidade.

\begin{tabular}{|c|c|c|c|c|c|}
\hline Variáveis & $R$ & $R^{2}$ & $F_{1,3}$ & $p$ & Equação de Reta \\
\hline $\begin{array}{l}\text { Veloc. média (eixo x) x } \\
\text { Erro angular absoluto }\end{array}$ & 0,918 & 0,842 & 16,04 & 0,028 & $y=1,449 x+0,507$ \\
\hline $\begin{array}{l}\text { Veloc. média (eixo x) x } \\
\text { Variabilidade }\end{array}$ & 0,991 & 0,981 & 156,80 & 0,001 & $y=1,472 x+0,220$ \\
\hline $\begin{array}{l}\text { Veloc. média (eixo y) x } \\
\text { Erro angular absoluto }\end{array}$ & 0,924 & 0,854 & 17,49 & 0,025 & $y=1,801 x+4,062$ \\
\hline $\begin{array}{l}\text { Veloc. média (eixo y) x } \\
\text { Variabilidade }\end{array}$ & 0,974 & 0,949 & 55,31 & 0,005 & $y=1,632 x+1,724$ \\
\hline $\begin{array}{l}\text { Maior veloc. (eixo } \mathrm{x}) \mathrm{x} \\
\text { Erro angular absoluto }\end{array}$ & 0,863 & 0,746 & 8,83 & 0,059 & $y=0,937 x+0,360$ \\
\hline $\begin{array}{l}\text { Maior veloc. (eixo x) x } \\
\text { Variabilidade }\end{array}$ & 0,990 & 0,980 & 149,68 & 0,001 & $y=1,208 x+0,166$ \\
\hline $\begin{array}{l}\text { Maior veloc. (eixo y) } \mathrm{x} \\
\text { Erro angular absoluto }\end{array}$ & 0,735 & 0,540 & 3,52 & 0,157 & $y=1,130 x+2,792$ \\
\hline $\begin{array}{l}\text { Maior velocidade (eixo y) x } \\
\text { Variabilidade }\end{array}$ & 0,936 & 0,876 & 21,12 & 0,019 & $y=1,227 x+1,430$ \\
\hline $\begin{array}{l}\text { Veloc. no contato (eixo x) x } \\
\text { Erro angular absoluto }\end{array}$ & 0,869 & 0,755 & 9,23 & 0,056 & $y=0,972 x+0,358$ \\
\hline $\begin{array}{l}\text { Veloc. no contato }(\text { eixo } x) \times \\
\text { Variabilidade }\end{array}$ & 0,992 & 0,983 & 175,94 & 0,001 & $y=1,227 x+0,165$ \\
\hline $\begin{array}{l}\text { Veloc. no contato (eixo y) x } \\
\text { Erro angular absoluto }\end{array}$ & 0,694 & 0,482 & 2,79 & 0,193 & $y=4,751 x-11,362$ \\
\hline $\begin{array}{l}\text { Veloc. no contato (eixo y) x } \\
\text { Variabilidade }\end{array}$ & 0,428 & 0,184 & 0,67 & 0,472 & $y=2,487 x-2,821$ \\
\hline $\begin{array}{l}\text { Veloc. média }(x) x \\
\text { Veloc. média }(y)\end{array}$ & 0,995 & 0,990 & 293,66 & 0,001 & $y=-0,087 x+0,125$ \\
\hline $\begin{array}{l}\text { Maior veloc. }(x) x \\
\text { Maior veloc. }(y)\end{array}$ & 0,975 & 0,951 & 58,79 & 0,005 & $y=0,026 x+0,107$ \\
\hline $\begin{array}{l}\text { Veloc. no contato }(\mathrm{x}) \mathrm{x} \\
\text { Veloc. no contato }(\mathrm{y})\end{array}$ & 0,320 & 0,103 & 0,34 & 0,599 & $y=0,204 x-0,595$ \\
\hline
\end{tabular}




\subsubsection{Variáveis angulares de desempenho (articulações)}

A tabela 12 e a tabela 13 apresentaram, respectivamente, as variáveis lineares espaciais e temporais da análise estatística (descritiva e inferencial), em função da velocidade de movimento. O aumento na velocidade de movimento resultou em maior ângulo do ombro no instante de contato manopla-disco, no qual a velocidade $1,46 \mathrm{~m} / \mathrm{s}$ apresentou menor ângulo comparado as demais $(1,70,1,95$, 2,27 e 2,93 m/s). Por outro lado, o acréscimo na velocidade diminuiu o ângulo do cotovelo no instante de contato manopla-disco, com diferença na velocidade $2,93 \mathrm{~m} / \mathrm{s}$ em comparação às demais velocidades $(1,46,1,70,1,95$ e 2,27 m/s), na velocidade $2,27 \mathrm{~m} / \mathrm{s}$ também em relação às demais velocidades $(1,46,1,70,1,95$ e 2,93 m/s); e na velocidade $1,95 \mathrm{~m} / \mathrm{s}$ em relação à 1,46, 2,27 e 2,93 m/s. Maior ângulo do punho no instante de contato manopla-disco foi verificado em função do aumento na velocidade, com diferença na velocidade $2,93 \mathrm{~m} / \mathrm{s}$ em comparação à 1,46, 1,70 e $1,95 \mathrm{~m} / \mathrm{s}$; e na velocidade $2,27 \mathrm{~m} / \mathrm{s}$ em relação à $1,46 \mathrm{~m} / \mathrm{s}$. O acréscimo na velocidade também aumentou a amplitude angular no ombro e no cotovelo. No qual, ombro e cotovelo apresentaram menor amplitude na velocidade $1,46 \mathrm{~m} / \mathrm{s}$ em comparação às demais $(1,70,1,95,2,27$ e $2,93 \mathrm{~m} / \mathrm{s})$; e menor amplitude na velocidade $1,70 \mathrm{~m} / \mathrm{s}$ em comparação à 2,27 e $2,93 \mathrm{~m} / \mathrm{s}$ para o cotovelo.

$O$ acréscimo na velocidade linear da manopla foi decorrente de aumentos na velocidade angular do ombro, do cotovelo e do punho. No qual, o ombro apresentou menor velocidade na condição $1,46 \mathrm{~m} / \mathrm{s}$ em comparação às demais velocidades $(1,70,1,95,2,27$ e 2,93 m/s); e menor velocidade na condição 1,70 em comparação à velocidade 2,27 e 2,93 m/s. O cotovelo apresentou aumento com diferença entre todas as condições de velocidades, em função da manipulação na velocidade. Enquanto o punho apresentou maior velocidade na condição 2,27 m/s em comparação à 1,46 e 1,70 m/s; e na condição 2,93 m/s em relação à 1,46, 1,70 e $1,95 \mathrm{~m} / \mathrm{s}$. A manipulação da velocidade também apresentou efeito sobre a velocidade no instante de contato na articulação do ombro e do cotovelo. No qual, o ombro apresentou menor velocidade no instante de contato manopla-disco na condição 1,46 $\mathrm{m} / \mathrm{s}$ em comparação à $1,70,1,95$ e 2,27 m/s; e na condição $2,93 \mathrm{~m} / \mathrm{s}$ em relação à 1,95 e $2,27 \mathrm{~m} / \mathrm{s}$. Ao passo que o cotovelo teve maior velocidade no instante de 
contato manopla-disco, com o aumento na velocidade, apresentando diferença entre todas as condições.

O acréscimo na velocidade da manopla foi realizado por meio de maiores aceleração do ombro e do cotovelo. No qual, houve diferença entre todas as condições para o ombro, exceto entre as condições de velocidade 1,70 e 1,95 m/s. Enquanto, o cotovelo aumentou a aceleração, com diferença entre todas as condições de velocidade. $O$ acréscimo de velocidade também aumentou as acelerações no contato manopla-disco das articulações. Com ombro e cotovelo apresentando diferença da aceleração no contato manopla-disco na velocidade 1,46 $\mathrm{m} / \mathrm{s}$ em comparação à 1,95, 2,27 e 2,93 m/s; na velocidade $1,70 \mathrm{~m} / \mathrm{s}$ em relação à 2,27 e $2,93 \mathrm{~m} / \mathrm{s}$; e na velocidade $1,95 \mathrm{~m} / \mathrm{s}$ em comparação à 1,46, 2,27 e 2,93 m/s. A aceleração no contato manopla-disco do punho demonstrou diferença na velocidade $2,27 \mathrm{~m} / \mathrm{s}$ em comparação à 1,46 e $1,70 \mathrm{~m} / \mathrm{s}$; e na velocidade $2,93 \mathrm{~m} / \mathrm{s}$ em relação à $1,46,1,70$ e $1,95 \mathrm{~m} / \mathrm{s}$.

O ombro, o cotovelo e o punho anteciparam o tempo da maior velocidade, em função do acréscimo na velocidade. No qual, foi verificada diferença no ombro e no cotovelo, no tempo da maior velocidade, entre todas as condições. O punho antecipou a maior velocidade na condição $2,27 \mathrm{~m} / \mathrm{s}$ em comparação à 1,46, 1,70 e $1,95 \mathrm{~m} / \mathrm{s}$; e na condição $2,93 \mathrm{~m} / \mathrm{s}$ em relação à 1,46 e 1,70 m/s. Também houve uma antecipação no tempo da maior aceleração, com o acréscimo na velocidade, para o ombro, o cotovelo e o punho. A maior aceleração do ombro foi antecipada na velocidade 2,93 m/s em comparação à 1,46, 1,70 e 1,95 m/s; na velocidade 2,27 m/s em relação à 1,46 e $1,70 \mathrm{~m} / \mathrm{s}$; e na velocidade $1,95 \mathrm{~m} / \mathrm{s}$ em comparação à $1,46 \mathrm{~m} / \mathrm{s}$. No cotovelo a antecipação do tempo da maior aceleração apresentou diferença entre todas as condições. No punho, a antecipação da maior aceleração foi diferente na velocidade 1,46 m/s em comparação à 1,95, 2,27 e 2,93 m/s; e na velocidade 1,70 em relação à $2,93 \mathrm{~m} / \mathrm{s}$. Estas modificações nas variáveis temporais angulares resultaram em maior fase de aceleração do ombro e maior fase de desaceleração do punho. Este aumento na fase de aceleração do ombro, e diminuição na fase de desaceleração, ocorreu na velocidade 2,93 m/s em comparação à 1,46, 1,70 e 1,95 $\mathrm{m} / \mathrm{s}$. Enquanto, o punho aumentou a fase de aceleração, e reduziu a fase de desaceleração, quando a velocidade aumentou de $2,93 \mathrm{~m} / \mathrm{s}$ para $1,70 \mathrm{~m} / \mathrm{s}$. 
TABELA 12 - Média, DP (entre parênteses), $F$ e $p$ para as variáveis angulares espaciais de desempenho (articulações), em função da velocidade de movimento.

\begin{tabular}{|c|c|c|c|c|c|c|c|c|}
\hline \multirow[b]{2}{*}{ Variável } & \multirow[b]{2}{*}{ Artic. } & \multicolumn{5}{|c|}{ Velocidade média eixo x (m/s) } & \multicolumn{2}{|c|}{ Estatística } \\
\hline & & $\begin{array}{l}1,46 \\
(0,06)\end{array}$ & $\begin{array}{l}1,70 \\
(0,06)\end{array}$ & $\begin{array}{l}1,95 \\
(0,07)\end{array}$ & $\begin{array}{l}2,27 \\
(0,07)\end{array}$ & $\begin{array}{l}2,93 \\
(0,11)\end{array}$ & $F_{1,15}$ & $p$ \\
\hline \multirow{3}{*}{ 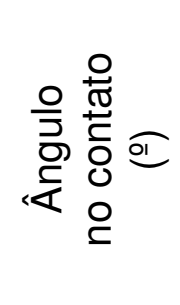 } & Ombro & $\begin{array}{l}118,94 \\
(2,19)^{2345}\end{array}$ & $\begin{array}{c}121,15 \\
(2,29)^{1}\end{array}$ & $\begin{array}{c}122,79 \\
(2,43)^{1}\end{array}$ & $\begin{array}{c}124,77 \\
(2,45)^{1}\end{array}$ & $\begin{array}{c}128,73 \\
(2,24)^{1}\end{array}$ & 56,51 & 0,0001 \\
\hline & Cotovelo & $\begin{array}{l}123,51 \\
(2,81)^{345}\end{array}$ & $\begin{array}{l}121,25 \\
(2,76)^{45}\end{array}$ & $\begin{array}{l}119,15 \\
(2,87)^{145}\end{array}$ & $\begin{array}{l}116,47 \\
(2,79)^{1235}\end{array}$ & $\begin{array}{l}112,15 \\
(2,71)^{1234}\end{array}$ & 57,16 & 0,0001 \\
\hline & Punho & $\begin{array}{l}174,44 \\
(3,14)^{45}\end{array}$ & $\begin{array}{c}175,12 \\
(2,99)^{5}\end{array}$ & $\begin{array}{c}175,72 \\
(2,79)^{5}\end{array}$ & $\begin{array}{c}176,79 \\
(2,58)^{4}\end{array}$ & $\begin{array}{l}178,31 \\
(2,50)^{123}\end{array}$ & 7,18 & 0,0001 \\
\hline \multirow{3}{*}{ 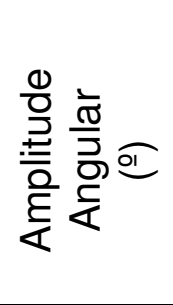 } & Ombro & $\begin{array}{c}14,99 \\
(0,59)^{2345}\end{array}$ & $\begin{array}{l}16,99 \\
(0,63)^{1}\end{array}$ & $\begin{array}{l}17,52 \\
(0,63)^{1}\end{array}$ & $\begin{array}{l}17,32 \\
(0,68)^{1}\end{array}$ & $\begin{array}{l}16,74 \\
(0,87)^{1}\end{array}$ & 5,24 & 0,001 \\
\hline & Cotovelo & $\begin{array}{c}95,78 \\
(1,85)^{2345}\end{array}$ & $\begin{array}{c}99,35 \\
(1,80)^{145}\end{array}$ & $\begin{array}{c}101,33 \\
(1,90)^{1}\end{array}$ & $\begin{array}{l}102,34 \\
(1,85)^{12}\end{array}$ & $\begin{array}{l}103,98 \\
(1,69)^{12}\end{array}$ & 21,49 & 0,0001 \\
\hline & Punho & $\begin{array}{c}16,36 \\
(1,90)\end{array}$ & $\begin{array}{c}16,86 \\
(2,08)\end{array}$ & $\begin{array}{c}16,07 \\
(1,98)\end{array}$ & $\begin{array}{c}16,92 \\
(2,13)\end{array}$ & $\begin{array}{c}16,54 \\
(1,90)\end{array}$ & 0,56 & 0,690 \\
\hline \multirow{3}{*}{ 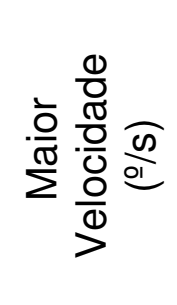 } & Ombro & $\begin{array}{l}112,48 \\
(4,11)^{2345}\end{array}$ & $\begin{array}{l}131,92 \\
(4,54)^{145}\end{array}$ & $\begin{array}{c}141,68 \\
(4,30)^{1}\end{array}$ & $\begin{array}{l}148,52 \\
(5,78)^{12}\end{array}$ & $\begin{array}{l}155,40 \\
(7,14)^{12}\end{array}$ & 21,31 & 0,0001 \\
\hline & Cotovelo & $\begin{array}{l}535,52 \\
(7,72)^{2345}\end{array}$ & $\begin{array}{l}605,58 \\
(7,52)^{1345}\end{array}$ & $\begin{array}{c}660,52 \\
(10,38)^{1245}\end{array}$ & $\begin{array}{c}708,09 \\
(11,52)^{1235}\end{array}$ & $\begin{array}{c}766,56 \\
(11,00)^{1234}\end{array}$ & 196,08 & 0,0001 \\
\hline & Punho & $\begin{array}{l}102,88 \\
(9,91)^{45}\end{array}$ & $\begin{array}{l}110,37 \\
(11,81)^{45} \\
\end{array}$ & $\begin{array}{l}117 \\
(12,7 \\
\end{array}$ & $\begin{array}{l}135 \\
(15, \\
\end{array}$ & $\begin{array}{r}150 \\
(17,1 \\
\end{array}$ & 13,12 & 0,0001 \\
\hline \multirow{3}{*}{ 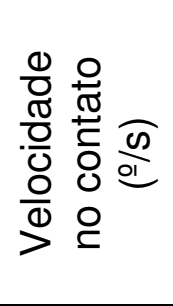 } & Ombro & $\begin{array}{l}104,66 \\
(5,09)^{234}\end{array}$ & $\begin{array}{c}120,28 \\
(6,26)^{1}\end{array}$ & $\begin{array}{c}128,74 \\
(5,64)^{5}\end{array}$ & $\begin{array}{c}127,21 \\
(6,11)^{5}\end{array}$ & $\begin{array}{c}108,14 \\
(9,45)^{34}\end{array}$ & 8,31 & 0,0001 \\
\hline & Cotovelo & $\begin{array}{l}526,47 \\
(8,66)^{2345}\end{array}$ & $\begin{array}{l}597,69 \\
(8,10)^{1345}\end{array}$ & $\begin{array}{c}651,92 \\
(10,47)^{1245}\end{array}$ & $\begin{array}{c}698,77 \\
(10,78)^{1235}\end{array}$ & $\begin{array}{l}745,97 \\
(7,57)^{1234}\end{array}$ & 232,71 & 0,0001 \\
\hline & Punho & $\begin{array}{l}70,80 \\
(15,24) \\
\end{array}$ & $\begin{array}{l}83,60 \\
(14,13) \\
\end{array}$ & $\begin{array}{l}87,04 \\
(15,07)\end{array}$ & $\begin{array}{l}97,90 \\
(19,46)\end{array}$ & $\begin{array}{l}90,11 \\
(22,79) \\
\end{array}$ & 1,90 & 0,120 \\
\hline \multirow{3}{*}{ 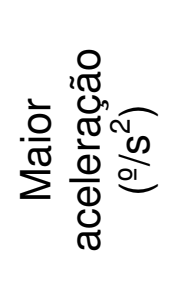 } & Ombro & $\begin{array}{l}1523,88 \\
(55,66)^{2345}\end{array}$ & $\begin{array}{l}1892,42 \\
(71,24)^{145}\end{array}$ & $\begin{array}{l}2206,33 \\
(86,38)^{145}\end{array}$ & $\begin{array}{c}2549,79 \\
(131,06)^{1235}\end{array}$ & $\begin{array}{c}3153,26 \\
(190,83)^{1234}\end{array}$ & 60,57 & 0,0001 \\
\hline & Cotovelo & $\begin{array}{c}4166,46 \\
(133,67)^{2345}\end{array}$ & $\begin{array}{c}5274,51 \\
(114,06)^{1345}\end{array}$ & $\begin{array}{c}6317,76 \\
(178,87)^{1245}\end{array}$ & $\begin{array}{c}7214,55 \\
(195,85)^{1235}\end{array}$ & $\begin{array}{l}8172,21 \\
(208,68)^{1234}\end{array}$ & 186,03 & 0,0001 \\
\hline & Punho & $\begin{array}{c}1341,32 \\
(123,75) \\
\end{array}$ & $\begin{array}{c}1382,98 \\
(114,22) \\
\end{array}$ & $\begin{array}{c}1407,63 \\
(151,11) \\
\end{array}$ & $\begin{array}{c}1644,61 \\
(200,07) \\
\end{array}$ & $\begin{array}{c}1700,56 \\
(229,07)\end{array}$ & 2,78 & 0,034 \\
\hline \multirow{3}{*}{ 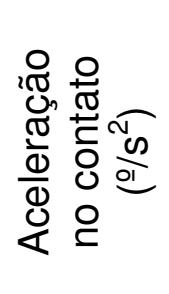 } & Ombro & $\begin{array}{c}321,46 \\
(131,79)^{345}\end{array}$ & $\begin{array}{c}614,29 \\
(159,39)^{45}\end{array}$ & $\begin{array}{c}901,71 \\
(181,37)^{145}\end{array}$ & $\begin{array}{c}1372,05 \\
(217,30)^{1235}\end{array}$ & $\begin{array}{l}2326,12 \\
(290,03)^{1234}\end{array}$ & 63,98 & 0,0001 \\
\hline & Cotovelo & $\begin{array}{c}50,37 \\
(277,14)^{345}\end{array}$ & $\begin{array}{l}308,78 \\
(304,91)^{45}\end{array}$ & $\begin{array}{c}523,63 \\
(339,81)^{145}\end{array}$ & $\begin{array}{c}1030,34 \\
(377,07)^{1235}\end{array}$ & $\begin{array}{c}2330,24 \\
(418,80)^{1234}\end{array}$ & 58,57 & 0,0001 \\
\hline & Punho & $\begin{array}{l}-688,98 \\
(134,65)^{45}\end{array}$ & $\begin{array}{l}-675,37 \\
(149,17)^{45}\end{array}$ & $\begin{array}{l}-872,51 \\
(198,55)^{5}\end{array}$ & $\begin{array}{c}-1069,97 \\
(233,76)^{12}\end{array}$ & $\begin{array}{l}-1375,83 \\
(298,58)^{123}\end{array}$ & 9,87 & 0,0001 \\
\hline
\end{tabular}

Diferente de $1,46 \mathrm{~m} / \mathrm{s},{ }^{2} 1,70 \mathrm{~m} / \mathrm{s},{ }^{3} 1,95 \mathrm{~m} / \mathrm{s},{ }^{4} 2,27 \mathrm{~m} / \mathrm{s}$ e ${ }^{5} 2,93 \mathrm{~m} / \mathrm{s}$. 
TABELA 13 - Média, DP (entre parênteses), $F$ e $p$ para as variáveis angulares temporais de desempenho (articulações), em função da velocidade de movimento.

\begin{tabular}{|c|c|c|c|c|c|c|c|c|}
\hline \multirow[b]{2}{*}{ Variável } & \multirow[b]{2}{*}{ Artic. } & \multicolumn{5}{|c|}{ Velocidade média eixo x (m/s) } & \multicolumn{2}{|c|}{ Estatística } \\
\hline & & $\begin{array}{l}1,46 \\
(0,06)\end{array}$ & $\begin{array}{l}1,70 \\
(0,06)\end{array}$ & $\begin{array}{l}1,95 \\
(0,07)\end{array}$ & $\begin{array}{l}2,27 \\
(0,07)\end{array}$ & $\begin{array}{l}2,93 \\
(0,11)\end{array}$ & $F_{1,15}$ & $p$ \\
\hline \multirow{3}{*}{ 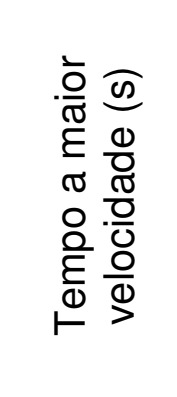 } & Ombro & $\begin{array}{c}0,241 \\
(0,012)^{2345}\end{array}$ & $\begin{array}{c}0,218 \\
(0,009)^{1345}\end{array}$ & $\begin{array}{c}0,193 \\
(0,009)^{1245}\end{array}$ & $\begin{array}{c}0,173 \\
(0,008)\end{array}$ & $\begin{array}{c}0,147 \\
(0,005)^{1234}\end{array}$ & 78,20 & 0,0001 \\
\hline & Cotovelo & $\begin{array}{c}0,230 \\
(0,012)^{2345}\end{array}$ & $\begin{array}{c}0,206 \\
(0,009)^{1345}\end{array}$ & $\begin{array}{c}0,181 \\
(0,009)_{1245}\end{array}$ & $\begin{array}{c}0,158 \\
(0,007)_{1235}\end{array}$ & $\begin{array}{c}0,128 \\
(0,005)_{1234}\end{array}$ & 78,20 & 0,0001 \\
\hline & Punho & $\begin{array}{l}0,170 \\
(0,025)^{45}\end{array}$ & $\begin{array}{l}0,169 \\
(0,021)^{45}\end{array}$ & $\begin{array}{l}0,123 \\
(0,019)^{5}\end{array}$ & $\begin{array}{l}0,087 \\
(0,016)^{12}\end{array}$ & $\begin{array}{c}0,059 \\
(0,012)^{123}\end{array}$ & 14,57 & 0,0001 \\
\hline \multirow{3}{*}{ 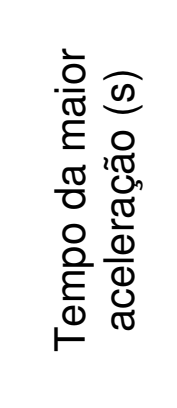 } & Ombro & $\begin{array}{c}0,187 \\
(0,017)^{2345}\end{array}$ & $\begin{array}{c}0,158 \\
(0,013)^{145}\end{array}$ & $\begin{array}{c}0,137 \\
(0,011)^{15}\end{array}$ & $\begin{array}{c}0,118 \\
(0,010)^{12}\end{array}$ & $\begin{array}{c}0,095 \\
(0,007)^{123}\end{array}$ & 31,89 & 0,0001 \\
\hline & Cotovelo & $\begin{array}{c}0,147 \\
(0,012)^{2345}\end{array}$ & $\begin{array}{c}0,128 \\
(0,009)^{1345}\end{array}$ & $\begin{array}{c}0,109 \\
(0,009)^{1245}\end{array}$ & $\begin{array}{c}0,089 \\
(0,008)^{1235}\end{array}$ & $\begin{array}{c}0,061 \\
(0,004)^{1234}\end{array}$ & 55,08 & 0,0001 \\
\hline & Punho & $\begin{array}{c}0,248 \\
(0,027)^{345}\end{array}$ & $\begin{array}{l}0,216 \\
(0,024)^{5}\end{array}$ & $\begin{array}{l}0,200 \\
(0,019)^{1}\end{array}$ & $\begin{array}{l}0,188 \\
(0,019)^{1}\end{array}$ & $\begin{array}{r}0,153 \\
(0,018)^{12}\end{array}$ & 8,56 & 0,0001 \\
\hline \multirow{3}{*}{  } & Ombro & $\begin{array}{l}60,66 \\
(11,97)^{5}\end{array}$ & $\begin{array}{l}62,71 \\
(10,19)^{5}\end{array}$ & $\begin{array}{l}64,09 \\
(11,57)^{5}\end{array}$ & $\begin{array}{l}66,12 \\
(11,16)\end{array}$ & $\begin{array}{c}70,04 \\
(10,00)^{123}\end{array}$ & 11,34 & 0,0001 \\
\hline & Cotovelo & $\begin{array}{l}57,79 \\
(11,07)\end{array}$ & $\begin{array}{c}59,10 \\
(9,01)\end{array}$ & $\begin{array}{r}59,97 \\
(10,23)\end{array}$ & $\begin{array}{c}60,65 \\
(2,40)\end{array}$ & $\begin{array}{c}60,69 \\
(7,15)\end{array}$ & 1,51 & 0,208 \\
\hline & Punho & $\begin{array}{l}41,70 \\
(24,17)\end{array}$ & $\begin{array}{l}47,38 \\
(22,70)^{5}\end{array}$ & $\begin{array}{l}39,83 \\
(23,73)\end{array}$ & $\begin{array}{c}33,37 \\
(24,11)\end{array}$ & $\begin{array}{l}28,33 \\
(22,44)^{2}\end{array}$ & 3,78 & 0,0082 \\
\hline \multirow{3}{*}{ 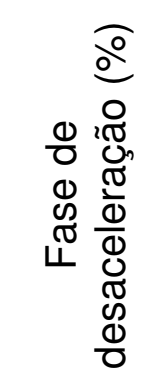 } & Ombro & $\begin{array}{l}39,34 \\
(11,97)^{5}\end{array}$ & $\begin{array}{l}37,29 \\
(10,19)^{5}\end{array}$ & $\begin{array}{l}35,91 \\
(11,57)^{5}\end{array}$ & $\begin{array}{c}33,88 \\
(11,16)\end{array}$ & $\begin{array}{c}29,96 \\
(10,00)^{123}\end{array}$ & 11,34 & 0,0001 \\
\hline & Cotovelo & $\begin{array}{r}42,21 \\
(11,07)\end{array}$ & $\begin{array}{c}40,90 \\
(9,01)\end{array}$ & $\begin{array}{c}40,03 \\
(10,23)\end{array}$ & $\begin{array}{c}39,35 \\
(9,62)\end{array}$ & $\begin{array}{c}39,31 \\
(7,15)\end{array}$ & 1,52 & 0,208 \\
\hline & Punho & $\begin{array}{r}58,30 \\
(24,17)\end{array}$ & $\begin{array}{l}52,62 \\
(22,70)^{5}\end{array}$ & $\begin{array}{l}60,17 \\
(23,73)\end{array}$ & $\begin{array}{c}66,63 \\
(24,11)\end{array}$ & $\begin{array}{l}71,67 \\
(22,44)^{2}\end{array}$ & 3,78 & 0,0082 \\
\hline
\end{tabular}

Diferente de ${ }^{1} 1,46 \mathrm{~m} / \mathrm{s},{ }^{2} 1,70 \mathrm{~m} / \mathrm{s},{ }^{3} 1,95 \mathrm{~m} / \mathrm{s},{ }^{4} 2,27 \mathrm{~m} / \mathrm{s} \mathrm{e}{ }^{5} 2,93 \mathrm{~m} / \mathrm{s}$. 


\subsection{Discussão}

5.6.1 Variáveis lineares de resultado (disco) e de desempenho (manopla)

Nos experimentos que analisaram o paradigma da relação inversa velocidade-precisão, a velocidade foi analisada a partir da velocidade média do movimento. Entretanto, no presente estudo, outros parâmetros da velocidade também foram analisados para entender a resposta do movimento, como o maior valor de velocidade e a velocidade no instante de contato manopla-disco. Em se tratando da resposta no movimento, no que diz respeito ao erro espacial (Meyer et al., 1982; Schmidt et al., 1978; Woodworth, 1899), o aumento da variabilidade espacial (desvio padrão do erro efetivo) tem sido atribuída a diminuição na precisão do movimento. Também foi sugerida maior demanda na precisão quando a restrição espacial utilizada como variável de controle é aumentada através da diminuição no tamanho dos alvos (Fitts, 1954; Fitts \& Pettersen, 1964; Mackenzie et al., 1987; Okazaki et al., 2008). No presente estudo, a precisão foi analisada através de uma medida representativa (média do erro angular absoluto) de quanto a resposta (contato do disco com o alvo remoto) diverge espacialmente do alvo objetivado (centro do alvo remoto); e, através das restrições controladas por meio do tamanho do disco e do tamanho do alvo remoto (respectivamente, experimentos III e IV). Contudo, a dispersão do erro entre as tentativas realizadas (desvio padrão do erro angular absoluto) foi analisada como variável de representativa da variabilidade, ou seja, da capacidade do sistema repetir a mesma resposta num conjunto de tentativas (consistência), e não como uma variável de precisão como em alguns estudos (cf. Schmidt et al., 1978, 1979; Soukoreff \& Mackenzie, 2004).

Os modelos de controle motor de variabilidade do impulso (Newell et al., 1982; Schmidt et al., 1978, 1979), de variabilidade do impulso simétrico (Meyer et al., 1982), de sub-movimentos otimizados (Meyer et al., 1988), de deslizamento da desaceleração (Zelaznik, 1993), da teoria cinemática (Plamondon, 1993, 1995a; Plamondon \& Alimi, 1997) e da capacidade limitada de transmissão da informação (Fitts, 1954; Fitts \& Petersen, 1964), que analisaram o paradigma da relação velocidade-precisão são congruentes em afirmar uma relação inversa entre essas 
duas variáveis. Desta forma, o aumento na velocidade média, na maior velocidade, e na velocidade no contato manopla-disco, resultaria em detrimento na precisão e aumento na variabilidade (hipótese $\mathrm{H6}$ ). Os resultados do presente estudo demonstraram aumentos na velocidade média (eixo $x$ e y), na velocidade no contato manopla-disco (eixo x), na maior aceleração (eixo x e y) e na aceleração no contato (eixo $x$ e y), em função do acréscimo na velocidade de movimento. Contudo, a manipulação da velocidade não apresentou efeito sobre a precisão e a variabilidade. Por outro lado, a análise de regressão linear demonstrou que com o aumento na velocidade média houve uma diminuição na precisão $(R=0,918$ e $R=0,924$; eixo x e $\mathrm{y}$, respectivamente) e um aumento na variabilidade $(R=0,991$ e $R=0,974$; eixo $\times \mathrm{e}$ $y$, respectivamente) do movimento. Também foi verificado um aumento na variabilidade do movimento com o aumento na maior velocidade $(R=0,990$ e $R=$ 0,936 ; eixo $\mathrm{x}$ e $\mathrm{y}$, respectivamente) e na velocidade no contato manopla-disco ( $R=$ 0,992; eixo x). Todavia, não foi verificada associação entre a precisão com a velocidade média (eixo $x$ e y), e com a velocidade no contato manopla-disco (eixo $x$ e $y$ ); e entre a variabilidade com a velocidade no contato manopla-disco (eixo y). Por conseguinte, foi refutada a hipótese $\mathrm{H} 6$ que sugeriu a menor precisão e maior variabilidade em função de aumentos nos parâmetros da velocidade de movimento. Duas hipóteses foram levantadas para explicar a manutenção da precisão e da variabilidade juntamente com o aumento na velocidade de movimento, a hipótese de dimensões velocidade-precisão independentes $(\mathrm{H} 7)$ e a hipótese da regulação do tempo do maior valor de velocidade (H8).

A hipótese de dimensões velocidade-precisão independentes aponta que, em movimentos no qual a geração de velocidade ocorre predominantemente numa dimensão espacial (eixo $\mathrm{x}$ ) e a precisão do movimento em outra (eixo y), o movimento poderia ser tanto veloz quanto preciso. Esta hipótese foi baseada no fato de que a velocidade gerada no movimento seria resultado de fontes de restrição diferentes das encontradas na precisão, que dependem das características (eixos diferentes em que ocorrem velocidade e precisão) e dos objetivos da tarefa (ênfase na velocidade, na precisão, ou em ambas). Por conseguinte, magnitudes de velocidades específicas seriam geradas e resultariam em variabilidades de movimento específicas, principalmente em relação à dimensão espacial em que as 
fontes de restrição ocorrem (por exemplo: eixos x e y de um plano cartesiano, ou eixos de rotação de uma determinada articulação). Na tarefa proposta, tem-se o objetivo de contatar um disco para direcioná-lo a um alvo remoto, com maior velocidade e maior precisão possíveis, no qual numa das dimensões ocorre predominantemente a geração de velocidade (eixo x; com pequena restrição espacial) enquanto em outra dimensão ocorre a regulação da precisão (eixo y; com grande restrição espacial). Por conseguinte, o erro apenas seria associado à geração de velocidade específica à sua dimensão (eixo y). Apenas seria verificada associação entre o erro (precisão) e a dimensão da velocidade se houvesse também associação entre as velocidades nos dois eixos (hipótese H7).

Os resultados do presente estudo apresentaram uma forte associação entre as duas dimensões (eixo x e eixo y) para as variáveis de velocidade média $(R=$ $0,995)$ e maior velocidade $(R=0,975)$. Como esperado pela hipótese de dimensões velocidade-precisão independentes, nas situações em que as dimensões apresentassem maior associação haveria predição do erro tanto pelas variáveis numa dimensão quanto na outra. Foi verificada a predição da precisão e da variabilidade pela velocidade média tanto no eixo x como no eixo y. Houve também a predição da variabilidade no movimento em função da velocidade no eixo $\mathrm{x}$ e $\mathrm{y}$. Contudo, não foi verificada associação na velocidade no instante de contato manopla-disco entre as dimensões $(R=0,320)$. A análise de variância com medidas repetidas também não verificou diferença na velocidade de contato no eixo y, em função do acréscimo na velocidade média de movimento (eixo $\mathrm{x}$ ). Tais achados poderiam sugerir sustentação para a hipótese de dimensões velocidade-precisão independentes. Contudo, não foi verificada associação entre a maior velocidade e a precisão para ambas as dimensões (eixo x e y). Ademais, a velocidade no instante de contato manopla-disco do eixo $x$ apenas foi capaz de predizer a variabilidade de resposta. A velocidade no contato manopla-disco no eixo y não apresentou associação com a precisão e nem com variabilidade. Além disso, a precisão não demonstrou associação com a maior velocidade e com a velocidade no contato manopla-disco (eixos x e y). Desta forma, foi refutada a hipótese H7, pois a precisão do movimento pareceu ser mais influenciada (associada) com a geração de velocidade no eixo $x$ do que no eixo $y$. Apesar de restrições particulares ao 
movimento em cada dimensão (eixo x e y) ocorrerem, o fato do movimento linear da manopla ser resultado de movimentos rotacionais (angulares) das articulações, não permitiu a dissociação entre as dimensões do movimento. Desta forma, explicar a ausência no efeito da velocidade sobre a precisão no movimento através da hipótese de dimensões independentes velocidade-precisão não demonstrou ser a melhor alternativa.

Outra possibilidade para o sistema manter a precisão do movimento, mesmo quando a velocidade e a aceleração fossem aumentadas, seria a regulação do tempo em que o maior valor de velocidade da manopla ocorresse. Tal estratégia permitiria que menor aceleração e, conseqüentemente, menor variabilidade ocorresse no instante de contato manopla-disco. Assim, o erro poderia ser independente da magnitude da velocidade gerada durante o movimento permitindo controlar tanto a geração de velocidade quanto a precisão no movimento. Em conjunto com o aumento na velocidade de movimento foi verificada diminuição na magnitude das variáveis temporais analisadas (tempo de movimento, tempo para contato, tempo após contato, tempo da maior velocidade e tempo da maior aceleração). Esta diminuição nas variáveis temporais do movimento permitiu que houvesse uma aproximação entre o tempo dos maiores valores de velocidade com o instante de contato manopla-disco. Assim, mesmo com o aumento na aceleração (de $26,83 \mathrm{~m} / \mathrm{s}^{2}$ até $66,72 \mathrm{~m} / \mathrm{s}^{2}$ ) o acréscimo na velocidade média (de 1,46 m/s até 2,27 $\mathrm{m} / \mathrm{s}$ ) não demonstrou aumentar a magnitude da aceleração no instante de contato manopla-disco (entre $-7,39$ e $-13,32 \mathrm{~m} / \mathrm{s}^{2}$ ). Ademais, quando a velocidade média aumentou para $2,93 \mathrm{~m} / \mathrm{s}$, a magnitude da aceleração no instante de contato diminuiu $\left(-7,39 \mathrm{~m} / \mathrm{s}^{2}\right)$. Por conseguinte, como a aceleração no instante de contato permaneceu constante entre as condições, ou até diminuiu como na condição de maior velocidade, a variabilidade de resposta no instante determinante do desempenho foi praticamente inalterada. Desta forma, foi aceita a hipótese H8 que previu uma aproximação do tempo da maior velocidade da manopla e do instante de contato manopla-disco, como estratégia para manutenção da precisão no movimento. Estas modificações nas variáveis temporais do movimento também tiveram efeito sobre as fases de aceleração e de desaceleração no movimento. 
Tem sido sugerido que, em situações na qual maior precisão é necessária no movimento, a fase de desaceleração seria aumentada. Ao passo que, quando há menor restrição espacial e maior possibilidade para gerar velocidade, a fase de aceleração seria aumentada (Teixeira, 2000; Van Muelen \& Gooskens, 1990; Zelaznik, 1993). No entanto, os resultados do presente estudo demonstraram que o aumento na velocidade de movimento não modificou as proporções entre as fases de aceleração e de desaceleração. Apesar da exigência na maior geração de velocidade no movimento entre as condições, houve também uma necessidade do sistema em manter o movimento preciso. Assim, se o sistema adotasse a estratégia de aumentar a fase de aceleração no movimento, possivelmente, haveria menor precisão e maior variabilidade de resposta. Desta forma, mesmo com a estratégia de modulação nos tempos em que ocorreram os maiores valores de velocidade, ou mesmo com os aumentos na velocidade entre as condições, não houve mudança nos tempos relativos das fases de aceleração e de desaceleração como estratégia para auxiliar a manutenção da precisão. Estes resultados estão em consonância com o trabalho de Adam (1992) que demonstrou a manutenção na precisão e na proporcionalidade entre a fase de aceleração e desaceleração, quando foi objetivado o desempenho de um movimento com velocidade e precisão simultaneamente. Desta forma, foi refutada a hipótese H9 que apontou para maior fase de aceleração do movimento para proporcionar maior geração de velocidade.

\subsubsection{Variáveis angulares de desempenho (articulações)}

O deslocamento linear da manopla é produto da organização espaçotemporal das articulações do ombro, do cotovelo e do punho. Desta forma, as estratégias utilizadas para regulação do deslocamento, da velocidade e da aceleração também foram analisadas através da ação das articulações. Assim como houve aumento na amplitude linear da manopla, também foram verificadas maiores amplitudes angulares no ombro e no cotovelo, em função do acréscimo na velocidade de movimento. Além disso, as condições de maior velocidade de movimento tenderam a apresentar maior ângulo no instante de contato manopladisco nas articulações (ombro, cotovelo e punho). Por conseguinte, o aumento na 
distância percorrida (angular e linear) pareceu ser uma estratégia utilizada pelo sistema para possibilitar maior geração de velocidade no movimento.

$O$ aumento na velocidade linear da manopla foi resultado do acréscimo na magnitude da velocidade angular das articulações (ombro, cotovelo e punho). Entretanto, no instante de contato manopla-disco apenas o ombro e o cotovelo apresentaram maior velocidade em função do acréscimo na velocidade da manopla. O acréscimo na velocidade angular também proporcionou maior aceleração (maior valor e no contato manopla-disco) das articulações do ombro, do cotovelo e do punho. Contudo, a regulação no tempo em que os maiores valores de velocidade e de aceleração ocorreram auxiliou na diminuição da magnitude destas variáveis no instante de contato manopla-disco. Esta regulação no tempo de movimento também modificou a estrutura temporal da fase de aceleração e desaceleração com o aumento na velocidade média do movimento.

Ombro e cotovelo aumentaram a fase de aceleração ( 60\%), enquanto o punho aumentou a fase de desaceleração ( 60\%), com o acréscimo na velocidade. Apesar da contribuição das três articulações no controle da geração de velocidade e da manutenção na precisão, tais resultados poderiam sugerir um papel distinto no controle do movimento entre as articulações. No qual, o ombro e o cotovelo estariam mais associados à geração de velocidade e o punho estaria mais associado à manutenção da precisão. Porém, o acréscimo na velocidade resultou em maior fase de aceleração no ombro, que foi compensado apenas pela maior fase de desaceleração no punho. O cotovelo não apresentou modificações nas fases relativas de aceleração e de desaceleração, com o aumento na velocidade da manopla. Essas modificações permitiram que as fases de aceleração e de desaceleração da manopla não tivessem o efeito do aumento na velocidade de movimento, o que pode ter auxiliado na manutenção da precisão e da variabilidade verificadas nos resultados. Por conseguinte, foi sugerido que as três articulações foram organizadas de forma integrada para auxiliar na manutenção da precisão e da variabilidade no movimento. Assim, foi refutada a hipótese $\mathrm{H} 10$ que sugeriu aumento na fase de aceleração do ombro e do cotovelo, e aumento na fase de desaceleração do punho, com o acréscimo na velocidade, em função da contribuição distinta das articulações no controle do movimento. 


\subsection{Conclusão}

O aumento de velocidade não teve efeito sobre a precisão e a variabilidade de resposta do movimento. Contudo, a precisão e a variabilidade foram preditas por alguns parâmetros da velocidade no movimento. Foi sugerido que o sistema utilizou a estratégia de tentar sincronizar os tempos das maiores velocidades com o instante de contato manopla-disco, em função do acréscimo na velocidade de movimento. Tal estratégia permitiu que grandes velocidades e acelerações fossem geradas, mas sem comprometer a precisão e a variabilidade de movimento. Pois, a aceleração (força/variabilidade) gerada no instante de contato manopla-disco atingiu níveis inferiores em relação aos maiores valores de aceleração gerados com 0 aumento da velocidade. Também foi proposta a estratégia da manutenção na proporção das fases de aceleração e de desaceleração, mesmo com o aumento na velocidade entre as condições. Esta estratégia permitiu o equilíbrio entre a geração de velocidade e a regulação da precisão, sem priorizar a velocidade ou a precisão.

A análise das variáveis angulares forneceu suporte para as estratégias de controle sugeridas para explicar as variáveis lineares da manopla. Ademais, a investigação do desempenho através das variáveis angulares também permitiu entender a contribuição das articulações no controle do movimento. Foi sugerido que ombro, cotovelo e punho contribuem tanto no controle da geração de velocidade como na regulação da manutenção da precisão no movimento. 
6.1 Introdução

O aumento na demanda de controle na precisão resulta em menor velocidade para desempenhar o movimento (Fitts, 1954; Gottlieb et al., 1989; Woodworth, 1899). Assim, maior tempo de movimento permite maior utilização do feedback sensorial para a realização de ajustes (sub-movimentos) para a correção da trajetória no movimento (Carlton, 1980; Jagacinski et al., 1980a). Contudo, movimentos mais rápidos em que não há possibilidade de utilização do feedback sensorial, também apresentam uma relação inversa entre velocidade e precisão (Tresilian \& Lonergan, 2002; Zelaznik, 1993; Zelaznik et al., 1986). Uma explicação para esta relação inversa velocidade-precisão, em habilidades que não oferecem tempo para utilização apropriada do feedback, foi realizada através da maior geração de ruído. Ou seja, há um ruído inerente ao sistema, aumentado em função da maior velocidade no movimento, que pode surgir no planejamento da resposta motora, na transmissão neural dos comandos para o sistema efetor, e no desempenho do sistema efetor (Schmidt et al., 1979). Fitts propôs que o sistema possui uma capacidade limitada em transmitir informações (Fitts, 1954; Fitts \& Petersen, 1964). Desta forma, quanto maior a demanda na precisão da tarefa, maiores especificações dos parâmetros de controle do movimento devem ser transmitidas e processadas para realizar a tarefa propriamente. Este aumento nas especificações dos parâmetros ocasiona maior tempo para desempenhar a resposta, em função da limitação do sistema em planejar e transmitir informações. A relação inversa velocidade-precisão também pode emergir como uma propriedade inerente às respostas efetoras das sinergias agonistas e antagonistas dos músculos que desempenham o movimento (Plamondon, 1993; Plamondon \& Alimi, 1997). Isto é, a simples modulação no tempo em que as forças de aceleração ou desaceleração ocorrem no movimento também pode resultar na troca entre velocidade e precisão (Zelaznik, 1993).

Independente dos processos de controle envolvidos, a relação inversa velocidade-precisão foi verificada em diversos estudos que analisaram tarefas 
discretas (Carlton, 1980; Guiard, 1997; Jax et al., 2007; Pereira \& Okazaki, 2008), cíclicas (Crossman \& Goodeve, 1963/1983; Fitts, 1954; Kvalseth, 1975), com mouse (Boritz et al., 1991; Jonhsgard, 1994; Okazaki et al., 2008), com joystick (Epps, 1986; Jagacinski et al., 1980a), de rotação de punho (Meyer et al., 1982; Write \& Meyer, 1983), de extensão de braço (Ker \& Langolf, 1977), e flexão de braço (Corcos et al., 1988). Esta relação também foi expressa matematicamente, permitindo a predição do tempo de movimento (TM) por meio da restrição espacial imposta sobre o movimento através de um índice de dificuldade. Este índice de dificuldade (ID) foi manipulado em função do tamanho do alvo (T) ou da distância de movimento (D) entre os alvos $\left(T M=a+b \log _{2}[2 \times D / T]\right)$. Assim, quanto menor o tamanho do alvo, ou maior $a$ distância do movimento, o movimento é desempenhado com maior tempo (Fitts, 1954; Fitts \& Petersen, 1964). Grande sustentação empírica também foi verificada para esta relação TM - ID (Plamondon \& Alimi, 1997; Soukoreff et al., 2004; Zhai et al., 2004), legitimando esta formulação para um dos fenômenos mais consistentes na área do comportamento motor (Bootsma et al., 2004; Elliott et al., 2004; Teixeira, 2006). Porém, como estas tarefas utilizadas para analisar os processos de controle envolvidos na relação velocidade-precisão eram demasiadamente simples (unidimensionais, rotação de apenas uma articulação, de mover uma ponteira em direção a um alvo), há diversas limitações na aplicabilidade destes conceitos em tarefas motoras complexas, nas quais nem mesmo a relação TM - ID tem sido contemplada em habilidades complexas. Por conseguinte, não é sabido se os mesmos princípios que regem o controle da geração de velocidade e a manutenção da precisão também podem ser verificados em tarefas motoras complexas.

A diminuição no tamanho do alvo, na tarefa de mover uma ponteira em direção a um alvo (tarefa que originou e tem sido normalmente utilizada para analisar o paradigma velocidade-precisão), resulta em maior tempo de movimento, maior número de ajustes, menor velocidade e maior fase de desaceleração no movimento (Adam, 1992; Adam et al., 1995; Langolf et al., 1976). Por outro lado, em tarefas motoras complexas outras estratégias de controle para a geração de velocidade e para a manutenção da precisão têm sido sugeridas. Por exemplo, como a maior geração de força está associada à maior variabilidade de resposta, a sincronização do tempo da maior velocidade (instante em que a aceleração é nula) com o instante 
crítico de desempenho (lançamento, arremesso, contato, impacto) pode proporcionar maior precisão no movimento. Esta estratégia tem sido sugerida em tarefas como o arremesso estilo beisebol (Teixeira, 1997), o arremesso no basquetebol (Okazaki \& Rodacki, 2005; Okazaki et al., 2006, 2008), o saque no tênis (Elliott et al., 1989), a rebatida (Caljouw et al., 2005) e o chute no futebol (Teixeira, 1999). Por outro lado, foi sugerido que a otimização na geração de força, através de um contra-movimento no cotovelo e no punho no arremesso do basquetebol, permitiu menor velocidade e, conseqüentemente, maiores estabilidade e precisão no movimento (Okazaki et al., 2008a, 2006b). Também foi sugerido que a regulação temporal do início das forças de desaceleração do movimento pode ser a principal estratégia para regular esta relação inversa entre velocidade e precisão (Zelaznik, 1993). Alguns estudos que analisaram lançamentos (Teixeira, 1997) e arremessos simulados por computador (Chowdary \& Challis, 2001; Zelaznik, 1993) corroboraram com tal idéia. Desta forma, a análise de tarefas motoras complexas também possui grande potencial para entender as estratégias utilizadas no controle da regulação velocidade-precisão no movimento. Contudo, em tarefas dessa natureza, ainda não é compreendido o fato de que a relação inversa velocidade-precisão pode ser violada.

Van Den Tillaar e Ettema (2006) demonstraram que a ênfase na precisão do arremesso reduziu a velocidade de movimento, mas não melhorou sua precisão. Enquanto, enfatizar a velocidade proporcionou maior rapidez no arremesso, contudo não diminuiu sua precisão. Okazaki e Rodacki (2005) manipularam o tamanho da bola e não verificaram alteração no controle e na coordenação do arremesso no basquetebol em crianças. Teixeira (1999) demonstrou que o menor tamanho da bola não modificou a velocidade linear do pé no chute do futebol. Apenas quando o tamanho do gol foi reduzido houve redução na velocidade do chute. Estes estudos parecem não estar em consonância com os experimentos que analisaram tarefas mais simples (Carlton, 1980; Jagacinski et al., 1980a; Mackenzie et al., 1987; Meyer et al., 1982, 1988). Contudo, Teixeira (1999) não procurou analisar as estratégias do controle e da coordenação adotadas no desempenho do chute, em função da manipulação da precisão (tamanho da bola e do gol). Por outro lado, Okazaki e Rodacki (2005) também não se preocuparam em quantificar a precisão no arremesso. Apenas Van Den Tillaar e Ettema (2006) analisaram o desempenho e a 
resposta do movimento. Porém, estes autores não manipularam a precisão por meio de restrições espaciais (tamanho da bola ou do alvo remoto). Além disso, não foram calculados os índices de dificuldade das condições nas tarefas para saber o quanto de restrição foi imposta sobre o sistema. Desta forma, à escassez de informações e de estudos, com tarefas motoras complexas, torna ainda pouco compreendido o efeito das restrições impostas pela precisão sobre as estratégias de controle na geração de velocidade e na manutenção da precisão do movimento.

$6.2 \quad$ Objetivo

Analisar o efeito do tamanho do disco na tarefa de contatar um disco com uma manopla em direção a um alvo remoto, sobre as variáveis cinemáticas de resposta e de desempenho no movimento.

\subsection{Hipóteses}

H11 A diminuição no tamanho do disco resulta em maiores tempo de movimento, tempo para contato e tempo após contato manopla-disco.

H12 O aumento na restrição do movimento, através da redução no tamanho do disco, proporciona maiores erro e variabilidade.

H13 O tempo do maior valor de velocidade é sincronizado com o instante em que ocorre o contato manopla-disco.

H14 Menor tamanho de disco resulta em maior índice de dificuldade que está diretamente relacionado ao tempo de movimento, tempo para contato e tempo após contato manopla-disco.

H15 Maior fase de desaceleração é verificada, nas articulações (ombro, cotovelo e punho), com a redução no tamanho do disco. 


\subsection{Procedimentos particulares do método}

Foi analisada a tarefa de contatar um disco com uma manopla em direção a um alvo remoto, realizada com máxima velocidade e maior precisão possíveis. Análises cinemáticas do resultado (variáveis lineares do disco) e do desempenho (variáveis angulares das articulações e lineares da manopla) foram realizadas para entender as estratégias de controle motor na geração de velocidade e na manutenção da precisão do movimento.

Foi utilizada uma distância manopla-disco de $32 \mathrm{~cm}$ e uma manopla circular com 7,5 cm de diâmetro e massa de $200 \mathrm{~g}$. Esta manopla foi utilizada para contatar um disco com massa de $100 \mathrm{~g}$. O tamanho do disco foi manipulado em cinco condições com 3,5, 4,5, 5,5, 6,5 e 7,5 cm de diâmetro. O disco era direcionado a um alvo remoto com tamanho de $10 \mathrm{~cm}$. As demais características do arranjo experimental foram descritas na sessão de métodos.

\subsection{Resultados}

6.5.1 Variáveis lineares de resultado (disco) e de desempenho (manopla)

A tabela 14 apresentou a estatística descritiva (média e desvio padrão) e inferencial (análise de variância com medidas repetidas) das variáveis espaciais e temporais de reposta (disco) e desempenho (manopla), em função do tamanho do disco. O aumento no tamanho disco proporcionou maior precisão e menor variabilidade. No qual, o maior disco $(7,5 \mathrm{~cm})$ apresentou menor erro angular absoluto (maior precisão) em comparação aos demais tamanhos de disco (3,5, 4,5, 5,5 e $6,5 \mathrm{~cm}$ ). $O$ disco $3,5 \mathrm{~cm}$ apresentou maior variabilidade (desvio padrão do erro angular absoluto) em relação ao disco 6,5 e $7,5 \mathrm{~cm}$; o disco $4,5 \mathrm{~cm}$ demonstrou maior variabilidade em comparação ao disco 5,5 e $7,5 \mathrm{~cm}$; enquanto, o disco $5,5 \mathrm{~cm}$ apresentou maior variabilidade em comparação aos discos 4,5, 6,5 e 7,5 cm. No instante de contato manopla-disco, o movimento demonstrou estar desacelerando (valor negativo da aceleração). Houve redução na desaceleração no instante de contato, em função do aumento no tamanho do disco; com diferença no disco $3,5 \mathrm{~cm}$ 
em comparação aos discos 5,5, 6,5 e 7,5 cm; e no disco $4,5 \mathrm{~cm}$ em relação aos discos 6,5 e $7,5 \mathrm{~cm}$. Esta redução na desaceleração no instante de contato foi realizada através de uma aproximação entre o tempo da maior velocidade e 0 instante de contato manopla disco. Na qual, houve uma redução na diferença entre o tempo para o contato e o maior valor de velocidade no tamanho do disco $3,5 \mathrm{~cm}$ em comparação aos discos 5,5, 6,5 e 7,5 cm; e do disco $4,5 \mathrm{~cm}$ em relação aos discos 6,5 e $7,5 \mathrm{~cm}$. Não foi verificado efeito do tamanho do disco nas variáveis de amplitude total, de maior velocidade, de velocidade no instante de contato manopladisco, de maior aceleração e nas demais variáveis temporais lineares.

A tabela 15 apresentou a estatística associativa através da análise de regressão linear simples entre os índices de dificuldade e algumas variáveis temporais no movimento selecionadas. A análise de regressão linear não apresentou associação significante entre os índices de dificuldade (ID' e ID") e as variáveis de tempo de movimento (TM), de tempo para contato $\left(T_{c}\right)$ e de tempo após contato $\left(T_{a}\right)$. A associação entre os índices de dificuldade ID' e ID" e o tempo de movimento (TM) demonstrou um coeficiente de $R^{2}=0,059(p>0,05)$. A análise entre os índices de dificuldade ID' e ID" e o tempo para contato $\left(T_{c}\right)$ apresentou um $R^{2}=0,763(p>0,05)$. A análise entre os índices de dificuldade ID' e ID" e o tempo após contato $\left(T_{a}\right)$ demonstrou um $R^{2}=0,749(p>0,05)$. Por conseguinte, as variáveis temporais do tempo de movimento, tempo para contato e tempo após contato manopla-disco não puderam ser preditas pelos dois índices de dificuldade calculados para a tarefa experimental proposta. A figura 5 apresentou os valores e uma linha de tendência linear de ajuste para os índices de dificuldade em função das variáveis temporais selecionadas. 
TABELA 14 - Média, DP (entre parênteses), $F$ e $p$ para as variáveis de resposta (disco) e de desempenho (manopla), em função do tamanho do disco.

\begin{tabular}{|c|c|c|c|c|c|c|c|}
\hline \multirow[b]{2}{*}{ Variáveis } & \multicolumn{5}{|c|}{ Tamanho (diâmetro) do disco (cm) } & \multicolumn{2}{|c|}{ Estatística } \\
\hline & 3,5 & 4,5 & 5,5 & 6,5 & 7,5 & $F_{1,15}$ & $p$ \\
\hline Erro angular absoluto $(\stackrel{\circ}{)})$ & $\begin{array}{l}4,58 \\
(1,81)^{5}\end{array}$ & $\begin{array}{l}4,45 \\
(1,80)^{5}\end{array}$ & $\begin{array}{l}4,41 \\
(1,52)^{5}\end{array}$ & $\begin{array}{l}4,01 \\
(1,59)^{5}\end{array}$ & $\begin{array}{c}2,55 \\
(1,13)^{1234}\end{array}$ & 6,24 & 0,0002 \\
\hline Variabilidade $(\stackrel{0}{ })$ & $\begin{array}{l}3,82 \\
(1,33)^{45}\end{array}$ & $\begin{array}{l}3,18 \\
(0,97)^{35}\end{array}$ & $\begin{array}{c}4,13 \\
(1,31)^{245}\end{array}$ & $\begin{array}{l}2,80 \\
(0,74)^{13}\end{array}$ & $\begin{array}{c}2,17 \\
(0,77)^{123}\end{array}$ & 13,63 & 0,0001 \\
\hline Amplitude de mov. (m) & $\begin{array}{l}0,617 \\
(0,035)\end{array}$ & $\begin{array}{l}0,613 \\
(0,037)\end{array}$ & $\begin{array}{l}0,614 \\
(0,047)\end{array}$ & $\begin{array}{c}0,614 \\
(0,044)\end{array}$ & $\begin{array}{l}0,618 \\
(0,040)\end{array}$ & 0,50 & 0,729 \\
\hline Maior velocidade $(\mathrm{m} / \mathrm{s})$ & $\begin{array}{r}5,30 \\
(0,34)\end{array}$ & $\begin{array}{l}5,23 \\
(0,39)\end{array}$ & $\begin{array}{l}5,24 \\
(0,36)\end{array}$ & $\begin{array}{r}5,30 \\
(0,36)\end{array}$ & $\begin{array}{l}5,26 \\
(0,35)\end{array}$ & 1,15 & 0,339 \\
\hline Veloc. no contato (m/s) & $\begin{array}{l}5,22 \\
(0,38)\end{array}$ & $\begin{array}{l}5,17 \\
(0,42)\end{array}$ & $\begin{array}{l}5,17 \\
(0,41)\end{array}$ & $\begin{array}{l}5,25 \\
(0,38)\end{array}$ & $\begin{array}{l}5,22 \\
(0,37)\end{array}$ & 1,48 & 0,218 \\
\hline Maior aceleração $\left(\mathrm{m} / \mathrm{s}^{2}\right)$ & $\begin{array}{c}65,32 \\
(6,35)\end{array}$ & $\begin{array}{c}66,01 \\
(7,70)\end{array}$ & $\begin{array}{c}65,25 \\
(6,38)\end{array}$ & $\begin{array}{c}67,17 \\
(5,98)\end{array}$ & $\begin{array}{c}64,78 \\
(6,08)\end{array}$ & 1,37 & 0,254 \\
\hline Acel. no contato $\left(\mathrm{m} / \mathrm{s}^{2}\right)$ & $\begin{array}{l}-14,70 \\
(8,75)^{345}\end{array}$ & $\begin{array}{l}-3,61 \\
(11,26)^{45}\end{array}$ & $\begin{array}{l}-10,17 \\
(12,27)^{1}\end{array}$ & $\begin{array}{l}-9,82 \\
(10,05)^{12}\end{array}$ & $\begin{array}{l}-6,75 \\
(10,98)^{12}\end{array}$ & 12,08 & 0,0001 \\
\hline Tempo de movimento (s) & $\begin{array}{l}0,220 \\
(0,033)\end{array}$ & $\begin{array}{c}0,233 \\
(0,044)\end{array}$ & $\begin{array}{l}0,223 \\
(0,036)\end{array}$ & $\begin{array}{c}0,225 \\
(0,050)\end{array}$ & $\begin{array}{l}0,228 \\
(0,046)\end{array}$ & 0,59 & 0,665 \\
\hline Tempo para contato (s) & $\begin{array}{l}0,135 \\
(0,028)\end{array}$ & $\begin{array}{l}0,140 \\
(0,027)\end{array}$ & $\begin{array}{c}0,132 \\
(0,025)\end{array}$ & $\begin{array}{c}0,129 \\
(0,022)\end{array}$ & $\begin{array}{l}0,126 \\
(0,014)\end{array}$ & 2,16 & 0,083 \\
\hline Tempo após contato (s) & $\begin{array}{l}0,081 \\
(0,013)\end{array}$ & $\begin{array}{c}0,092 \\
(0,037)\end{array}$ & $\begin{array}{c}0,086 \\
(0,020)\end{array}$ & $\begin{array}{l}0,095 \\
(0,044)\end{array}$ & $\begin{array}{c}0,100 \\
(0,041)\end{array}$ & 2,13 & 0,088 \\
\hline Tempo da maior veloc. (s) & $\begin{array}{l}0,129 \\
(0,028)\end{array}$ & $\begin{array}{l}0,135 \\
(0,027)\end{array}$ & $\begin{array}{l}0,128 \\
(0,027)\end{array}$ & $\begin{array}{c}0,125 \\
(0,023)\end{array}$ & $\begin{array}{l}0,123 \\
(0,014)\end{array}$ & 1,36 & 0,257 \\
\hline $\begin{array}{l}\text { Tempo para contato menos } \\
\text { tempo da maior veloc. (s) }\end{array}$ & $\begin{array}{c}0,007 \\
(0,004)^{345}\end{array}$ & $\begin{array}{l}0,006 \\
(0,005)^{45}\end{array}$ & $\begin{array}{l}0,005 \\
(0,006)^{1}\end{array}$ & $\begin{array}{l}0,004 \\
(0,004)^{12}\end{array}$ & $\begin{array}{l}0,003 \\
(0,005)^{12}\end{array}$ & 11,50 & 0,0001 \\
\hline Tempo da maior acel. (s) & $\begin{array}{l}0,075 \\
(0,030)\end{array}$ & $\begin{array}{l}0,080 \\
(0,028)\end{array}$ & $\begin{array}{c}0,073 \\
(0,028)\end{array}$ & $\begin{array}{c}0,070 \\
(0,026)\end{array}$ & $\begin{array}{l}0,069 \\
(0,015)\end{array}$ & 1,50 & 0,212 \\
\hline Fase de aceleração (\%) & $\begin{array}{c}58,32 \\
(6,80)\end{array}$ & $\begin{array}{c}58,17 \\
(9,93)\end{array}$ & $\begin{array}{c}57,33 \\
(7,99)\end{array}$ & $\begin{array}{c}56,50 \\
(8,80)\end{array}$ & $\begin{array}{c}55,18 \\
(8,32)\end{array}$ & 1,10 & 0,364 \\
\hline Fase de desaceleração (\%) & $\begin{array}{c}46,68 \\
(6,80)\end{array}$ & $\begin{array}{c}41,83 \\
(9,93)\end{array}$ & $\begin{array}{c}42,67 \\
(7,99)\end{array}$ & $\begin{array}{c}43,50 \\
(8,80)\end{array}$ & $\begin{array}{c}44,82 \\
(8,32)\end{array}$ & 1,10 & 0,364 \\
\hline
\end{tabular}

Diferente de ${ }^{1} 3,5 \mathrm{~cm} ;{ }^{2} 4,5 \mathrm{~cm} ;{ }^{3} 5,5 \mathrm{~cm} ;{ }^{4} 6,5 \mathrm{~cm} \mathrm{e}{ }^{5} 7,5 \mathrm{~cm}$. 
Tabela 15 - Valores da regressão linear do tempo de movimento, tempo para 0 contato e tempo após o contato, em função dos índices de dificuldade (ID' e ID').

\begin{tabular}{lccccc}
\hline Variáveis & $R$ & $R^{2}$ & $F_{1,3}$ & $p$ & Equação de Reta \\
\hline ID' x Tempo de movimento & 0,242 & 0,059 & 0,19 & 0,695 & $y=2,49 x+22,09$ \\
ID" x Tempo de movimento & 0,242 & 0,059 & 0,19 & 0,695 & $y=3,33 x+22,09$ \\
ID' x Tempo para o contato & 0,873 & 0,763 & 9,65 & 0,053 & $y=2,65 x+53,06$ \\
ID" x Tempo para o contato & 0,873 & 0,763 & 9,65 & 0,053 & $y=3,49 x+53,06$ \\
ID' x Tempo após o contato & 0,865 & 0,749 & 8,94 & 0,058 & $y=17,07 x-72,47$ \\
ID" x Tempo após o contato & 0,865 & 0,749 & 8,94 & 0,058 & $y=17,91 x-72,47$ \\
\hline
\end{tabular}



FIGURA 5 - Tempo de movimento (TM), tempo para contato $\left(T_{c}\right)$ e tempo após contato ( $T_{a}$ ), em função dos índices de dificuldade (ID' e ID'). 


\subsubsection{Variáveis angulares de desempenho (articulações)}

A tabela 16 e a tabela 17 apresentaram, respectivamente, as variáveis espaciais e temporais da análise estatística (descritiva e inferencial), em função do tamanho do disco. Menor ângulo no contato manopla-disco foi verificado no cotovelo e no punho com o aumento no tamanho do disco. No qual, o ângulo do cotovelo, no instante de contato, foi menor no disco 6,5 e 7,5 cm em comparação ao disco 3,5 cm. Enquanto, no punho o disco $6,5 \mathrm{~cm}$ demonstrou menor ângulo de contato manopladisco em comparação ao disco $4,5 \mathrm{~cm}$. O aumento no tamanho do disco também resultou em maior aceleração no cotovelo no instante de contato manopla-disco, com diferença entre o disco $6,5 \mathrm{~cm}$ em comparação aos discos 3,5 e $4,5 \mathrm{~cm}$; e no disco $7,5 \mathrm{~cm}$ em relação aos discos $3,5,4,5$ e $5,5 \mathrm{~cm}$. Não foi encontrado efeito do tamanho do disco sobre as demais variáveis lineares espaciais (amplitude total, maior velocidade, velocidade no contato manopla-disco e maior aceleração) e temporais do movimento (tempo da maior velocidade, tempo da maior aceleração, fase de aceleração e fase de desaceleração). 
TABELA 16 - Média, DP (entre parênteses), $F$ e $p$ para as variáveis angulares espaciais de desempenho (articulações), em função do tamanho do disco.

\begin{tabular}{|c|c|c|c|c|c|c|c|c|}
\hline \multirow[b]{2}{*}{ Variável } & \multirow[b]{2}{*}{ Artic. } & \multicolumn{5}{|c|}{ Tamanho (diâmetro) do disco $(\mathrm{cm})$} & \multicolumn{2}{|c|}{ Estatística } \\
\hline & & 3,5 & 4,5 & 5,5 & 6,5 & 7,5 & $F_{1,15}$ & $P$ \\
\hline \multirow{3}{*}{ 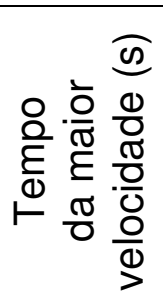 } & Ombro & $\begin{array}{l}0,156 \\
(0,007)\end{array}$ & $\begin{array}{c}0,152 \\
(0,012)\end{array}$ & $\begin{array}{l}0,146 \\
(0,011)\end{array}$ & $\begin{array}{l}0,155 \\
(0,006)\end{array}$ & $\begin{array}{c}0,135 \\
(0,013)\end{array}$ & 1,19 & 0,323 \\
\hline & Cotovelo & $\begin{array}{r}0,140 \\
(0,007)\end{array}$ & $\begin{array}{r}0,146 \\
(0,007)\end{array}$ & $\begin{array}{l}0,139 \\
(0,006)\end{array}$ & $\begin{array}{l}0,137 \\
(0,006)\end{array}$ & $\begin{array}{l}0,137 \\
(0,004)\end{array}$ & 1,04 & 0,390 \\
\hline & Punho & $\begin{array}{r}0,064 \\
(0,012) \\
\end{array}$ & $\begin{array}{r}0,072 \\
(0,012) \\
\end{array}$ & $\begin{array}{l}0,084 \\
(0,014) \\
\end{array}$ & $\begin{array}{l}0,080 \\
(0,013)\end{array}$ & $\begin{array}{l}0,066 \\
(0,012)\end{array}$ & 1,29 & 0,280 \\
\hline \multirow{3}{*}{ 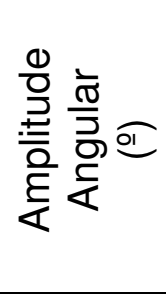 } & Ombro & $\begin{array}{c}17,53 \\
(1,19)\end{array}$ & $\begin{array}{c}18,28 \\
(1,08)\end{array}$ & $\begin{array}{c}18,25 \\
(0,98)\end{array}$ & $\begin{array}{c}18,25 \\
(1,00)\end{array}$ & $\begin{array}{c}17,69 \\
(1,01)\end{array}$ & 0,51 & 0,726 \\
\hline & Cotovelo & $\begin{array}{c}107,30 \\
(1,81)\end{array}$ & $\begin{array}{c}107,04 \\
(1,77)\end{array}$ & $\begin{array}{c}107,94 \\
(1,81)\end{array}$ & $\begin{array}{c}107,75 \\
(1,46)\end{array}$ & $\underset{(1,59)}{106,62}$ & 0,56 & 0,687 \\
\hline & Punho & $\begin{array}{c}14,98 \\
(2,14)\end{array}$ & $\begin{array}{c}15,65 \\
(2,07)\end{array}$ & $\begin{array}{c}15,05 \\
(1,90)\end{array}$ & & $\begin{array}{c}15,38 \\
(2,15)\end{array}$ & 0,41 & 793 \\
\hline \multirow{3}{*}{ 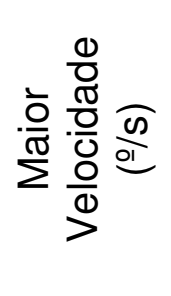 } & Ombro & $\begin{array}{c}154,50 \\
(9,91)\end{array}$ & $\begin{array}{c}159,85 \\
(8,62)\end{array}$ & $\begin{array}{c}159,83 \\
(8,00)\end{array}$ & $\begin{array}{c}162,40 \\
(8,12)\end{array}$ & $\begin{array}{c}158,14 \\
(7,03)\end{array}$ & 0,56 & 0,691 \\
\hline & Cotovelo & $\begin{array}{c}781,80 \\
(10,36)\end{array}$ & $\begin{array}{c}773,31 \\
(11,27)\end{array}$ & $\begin{array}{c}781,59 \\
(11,25)\end{array}$ & $\begin{array}{c}783,34 \\
(9,85)\end{array}$ & $\begin{array}{c}769,75 \\
(8,68)\end{array}$ & 1,76 & 0,147 \\
\hline & Punho & $\begin{array}{c}131,94 \\
(16,66)\end{array}$ & $\begin{array}{c}137,79 \\
(17,07)\end{array}$ & $\begin{array}{c}138,20 \\
(15,45)\end{array}$ & $\begin{array}{c}156,61 \\
(17,84)\end{array}$ & $\begin{array}{r}139 \\
(17,4\end{array}$ & 1,53 & 0,202 \\
\hline \multirow{3}{*}{ 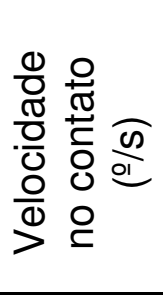 } & Ombro & $\begin{array}{c}134,16 \\
(8,37)\end{array}$ & $\begin{array}{c}134,26 \\
(7,17)\end{array}$ & $\begin{array}{c}133,52 \\
(6,21)\end{array}$ & $\begin{array}{c}132,48 \\
(7,61)\end{array}$ & $\begin{array}{c}124,35 \\
(8,09)\end{array}$ & 0,992 & 0,418 \\
\hline & Cotovelo & $\begin{array}{c}107,30 \\
(1,81)\end{array}$ & $\begin{array}{c}107,04 \\
(1,77)\end{array}$ & $\begin{array}{c}107,94 \\
(1,81)\end{array}$ & $\begin{array}{c}107,75 \\
(1,46)\end{array}$ & $\begin{array}{c}106,62 \\
(1,59)\end{array}$ & 0,567 & 0,687 \\
\hline & Punho & $\begin{array}{r}65,46 \\
(20,87) \\
\end{array}$ & $\begin{array}{l}63,74 \\
(22,31) \\
\end{array}$ & $\begin{array}{r}66,07 \\
(22,09) \\
\end{array}$ & $\begin{array}{r}80,98 \\
(25,72)\end{array}$ & $\begin{array}{r}78,61 \\
(22,37) \\
\end{array}$ & 1,00 & 0,411 \\
\hline \multirow{3}{*}{ 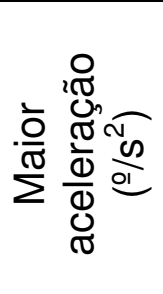 } & Ombro & $\begin{array}{c}2707,45 \\
(151,45)\end{array}$ & $\begin{array}{c}2703,13 \\
(171,68)\end{array}$ & $\begin{array}{c}2739,68 \\
(185,05)\end{array}$ & $\begin{array}{c}2869,76 \\
(145,53)\end{array}$ & $\begin{array}{c}2774,18 \\
(145,96)\end{array}$ & 1,20 & 0,318 \\
\hline & Cotovelo & $\begin{array}{c}8139,42 \\
(177,24)\end{array}$ & $\begin{array}{c}8009,07 \\
(216,93)\end{array}$ & $\begin{array}{c}8068,93 \\
(218,36)\end{array}$ & $\begin{array}{c}8115,77 \\
(192,91)\end{array}$ & $\begin{array}{c}8073,99 \\
(195,12)\end{array}$ & 0,39 & 0,814 \\
\hline & Punho & $\begin{array}{c}1912,28 \\
(234,94) \\
\end{array}$ & $\begin{array}{c}2136,14 \\
(331,59) \\
\end{array}$ & $\begin{array}{c}2307,85 \\
(329,97) \\
\end{array}$ & $\begin{array}{c}2148,32 \\
(259,75) \\
\end{array}$ & $\begin{array}{c}1739,28 \\
(206,61)\end{array}$ & 2,48 & 0,052 \\
\hline \multirow{3}{*}{ 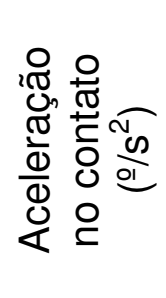 } & Ombro & $\begin{array}{c}127,01 \\
(1,98)\end{array}$ & $\begin{array}{c}126,89 \\
(1,78)\end{array}$ & $\begin{array}{c}126,89 \\
(2,02)\end{array}$ & $\begin{array}{c}127,04 \\
(1,96)\end{array}$ & $\begin{array}{c}127,25 \\
(1,98)\end{array}$ & 0,07 & 0,989 \\
\hline & Cotovelo & $\begin{array}{c}115,22 \\
(2,55)\end{array}$ & $\begin{array}{c}113,74 \\
(2,72)\end{array}$ & $\begin{array}{c}113,34 \\
(2,68)\end{array}$ & $\begin{array}{c}111,86 \\
(2,63)^{1}\end{array}$ & $\begin{array}{c}111,84 \\
(2,68)^{1}\end{array}$ & 7,73 & 0,0001 \\
\hline & Punho & $\begin{array}{c}183,06 \\
(3,22)\end{array}$ & $\begin{array}{c}185,07 \\
(3,22)^{4}\end{array}$ & $\begin{array}{c}181,99 \\
(3,30)\end{array}$ & $\begin{array}{c}180,67 \\
(3,02)^{2}\end{array}$ & $\begin{array}{c}183,49 \\
(3,16)\end{array}$ & 3,04 & 23 \\
\hline
\end{tabular}

Diferente de ${ }^{1} 3,5 \mathrm{~cm} ;{ }^{2} 4,5 \mathrm{~cm} ;{ }^{3} 5,5 \mathrm{~cm} ;{ }^{4} 6,5 \mathrm{~cm} \mathrm{e}^{5} 7,3 \mathrm{~cm}$. 
TABELA 17 - Média, DP (entre parênteses), $F$ e $p$ para as variáveis angulares temporais de desempenho (articulações), em função do tamanho do disco.

\begin{tabular}{|c|c|c|c|c|c|c|c|c|}
\hline \multirow[b]{2}{*}{ Variável } & \multirow[b]{2}{*}{ Artic. } & \multicolumn{5}{|c|}{ Tamanho (diâmetro) do disco (cm) } & \multicolumn{2}{|c|}{ Estatística } \\
\hline & & 3,5 & 4,5 & 5,5 & 6,5 & 7,5 & $F_{1,15}$ & $P$ \\
\hline \multirow{3}{*}{ 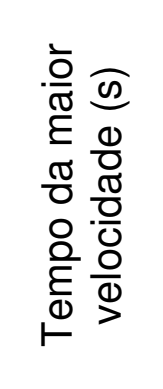 } & Ombro & $\begin{array}{c}0,156 \\
(0,007)\end{array}$ & $\begin{array}{c}0,152 \\
(0,012)\end{array}$ & $\begin{array}{c}0,146 \\
(0,011)\end{array}$ & $\begin{array}{c}0,155 \\
(0,006)\end{array}$ & $\begin{array}{c}0,135 \\
(0,013)\end{array}$ & 1,19 & 0,323 \\
\hline & Cotovelo & $\begin{array}{r}0,140 \\
(0,007)\end{array}$ & $\begin{array}{r}0,146 \\
(0,007)\end{array}$ & $\begin{array}{c}0,139 \\
(0,006)\end{array}$ & $\begin{array}{l}0,137 \\
(0,006)\end{array}$ & $\begin{array}{l}0,137 \\
(0,004)\end{array}$ & 1,04 & 0,390 \\
\hline & Punho & $\begin{array}{r}0,064 \\
(0,012)\end{array}$ & $\begin{array}{r}0,072 \\
(0,012)\end{array}$ & $\begin{array}{c}0,084 \\
(0,014)\end{array}$ & $\begin{array}{l}0,080 \\
(0,013)\end{array}$ & $\begin{array}{l}0,066 \\
(0,012)\end{array}$ & 1,29 & 0,280 \\
\hline \multirow{3}{*}{  } & Ombro & $\begin{array}{l}0,105 \\
(0,008)\end{array}$ & $\begin{array}{l}0,111 \\
(0,009)\end{array}$ & $\begin{array}{c}0,104 \\
(0,010)\end{array}$ & $\begin{array}{l}0,098 \\
(0,006)\end{array}$ & $\begin{array}{l}0,101 \\
(0,007)\end{array}$ & 1,11 & 0,355 \\
\hline & Cotovelo & $\begin{array}{r}0,073 \\
(0,007)\end{array}$ & $\begin{array}{r}0,078 \\
(0,007)\end{array}$ & $\begin{array}{c}0,071 \\
(0,007)\end{array}$ & $\begin{array}{l}0,070 \\
(0,006)\end{array}$ & $\begin{array}{l}0,068 \\
(0,004)\end{array}$ & 1,11 & 0,357 \\
\hline & Punho & $\begin{array}{r}0,172 \\
(0,024)\end{array}$ & $\begin{array}{r}0,180 \\
(0,023)\end{array}$ & $\begin{array}{c}0,187 \\
(0,021)\end{array}$ & $\begin{array}{l}0,161 \\
(0,022)\end{array}$ & $\begin{array}{l}0,160 \\
(0,021)\end{array}$ & 1,04 & 0,390 \\
\hline \multirow{3}{*}{ 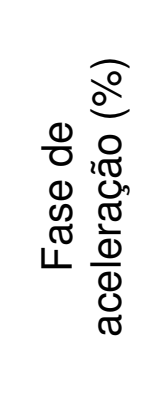 } & Ombro & $\begin{array}{c}71,19 \\
(6,43)\end{array}$ & $\begin{array}{c}67,54 \\
(19,98)\end{array}$ & $\begin{array}{c}65,83 \\
(18,50)\end{array}$ & $\begin{array}{c}70,29 \\
(10,43)\end{array}$ & $\begin{array}{c}62,53 \\
(24,66)\end{array}$ & 1,43 & 0,235 \\
\hline & Cotovelo & $\begin{array}{c}63,56 \\
(5,83)\end{array}$ & $\begin{array}{c}63,21 \\
(9,03)\end{array}$ & $\begin{array}{c}62,32 \\
(7,10)\end{array}$ & $\begin{array}{c}61,79 \\
(8,66)\end{array}$ & $\begin{array}{c}61,11 \\
(8,31)\end{array}$ & 0,565 & 0,689 \\
\hline & Punho & $\begin{array}{c}29,36 \\
(21,43)\end{array}$ & $\begin{array}{c}32,42 \\
(22,87)\end{array}$ & $\begin{array}{l}38,17 \\
(24,54)\end{array}$ & $\begin{array}{c}37,44 \\
(26,16)\end{array}$ & $\begin{array}{c}29,66 \\
(21,69)\end{array}$ & 1,39 & 0,249 \\
\hline \multirow{3}{*}{ 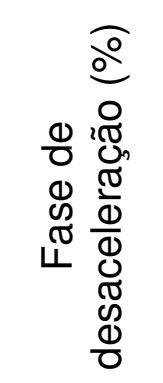 } & Ombro & $\begin{array}{c}28,81 \\
(6,43)\end{array}$ & $\begin{array}{c}32,46 \\
(19,98)\end{array}$ & $\begin{array}{c}34,17 \\
(18,50)\end{array}$ & $\begin{array}{r}29,71 \\
(10,43)\end{array}$ & $\begin{array}{c}37,47 \\
(24,66)\end{array}$ & 1,43 & 0,235 \\
\hline & Cotovelo & $\begin{array}{c}36,44 \\
(5,83)\end{array}$ & $\begin{array}{c}36,79 \\
(9,03)\end{array}$ & $\begin{array}{c}37,68 \\
(7,10)\end{array}$ & $\begin{array}{c}38,21 \\
(8,66)\end{array}$ & $\begin{array}{c}38,89 \\
(8,31)\end{array}$ & 0,565 & 0,689 \\
\hline & Punho & $\begin{array}{c}70,64 \\
(21,43)\end{array}$ & $\begin{array}{c}67,58 \\
(22,87)\end{array}$ & $\begin{array}{c}61,83 \\
(24,54)\end{array}$ & $\begin{array}{c}62,56 \\
(26,16)\end{array}$ & $\begin{array}{c}70,34 \\
(21,69)\end{array}$ & 1,39 & 0,249 \\
\hline
\end{tabular}

Diferente de ${ }^{1} 3,5 \mathrm{~cm} ;{ }^{2} 4,5 \mathrm{~cm} ;{ }^{3} 5,5 \mathrm{~cm} ;{ }^{4} 6,5 \mathrm{~cm} \mathrm{e}{ }^{5} 7,3 \mathrm{~cm}$. 


\subsection{Discussão}

6.6.1 Variáveis lineares de resultado (disco) e de desempenho (manopla)

No paradigma da relação inversa velocidade-precisão, a diminuição do tamanho do alvo (no presente experimento referente à redução no tamanho do disco) proporciona uma restrição espacial que demanda maior precisão para a regulação do movimento (Fitts, 1954; Crossman \& Goodeve, 1963/1983; Okazaki et al., 2008). Os modelos que analisaram este efeito da redução no tamanho do alvo são congruentes em apontar a estratégia de diminuição no tempo de movimento (Elliott et al., 2004; Fitts \& Petersen, 1964; Meyer et al., 1988; Plamondon \& Alimi, 1997). Esta estratégia permitiria menor velocidade (menores força e variabilidade de resposta; Schmidt et al., 1978, 1979), maior tempo para utilização de feedback (Crossman \& Goodeve, 1963/1983; Keele, 1968; Meyer et al., 1982), ou maior tempo para a fase de desaceleração do movimento (Teixeira, 2000; Zelaznik, 1993), em função da diminuição no tamanho do alvo. Por conseguinte, a hipótese H11 apontou um aumento nas variáveis de tempo de movimento, de tempo para contato manopladisco e de tempo após contato manopla-disco com a diminuição no tamanho do disco. No entanto, os resultados do presente estudo não verificaram efeito do tamanho do disco nessas variáveis de temporais. Tais resultados refutaram a hipótese $\mathrm{H} 11$ e foram explicados pela existência de duas restrições espaciais externas na tarefa utilizada.

$\mathrm{Na}$ tarefa de lançar um disco, através de um movimento de contato com uma manopla, em direção a um alvo remoto, há duas fontes de restrição espacial externa que atuam no movimento, o tamanho do disco e o tamanho do alvo remoto. Os sujeitos foram instruídos para contatarem o disco com máxima velocidade, mas sempre direcionando o disco para atingir o alvo remoto. Desta forma, a restrição proporcionada pela área central do disco pode ter sido a maior fonte de restrição sobre o movimento, independente do tamanho do disco ou alvo remoto. Tais resultados estariam em consonância com estudos que demonstraram que quando há duas ou mais fontes de restrição sobre o movimento, a maior fonte de restrição é quem determina as maiores alterações sobre o desempenho (Short et al., 1996; 
Sidaway, 1991; Yao et al., 2007). Por outro lado, pode ter ocorrido apenas a restrição do alvo remoto sem considerar o tamanho do disco. Tal estratégia estaria em consonância com o estudo que analisou o chute no futebol, no qual apenas a manipulação do tamanho do gol (alvo remoto) proporcionou diminuição na velocidade linear do pé no instante de contato com a bola, enquanto a manipulação do tamanho da bola não apresentou efeito sobre as características cinemáticas do chute (Teixeira, 1999). Para entender o efeito isolado da manipulação do tamanho do alvo remoto, foi realizado o experimento $\mathrm{V}$. Estudos que manipularam o objetivo da tarefa, através da ênfase na velocidade ou na precisão do movimento (Adam, 1992; Rival et al., 2003), também corroboram com a idéia de que apenas foi considerada a restrição proporcionada pelo centro do alvo, ou pelo alvo remoto, para auxiliar na regulação do movimento. Tais explicações também auxiliaram no entendimento da menor precisão e da maior variabilidade encontrada em função do tamanho do disco.

A redução no tamanho do disco proporcionou menor área de contato manopla-disco $\left(T_{v}\right)$ em condições que direcionem o disco para o centro do alvo remoto. Desta forma, foi levantada a hipótese $(\mathrm{H} 12)$ de que maior erro e variabilidade seriam encontrados com a diminuição no tamanho do disco. Esta hipótese (H12) foi aceita para auxiliar a explicar o maior erro verificado em função da diminuição no tamanho do disco. Entretanto, a alteração na magnitude da desaceleração no instante de impacto e as diferentes estratégias de sincronização, entre o tempo da maior velocidade e do tempo de contato manopla-disco, sugerem que a estratégia de controle adotada também contribuiu para o aumento no erro e na variabilidade verificados.

Uma possível estratégia para a manutenção na precisão do movimento é a sincronização entre o tempo da maior velocidade e do instante determinante (contato manopla-disco) no desempenho (Okazaki et al., 2006b; Teixeira, 1999). Tal estratégia permitiria que menor aceleração e, conseqüentemente, menor variabilidade de resposta, ocorresse no instante de contato manopla-disco. Por conseguinte, o erro seria independente da magnitude da velocidade e da aceleração, permitindo controlar tanto a geração de velocidade quanto a manutenção da precisão no movimento. Porém, foi verificado aumento na magnitude da desaceleração no instante de contato manopla-disco, em função da diminuição no tamanho do disco. 
Pois, não houve uma sincronização apropriada entre o instante em que o maior valor de velocidade ocorreu e o instante de contato manopla-disco. Como não houve um ajuste apropriado para compensar o aumento na demanda da precisão, através da diminuição no tamanho do disco, maior erro e variabilidade foram verificados. $O$ fato de não ter ocorrido modificação na maior aceleração entre as condições, mas apenas na aceleração no instante de contato manopla-disco, também corrobora com a idéia de que a precisão e a variabilidade estariam mais relacionadas ao instante determinante do desempenho no movimento. Todavia, foi refutada a hipótese $\mathrm{H} 13$, que sugeriu a utilização desta estratégia de controle para a manutenção da precisão no movimento. Pois, como a maioria das variáveis lineares temporais foi mantida constante (apenas houve na diferença entre o tempo da maior velocidade e do tempo do instante de contato), com a redução no tamanho do disco, não foi possível utilizar a estratégia de regulação dos maiores valores de velocidade propriamente. O cálculo dos índices de dificuldade (ID' e ID") auxiliou no entendimento da quantidade de restrição imposta sobre o movimento através da diminuição no tamanho do disco.

A diminuição do tamanho do disco resultou em maior índice de dificuldade (ID' de 6,95 para 8,10 bits e ID" de 7,79 para 8,94 bits), pois maior restrição espacial foi colocada sobre o movimento. Segundo a lei de Fitts (1954), o aumento neste índice de dificuldade resultaria em maior tempo de movimento para que as demandas de precisão espaciais impostas sobre o movimento fossem atendidas. Suporte para esta relação entre o tempo de movimento e o índice de dificuldade, manipulado tanto pela distância de movimento quanto pelo tamanho do alvo, foram verificados em diversos estudos (Boritz et al., 1991; Card et al., 1978; Corcos et al., 1988; Epps, 1986; Fitts, 1954; Johnsgard, 1994; Kerr, 1973, 1978; Kerr \& Langolf, 1977; Okazaki et al., 2008). Por conseguinte, o tempo de movimento, o tempo para contato e o tempo após contato manopla-disco estariam diretamente relacionados com o aumento do índice de dificuldade (hipótese H14). Dois índices de dificuldade foram calculados na tarefa proposta, considerando o ângulo da margem de acerto (ID') e o tamanho do alvo virtual ( $\left.T_{v}\right)$ com e a amplitude até o contato manopla-disco (ID"). Ao contrário do que era esperado, não foi verificada significância na associação entre os IDs e as variáveis de tempo de movimento, tempo para contato e tempo após contato manopla-disco. Houve apenas uma tendência para significância na 
relação entre os IDs com as variáveis de tempo para contato $(p=0,053)$ e tempo após contato manopla-disco $(p=0,058)$, no qual o tempo para contato apresentou uma relação direta com os IDs e o tempo após contato uma relação inversa. Esta tendência para uma diminuição no tempo após o contato em função do aumento no índice de dificuldade (também encontrada com o aumento no ID através da maior amplitude de movimento no Experimento I do presente estudo) sugere que o sistema também poderia ter utilizada a regulação temporal dos instantes que procede ao contato manopla-disco como estratégia para auxiliar na manutenção da precisão no movimento. No entanto, a ausência de significância na predição destas variáveis temporais ( $T M, T_{c}$ e $T_{a}$ ), em função dos IDs, pareceu corroborar mais com a explicação de que apenas a região central do disco ou o alvo remoto atuaram como fonte de restrição determinante sobre o movimento. Estes resultados, com a ausência de significância na análise de regressão linear entre os IDs e as variáveis temporais $\left(T M, T_{c}\right.$ e $\left.T_{a}\right)$ refutaram a hipótese $H 14$, propondo uma relação direta entre estas variáveis. A ação conjunta das articulações também auxiliou no entendimento das estratégias utilizadas para a geração de velocidade e da manutenção da precisão no movimento.

\subsubsection{Variáveis angulares de desempenho (articulações)}

O deslocamento linear da manopla é resultado da ação conjunta espaçotemporal das articulações do ombro, do cotovelo e do punho. Assim, as estratégias utilizadas no controle do movimento para a geração de velocidade e para a manutenção da precisão também foram analisadas através da ação das articulações (ombro, cotovelo e punho). Foram verificadas tendências para diminuições nos ângulos no instante de contato manopla-disco para o ombro e o cotovelo, além de acréscimo na aceleração no instante de contato para o cotovelo, em função do aumento no tamanho do disco. Isto resultou em menores magnitudes de desacelerações lineares nos instantes próximos ao contato manopla-disco nas condições com maiores tamanhos de disco. Porém, não foram verificadas modificações nas variáveis temporais angulares com o aumento na restrição espacial externa imposta através da redução no tamanho do disco. Por conseguinte, foi 
refutada a hipótese $\mathrm{H} 15$ que previu aumento na fase de desaceleração como estratégia para compensar a maior demanda de precisão com a diminuição no tamanho do disco. Estes resultados estão em consonância com a explicação apresentada, na qual a maior restrição imposta no movimento ocorreu devido ao foco de atenção direcionado ao centro do disco, ou ao alvo remoto, de forma que praticamente as mesmas estratégias de movimento foram utilizadas entre as condições. Esta suposta ausência na percepção da restrição proporcionada pela diminuição no tamanho do disco também não permitiu ajustes nos tempos dos maiores valores de velocidade da manopla e das articulações.

\subsection{Conclusão}

A diminuição do tamanho do alvo primário ocasionou menor precisão e maior variabilidade. Isto ocorreu em função do aumento na magnitude da desaceleração no instante de contato manopla-disco. Foi sugerido que a estratégia de sincronizar os maiores valores de velocidade com o instante de contato manopladisco não foi utilizada propriamente. Isto foi explicado pelas duas restrições externas impostas sobre o movimento: disco e alvo remoto. Como o objetivo da tarefa foi direcionar o disco para o centro do alvo remoto, a restrição proporcionada apenas pela pequena região central do disco que garantia certa margem de acerto pode ter sido a fonte de restrição determinante no movimento. Por outro lado, o centro do alvo remoto pode ter sido responsável pela maior restrição imposta, independentemente da redução no tamanho do disco.

As modificações na desaceleração no instante de contato manopla-disco, e as alterações nas sincronizações entre os tempos da maior velocidade e do contato, foram realizadas em função de ajustes no ângulo do cotovelo e do punho, e na aceleração do cotovelo, no instante de contato manopla-disco. 
7.1 Introdução

Movimentos destinados a atingir alvos espaciais com máxima velocidade estão sujeitos a uma diminuição no tempo de movimento quando o tamanho do alvo é reduzido (Fitts, 1954; Pereira \& Okazaki, 2008; Woodworth, 1899). Esta diminuição no tempo de movimento ocorre para que as demandas nas restrições espaciais impostas sobre o movimento sejam atendidas de forma satisfatória. Desta forma, maior tempo para a regulação via feedback (Crossman \& Goodeve, 1963/1983), menor quantidade de ruído gerado (Schmidt et al., 1978, 1979), maior tempo para desacelerar o movimento (Zelaznik, 1993; Teixeira, 2000), e melhor integração entre as sinergias agonistas e antagonistas que participam da regulação no movimento (Plamondon, 1995a, 1995b; Plamondon \& Alimi, 1997) e maior tempo para que o sistema consiga processar as informações do movimento (Fitts, 1954; Fitts \& Petersen, 1964), ocorrem para proporcionar melhor controle para a manutenção da precisão.

Diversos estudos corroboraram a relação inversa entre a geração de velocidade e o controle na precisão do movimento (cf. Plamondon \& Alimi, 1997; Soukoreff \& Mackenzie, 2004; Teixeira, 2000). Entretanto, a maioria dos estudos que analisou este paradigma utilizou tarefas simples, tais como tocar em dois alvos paralelos com uma ponteira (Fitts, 1954; Fitts \& Petersen, 1964), transportar pinos ou discos de um lado para o outro (Fitts, 1954), rodar a mão (Crossman \& Goodeve, 1963/1983) ou mover um mouse clicando em duas barras paralelas (Johnsgard, 1994; Okazaki et al., 2008b; Pereira \& Okazaki, 2008). Ademais, algumas tarefas motoras mais complexas não demonstraram obedecer fielmente esta relação inversa velocidade-precisão, tais como chute no futebol (Teixeira, 1999), arremesso estilo beisebol (Van Den Tillaar \& Ettema, 2006) e arremesso no basquetebol (Okazaki \& Rodacki, 2005). Desta forma, um importante aspecto para ser analisado no paradigma da relação velocidade-precisão é sua capacidade de generalização para tarefas motoras mais complexas como as esportivas e/ou do cotidiano. 
As tarefas motoras complexas também possuem outras particularidades, no que diz respeito às estratégias de controle na geração de velocidade e regulação do movimento. Por exemplo, quando é objetivado atingir um objeto com máxima potência e grande precisão, o tempo da maior velocidade tende a coincidir com instante determinante do desempenho (contato com o objeto). Isto foi observado no chute no futebol (Anderson \& Sidaway, 1994; Teixeira, 1999), arremesso no basquetebol (Okazaki et al., 2006; Rodacki et al., 2005), arremesso estilo beisebol (Teixeira, 1997), e saque no tênis (Elliott et al., 1989). Tal estratégia é associada com a maior precisão, uma vez que no instante em que ocorre a maior velocidade a aceleração é igual a zero. Desta forma, menor força e variabilidade são geradas nos instantes de maior velocidade permitindo melhor manutenção da precisão no movimento. Contudo, nas tarefas que analisaram o paradigma da relação inversa (realizando movimentos de toque entre dois alvos paralelos; cf. Fitts, 1954) o tempo da maior velocidade ocorreu nas porções mediais do movimento. Esta estratégia permite controlar as proporções das fases de aceleração e desaceleração no movimento (Mackenzie et al., 1987; Teixeira, 2000). Quando o tempo da maior velocidade é antecipado, aumentando a fase de desaceleração, ocorre ênfase na precisão do movimento. Ao passo que, quando o tempo da maior velocidade é atrasado, ocorre ênfase na geração de velocidade no movimento. Por conseguinte, estratégias ímpares na geração de velocidade e na manutenção da precisão estão presentes em tarefas motoras simples (unidimensionais, mono-articulares, laboratoriais) e complexas (bi- ou tridimensionais, multi-articulares, esportivas). Porém, ainda são necessários mais estudos que auxiliem a entender os processos de controle na geração de velocidade e na manutenção da precisão em tarefas motoras complexas.

Outro aspecto que diferencia as tarefas motoras simples das tarefas motoras complexas é a restrição total imposta sobre o movimento. Em tarefas motoras complexas, além das estratégias de controle adotadas (fonte de restrição interna), de forma geral, há mais fontes externas de restrição sobre o movimento (objeto, implemento, alvo remoto). Teixeira (1999) demonstrou que a bola (objeto) e gol (alvo) são fontes espaciais externas de restrição na tarefa de chute no futebol. Em geral, quando manipuladas estas duas fontes de restrição externa, o chute 
demonstrou ser mais influenciado pelo tamanho do alvo remoto (gol) quando comparado à bola (Teixeira, 1999). O arremesso no basquetebol também não apresentou modificações com a manipulação no tamanho da bola (Okazaki \& Rodacki, 2005), entretanto, demonstrou modificações com o aumento na distância que diminui a área virtual de passagem da cesta quando o ângulo de lançamento é mantido constante (Rodacki et al., 2005). Tarefas simples de tocar em dois alvos sucessivos também demonstraram que o segundo alvo é a fonte de restrição determinante sobre o movimento (tempo de movimento e de reação) (Short et al., 1996; Sidaway, 1991). Contudo, ainda não é compreendido o efeito da manipulação do tamanho do alvo em tarefas complexas sobre as estratégias de geração da velocidade e de manutenção da precisão no movimento.

\subsection{Objetivo}

Analisar o efeito do tamanho do alvo, na tarefa de contatar um disco com uma manopla em direção a um alvo remoto, sobre as variáveis cinemáticas de resposta e de desempenho no movimento.

\subsection{Hipóteses}

H16 A diminuição no tamanho do alvo resulta em maiores tempo de movimento, tempo para contato e tempo após contato manopla-disco.

H17 A restrição imposta pela redução no tamanho do alvo remoto leva a menores erro e variabilidade espaciais.

H18 O tempo do maior valor de velocidade é sincronizado com o instante em que ocorre o contato manopla-disco.

H19 Menor tamanho do alvo resulta em maior índice de dificuldade que está diretamente relacionado ao tempo de movimento, tempo para contato e tempo após contato manopla-disco. 
H20 A redução no tamanho do alvo remoto leva a uma maior fase de desaceleração nas articulações (ombro, cotovelo e punho).

\subsection{Procedimentos particulares do método}

Foi analisada a tarefa de contatar um disco com uma manopla em direção a um alvo remoto, realizada com máxima velocidade e maior precisão possíveis. Análises cinemáticas do resultado (variáveis lineares do disco) e do desempenho (variáveis angulares das articulações e lineares da manopla) foram realizadas para entender as estratégias de controle motor na geração de velocidade e na manutenção da precisão do movimento.

Foi utilizada uma distância manopla-disco de $32 \mathrm{~cm}$ e uma manopla circular com 7,5 cm de diâmetro e massa de $200 \mathrm{~g}$. Esta manopla foi utilizada para contatar um disco com massa de $100 \mathrm{~g}$ e tamanho de $7,5 \mathrm{~cm}$ de diâmetro. $\mathrm{O}$ disco era direcionado a um alvo remoto com tamanhos de 2, 4, 6, 8 e $10 \mathrm{~cm}$ de largura. As demais características do arranjo experimental foram descritas na sessão de métodos.

\subsection{Resultados}

7.5.1 Variáveis lineares de resultado (disco) e de desempenho (manopla)

A tabela 18 apresentou a estatística descritiva (média e desvio padrão) e inferencial (análise de variância com medidas repetidas) das variáveis espaciais e temporais de reposta (disco) e desempenho (manopla), em função do tamanho do alvo remoto. Maior aceleração da manopla foi verificada no tamanho de alvo de 10 $\mathrm{cm}$ em comparação ao alvo de $6 \mathrm{~cm}$. Entretanto, o tamanho do alvo remoto não apresentou efeito sobre as demais variáveis espaciais, tais como precisão (média do erro angular), variabilidade (desvio padrão do erro angular), maior velocidade linear da manopla, velocidade da manopla no instante de contato manopla-disco e aceleração da manopla no instante de contato manopla-disco. O aumento no 
tamanho do alvo remoto levou a um menor tempo após contato no alvo de $10 \mathrm{~cm}$ em comparação aos alvos de 2 e $8 \mathrm{~cm}$. O alvo remoto com maior tamanho apresentou maior fase de desaceleração e menor fase de desaceleração, no alvo de 10 em comparação aos alvos 2 e $6 \mathrm{~cm}$. As demais variáveis temporais não apresentaram diferença significante, em função do tamanho do alvo remoto: tempo de movimento, tempo para contato, tempo da maior velocidade, diferença entre o tempo para contato e o tempo da maior velocidade e tempo da maior aceleração.

A tabela 19 apresentou a estatística associativa através da análise de regressão linear simples entre os índices de dificuldade e algumas variáveis temporais no movimento selecionadas. A análise de regressão linear não apresentou associação significante entre os índices de dificuldade (ID' e ID") e as variáveis de tempo de movimento (TM), de tempo para contato $\left(\mathrm{T}_{\mathrm{c}}\right)$ e de tempo após contato manopla $\left(T_{\mathrm{a}}\right)$. A regressão linear entre o tempo de movimento e índice de dificuldade ID' e ID" apresentou um coeficiente de $R^{2}=0,098(p>0,05)$ e $R^{2}=0,100(p>0,05)$, respectivamente. A análise entre o tempo para o contato e o índice de dificuldade ID' e ID" apresentou, respectivamente, um coeficiente de $R^{2}=0,242(p>0,05)$ e $R^{2}=$ $0,243(p>0,05)$. A análise entre os índices de dificuldade ID' e ID" e o tempo após o contato demonstrou, respectivamente, coeficientes de $R^{2}=0,559(p>0,05)$ e de $R^{2}$ $=0,561(p>0,05)$. Por conseguinte, as variáveis temporais do tempo de movimento, do tempo para o contato e do tempo após o contato não apresentaram associação com os índices de dificuldade calculados na tarefa experimental proposta. A figura 6 apresentou os valores e uma linha de tendência linear de ajuste para os índices de dificuldade em função das variáveis temporais selecionadas, em função da manipulação no tamanho do alvo remoto. 
TABELA 18 - Media, DP (entre parênteses), $F$ e $p$ para as variáveis de resposta (disco) e de desempenho (manopla), em função do tamanho do alvo.

\begin{tabular}{|c|c|c|c|c|c|c|c|}
\hline \multirow[b]{2}{*}{ Variáveis } & \multicolumn{5}{|c|}{ Tamanho do alvo secundário (cm) } & \multicolumn{2}{|c|}{ Estatística } \\
\hline & 2 & 4 & 6 & 8 & 10 & $F_{1,15}$ & $p$ \\
\hline Erro angular absoluto $\left(^{\circ}\right)$ & $\begin{array}{l}2,53 \\
(1,19)\end{array}$ & $\begin{array}{l}2,21 \\
(0,80)\end{array}$ & $\begin{array}{l}2,18 \\
(0,80)\end{array}$ & $\begin{array}{l}2,45 \\
(1,17)\end{array}$ & $\begin{array}{l}2,75 \\
(1,06)\end{array}$ & 0,96 & 0,435 \\
\hline Variabilidade $(\stackrel{\circ}{)})$ & $\begin{array}{l}1,90 \\
(0,62)\end{array}$ & $\begin{array}{l}2,06 \\
(0,70)\end{array}$ & $\begin{array}{l}1,94 \\
(0,55)\end{array}$ & $\begin{array}{l}1,84 \\
(1,04)\end{array}$ & $\begin{array}{l}2,20 \\
(0,34)\end{array}$ & 0,68 & 0,605 \\
\hline Amplitude de mov. (m) & $\begin{array}{c}0,635 \\
(0,062)\end{array}$ & $\begin{array}{c}0,630 \\
(0,065)\end{array}$ & $\begin{array}{c}0,635 \\
(0,065)\end{array}$ & $\begin{array}{c}0,642 \\
(0,065)\end{array}$ & $\begin{array}{c}0,638 \\
(0,072)\end{array}$ & 1,93 & 0,116 \\
\hline Maior velocidade (m/s) & $\begin{array}{l}4,82 \\
(0,90)\end{array}$ & $\begin{array}{l}4,83 \\
(0,94)\end{array}$ & $\begin{array}{l}4,82 \\
(0,91)\end{array}$ & $\begin{array}{l}4,85 \\
(0,90)\end{array}$ & $\begin{array}{l}4,89 \\
(0,98)\end{array}$ & 1,26 & 0,293 \\
\hline Veloc. no contato $(\mathrm{m} / \mathrm{s})$ & $\begin{array}{l}4,65 \\
(1,10)\end{array}$ & $\begin{array}{l}4,68 \\
(1,11)\end{array}$ & $\begin{array}{l}4,65 \\
(1,11)\end{array}$ & $\begin{array}{l}4,68 \\
(1,09)\end{array}$ & $\begin{array}{l}4,71 \\
(1,17)\end{array}$ & 0,72 & 0,579 \\
\hline Maior aceleração $\left(\mathrm{m} / \mathrm{s}^{2}\right)$ & $\begin{array}{c}55,36 \\
(18,15)\end{array}$ & $\begin{array}{c}56,08 \\
(18,97)\end{array}$ & $\begin{array}{l}54,98 \\
(18,30)^{5}\end{array}$ & $\begin{array}{c}56,26 \\
(18,99)\end{array}$ & $\begin{array}{l}57,63 \\
(20,20)^{3}\end{array}$ & 2,84 & 0,031 \\
\hline Acel. no contato $\left(\mathrm{m} / \mathrm{s}^{2}\right)$ & $\begin{array}{l}0,31 \\
(16,89)\end{array}$ & $\begin{array}{l}-1,07 \\
(17,81)\end{array}$ & $\begin{array}{l}-0,32 \\
(16,88)\end{array}$ & $\begin{array}{l}-0,53 \\
(17,05)\end{array}$ & $\begin{array}{l}-0,03 \\
(19,82)\end{array}$ & 0,55 & 0,669 \\
\hline Tempo de movimento (s) & $\begin{array}{c}0,327 \\
(0,121)\end{array}$ & $\begin{array}{l}0,315 \\
(0,131)\end{array}$ & $\begin{array}{c}0,326 \\
(0,124)\end{array}$ & $\begin{array}{r}0,331 \\
(0,122)\end{array}$ & $\begin{array}{c}0,314 \\
(0,129)\end{array}$ & 2,1 & 0,089 \\
\hline Tempo para contato (s) & $\begin{array}{c}0,163 \\
(0,069)\end{array}$ & $\begin{array}{c}0,165 \\
(0,076)\end{array}$ & $\begin{array}{c}0,160 \\
(0,067)\end{array}$ & $\begin{array}{c}0,160 \\
(0,065)\end{array}$ & $\begin{array}{c}0,172 \\
(0,071)\end{array}$ & 1,47 & 0,220 \\
\hline Tempo após contato (s) & $\begin{array}{l}0,165 \\
(0,070)^{5}\end{array}$ & $\begin{array}{c}0,142 \\
(0,070)\end{array}$ & $\begin{array}{c}0,156 \\
(0,076)\end{array}$ & $\begin{array}{l}0,166 \\
(0,072)^{5}\end{array}$ & $\begin{array}{l}0,135 \\
(0,066)^{14}\end{array}$ & 3,5 & 0,013 \\
\hline Tempo da maior veloc. (s) & $\begin{array}{r}0,171 \\
(0,089)\end{array}$ & $\begin{array}{c}0,174 \\
(0,095)\end{array}$ & $\begin{array}{c}0,168 \\
(0,087)\end{array}$ & $\begin{array}{c}0,173 \\
(0,086)\end{array}$ & $\begin{array}{c}0,182 \\
(0,092)\end{array}$ & 1,95 & 0,113 \\
\hline $\begin{array}{l}\text { Tempo para contato menos } \\
\text { tempo da maior veloc. (s) }\end{array}$ & $\begin{array}{c}-0,009 \\
(0,022)\end{array}$ & $\begin{array}{c}-0,008 \\
(0,021)\end{array}$ & $\begin{array}{c}-0,009 \\
(0,022)\end{array}$ & $\begin{array}{c}-0,009 \\
(0,022)\end{array}$ & $\begin{array}{c}-0,010 \\
(0,023)\end{array}$ & 1,30 & 0,278 \\
\hline Tempo da maior acel. (s) & $\begin{array}{c}0,110 \\
(0,078)\end{array}$ & $\begin{array}{c}0,114 \\
(0,084)\end{array}$ & $\begin{array}{c}0,108 \\
(0,076)\end{array}$ & $\begin{array}{c}0,113 \\
(0,074)\end{array}$ & $\begin{array}{l}0,120 \\
(0,080)\end{array}$ & 1,44 & 0,229 \\
\hline Fase de aceleração (\%) & $\begin{array}{l}51,35 \\
(10,43)^{5}\end{array}$ & $\begin{array}{c}54,25 \\
(11,41)\end{array}$ & $\begin{array}{l}51,01 \\
(11,16)^{5}\end{array}$ & $\begin{array}{c}51,58 \\
(9,82)\end{array}$ & $\begin{array}{c}56,62 \\
(6,78)^{13}\end{array}$ & 3,35 & 0,015 \\
\hline Fase de desaceleração (\%) & $\begin{array}{l}48,65 \\
(10,43)^{5}\end{array}$ & $\begin{array}{c}45,75 \\
(11,41)\end{array}$ & $\begin{array}{l}48,99 \\
(11,16)^{5}\end{array}$ & $\begin{array}{c}48,42 \\
(9,82)\end{array}$ & $\begin{array}{c}43,38 \\
(6,78)^{13}\end{array}$ & 3,35 & 0,015 \\
\hline
\end{tabular}


TABELA 19 - Valores da regressão linear do tempo de movimento, tempo para contato e tempo após contato, em função dos índices de dificuldade (ID' e ID').

\begin{tabular}{lccccc}
\hline Variáveis & $R$ & $R^{2}$ & $F_{1,3}$ & $p$ & Equação de Reta \\
\hline ID' x Tempo de movimento & 0,314 & 0,098 & 0,33 & 0,607 & $y=20,03 x-37,62$ \\
ID" x Tempo de movimento & 0,316 & 0,100 & 0,33 & 0,605 & $y=20,99 x-37,98$ \\
ID' x Tempo para contato & 0,492 & 0,242 & 0,96 & 0,400 & $y=12,86 x-32,52$ \\
ID" x Tempo para contato & 0,493 & 0,243 & 0,96 & 0,398 & $y=13,74 x-32,75$ \\
ID' x Tempo após contato & 0,748 & 0,559 & 3,81 & 0,146 & $y=-17,52 x+154,24$ \\
ID" x Tempo após contato & 0,749 & 0,561 & 3,84 & 0,145 & $y=-16,83 x+155,15$ \\
\hline
\end{tabular}

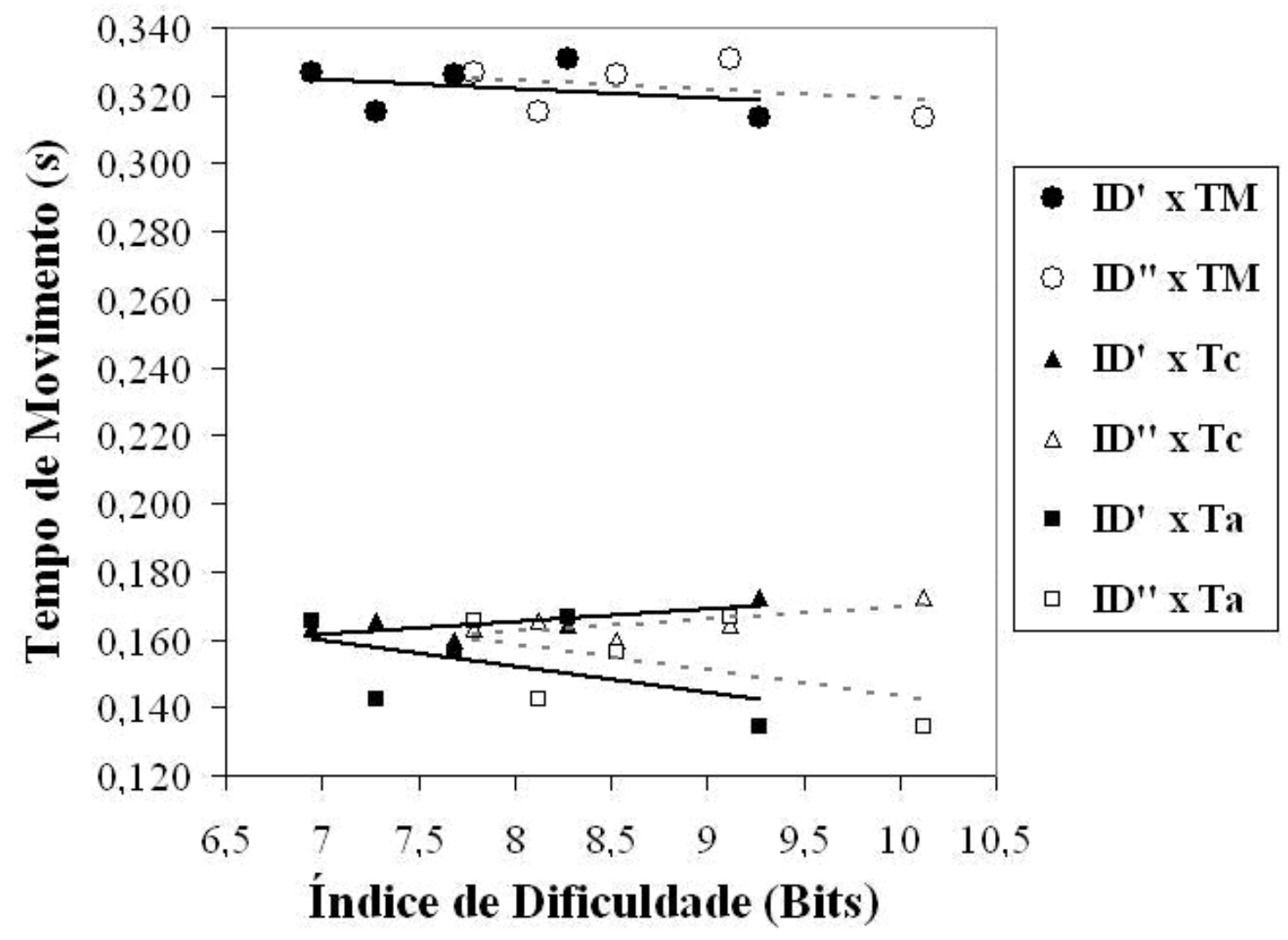

FIGURA 6 - Tempo de movimento (TM), tempo para contato $\left(T_{c}\right)$ e tempo após contato ( $\mathrm{T}_{a}$ ), em função dos índices de dificuldade (ID' e ID"). 
7.5.2 Variáveis angulares de desempenho (manopla)

A tabela 20 e a tabela 21 apresentaram, respectivamente, as variáveis espaciais e temporais da análise estatística (descritiva e inferencial), em função do tamanho do alvo remoto. O aumento no alvo remoto levou à maior amplitude do punho entre a condição de alvo $6,5 \mathrm{~cm}$ em comparação com a condição de alvo com $7,5 \mathrm{~cm}$. O aumento no tamanho do alvo remoto também conduziu à maior magnitude de velocidade no punho entre na condição 4,5 em relação à condição $7,5 \mathrm{~cm}$. As demais variáveis espaciais (ângulo no contato manopla-disco, velocidade no contato manopla-disco, maior aceleração e aceleração no contato manopla-disco) e temporais (tempo da maior velocidade e tempo da maior aceleração) do movimento não apresentaram efeito da manipulação no tamanho do alvo remoto. 
TABELA 20 - Média, DP (entre parênteses), $F$ e $p$ para as variáveis angulares espaciais de desempenho (articulações), em função do tamanho do alvo.

\begin{tabular}{|c|c|c|c|c|c|c|c|c|}
\hline \multirow[b]{2}{*}{ Variável } & \multirow[b]{2}{*}{ Artic. } & \multicolumn{5}{|c|}{ Tamanho do alvo secundário $(\mathrm{cm})$} & \multicolumn{2}{|c|}{ Estatística } \\
\hline & & 3,5 & 4,5 & 5,5 & 6,5 & 7,5 & $F_{1,15}$ & $p$ \\
\hline \multirow{3}{*}{ 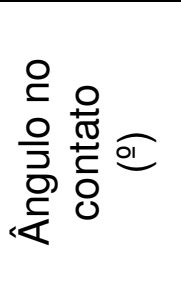 } & Ombro & $\begin{array}{c}127,32 \\
(7,50)\end{array}$ & $(8,26)$ & $(7,62)$ & & $(9,98)$ & 47 &, 220 \\
\hline & Cotovelo & $\begin{array}{c}105,14 \\
(18,73)\end{array}$ & $\begin{array}{c}105,72 \\
(17,13)\end{array}$ & $\begin{array}{c}106,55 \\
(18,63)\end{array}$ & 5 & & 13 & 0,349 \\
\hline & Punt & $\begin{array}{r}180, \\
(14,7\end{array}$ & $\begin{array}{r}175 \\
(14\end{array}$ & $\begin{array}{r}17 \varepsilon \\
(15\end{array}$ & & & 89 & 0,122 \\
\hline \multirow{3}{*}{ 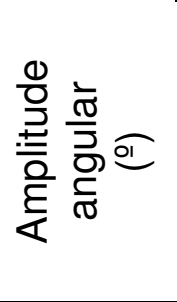 } & Ombro & $(3,27)$ & & & & & 31 & 0,274 \\
\hline & Cotovelo & $\begin{array}{c}108,74 \\
(8,93)\end{array}$ & 10 & $\begin{array}{r}107 \\
(8,7\end{array}$ & & & 0,67 & 0,609 \\
\hline & Pun & $\begin{array}{r}14, \\
(7,2\end{array}$ & & & & & 03 & 024 \\
\hline \multirow{3}{*}{ 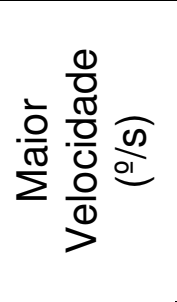 } & & ( & & & & & 46 & 764 \\
\hline & Cotovelo & $\begin{array}{c}750,01 \\
(83,00)\end{array}$ & & $\begin{array}{r}738 \\
(81\end{array}$ & & $\begin{array}{r}752 \\
(94\end{array}$ & 4 & ,343 \\
\hline & Pun & $\begin{array}{c}95,74 \\
(65,51) \\
\end{array}$ & & $\begin{array}{r}103 \\
(67,3\end{array}$ & & & 87 & 030 \\
\hline \multirow{3}{*}{ 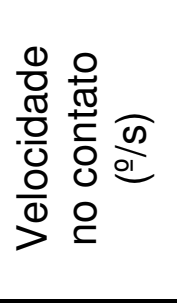 } & $\mathrm{C}$ & $\begin{array}{c}108,63 \\
(52,92)\end{array}$ & & $\begin{array}{c}103,99 \\
(55,27)\end{array}$ & & & 18 & 944 \\
\hline & Cotovelo & $\begin{array}{c}695,25 \\
(133,56)\end{array}$ & & $\begin{array}{r}686 \\
(140,\end{array}$ & & & 5 & 340 \\
\hline & Pun & $\begin{array}{r}27,90 \\
(75,16)\end{array}$ & & م2 & & & 55 & 0,698 \\
\hline \multirow{3}{*}{ 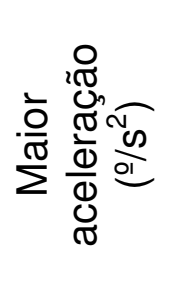 } & Ombro & & & $\begin{array}{c}2561,91 \\
(774,34)\end{array}$ & & & 88 & 0,480 \\
\hline & Cotovelo & $\begin{array}{c}7704,91 \\
(1226,48)\end{array}$ & & & & & 1 & ,241 \\
\hline & Punho & $\begin{array}{r}1321 \\
(645, \\
\end{array}$ & & $\begin{array}{r}1411, \\
(780,4 \\
\end{array}$ & & 3 &, 82 & 0,513 \\
\hline \multirow{3}{*}{ 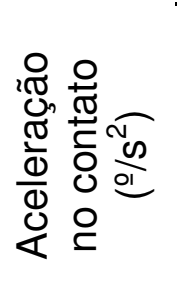 } & Ombro & $\begin{array}{c}1841,20 \\
(817,58)\end{array}$ & $(941,23)$ & $\begin{array}{c}1803,24 \\
(728,33)\end{array}$ & $\begin{array}{c}1864,27 \\
(817,68)\end{array}$ & $(949,65)$ &, 26 & 0,901 \\
\hline & Cotovelo & $\begin{array}{c}3220,78 \\
(1938,09)\end{array}$ & & $\begin{array}{c}3011,06 \\
(1917,87)\end{array}$ & & $\begin{array}{r}3038 \\
(2299\end{array}$ & 0,86 & 0,490 \\
\hline & & $\begin{array}{c}-857,59 \\
(1436,30)\end{array}$ & $\begin{array}{c}-889,89 \\
(1289,03)\end{array}$ & $\begin{array}{c}-826,70 \\
(1452,38)\end{array}$ & $\begin{array}{c}-996,36 \\
(1132,81)\end{array}$ & $\begin{array}{c}-880,59 \\
(1224,94)\end{array}$ & 0,54 & 4 \\
\hline
\end{tabular}

Diferente de ${ }^{1} 2 \mathrm{~cm},{ }^{2} 4 \mathrm{~cm},{ }^{3} 6 \mathrm{~cm} ;{ }^{4} 8 \mathrm{~cm} \mathrm{e}{ }^{5} 10 \mathrm{~cm}$. 
TABELA 21 - Média, DP (entre parênteses), $F$ e $p$ para as variáveis angulares temporais de desempenho (articulações), em função do tamanho do alvo.

\begin{tabular}{|c|c|c|c|c|c|c|c|c|}
\hline \multirow[b]{2}{*}{ Variável } & \multirow[b]{2}{*}{ Artic. } & \multicolumn{5}{|c|}{ Tamanho do alvo secundário $(\mathrm{cm})$} & \multicolumn{2}{|c|}{ Estatística } \\
\hline & & 3,5 & 4,5 & 5,5 & 6,5 & 7,5 & $F_{1,15}$ & $p$ \\
\hline \multirow{3}{*}{ 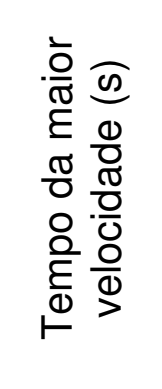 } & Ombro & $\begin{array}{c}0,203 \\
(0,093)\end{array}$ & $\begin{array}{c}0,203 \\
(0,092)\end{array}$ & $\begin{array}{c}0,199 \\
(0,087)\end{array}$ & $\begin{array}{c}0,203 \\
(0,083)\end{array}$ & $\begin{array}{c}0,209 \\
(0,088)\end{array}$ & 0,57 & 0,681 \\
\hline & Cotovelo & $\begin{array}{r}0,183 \\
(0,084)\end{array}$ & $\begin{array}{r}0,186 \\
(0,090)\end{array}$ & $\begin{array}{r}0,181 \\
(0,084)\end{array}$ & $\begin{array}{l}0,186 \\
(0,081)\end{array}$ & $\begin{array}{l}0,193 \\
(0,087)\end{array}$ & 1,38 & 0,250 \\
\hline & Punho & $\begin{array}{r}0,083 \\
(0,114)\end{array}$ & $\begin{array}{r}0,101 \\
(0,096)\end{array}$ & $\begin{array}{r}0,107 \\
(0,113)\end{array}$ & $\begin{array}{l}0,087 \\
(0,106)\end{array}$ & $\begin{array}{l}0,095 \\
(0,101)\end{array}$ & 1,98 & 0,108 \\
\hline \multirow{3}{*}{ 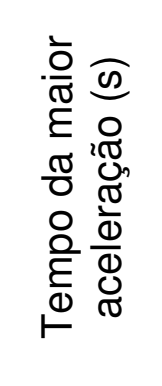 } & Ombro & $\begin{array}{c}0,139 \\
(0,085)\end{array}$ & $\begin{array}{r}0,142 \\
(0,089)\end{array}$ & $\begin{array}{c}0,139 \\
(0,083)\end{array}$ & $\begin{array}{r}0,141 \\
(0,079)\end{array}$ & $\begin{array}{c}0,149 \\
(0,084)\end{array}$ & 0,94 & 0,445 \\
\hline & Cotovelo & $\begin{array}{r}0,116 \\
(0,084)\end{array}$ & $\begin{array}{r}0,118 \\
(0,090)\end{array}$ & $\begin{array}{c}0,113 \\
(0,083)\end{array}$ & $\begin{array}{l}0,118 \\
(0,080)\end{array}$ & $\begin{array}{l}0,124 \\
(0,086)\end{array}$ & 1,19 & 0,321 \\
\hline & Punho & $\begin{array}{r}0,231 \\
(0,095)\end{array}$ & $\begin{array}{r}0,212 \\
(0,122)\end{array}$ & $\begin{array}{c}0,214 \\
(0,095)\end{array}$ & $\begin{array}{c}0,240 \\
(0,106)\end{array}$ & $\begin{array}{l}0,226 \\
(0,128)\end{array}$ & 0,91 & 0,463 \\
\hline \multirow{3}{*}{ 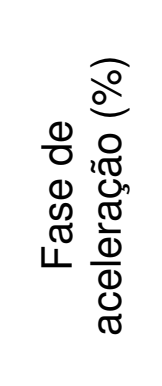 } & Ombro & $\begin{array}{c}62,34 \\
(12,51)\end{array}$ & $\begin{array}{c}64,99 \\
(12,63)\end{array}$ & $\begin{array}{c}62,15 \\
(13,00)\end{array}$ & $\begin{array}{c}62,00 \\
(10,85)\end{array}$ & $\begin{array}{c}66,77 \\
(7,29)\end{array}$ & 1,90 & 0,122 \\
\hline & Cotovelo & $\begin{array}{c}55,99 \\
(9,63)\end{array}$ & $\begin{array}{c}58,85 \\
(10,53)\end{array}$ & $\begin{array}{r}55,64 \\
(10,59)\end{array}$ & $\begin{array}{c}56,18 \\
(8,80)\end{array}$ & $\begin{array}{c}60,96 \\
(5,97)\end{array}$ & 2,78 & 0,034 \\
\hline & Punho & $\begin{array}{c}21,43 \\
(24,08)\end{array}$ & $\begin{array}{c}30,15 \\
(21,47)\end{array}$ & $\begin{array}{r}32,37 \\
(31,59)\end{array}$ & $\begin{array}{c}23,09 \\
(22,25)\end{array}$ & $\begin{array}{r}27,71 \\
(22,65)\end{array}$ & 2,58 & 0,046 \\
\hline 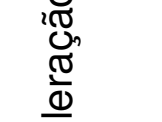 & Ombro & $\begin{array}{c}37,66 \\
(12,51)\end{array}$ & $\begin{array}{r}35,01 \\
(12,63)\end{array}$ & $\begin{array}{c}37,85 \\
(13,00)\end{array}$ & $\begin{array}{c}38,00 \\
(10,85)\end{array}$ & $\begin{array}{c}33,23 \\
(7,29)\end{array}$ & 1,90 & 0,122 \\
\hline$\underset{\mathscr{d}}{\mathbb{d}} \stackrel{0}{0}$ & Cotovelo & $\begin{array}{c}44,01 \\
(9,63)\end{array}$ & $\begin{array}{c}41,15 \\
(10,53)\end{array}$ & $\begin{array}{c}44,36 \\
(10,59)\end{array}$ & $\begin{array}{c}43,82 \\
(8,80)\end{array}$ & $\begin{array}{c}39,04 \\
(5,97)\end{array}$ & 2,78 & 0,034 \\
\hline $\begin{array}{l}0 \\
\Phi \\
\mathscr{\mho} \\
\ddot{1}\end{array}$ & Punho & $\begin{array}{c}78,57 \\
(24,08)\end{array}$ & $\begin{array}{c}69,85 \\
(21,47)\end{array}$ & $\begin{array}{c}67,63 \\
(31,59)\end{array}$ & $\begin{array}{r}76,91 \\
(22,25)\end{array}$ & $\begin{array}{c}72,29 \\
(22,65)\end{array}$ & 2,58 & 0,046 \\
\hline
\end{tabular}




\subsection{Discussão}

7.6.1 Variáveis lineares de resultado (disco) e de desempenho (manopla)

Estudos que analisaram a relação inversa velocidade-precisão apontam que a diminuição no tamanho do alvo resulta em maior restrição espacial (Crosman \& Goodeve, 1963/1983; Fitts \& Petersen, 1964; Woodworth, 1899). Maior restrição espacial, através da diminuição no tamanho do alvo, tende a ser compensada por aumentos no tempo de movimento quando a tarefa demanda grande velocidade e precisão concomitantemente (Fitts, 1954; Meyer et al., 1988; Pereira \& Okazaki, 2008; Plamondon \& Alimi, 1997). Este aumento no tempo do movimento permitiria vantagens em termos de processamento das informações (Fitts, 1954; Fitts \& Petersen, 1964), do uso no feedback sensorial (Crossman \& Goodeve, 1963/1983; Meyer et al., 1982), da redução na geração de ruído no movimento (Meyer et al., 1988; Schmidt et al., 1978, 1979) e da melhor regulação entre as fases de aceleração e de desaceleração no movimento (Zelaznik, 1993). Por conseguinte, foi formulada a hipótese $(\mathrm{H} 16)$ de que a diminuição do tamanho do alvo resultaria em maiores tempo de movimento, tempo para contato e tempo após contato, como estratégia para a manutenção da precisão. Entretanto, a diminuição no tamanho do alvo remoto apenas demonstrou reduzir o tempo após contato (comparando o alvo de $10 \mathrm{~cm}$ com os alvos de 2 e de $6 \mathrm{~cm}$ ). Estes resultados refutaram a hipótese $\mathrm{H} 16 \mathrm{e}$ foram explicados pela estratégia de controle adotada no movimento.

Tarefas que possuem a particularidade de lançar um objeto em direção a um alvo parecem não obedecer fielmente às proposições encontradas em experimentos com tarefas laboratoriais mais simples. Por exemplo, Teixeira (1999) demonstrou que a manipulação da restrição espacial, através da redução do tamanho da bola, não modificou as características cinemáticas do chute no futebol. Apenas quando o tamanho do alvo remoto (gol) foi manipulado, foi verificada uma redução na velocidade linear do pé no instante de contato com a bola. Na tarefa utilizada, a regulação do movimento depende das especificações nos parâmetros de controle adquiridas através da posição relativa do disco em função do alvo remoto. Como o foco visual foi direcionado ao disco, a restrição espacial percebida que o alvo 
remoto possui pode ter sido transmitida virtualmente ao disco. Ademais, o objetivo da tarefa foi direcionar o disco para o centro do alvo remoto. Isto pode ter induzido à estratégia de utilizar uma restrição espacial virtual localizada na região mais central do disco que garantisse apenas seu direcionamento para o centro do alvo. Ou seja, nas condições em que poderiam ser aproveitados os maiores tamanhos de alvos, houve praticamente a mesma restrição percebida, e imposta pela estratégia de precisão adotada, que resultou em movimentos muito parecidos entre as condições analisadas. Isto explica o fato da maioria das variáveis cinemáticas utilizadas para descrever o movimento não ter apresentado efeito com a manipulação do alvo remoto. Tais resultados estão em conformidade com estudos que manipularam o objetivo da tarefa através da ênfase na velocidade ou na precisão do movimento (Adam, 1992; Rival et al., 2003) e com os resultados do experimento III. Desta forma, também foi refutada a hipótese $\mathrm{H} 17$ que previa menor erro e menor variabilidade em função da diminuição no tamanho do alvo remoto. Contudo, a redução no tempo após contato manopla-disco e as maiores magnitude e fase de aceleração, sugerem que, pelo menos no alvo de maior tamanho $(10 \mathrm{~cm})$, pode ter havido menor restrição sobre o movimento.

Apesar da menor restrição sugerida na condição com maior tamanho de alvo, a estratégia de tentar sincronizar o tempo da maior velocidade com o instante de contato manopla-disco pareceu comum entre as tentativas. Esta estratégia teria permitido que, apesar da grande aceleração gerada no movimento (superior a 50 $\mathrm{m} / \mathrm{s}^{2}$ ), magnitudes inferiores a 1,2 $\mathrm{m} / \mathrm{s}^{2}$ ocorressem no instante de contato manopladisco. Por conseguinte, foi garantida a precisão do movimento mesmo quando o tamanho do alvo remoto foi diminuído. Assim, foi aceita a hipótese H18, que previa a estratégia para manutenção da precisão no movimento através da aproximação entre o tempo da maior velocidade da manopla e o instante de contato manopla-disco. Estes resultados estão em consonância com os estudos que analisaram tarefas motoras complexas, como, tais como chute no futebol (Anderson \& Sidaway, 1994; Teixeira, 1999), arremesso no basquetebol (Okazaki et al., 2006b; Rodacki et al., 2005), arremesso estilo beisebol (Teixeira, 1997), rebatida (Caljouw et al., 2005) e saque no tênis (Elliott et al., 1989). 
Outro fator que deve ser levado em consideração é que a diminuição no tamanho do alvo remoto gera em maior índice de dificuldade (ID' de 6,95 para 9,27 bits e ID" de 7,79 para 10,12 bits). Através deste índice de dificuldade o tempo de movimento foi predito em diversas tarefas desempenhadas com grande velocidade e precisão, tais como toques sucessivos em alvos alternados utilizando uma ponteira (Fitts, 1954), movimentos de rotação angular (Crosman \& Goodeve, 1963/1983; Meyer et al., 1982, 1988), lançamento de dardo (Kerr \& Langolf, 1977) e movimentos com mouse (Okazaki et al., 2008b; Perreira \& Okazaki, 2008). Por conseguinte, foi formulada a hipótese $(\mathrm{H} 19)$ de que as variáveis temporais da manopla (tempo de movimento, para contato e após contato manopla-disco) também seriam preditas pelo ID. Dois índices de dificuldade foram calculados na tarefa proposta, considerando o ângulo da margem de acerto (ID') e o tamanho do alvo virtual ( $\left.T_{\mathrm{v}}\right)$ com a amplitude para contato manopla-disco (ID"). No entanto, os resultados do presente estudo demonstraram que os IDs calculados não foram capazes de predizer as variáveis de tempo de movimento, de tempo para contato e de tempo após contato. Desta forma, foi refutada a hipótese H19 prevendo uma relação direta entre estas variáveis temporais selecionadas e os IDs. Estes resultados reforçam a proposição de que houve apenas uma restrição virtual projetada sobre o disco em função do centro do alvo remoto. Por conseguinte, não foram verificadas modificações nas variáveis temporais (tempo de movimento, tempo para contato e tempo após contato manopla-disco), mesmo com a modificação nos IDs, em função da estratégia de controle adotada para a manutenção da precisão.

\subsubsection{Variáveis angulares de desempenho (articulações)}

Como o comportamento linear da manopla é resultado das ações angulares das articulações, uma das possibilidades de compreender as estratégias de controle utilizadas no movimento é analisar o comportamento das variáveis angulares. Em função da maior restrição causada pela diminuição no tamanho do alvo remoto, foi levantada a hipótese de que a fase de desaceleração aumentaria nas articulações do ombro, do cotovelo e do punho (H20). Entretanto, os resultados do presente estudo não verificaram a estratégia do aumento na fase de desaceleração 
para aumentar a precisão no movimento. Assim, foi refutada a hipótese H20. A diminuição no tamanho do alvo apenas demonstrou no punho, com o alvo remoto de maior tamanho $(10 \mathrm{~cm})$, maiores amplitude angular (comparado com o alvo $8 \mathrm{~cm}) \mathrm{e}$ magnitude de aceleração (comparado com o alvo de $4 \mathrm{~cm}$ ). A ausência de modificações, na maioria das variáveis cinemáticas de desempenho das articulações, reforça a idéia de que a restrição virtual projetada sobre o disco, para direcioná-lo ao centro do alvo remoto, atuou de forma comum entre as diferentes condições de tamanho de alvo remoto.

\subsection{Conclusão}

A diminuição no tamanho do alvo remoto não demonstrou modificar a estratégia de controle da geração de velocidade e da manutenção da precisão no movimento. Como existiram duas fontes de restrição espacial (disco e o alvo remoto), e o objetivo da tarefa foi lançar o disco para a área central do alvo remoto, apenas a região central do disco teria atuado como fonte determinante na restrição do movimento. Foi sugerida a estratégia de sincronizar o maior valor de velocidade com o instante de contato manopla-disco. Esta estratégia permitiu que, apesar dos grandes valores de aceleração gerados no movimento, menores acelerações fossem realizadas no instante determinante do desempenho. Por conseguinte, a precisão não foi modificada em função dos diferentes tamanhos de alvo remoto. 
8.1 Introdução

No comportamento motor, a investigação da distância, do tamanho do alvo e do tempo de movimento, tem produzido a formulação de lei e de modelos capazes de explicar a relação destas variáveis. Por exemplo, Fitts (1954) estabeleceu uma relação linear logarítmica entre um índice de dificuldade (ID $=\log _{2}[2 \times D / T]$ ) e 0 tempo de movimento. Assim, quanto maior a restrição espacial definida pelo ID, ou quanto maior a demanda no controle da precisão do movimento, maior o tempo de movimento. Esta relação demonstrou consistência em diversas classes de movimentos (Fitts, 1954; Fitts \& Petersen, 1964; Kvalseth, 1975), em várias condições ambientais (Glencross \& Barrett, 1989; Hancock et al., 1973; Langolf \& Hancock, 1975) e movimentos realizados por diferentes segmentos corporais (Hoffmann \& Sheikh, 1991; Langolf et al., 1976; Meyer et al., 1988). Por conseguinte, tornou-se um dos fenômenos mais consistentes na área do comportamento motor, conhecido posteriormente como paradigma da relação inversa velocidade-precisão (Bootsma et al., 2004; Elliott et al., 2004; Teixeira, 2006).

Diversos modelos tentaram explicar este paradigma da relação inversa velocidade-precisão através de diferentes mecanismos de controle, como uso do feedback, geração de ruído, capacidade limitada de processar informações, modulação das fases de aceleração-desaceleração, organização das sinergias agonistas-antagonistas no movimento. Os pesquisadores que explicaram a relação inversa velocidade-precisão através da informação de feedback apontam que o aumento da velocidade permite menor tempo para a utilização do feedback (Beggs \& Howart, 1972a; Crossman \& Goodeve, 1963/1983; Woodworth, 1899). Entretanto, em movimentos em que não há tempo para a utilização do feedback, outra fonte de erro também contribui para a redução da precisão, isto é, a geração de ruído neural (Meyer et al., 1982, 1988; Schmidt et al., 1978, 1979). Este ruído pode ser gerado, com o aumento na velocidade, em três níveis diferentes do sistema: processamento da informação (níveis superiores de comando), transmissão da informação para o sistema efetor e no sistema efetor durante o desempenho do movimento (Schmidt et 
al., 1978, 1979). No que diz respeito ao processamento de informações, foi proposto que a capacidade limitada de processar informações também poderia regular esta relação inversa entre velocidade e precisão. Quanto maior a demanda na precisão, através de maiores informações para especificar os parâmetros de controle, maior é o tempo necessário para processar as informações para controlar o movimento (Fitts, 1954; Fitts \& Petersen, 1964). A relação inversa velocidade-precisão também pode ser explicada pela proporção na fase aceleração-desaceleração do movimento (Zelaznik, 1993). Ou seja, quando a velocidade é priorizada no movimento, maior fase de aceleração ocorre para potencializar a geração de velocidade. Ao passo que, para manter a precisão aumenta-se a fase de desaceleração do movimento. Entretanto, esta relação inversa velocidade-precisão também é sugerida como uma característica inata do sistema (Van Galen \& Shomaker, 1992), que emerge em função das respostas da musculatura agonista e antagonista que atuam no movimento (Plamondon, 1995a; Plamondon \& Alimi, 1997). Estes modelos auxiliaram na compreensão geral de algumas estratégias de controle na geração da velocidade e na manutenção da precisão dos movimentos. Contudo, ainda existem diversas lacunas não contempladas no paradigma da relação velocidade-precisão.

Considerando que as forças ambientais agindo sobre o sistema efetor podem ter grande influência sobre o movimento (Pfann et al., 2002; Sherwood et al., 1988; Southard, 1998), torna-se necessário analisar o efeito da inércia sobre as estratégias de controle utilizadas para a geração de velocidade e manutenção da precisão no movimento (Desmurget et al., 1997; Smeets et al., 1995; SmitsEngelsman et al., 2006). Por exemplo, o aumento da inércia no arremesso estilo boliche, através de acréscimos de massas nos segmentos do braço, foi capaz de mudar o movimento para um novo padrão de coordenação e controle (Southard, 1998). Arremessos com máxima potência simulados por computador, através de modelos de ativação muscular, demonstraram que o aumento da massa dos segmentos também modifica a seqüência e o padrão de ativação dos músculos (Chowdhary \& Challis, 2001). Na tarefa de extensão de cotovelo em direção a um alvo espacial, o aumento na carga inercial diminuiu a variabilidade dos pontos finais e a velocidade do impulso inicial, além de modificar a taxa de ativação em alvos menores. Contudo, a manipulação da inércia não modificou a ativação muscular em 
alvos maiores (Khan et al., 1999). Movimentos de rotação interna de ombro, acrescidos de carga inercial, para relembrar um posicionamento alvo, apresentaram maior erro variável, mas sem diferença no erro constante e absoluto; além de menor geração de velocidade (Brindle et al., 2006). Quando a massa da bola no arremesso do basquetebol foi aumentada, as crianças foram capazes de desempenhar 0 lançamento apenas com modificações nos parâmetros de controle no movimento (Okazaki \& Rodacki, 2005). No entanto, ainda não são claros os efeitos da inércia de movimento sobre a regulação do movimento. Ademais, a análise do efeito da inércia de movimento no paradigma da relação inversa velocidade-precisão não tem sido foco de estudo dos pesquisadores.

Outro aspecto a ser destacado nas análises realizadas para entender 0 paradigma velocidade-precisão diz respeito às tarefas utilizadas nos experimentos. A maioria dos experimentos que analisou a relação inversa velocidade-precisão foi limitada a tarefas simples, tais como tocar em alvos paralelos (Fitts, 1954; Fitts \& Petersen, 1964; Kvalseth, 1975), movimentos de rotação de uma articulação (Corcos et al., 1988; Crosman \& Goodeve, 1963/1983; Meyer et al., 1982, 1988), movimentos com o mouse (Johnsgard, 1994, Okazaki et al., 2008b; Pereira \& Okazaki, 2008). Ademais, em algumas tarefas motoras complexas a relação inversa velocidadeprecisão parece não ocorrer como nas tarefas laboratoriais normalmente utilizadas (Okazaki et al., 2006c; Teixeira, 1999; Van Den Tillaar \& Ettema, 2006). Desta forma, mais estudos que contemplem tarefas motoras complexas, como as esportivas ou do cotidiano, devem ser investigadas para melhor entendimento dos processos concernentes ao paradigma da relação inversa velocidade-precisão. Além disso, os estudos devem explorar mais as estratégias de controle verificadas por meio das ações no desempenho do movimento, uma vez que a maioria dos estudos conduzidos para entender a relação inversa velocidade-precisão tem utilizado apenas medidas de resultados para fundamentar suas inferências. 


\subsection{Objetivo}

Analisar o efeito da massa da manopla, na tarefa de contatar um disco com uma manopla em direção a um alvo remoto, sobre as variáveis cinemáticas de resposta e de desempenho no movimento.

\subsection{Hipóteses}

H21 O aumento na massa da manopla resulta em maiores erro e variabilidade.

H22 O aumento na massa da manopla resulta em maiores tempos de movimento, tempo para contato e tempo para contato manopla-disco.

H23 O tempo do maior valor de velocidade é sincronizado com o instante de contato manopla-disco.

H24 Maior fase de aceleração é verificada com o aumento na massa da manopla.

H25 Maior fase de aceleração é verificada nas articulações (ombro, cotovelo e punho) com o aumento na massa da manopla.

\subsection{Procedimentos particulares do método}

Foi analisada a tarefa de contatar um disco com uma manopla em direção a um alvo remoto, realizada com máxima velocidade e maior precisão possíveis. Analises cinemáticas do resultado (variáveis lineares do disco) e do desempenho (variáveis angulares das articulações e lineares da manopla) foram realizadas para entender as estratégias de controle motor na geração de velocidade e na manutenção da precisão do movimento.

Foi utilizada uma distância manopla-disco de $32 \mathrm{~cm}$ e uma manopla circular com 7,5 cm de diâmetro e massas de 200, 300, 400, 500 e 600 g. Esta 
manopla foi utilizada para contatar um disco com massa de $100 \mathrm{~g}$ e tamanho de 7,5 $\mathrm{cm}$ de diâmetro. $\mathrm{O}$ disco era direcionado a um alvo remoto com tamanhos de $10 \mathrm{~cm}$ de comprimento. As demais características do arranjo experimental foram descritas na sessão de métodos.

\subsection{Resultados}

8.5.1 Variáveis lineares de resultado (disco) e de desempenho (manopla)

A tabela 22 apresentou a estatística descritiva (média e desvio padrão) e inferencial (análise de variância com medidas repetidas) das variáveis espaciais e temporais de reposta (disco) e desempenho (manopla), em função da massa da manopla. A amplitude linear diminuiu com o acréscimo na massa da manopla, no qual a manopla de $200 \mathrm{~g}$ apresentou menor amplitude em relação às manoplas de 400 e de $600 \mathrm{~g}$. O acréscimo na massa da manopla levou a uma menor geração de velocidade, sendo menor na massa de $600 \mathrm{~g}$ do que nas demais (200 - $500 \mathrm{~g}$ ), e a manopla de $200 \mathrm{~g}$ apresentou maior velocidade que as manoplas de 400, de $500 \mathrm{e}$ de $600 \mathrm{~g}$. Esta diminuição da magnitude da velocidade decorrente do aumento na massa da manopla também resultou em menores velocidades no instante de contato manopla-disco. No qual, a manopla de $200 \mathrm{~g}$ apresentou maior velocidade no contato manopla-disco em comparação à manopla 400, 500 e $600 \mathrm{~g}$; e a manopla de $600 \mathrm{~g}$ apresentou menor velocidade no contato em relação às manoplas 200, 300 e $500 \mathrm{~g}$. Foi verificada também uma redução na magnitude da aceleração, em função do aumento na massa da manopla. A manopla de $600 \mathrm{~g}$ apresentou menor aceleração em relação às manoplas 200, 300 e $400 \mathrm{~g}$, ao passo que, a manopla $200 \mathrm{~g}$ demonstrou maior aceleração comparada às demais manoplas. Contudo, não houve efeito da massa sobre as demais variáveis espaciais: erro angular absoluto, desvio padrão do erro angular absoluto, maior velocidade, velocidade no contato e aceleração no contato. 
TABELA 22 - Média, DP (entre parênteses), $F$ e $p$ para as variáveis de resposta (disco) e de desempenho (manopla), em função da massa da manopla.

\begin{tabular}{|c|c|c|c|c|c|c|c|}
\hline \multirow[b]{2}{*}{ Variáveis } & \multicolumn{5}{|c|}{ Massa da manopla (g) } & \multicolumn{2}{|c|}{ Estatística } \\
\hline & 200 & 300 & 400 & 500 & 600 & $F_{1,15}$ & $p$ \\
\hline Erro angular absoluto $(\stackrel{\circ}{ })$ & $\begin{array}{c}2,586 \\
(1,01)\end{array}$ & $\begin{array}{c}3,021 \\
(1,07)\end{array}$ & $\begin{array}{c}2,932 \\
(0,95)\end{array}$ & $\begin{array}{c}2,498 \\
(0,92)\end{array}$ & $\begin{array}{c}2,345 \\
(1,41)\end{array}$ & 1,30 & 0,279 \\
\hline Variabilidade $(\stackrel{\circ}{)})$ & $\begin{array}{c}2,405 \\
(0,86)\end{array}$ & $\begin{array}{c}2,143 \\
(0,74)\end{array}$ & $\begin{array}{c}2,360 \\
(1,02)\end{array}$ & $\begin{array}{c}2,223 \\
(0,95)\end{array}$ & $\begin{array}{c}1,944 \\
(0,54)\end{array}$ & 1,02 & 0,401 \\
\hline Amplitude de mov. (m) & $\begin{array}{c}0,604 \\
(0,045)^{35}\end{array}$ & $\begin{array}{r}0,590 \\
(0,044)\end{array}$ & $\begin{array}{l}0,582 \\
(0,050)\end{array}$ & $\begin{array}{l}0,598 \\
(0,045)\end{array}$ & $\begin{array}{l}0,581 \\
(0,051)\end{array}$ & 5,02 & 0,001 \\
\hline Maior velocidade $(\mathrm{m} / \mathrm{s})$ & $\begin{array}{c}5,20 \\
(0,34)^{345}\end{array}$ & $\begin{array}{l}5,03 \\
(0,42)^{5}\end{array}$ & $\begin{array}{c}4,86 \\
(0,58)^{51}\end{array}$ & $\begin{array}{c}4,88 \\
(0,50)^{51}\end{array}$ & $\begin{array}{c}4,67 \\
(0,54)^{1234}\end{array}$ & 16,90 & 0,0001 \\
\hline Veloc. no contato $(\mathrm{m} / \mathrm{s})$ & $\begin{array}{c}5,14 \\
(0,38)^{345}\end{array}$ & $\begin{array}{l}4,99 \\
(0,45)^{5}\end{array}$ & $\begin{array}{l}4,80 \\
(0,62)^{1}\end{array}$ & $\begin{array}{c}4,84 \\
(0,53)^{15}\end{array}$ & $\begin{array}{c}4,62 \\
(0,56)^{124}\end{array}$ & 14,63 & 0,0001 \\
\hline Maior aceleração $\left(\mathrm{m} / \mathrm{s}^{2}\right)$ & $\begin{array}{c}65,56 \\
(6,51)^{2345}\end{array}$ & $\begin{array}{l}60,67 \\
(6,29)^{15}\end{array}$ & $\begin{array}{l}58,96 \\
(8,19)^{15}\end{array}$ & $\begin{array}{c}57,29 \\
(7,75)^{1}\end{array}$ & $\begin{array}{c}52,69 \\
(8,92)^{123}\end{array}$ & 17,53 & 0,0001 \\
\hline Acel. no contato $\left(\mathrm{m} / \mathrm{s}^{2}\right)$ & $\begin{array}{l}-9,08 \\
(12,38)\end{array}$ & $\begin{array}{l}-9,59 \\
(10,36)\end{array}$ & $\begin{array}{l}-7,65 \\
(11,07)\end{array}$ & $\begin{array}{l}-8,24 \\
(10,30)\end{array}$ & $\begin{array}{l}-9,54 \\
(10,93)\end{array}$ & 0,42 & 0,791 \\
\hline Tempo de movimento (s) & $\begin{array}{l}0,215 \\
(0,031)\end{array}$ & $\begin{array}{c}0,212 \\
(0,027)\end{array}$ & $\begin{array}{c}0,210 \\
(0,031)\end{array}$ & $\begin{array}{l}0,216 \\
(0,023)\end{array}$ & $\begin{array}{c}0,234 \\
(0,043)\end{array}$ & 2,26 & 0,072 \\
\hline Tempo para contato (s) & $\begin{array}{l}0,121 \\
(0,019)\end{array}$ & $\begin{array}{c}0,123 \\
(0,022)\end{array}$ & $\begin{array}{l}0,121 \\
(0,032)\end{array}$ & $\begin{array}{l}0,124 \\
(0,014)\end{array}$ & $\begin{array}{c}0,133 \\
(0,021)\end{array}$ & 1,59 & 0,188 \\
\hline Tempo após contato (s) & $\begin{array}{l}0,093 \\
(0,025)\end{array}$ & $\begin{array}{l}0,083 \\
(0,012)^{5}\end{array}$ & $\begin{array}{c}0,088 \\
(0,018)\end{array}$ & $\begin{array}{c}0,092 \\
(0,014)\end{array}$ & $\begin{array}{l}0,100 \\
(0,030)^{2}\end{array}$ & 2,60 & 0,045 \\
\hline Tempo da maior veloc. (s) & $\begin{array}{l}0,117 \\
(0,018)\end{array}$ & $\begin{array}{c}0,119 \\
(0,023)\end{array}$ & $\begin{array}{l}0,117 \\
(0,030)\end{array}$ & $\begin{array}{l}0,120 \\
(0,013)\end{array}$ & $\begin{array}{c}0,129 \\
(0,020)\end{array}$ & 1,67 & 0,168 \\
\hline $\begin{array}{l}\text { Tempo para contato menos } \\
\text { tempo da maior veloc. (s) }\end{array}$ & $\begin{array}{l}0,005 \\
(0,005)\end{array}$ & $\begin{array}{c}0,005 \\
(0,005)\end{array}$ & $\begin{array}{c}0,004 \\
(0,006)\end{array}$ & $\begin{array}{c}0,004 \\
(0,006)\end{array}$ & $\begin{array}{l}0,005 \\
(0,006)\end{array}$ & 0,52 & 0,717 \\
\hline Tempo da maior acel. (s) & $\begin{array}{l}0,061 \\
(0,019)\end{array}$ & $\begin{array}{c}0,060 \\
(0,023)\end{array}$ & $\begin{array}{c}0,053 \\
(0,032)\end{array}$ & $\begin{array}{l}0,056 \\
(0,016)\end{array}$ & $\begin{array}{c}0,064 \\
(0,023)\end{array}$ & 1,22 & 0,309 \\
\hline Fase de aceleração (\%) & $\begin{array}{c}54,91 \\
(7,12)\end{array}$ & $\begin{array}{c}55,82 \\
(6,31)\end{array}$ & $\begin{array}{c}55,21 \\
(7,95)\end{array}$ & $\begin{array}{c}55,38 \\
(4,17)\end{array}$ & $\begin{array}{c}55,58 \\
(5,53)\end{array}$ & 0,148 & 0,963 \\
\hline Fase de desaceleração (\%) & $\begin{array}{c}45,09 \\
(7,12)\end{array}$ & $\begin{array}{c}44,18 \\
(6,31)\end{array}$ & $\begin{array}{c}44,79 \\
(7,95)\end{array}$ & $\begin{array}{c}44,62 \\
(4,17)\end{array}$ & $\begin{array}{c}44,42 \\
(55,53)\end{array}$ & 0,148 & 0,963 \\
\hline
\end{tabular}

Diferente de ${ }^{1} 200 \mathrm{~g},{ }^{2} 300 \mathrm{~g},{ }^{3} 400 \mathrm{~g},{ }^{4} 500 \mathrm{~g} \mathrm{e}{ }^{5} 600 \mathrm{~g}$. 
O tempo após contato manopla-disco demonstrou efeito do aumento na massa da manopla, no qual a manopla $300 \mathrm{~g}$ apresentou menor tempo após contato comparada à manopla $600 \mathrm{~g}$. As demais variáveis temporais não apresentaram efeito da manipulação da massa da manopla: tempo de movimento, tempo para contato, tempo da maior velocidade, diferença entre o tempo para contato manopla-disco e o tempo da maior velocidade, e tempo da maior aceleração.

\subsubsection{Variáveis angulares de desempenho (manopla)}

A tabela 23 e a tabela 24 apresentaram, respectivamente, as variáveis espaciais e temporais da análise estatística (descritiva e inferencial), em função da massa da manopla. A manipulação na massa da manopla proporcionou maior amplitude de movimento nas manoplas 200 e 600 g em comparação à manopla 400 g. O aumento na massa da manopla levou a menor magnitude da velocidade gerada no cotovelo, na manopla $600 \mathrm{~g}$ em comparação à manopla 200, 300 e 400 g. A magnitude da velocidade no punho também diminuiu, no qual a manopla $400 \mathrm{~g}$ apresentou menor velocidade em comparação à manopla $200 \mathrm{~g}$. Esta redução na geração de velocidade proporcionou menor velocidade no instante de contato manopla-disco. O cotovelo apresentou redução na velocidade no contato manopladisco na manopla $600 \mathrm{~g}$ em comparação à manopla 200, 300 e $400 \mathrm{~g}$. Ao passo que, o punho apresentou menor velocidade no contato manopla-disco na manopla $400 \mathrm{~g}$ em comparação à manopla 200 e $600 \mathrm{~g}$.

O acréscimo na massa da manopla reduziu a magnitude da aceleração do cotovelo da manopla $600 \mathrm{~g}$ em comparação à manopla 200, 300 e $400 \mathrm{~g}$, e da manopla $500 \mathrm{~g}$ em relação à manopla 200 e 300 g. A aceleração no instante de contato manopla-disco também foi reduzida, em função do acréscimo na massa da manopla, no ombro e no cotovelo. Nos quais, as acelerações, no contato manopladisco, foram menores nas manoplas $600 \mathrm{~g}$ em comparação às manoplas $200 \mathrm{~g}$. O acréscimo na massa da manopla também atrasou o instante em que o tempo da maior velocidade do punho ocorreu, no qual a manopla $600 \mathrm{~g}$ apresentou maior atraso no instante da maior velocidade em comparação à manopla $200 \mathrm{~g}$. 
TABELA 23 - Média, DP (entre parênteses), $F$ e $p$ para as variáveis angulares espaciais de desempenho (articulações), em função da massa da manopla.

\begin{tabular}{|c|c|c|c|c|c|c|c|c|}
\hline \multirow[b]{2}{*}{ Variável } & \multirow[b]{2}{*}{ Artic. } & \multicolumn{5}{|c|}{ Massa da manopla (g) } & \multicolumn{2}{|c|}{ Estatística } \\
\hline & & 200 & 300 & 400 & 500 & 600 & $F_{1,15}$ & $p$ \\
\hline \multirow{3}{*}{  } & Ombro & $\begin{array}{c}127,42 \\
(6,90)\end{array}$ & $\begin{array}{c}127,01 \\
(5,95)\end{array}$ & $\begin{array}{c}126,58 \\
(6,66)\end{array}$ & $\begin{array}{c}126,12 \\
(7,47)\end{array}$ & $\begin{array}{c}125,75 \\
(8,27)\end{array}$ & 1,34 & 0,264 \\
\hline & Cotovelo & $\begin{array}{c}111,81 \\
(11,54) 5\end{array}$ & $\begin{array}{c}113,07 \\
(11,21)\end{array}$ & $\begin{array}{c}112,52 \\
(11,39)^{5}\end{array}$ & $\begin{array}{c}114,80 \\
(13,06)\end{array}$ & $\begin{array}{l}116,07 \\
(13,90)^{13}\end{array}$ & 4,10 & 0,005 \\
\hline & Punho & $\begin{array}{c}182,36 \\
(17,26)\end{array}$ & $\begin{array}{c}181,93 \\
(15,80)\end{array}$ & $\begin{array}{c}182,66 \\
(13,58)\end{array}$ & $\begin{array}{c}181,76 \\
(15,38)\end{array}$ & $\begin{array}{c}181,95 \\
(15,25)\end{array}$ & 0,01 & 0,981 \\
\hline \multirow{3}{*}{ 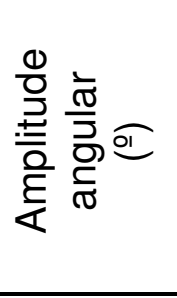 } & Ombro & $\begin{array}{c}19,17 \\
(4,32)\end{array}$ & $\begin{array}{c}18,88 \\
(1,97)\end{array}$ & $\begin{array}{c}18,39 \\
(3,19)\end{array}$ & $\begin{array}{c}17,48 \\
(2,98)\end{array}$ & $\begin{array}{c}17,65 \\
(2,98)\end{array}$ & 2,32 & 0,066 \\
\hline & Cotovelo & $\begin{array}{c}104,57 \\
(7,19)\end{array}$ & $\begin{array}{c}104,14 \\
(6,08)\end{array}$ & $\begin{array}{c}102,84 \\
(8,58)\end{array}$ & $\begin{array}{c}103,61 \\
(7,89)\end{array}$ & $\begin{array}{c}101,44 \\
(5,93)\end{array}$ & 2,47 & 0,053 \\
\hline & Punho & $\begin{array}{l}17,92 \\
(8,62)^{3} \\
\end{array}$ & $\begin{array}{c}15,58 \\
(8,77) \\
\end{array}$ & $\begin{array}{l}14,07 \\
(7,17)^{16} \\
\end{array}$ & $\begin{array}{c}17,10 \\
(8,11) \\
\end{array}$ & $\begin{array}{l}17,99 \\
(8,19)^{3} \\
\end{array}$ & 4,82 & 0,001 \\
\hline \multirow{3}{*}{  } & Ombro & $\begin{array}{c}163,89 \\
(35,22)\end{array}$ & $\begin{array}{c}164,64 \\
(15,66)\end{array}$ & $\begin{array}{c}162,72 \\
(24,94)\end{array}$ & $\begin{array}{c}158,46 \\
(22,02)\end{array}$ & $\begin{array}{c}155,95 \\
(21,92)\end{array}$ & 0,87 & 0,486 \\
\hline & Cotovelo & $\begin{array}{c}760,41 \\
(48,79)^{5}\end{array}$ & $\begin{array}{c}754,64 \\
(43,83)^{5}\end{array}$ & $\begin{array}{c}749,00 \\
(56,93)^{5}\end{array}$ & $\begin{array}{c}740,66 \\
(37,57)\end{array}$ & $\begin{array}{c}719,67 \\
(38,21)^{123}\end{array}$ & 8,06 & 0,0001 \\
\hline & Punho & $\begin{array}{c}151,32 \\
(66,47)^{3} \\
\end{array}$ & $\begin{array}{c}126,19 \\
(69,21) \\
\end{array}$ & $\begin{array}{c}120,82 \\
(60,11) \\
\end{array}$ & $\begin{array}{c}145,37 \\
(58,84) \\
\end{array}$ & $\begin{array}{c}136,34 \\
(57,88) \\
\end{array}$ & 2,78 & 0,034 \\
\hline \multirow{3}{*}{  } & Ombro & $\begin{array}{c}127,23 \\
(45,87)\end{array}$ & $\begin{array}{c}135,56 \\
(35,85)\end{array}$ & $\begin{array}{c}133,76 \\
(35,37)\end{array}$ & $\begin{array}{c}125,48 \\
(43,75)\end{array}$ & $\begin{array}{c}127,36 \\
(41,15)\end{array}$ & 1,08 & 0,373 \\
\hline & Cotovelo & $\begin{array}{c}746,94 \\
(40,29)^{5}\end{array}$ & $\begin{array}{c}743,88 \\
(38,43)^{5}\end{array}$ & $\begin{array}{c}737,66 \\
(49,50)^{5}\end{array}$ & $\begin{array}{c}727,90 \\
(34,02)\end{array}$ & $\begin{array}{l}709,20 \\
(35,09)^{123}\end{array}$ & 7,75 & 0,0001 \\
\hline & Punho & $\begin{array}{l}97,66 \\
(91,69)^{3} \\
\end{array}$ & $\begin{array}{l}71,56 \\
(98,94) \\
\end{array}$ & $\begin{array}{c}58,36 \\
(90,47)^{14} \\
\end{array}$ & $\begin{array}{l}99,32 \\
(84,38)^{3} \\
\end{array}$ & $\begin{array}{c}83,70 \\
(88,41) \\
\end{array}$ & 4,39 & 0,003 \\
\hline \multirow{3}{*}{  } & Ombro & $\begin{array}{c}2888,37 \\
(779,05)\end{array}$ & $\begin{array}{c}2915,29 \\
(469,99)\end{array}$ & $\begin{array}{c}2889,95 \\
(481,60)\end{array}$ & $\begin{array}{c}2865,92 \\
(583,84)\end{array}$ & $\begin{array}{c}2713,33 \\
(539,02)\end{array}$ & 1,70 & 0,160 \\
\hline & Cotovelo & $\begin{array}{l}7974,20 \\
(810,52)\end{array}$ & $\begin{array}{c}7843,98 \\
(853,65)\end{array}$ & $\begin{array}{c}7711,89 \\
(931,16)^{5}\end{array}$ & $\begin{array}{c}7429,69 \\
(726,14)^{12}\end{array}$ & $\begin{array}{l}7153,28 \\
(857,64)\end{array}$ & 18,65 & 0,0001 \\
\hline & Punho & $\begin{array}{c}1844,45 \\
(847,77) \\
\end{array}$ & $\begin{array}{c}1672,35 \\
(764,58) \\
\end{array}$ & $\begin{array}{c}1679,55 \\
(1044,46)\end{array}$ & $\begin{array}{c}1875,83 \\
(764,35) \\
\end{array}$ & $\begin{array}{c}1615,02 \\
(542,45)\end{array}$ & 0,61 & 0,655 \\
\hline \multirow{3}{*}{ 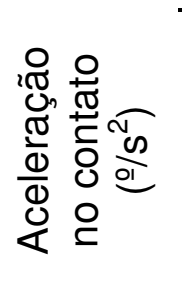 } & Ombro & $\begin{array}{c}1894,46 \\
(1072,54)^{5}\end{array}$ & $\begin{array}{c}1801,56 \\
(876,40)\end{array}$ & $\begin{array}{c}1763,67 \\
(941,19)\end{array}$ & $\begin{array}{c}1810,23 \\
(1053,56)\end{array}$ & $\begin{array}{l}1578,07 \\
(1029,58){ }^{1}\end{array}$ & 3,05 & 0,023 \\
\hline & Cotovelo & $\begin{array}{l}1778,44 \\
(1521,57)^{5}\end{array}$ & $\begin{array}{c}1524,44 \\
(1440,29)\end{array}$ & $\begin{array}{c}1481,37 \\
(1552,97)\end{array}$ & $\begin{array}{c}1529,66 \\
(1469,01)\end{array}$ & $\begin{array}{l}1181,98 \\
(1411,38)\end{array}$ & 4,31 & 0,003 \\
\hline & Punho & $\begin{array}{c}-1308,61 \\
(1002,63)\end{array}$ & $\begin{array}{c}-1260,43 \\
(763,86)\end{array}$ & $\begin{array}{c}-864,85 \\
(1035,65)\end{array}$ & $\begin{array}{c}-1161,47 \\
(1037,83)\end{array}$ & $\begin{array}{c}-898,88 \\
(1080,57)\end{array}$ & 1,92 & 0,117 \\
\hline
\end{tabular}

Diferente de ${ }^{1} 200 \mathrm{~g},{ }^{2} 300 \mathrm{~g},{ }^{3} 400 \mathrm{~g},{ }^{4} 500 \mathrm{~g} \mathrm{e}{ }^{5} 600 \mathrm{~g}$. 
TABELA 24 - Média, DP (entre parênteses), $F$ e $p$ para as variáveis angulares temporais de desempenho (articulações), em função da massa da manopla.

\begin{tabular}{|c|c|c|c|c|c|c|c|c|}
\hline \multirow[b]{2}{*}{ Variável } & \multirow[b]{2}{*}{ Artic. } & \multicolumn{5}{|c|}{ Massa da manopla (g) } & \multicolumn{2}{|c|}{ Estatística } \\
\hline & & 200 & 300 & 400 & 500 & 600 & $F_{1,15}$ & $p$ \\
\hline \multirow{3}{*}{ 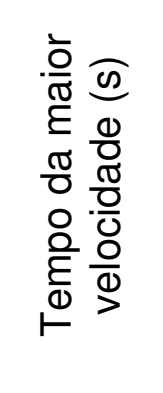 } & Ombro & $\begin{array}{c}0,149 \\
(0,019)\end{array}$ & $\begin{array}{c}0,148 \\
(0,022)\end{array}$ & $\begin{array}{c}0,144 \\
(0,032)\end{array}$ & $\begin{array}{c}0,148 \\
(0,017)\end{array}$ & $\begin{array}{c}0,149 \\
(0,034)\end{array}$ & 0,13 & 0,967 \\
\hline & Cotovelo & $\begin{array}{r}0,130 \\
(0,018)\end{array}$ & $\begin{array}{l}0,131 \\
(0,023)\end{array}$ & $\begin{array}{c}0,128 \\
(0,029)\end{array}$ & $\begin{array}{c}0,132 \\
(0,014)\end{array}$ & $\begin{array}{c}0,140 \\
(0,021)\end{array}$ & 1,34 & 0,264 \\
\hline & Punho & $\begin{array}{l}0,063 \\
(0,048)^{5}\end{array}$ & $\begin{array}{c}0,072 \\
(0,044)\end{array}$ & $\begin{array}{c}0,076 \\
(0,059)\end{array}$ & $\begin{array}{c}0,082 \\
(0,049)\end{array}$ & $\begin{array}{l}0,093 \\
(0,055)\end{array}$ & 2,72 & 0,037 \\
\hline \multirow{3}{*}{ 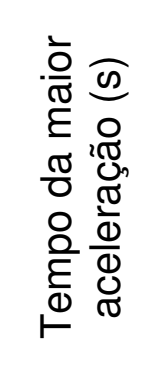 } & Ombro & $\begin{array}{c}0,090 \\
(0,021)\end{array}$ & $\begin{array}{l}0,091 \\
(0,023)\end{array}$ & $\begin{array}{c}0,087 \\
(0,033)\end{array}$ & $\begin{array}{c}0,091 \\
(0,019)\end{array}$ & $\begin{array}{c}0,098 \\
(0,024)\end{array}$ & 1,24 & 0,301 \\
\hline & Cotovelo & $\begin{array}{r}0,061 \\
(0,018)\end{array}$ & $\begin{array}{c}0,063 \\
(0,022)\end{array}$ & $\begin{array}{c}0,060 \\
(0,029)\end{array}$ & $\begin{array}{c}0,063 \\
(0,014)\end{array}$ & $\begin{array}{c}0,070 \\
(0,020)\end{array}$ & 1,20 & 0,316 \\
\hline & Punho & $\begin{array}{c}0,126 \\
(0,086)\end{array}$ & $\begin{array}{l}0,151 \\
(0,088)\end{array}$ & $\begin{array}{c}0,139 \\
(0,084)\end{array}$ & $\begin{array}{c}0,119 \\
(0,088)\end{array}$ & $\begin{array}{c}0,150 \\
(0,083)\end{array}$ & 0,75 & 0,559 \\
\hline \multirow{3}{*}{ 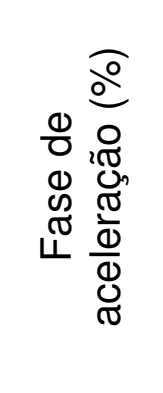 } & Ombro & $\begin{array}{c}70,14 \\
(9,64)\end{array}$ & $\begin{array}{c}70,21 \\
(8,09)\end{array}$ & $\begin{array}{c}68,71 \\
(9,87)\end{array}$ & $\begin{array}{c}68,70 \\
(7,77)\end{array}$ & $\begin{array}{c}64,07 \\
(13,11)\end{array}$ & 1,89 & 0,123 \\
\hline & Cotovelo & $\begin{array}{c}61,24 \\
(7,71)\end{array}$ & $\begin{array}{c}61,57 \\
(6,01)\end{array}$ & $\begin{array}{c}60,61 \\
(8,07)\end{array}$ & $\begin{array}{c}61,18 \\
(5,01)\end{array}$ & $\begin{array}{c}60,29 \\
(5,85)\end{array}$ & 0,341 & 0,849 \\
\hline & Punho & $\begin{array}{c}30,19 \\
(22,15)\end{array}$ & $\begin{array}{c}33,27 \\
(19,13)\end{array}$ & $\begin{array}{c}34,95 \\
(24,88)\end{array}$ & $\begin{array}{c}36,77 \\
(20,74)\end{array}$ & $\begin{array}{c}39,73 \\
(22,85)\end{array}$ & 1,51 & 0,211 \\
\hline \multirow{3}{*}{ 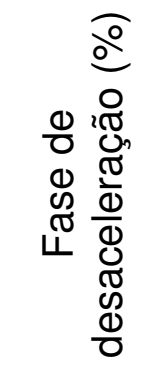 } & Ombro & $\begin{array}{c}29,86 \\
(9,64)\end{array}$ & $\begin{array}{c}29,79 \\
(8,09)\end{array}$ & $\begin{array}{c}31,29 \\
(9,87)\end{array}$ & $\begin{array}{c}31,30 \\
(7,77)\end{array}$ & $\begin{array}{c}35,93 \\
(13,11)\end{array}$ & 1,89 & 0,123 \\
\hline & Cotovelo & $\begin{array}{c}38,76 \\
(7,71)\end{array}$ & $\begin{array}{c}38,43 \\
(6,01)\end{array}$ & $\begin{array}{c}39,39 \\
(8,07)\end{array}$ & $\begin{array}{c}38,82 \\
(5,01)\end{array}$ & $\begin{array}{c}39,71 \\
(5,85)\end{array}$ & 0,341 & 0,849 \\
\hline & Punho & $\begin{array}{c}69,81 \\
(22,15)\end{array}$ & $\begin{array}{c}66,73 \\
(19,13)\end{array}$ & $\begin{array}{c}65,05 \\
(24,88)\end{array}$ & $\begin{array}{c}63,23 \\
(20,74)\end{array}$ & $\begin{array}{c}60,27 \\
(22,85)\end{array}$ & 1,51 & 0,211 \\
\hline
\end{tabular}

Diferente de $200 \mathrm{~g},{ }^{2} 300 \mathrm{~g},{ }^{3} 400 \mathrm{~g},{ }^{4} 500 \mathrm{~g} \mathrm{e}{ }^{5} 600 \mathrm{~g}$. 


\subsection{Discussão}

8.6.1 Variáveis lineares de resultado (disco) e de desempenho (manopla)

O aumento na massa da manopla demanda maior geração de força para iniciar o movimento. Assim, segundo os modelos de variabilidade de impulso (Meyer et al., 1982; Schmidt et al., 1978, 1979), de sub-movimentos otimizados (Meyer et al., 1988; Okazaki et al., 2008), e da teoria cinemática (Plamondon, 1995, 1997; Plamondon \& Alimi, 1997), maior erro e variabilidade seriam verificados nas condições com maior massa na manopla (hipótese H21), uma vez que o aumento na geração de força resulta em maior variabilidade de resposta no movimento (Schmidt et al., 1978, 1979). Porém, o presente experimento não verificou alteração no erro e na variabilidade do movimento, em função da manipulação da massa da manopla. Esta manutenção na precisão do movimento refutou a hipótese H21 e foi explicada pela maior estabilidade proporcionada pela massa da manopla e pelas estratégias de controle utilizadas na geração de velocidade e na manutenção da precisão.

Um aspecto positivo para a manutenção da precisão, com a manipulação da inércia, é a maior estabilidade de movimento proporcionada pelo aumento da massa na manopla. Mesmo que o acréscimo na massa da manopla proporcione aumento na resistência para iniciar o movimento, os níveis de força necessários para vencer esta força inercial para fora da trajetória desejada durante o movimento (erro perpendicular à direção do alvo remoto) deveriam ter magnitudes ainda maiores que em condições com manoplas mais leves. Este aumento na massa da manopla também reduziu a magnitude da velocidade, a velocidade no instante de contato e a magnitude da aceleração. Estes resultados pareceram estar em congruência com o princípio muscular da relação inversa entre a geração de força e de velocidade (Fenn \& Marsh, 1935; Hill, 1938; Patterson \& Moreno, 1990). Assim, o sistema aumentou a produção de força para vencer a resistência do aumento da inércia da manopla, mas teve o detrimento na geração de velocidade e de aceleração no movimento. Contudo, esta troca entre a produção de força e a geração de velocidade não resultou em menor precisão no movimento. Uma compensação entre a maior variabilidade que resultaria desta produção de força e a redução nesta variabilidade por meio da menor 
geração de velocidade foi sugerida para auxiliar no controle da precisão do movimento. Estes resultados estão em consonância com o estudo de Khan e colaboradores (1999) que verificaram a redução na velocidade (do impulso inicial) e da variabilidade de resposta em função do aumento na carga inercial, sugerindo maior estabilidade para o movimento. Em função desta esperada redução na velocidade do movimento com o acréscimo na massa da manopla, foi levantada a hipótese (H22) de que maiores tempo de movimento, tempo para contato e tempo após contato, ocorreriam com o acréscimo na massa da manopla. Todavia, apenas foi verificado efeito da massa da manopla sobre o tempo após contato, com maior tempo na manopla de $600 \mathrm{~g}$ em comparação com a de $300 \mathrm{~g}$. Por conseguinte, a manipulação da inércia não demonstrou efeito sobre a maioria das condições e das variáveis temporais lineares da manopla. Esta consistência na estrutura temporal do movimento refutou a hipótese $\mathrm{H} 22$ e foi sugerida como estratégia utilizada para $\mathrm{O}$ controle da precisão através da regulação do tempo da maior velocidade e das fases de aceleração e de desaceleração no movimento.

Uma estratégia sugerida para o controle da geração de velocidade e a manutenção da precisão é a regulação entre o tempo do maior valor de velocidade $\mathrm{e}$ o instante determinante no desempenho (Elliott et al., 1989; Okazaki, 2006; Okazaki et al., 2006; Teixeira, 1999), pois no instante em que ocorre o maior valor de velocidade a variabilidade do movimento seria reduzida em função da menor geração de aceleração (Schmidt et al., 1978, 1979). Desta forma, mesmo com a grande magnitude de aceleração gerada no movimento (entre 52,69 e $65,56 \mathrm{~m} / \mathrm{s}^{2}$ ), a aceleração no instante de contato manopla disco foi reduzida $\left(\sim 9 \mathrm{~m} / \mathrm{s}^{2}\right)$. Tal estratégia de controle foi sugerida (hipótese H23) e aceita, para auxiliar a explicar a produção de um movimento rápido e preciso. Esta estratégia também foi sugerida para auxiliar o controle da precisão no movimento de tarefas como o arremesso no basquetebol (Okazaki et al., 2006; Okazaki \& Rodacki, 2005), o chute do futebol (Teixeira, 1999), a rebatida do saque no tênis (Elliott et al., 1999) e a rebatida (Caljouw et al., 2005). A consistência na estrutura temporal do movimento aponta esta mesma estratégia de controle entre as diferentes condições de massa na manopla, além da manutenção na proporção entre as fases de aceleração e de desaceleração. 
Foi sugerido que a regulação da troca velocidade-precisão no movimento poderia ser realizada por meio da proporção entre as fases de aceleração e de desaceleração (Mackenzie et al., 1987; Teixeira, 2000). Quando grande velocidade fosse requisitada, haveria aumento na fase de aceleração do movimento. Ao passo que, o aumento na precisão demandaria maior fase de desaceleração. Como o acréscimo na massa da manopla necessita de maior força para vencer a maior inércia da manopla, foi levantada a hipótese $(\mathrm{H} 24)$ de que as maiores cargas inerciais exigiram maior tempo para acelerar o movimento. Este aumento, contudo, não foi verificado na fase de aceleração do movimento com o acréscimo na massa da manopla, refutando, assim, a hipótese H24. Desta forma, foi sugerido que o sistema adotou a estratégia de manter a proporção entre as fases de aceleração e de desaceleração no movimento para garantir a precisão no movimento entre as diferentes condições analisadas. Esta estratégia está em consonância com o modelo de deslizamento da aceleração de Zelaznik (1993). Segundo este modelo, a relação velocidade-precisão apenas seria modificada se houvesse alteração no instante em que as forças de aceleração-desaceleração (fases do movimento) fossem alteradas. Como a estrutura temporal foi mantida praticamente sem alterações com o acréscimo na massa da manopla, não foi modificada a precisão entre as condições analisadas. Desta forma, esta manutenção na proporção entre as fases de aceleração e de desaceleração pode ter auxiliado na manutenção da precisão, mesmo com o aumento na massa da manopla.

\subsubsection{Variáveis angulares de desempenho (manopla)}

A organização espaço-temporal das articulações do ombro, do cotovelo e do punho resulta no comportamento linear da manopla. Desta forma, as estratégias utilizadas na regulação do movimento de cada articulação também auxiliaram no entendimento das estratégias de controle no movimento. $O$ aumento na massa da manopla resultou em diversas modificações nas variáveis angulares do ombro, do cotovelo e do punho. Houve aumento no ângulo do cotovelo no instante de contato manopla-disco. A diminuição na magnitude da velocidade linear foi decorrente da redução na velocidade angular do cotovelo e do punho, enquanto a menor 
velocidade no instante de contato manopla-disco ocorreu, principalmente, através da redução na velocidade angular do cotovelo. A maior aceleração linear diminuiu, principalmente, em função da redução na aceleração da articulação do cotovelo. Entretanto, a aceleração linear no contato manopla-disco e o tempo da maior velocidade linear permaneceram sem efeito da massa da manopla, em função da diminuição na aceleração angular no contato do ombro e do cotovelo, e da redução no tempo da maior aceleração angular do punho, respectivamente. Também, não houve efeito da massa da manopla sobre as fases de aceleração e de desaceleração das articulações. Estes resultados reforçam a idéia da estratégia de precisão adotada através da manutenção da proporção nas fases de aceleração e de desaceleração, em função da massa da manopla. Assim, foi refutada a hipótese H25 que previu aumentos na fase de aceleração em função do aumento na massa da manopla.

\subsection{Conclusão}

O aumento na massa da manopla não demonstrou modificar o erro e a variabilidade do movimento. Contudo, foi verificada menor aceleração, velocidade e velocidade no instante de contato manopla-disco com o acréscimo na massa da manopla. Foi sugerido que o sistema aproveitou a maior estabilidade proporcionada pelo aumento na massa da manopla, manteve a estrutura temporal do movimento para sincronizar o instante de menor aceleração com o tempo de contato manopladisco, e para garantir a proporção entre as fases de aceleração e de desaceleração no movimento. 
9.1 Introdução

Um dos fenômenos mais consistentes e investigados em comportamento motor é a relação inversa entre a geração de velocidade e a manutenção da precisão (Bootsma et al., 2004; Elliott et al., 2004; Teixeira, 2006). Esta relação estabelece que quando há necessidade de maior precisão para desempenhar um movimento direcionado a um alvo, há uma redução na velocidade de movimento. Por outro lado, quando se deseja obter maior velocidade, há detrimento na precisão do movimento (Fitts, 1954; Woodworth, 1899). A explicação para esta relação inversa foi realizada com base na diminuição do tempo para a utilização do feedback para regular o movimento (Beggs \& Howart, 1970, 1972a; Crossman \& Goodeve, 1963/1983; Meyer et al., 1982), na maior produção de ruído quando a velocidade é aumentada (Meyer et al., 1988; Schmidt et al., 1978, 1979), na diminuição da fase de desaceleração quando a velocidade é aumentada (modulação entre as fases de aceleração e de desaceleração; Zelaznik, 1993), na capacidade limitada de processar informações (Fitts, 1954; Fitts \& Petersen, 1964), e na característica inata do sistema que emerge nas respostas da musculaturas agonistas e antagonistas (Plamondon, 1995; Plamondon \& Alimi, 1997). Esta relação inversa foi analisada com diferentes grupos musculares, como: extensão de cotovelo (Kerr \& Langolf, 1977; Khan et al., 1999), flexão de cotovelo (Corcos et al., 1988), rotação de punho (Write \& Meyer, 1983), movimento dos pés (Hoffman, 1991), movimento da cabeça (Andres \& Hartung, 1989); também com diferentes tipos de tarefas, como: toques sucessivos (Fitts \& Petersen, 1964), transferência de objetos (Fitts, 1954), arremessos de dardo (Kerr \& Langol, 1977), movimentos com mouse (Okazaki et al., 2008b; Pereira \& Okazaki, 2008); e, com diferentes populações, como: crianças (Jones, 1991), adolescentes (Wallace et al., 1978), adultos (Okazaki et al., 2008b), idosos (Welford, 1969). Entretanto, ainda não é conhecido o efeito das forças de impacto no movimento sobre as estratégias de controle na geração de velocidade e na manutenção da precisão no movimento. 
Estudos prévios, em tarefas de contatar dois alvos espaciais, sugerem a estratégia de organização no movimento que explora o impacto com o alvo como um mecanismo passivo de controle para desacelerar o movimento (Adam et al., 1997; Biegstraaten et al., 2003; Guiard, 1997). Esta estratégia permite que maior geração de velocidade e de força, além de maiores fases de aceleração, ocorra antes do instante determinante do desempenho, pois as forças resultantes do impacto auxiliam na desaceleração do movimento (Adam et al., 1997). Outros estudos que analisaram movimentos como o movimento de rebatida (Caljow et al., 2005) e o movimento de saque no tênis (Elliott et al., 1989) têm corroborado essa proposição. Caljouw e colaboradores (2005) sugeriram que o desempenho na rebatida foi determinado por duas variáveis que restringiram o controle do movimento, uma temporal (percepção-ação) e outra do impacto (movimento). Elliott, Marsh e Overheu (1989) verificaram no saque do tênis uma antecipação do maior valor de velocidade em relação ao contato raquete-bola, devido à preparação do sistema para o impacto eminente. Por conseguinte, o impacto também demonstrou ser fonte de restrição atuante no sistema. Entretanto, há poucos estudos que analisaram o efeito do impacto sobre o controle de movimentos. Ademais, como a maior variabilidade espacial de resposta está associada ao aumento na velocidade (Meyer et al., 1982; 1988; Schmidt et al., 1978, 1979), proporcionada em situações com maiores forças de impacto para desacelerar o movimento (Adam et al., 1997; Biegstraaten et al., 2003), temos características opostas ocorrendo concomitantemente, as quais deverão ser reguladas e compensadas pelo sistema. Dessa forma, torna-se importante conhecer o efeito do impacto sobre as estratégias de controle no movimento. Além disso, pouca atenção foi voltada para a análise de tarefas complexas (bidimensionais, multi-articulares, com mais de uma fonte de restrição espacial, etc.) que possuem o impacto como fonte de restrição.

Algumas tarefas complexas, na qual um objeto deve ser contatado por outro para ser lançado em direção a um alvo, não demonstraram obedecer estritamente a relação inversa velocidade-precisão (Okazaki et al., 2006; Teixeira, 1999; Van Den Tillaar \& Ettema, 2006). Por exemplo, Teixeira (1999) demonstrou que a maior demanda na precisão, através da diminuição do tamanho da bola, não demonstrou efeito sobre o chute no futebol. Apenas quando a restrição na demanda 
da precisão foi aumentada, através da diminuição do tamanho do gol, houve redução na velocidade linear do pé no instante de contato com a bola. Contudo, a maior geração de velocidade pode resultar em menor precisão em algumas tarefas complexas (Chow et al., 2003; Kerr \& Langolf, 1977). Por exemplo, Chow e colaboradores (2003) demonstraram que o primeiro saque no tênis, que resulta em maior impacto e geração de velocidade, apresentou maior deslocamento para frente da raquete e maior velocidade (vertical e lateral) da raquete antes do contato raquete-bola. Porém, em função da escassez de estudos com tarefas motoras complexas ainda não é entendido o controle na geração de velocidade e na manutenção da precisão nestas tarefas.

\section{$9.2 \quad$ Objetivo}

Analisar o efeito da massa do disco, na tarefa de contatar um disco com uma manopla em direção a um alvo remoto, sobre as variáveis cinemáticas de resposta e de desempenho no movimento.

\section{$9.3 \quad$ Hipóteses}

H26 O aumento na massa do disco resulta em maiores erro e variabilidade.

H27 O aumento na massa do disco leva a maior geração de velocidade e de aceleração no movimento.

H28 O tempo do maior valor de velocidade é sincronizado com o instante de contato manopla-disco.

H29 Maior fase de aceleração é verificada com o aumento na massa do disco.

H30 Maior fase de aceleração é verificada nas articulações (ombro, cotovelo e punho) com o aumento na massa do disco. 


\subsection{Procedimentos particulares do método}

Foi analisada a tarefa de contatar um disco com uma manopla em direção a um alvo remoto, realizada com máxima velocidade e maior precisão possíveis. Análises cinemáticas do resultado (variáveis lineares do disco) e do desempenho (variáveis angulares das articulações e lineares da manopla) foram realizadas para entender as estratégias de controle motor na geração de velocidade e na manutenção da precisão do movimento.

Foi utilizada uma distância manopla-disco de $32 \mathrm{~cm}$ e uma manopla circular com 7,5 cm de diâmetro e massa de $200 \mathrm{~g}$. Esta manopla foi utilizada para contatar um disco com tamanho de 7,5 cm de diâmetro e massa de 100, 200, 300, 400 e $500 \mathrm{~g}$. O disco era direcionado a um alvo remoto com tamanhos de $10 \mathrm{~cm}$ de comprimento. As demais características do arranjo experimental foram descritas na sessão de métodos.

\section{$9.5 \quad$ Resultados}

9.5.1 Variáveis lineares de resultado (disco) e de desempenho (manopla)

A tabela 25 apresentou a estatística descritiva (média e desvio padrão) e inferencial (análise de variância com medidas repetidas) das variáveis espaciais e temporais de reposta (disco) e desempenho (manopla), em função da massa do disco. $\mathrm{O}$ acréscimo na massa do disco levou à menor precisão, no qual o disco de $100 \mathrm{~g}$ apresentou menor erro angular absoluto em comparação ao disco de $500 \mathrm{~g}$, e o disco $200 \mathrm{~g}$ menor erro angular absoluto comparado aos discos 400 e $500 \mathrm{~g}$. Menor variabilidade também foi verificada em função do aumento na massa do disco, no qual a massa $100 \mathrm{~g}$ apresentou menor variabilidade em relação às massas 200, 300, 400 e $500 \mathrm{~g}$. A amplitude linear da manopla aumentou em função do acréscimo na massa do disco, no qual o disco com massa 200 e $300 \mathrm{~g}$ apresentaram menor amplitude comparado ao disco $400 \mathrm{~g}$. Um aumento na aceleração no instante de contato manopla-disco também foi verificado, em função do acréscimo na massa do disco, com diferenças entre todos os massas de disco. 
TABELA 25 - Média, DP (entre parênteses), $F$ e $p$ para as variáveis de resposta (disco) e de desempenho (manopla), em função da massa do disco.

\begin{tabular}{|c|c|c|c|c|c|c|c|}
\hline \multirow[b]{2}{*}{ Variáveis } & \multicolumn{5}{|c|}{ Massa do disco (g) } & \multicolumn{2}{|c|}{ Estatística } \\
\hline & 100 & 200 & 300 & 400 & 500 & $F_{1,15}$ & $p$ \\
\hline Erro angular absoluto $\left(^{\circ}\right)$ & $\begin{array}{l}2,192 \\
(0,69)^{35}\end{array}$ & $\begin{array}{c}3,230 \\
(1,23)\end{array}$ & $\begin{array}{l}3,856 \\
(1,33)^{1}\end{array}$ & $\begin{array}{c}3,347 \\
(1,57)\end{array}$ & $\begin{array}{l}3,820 \\
(1,66)^{1}\end{array}$ & 4,00 & 0,006 \\
\hline Variabilidade $(\stackrel{\circ}{)})$ & $\begin{array}{c}2,025 \\
(0,55)^{2345}\end{array}$ & $\begin{array}{l}3,032 \\
(1,26)^{1}\end{array}$ & $\begin{array}{l}3,245 \\
(1,10)^{1}\end{array}$ & $\begin{array}{l}3,289 \\
(1,44)^{1}\end{array}$ & $\begin{array}{c}3,465 \\
(1,01)^{1}\end{array}$ & 5,82 & 0,0005 \\
\hline Amplitude de mov. (m) & $\begin{array}{c}0,597 \\
(0,043)\end{array}$ & $\begin{array}{l}0,595 \\
(0,036)\end{array}$ & $\begin{array}{l}0,595 \\
(0,030)^{4}\end{array}$ & $\begin{array}{c}0,609 \\
(0,041)^{23}\end{array}$ & $\begin{array}{l}0,597 \\
(0,042)\end{array}$ & 2,91 & 0,028 \\
\hline Maior velocidade $(\mathrm{m} / \mathrm{s})$ & $\begin{array}{l}5,14 \\
(0,44)\end{array}$ & $\begin{array}{l}5,18 \\
(0,44)\end{array}$ & $\begin{array}{l}5,12 \\
(0,43)\end{array}$ & $\begin{array}{l}5,15 \\
(0,53)\end{array}$ & $\begin{array}{l}5,12 \\
(0,56)\end{array}$ & 0,396 & 0,810 \\
\hline Veloc. no contato (m/s) & $\begin{array}{l}5,08 \\
(0,46)\end{array}$ & $\begin{array}{l}5,11 \\
(0,47)\end{array}$ & $\begin{array}{l}5,01 \\
(0,45)\end{array}$ & $\begin{array}{l}5,04 \\
(0,56)\end{array}$ & $\begin{array}{r}4,97 \\
(0,60)\end{array}$ & 1,73 & 0,155 \\
\hline Maior aceleração $\left(\mathrm{m} / \mathrm{s}^{2}\right)$ & $\begin{array}{c}64,62 \\
(8,46)\end{array}$ & $\begin{array}{c}66,22 \\
(7,85)\end{array}$ & $\begin{array}{c}65,40 \\
(8,88)\end{array}$ & $\begin{array}{c}64,55 \\
(9,94)\end{array}$ & $\begin{array}{l}65,24 \\
(10,87)\end{array}$ & 0,68 & 0,604 \\
\hline Acel. no contato $\left(\mathrm{m} / \mathrm{s}^{2}\right)$ & $\begin{array}{l}-11,26 \\
(8,33)\end{array}$ & $\begin{array}{l}-17,08 \\
(7,23)\end{array}$ & $\begin{array}{l}-21,41 \\
(7,30)\end{array}$ & $\begin{array}{l}-22,30 \\
(8,85)^{1235}\end{array}$ & $\begin{array}{l}-27,93 \\
(7,56)^{1234}\end{array}$ & 44,46 & 0,0001 \\
\hline Tempo de movimento (s) & $\begin{array}{l}0,214 \\
(0,026)\end{array}$ & $\begin{array}{l}0,219 \\
(0,040)^{4}\end{array}$ & $\begin{array}{c}0,233 \\
(0,041)\end{array}$ & $\begin{array}{c}0,244 \\
(0,047)\end{array}$ & $\begin{array}{l}0,241 \\
(0,034)\end{array}$ & 4,43 & 0,003 \\
\hline Tempo para contato (s) & $\begin{array}{c}0,128 \\
(0,023)\end{array}$ & $\begin{array}{l}0,125 \\
(0,022)\end{array}$ & $\begin{array}{c}0,129 \\
(0,017)\end{array}$ & $\begin{array}{c}0,132 \\
(0,029)\end{array}$ & $\begin{array}{l}0,135 \\
(0,023)\end{array}$ & 1,80 & 0,139 \\
\hline Tempo após contato (s) & $\begin{array}{l}0,084 \\
(0,012)\end{array}$ & $\begin{array}{l}0,095 \\
(0,032)\end{array}$ & $\begin{array}{l}0,103 \\
(0,037)\end{array}$ & $\begin{array}{l}0,110 \\
(0,037)^{1}\end{array}$ & $\begin{array}{c}0,102 \\
(0,017)\end{array}$ & 3,91 & 0,0068 \\
\hline Tempo da maior veloc. (s) & $\begin{array}{c}0,122 \\
(0,025)\end{array}$ & $\begin{array}{l}0,118 \\
(0,024)\end{array}$ & $\begin{array}{l}0,120 \\
(0,018)\end{array}$ & $\begin{array}{c}0,124 \\
(0,031)\end{array}$ & $\begin{array}{c}0,124 \\
(0,025)\end{array}$ & 0,791 & 0,535 \\
\hline $\begin{array}{l}\text { Tempo para contato menos } \\
\text { tempo da maior veloc. (s) }\end{array}$ & $\begin{array}{c}0,005 \\
(0,004)^{2345}\end{array}$ & $\begin{array}{l}0,007 \\
(0,003)^{15}\end{array}$ & $\begin{array}{l}0,008 \\
(0,003)^{15}\end{array}$ & $\begin{array}{c}0,009 \\
(0,004)\end{array}$ & $\begin{array}{c}0,010 \\
(0,004)^{1234}\end{array}$ & 21,58 & 0,0001 \\
\hline Tempo da maior acel. (s) & $\begin{array}{l}0,067 \\
(0,027)\end{array}$ & $\begin{array}{l}0,065 \\
(0,027)\end{array}$ & $\begin{array}{l}0,069 \\
(0,019)\end{array}$ & $\begin{array}{c}0,074 \\
(0,034)\end{array}$ & $\begin{array}{l}0,074 \\
(0,028)\end{array}$ & 1,49 & 0,214 \\
\hline Fase de aceleração (\%) & $\begin{array}{l}56,78 \\
(5,96)^{345}\end{array}$ & $\begin{array}{c}54,54 \\
(9,18)\end{array}$ & $\begin{array}{l}52,05 \\
(7,66)\end{array}$ & $\begin{array}{l}51,11 \\
(8,49)\end{array}$ & $\begin{array}{l}51,38 \\
(5,26)\end{array}$ & 5,87 & 0,0004 \\
\hline Fase de desaceleração (\%) & $\begin{array}{l}43,22 \\
(5,96)^{345}\end{array}$ & $\begin{array}{c}45,46 \\
(9,18)\end{array}$ & $\begin{array}{c}47,95 \\
(7,66)^{1}\end{array}$ & $\begin{array}{c}48,89 \\
(8,49)^{1}\end{array}$ & $\begin{array}{c}48,62 \\
(5,26)^{1}\end{array}$ & 5,87 & 0,0004 \\
\hline
\end{tabular}

Diferente de ${ }^{1} 100 \mathrm{~g},{ }^{2} 200 \mathrm{~g},{ }^{3} 300 \mathrm{~g},{ }^{4} 400 \mathrm{~g} \mathrm{e}{ }^{5} 500 \mathrm{~g}$. 
Houve um aumento no tempo de movimento em função do acréscimo na massa do disco, no qual o disco $400 \mathrm{~g}$ apresentou maior tempo em relação ao disco 100 e 200 g; e o disco 500 g apresentou maior tempo em relação ao disco 100 g. O tempo após contato manopla-disco também aumentou em função do acréscimo na massa do disco, com diferença entre o disco $100 \mathrm{~g}$ e o disco $400 \mathrm{~g}$. O acréscimo na massa do disco aumentou a magnitude da diferença entre o tempo para o contato manopla-disco e para a maior velocidade da manopla, este aumento foi verificado entre o disco $100 \mathrm{~g}$ em comparação aos discos 200, 300, 400 e $500 \mathrm{~g}$, e entre o disco de $500 \mathrm{~g}$ em comparação aos 100, 200, 300 e $400 \mathrm{~g}$.

\subsubsection{Variáveis angulares de desempenho (articulações)}

A tabela 26 e a tabela 27 apresentaram, respectivamente, as variáveis espaciais e temporais da análise estatística (descritiva e inferencial), em função da massa do disco. O acréscimo na massa do disco levou à maior ângulo do punho, no instante de contato manopla-disco, no disco 200 g em comparação ao disco 500 e 600 g. A massa do disco também apresentou efeito sobre a maior velocidade gerada no cotovelo; no qual, o disco $100 \mathrm{~g}$ apresentou maior velocidade em comparação ao disco 300, 400 e $500 \mathrm{~g}$, e o disco $600 \mathrm{~g}$ demonstrou menor velocidade em comparação ao disco 100, 200 e 300 g. Também houve menor velocidade no instante de contato manopla-disco no ombro e no cotovelo. Na qual, a velocidade do ombro no contato no disco $100 \mathrm{~g}$ foi maior que no disco 400 e $500 \mathrm{~g}$, e no disco 200 $\mathrm{g}$ foi maior que no disco $400 \mathrm{~g}$. Enquanto, o cotovelo no instante de contato apresentou no disco $100 \mathrm{~g}$ maior velocidade em comparação ao disco 300, 400 e 500 g; e no disco $600 \mathrm{~g}$ apresentou menor velocidade em relação ao disco 100, 200 e $300 \mathrm{~g}$.

A magnitude da aceleração do cotovelo diminuiu em função do acréscimo na massa do disco. No qual, a magnitude da aceleração no cotovelo foi menor nos discos 600 e 500 g, em comparação aos discos 100, 200 e 300 g. A magnitude da aceleração do punho apresentou aumento do disco $300 \mathrm{~g}$ em relação ao disco $400 \mathrm{~g}$. Entretanto, a magnitude da aceleração no punho, durante o instante de contato manopla-disco, aumentou em função acréscimo na massa do disco. No instante de 
contato manopla-disco, o disco $500 \mathrm{~g}$ apresentou maior aceleração em comparação ao disco 100, 200 e 300 g; enquanto, o disco 400 g apresentou maior aceleração em relação ao disco 100 e $200 \mathrm{~g}$. Houve um atraso no tempo da maior velocidade e no tempo da maior aceleração do ombro, em função do acréscimo na massa do disco. No qual, os discos 500 e $600 \mathrm{~g}$ apresentaram atraso na maior velocidade e aceleração em comparação ao disco $100 \mathrm{~g}$. 
TABELA 26 - Média, DP (entre parênteses), $F$ e $p$ para as variáveis angulares espaciais de desempenho (articulações), em função da massa do disco.

\begin{tabular}{|c|c|c|c|c|c|c|c|c|}
\hline \multirow[b]{2}{*}{ Variável } & \multirow[b]{2}{*}{ Artic. } & \multicolumn{5}{|c|}{ Massa do disco (g) } & \multicolumn{2}{|c|}{ Estatística } \\
\hline & & 100 & 200 & 300 & 400 & 500 & $F_{1,15}$ & $p$ \\
\hline \multirow{3}{*}{ 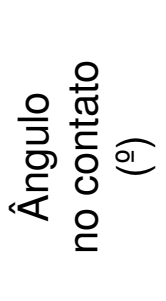 } & Ombro & $\begin{array}{c}125,59 \\
(6,48)\end{array}$ & $\begin{array}{c}126,36 \\
(7,62)\end{array}$ & $\begin{array}{c}125,32 \\
(7,30)\end{array}$ & $\begin{array}{c}126,94 \\
(6,61)\end{array}$ & $\begin{array}{c}126,62 \\
(7,19)\end{array}$ & 2,53 & 0,051 \\
\hline & Cotovelo & $\begin{array}{c}113,73 \\
(8,86)\end{array}$ & $\begin{array}{c}112,55 \\
(9,72)\end{array}$ & $\begin{array}{c}113,50 \\
(9,22)\end{array}$ & $\begin{array}{c}112,31 \\
(9,31)\end{array}$ & $\begin{array}{c}112,39 \\
(10,84)\end{array}$ & 1,37 & 0,253 \\
\hline & Punho & $\begin{array}{c}182,44 \\
(14,20)\end{array}$ & $\begin{array}{l}180,58 \\
(15,26)\end{array}$ & $\begin{array}{c}183,68 \\
(13,92)\end{array}$ & $\begin{array}{c}185,07 \\
(15,19)^{2} \\
\end{array}$ & $\begin{array}{c}185,99 \\
(15,68)^{2}\end{array}$ & 5,01 & 0,001 \\
\hline \multirow{3}{*}{  } & Ombro & $\begin{array}{c}17,66 \\
(4,45)\end{array}$ & $\begin{array}{c}18,36 \\
(4,62)\end{array}$ & $\begin{array}{c}17,55 \\
(3,57)\end{array}$ & $\begin{array}{c}17,83 \\
(5,38)\end{array}$ & $\begin{array}{c}18,20 \\
(5,02)\end{array}$ & 0,60 & 0,664 \\
\hline & Cotovelo & $\begin{array}{c}105,68 \\
(8,83)\end{array}$ & $\begin{array}{c}105,31 \\
(7,96)\end{array}$ & $\begin{array}{c}105,54 \\
(7,81)\end{array}$ & $\begin{array}{c}106,69 \\
(8,73)\end{array}$ & $\begin{array}{c}106,26 \\
(9,07)\end{array}$ & 0,85 & 0,498 \\
\hline & Punho & $\begin{array}{c}14,42 \\
(8,10) \\
\end{array}$ & $\begin{array}{c}15,78 \\
(8,53) \\
\end{array}$ & $\begin{array}{c}15,65 \\
(8,25) \\
\end{array}$ & $\begin{array}{c}16,90 \\
(7,31) \\
\end{array}$ & $\begin{array}{c}16,74 \\
(6,49) \\
\end{array}$ & 1,97 & 0,110 \\
\hline \multirow{3}{*}{ 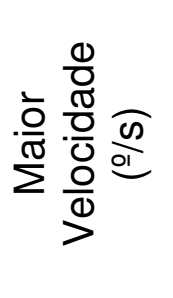 } & Ombro & $\begin{array}{c}152,13 \\
(33,67)\end{array}$ & $\begin{array}{c}152,92 \\
(32,14)\end{array}$ & $\begin{array}{c}148,01 \\
(27,19)\end{array}$ & $\begin{array}{c}146,31 \\
(36,98)\end{array}$ & $\begin{array}{c}146,93 \\
(34,59)\end{array}$ & 0,72 & 0,581 \\
\hline & Cotovelo & $\begin{array}{l}762,12 \\
(51,42)\end{array}$ & $\begin{array}{l}751,45 \\
(42,98) 45\end{array}$ & $\begin{array}{l}736,58 \\
(43,38)\end{array}$ & $\begin{array}{l}722,22 \\
(54,23)\end{array}$ & $\begin{array}{l}714,23 \\
(56,14)^{123}\end{array}$ & 17,32 & 0,0001 \\
\hline & Punho & $\begin{array}{c}128,23 \\
(72,87)\end{array}$ & $\begin{array}{c}134,91 \\
(64,66)\end{array}$ & $\begin{array}{c}139,02 \\
(69,32)\end{array}$ & $\begin{array}{c}143,36 \\
(66,70)\end{array}$ & $\begin{array}{c}149,34 \\
(65,61)\end{array}$ & 1,77 & 0,145 \\
\hline \multirow{3}{*}{  } & Ombro & $\begin{array}{l}131,83 \\
(38,23) 45\end{array}$ & $\begin{array}{c}126,40 \\
(37,70)^{4}\end{array}$ & $\begin{array}{c}122,20 \\
(30,93)\end{array}$ & $\begin{array}{l}109,80 \\
(43,01)^{12}\end{array}$ & $\begin{array}{c}114,54 \\
(41,17)^{1}\end{array}$ & 4,80 & 0,001 \\
\hline & Cotovelo & $\begin{array}{l}755,81 \\
(49,80)^{345}\end{array}$ & $\begin{array}{l}745,07 \\
(42,21)\end{array}$ & $\begin{array}{l}731,46 \\
(42,79)\end{array}$ & $\begin{array}{l}713,02 \\
(54,75)\end{array}$ & $\begin{array}{l}708,82 \\
(55,98)\end{array}$ & 16,29 & 0,0001 \\
\hline & Punho & $\begin{array}{r}62,54 \\
(72,37) \\
\end{array}$ & $\begin{array}{r}89,38 \\
(75,82) \\
\end{array}$ & $\begin{array}{c}80,88 \\
(75,74) \\
\end{array}$ & $\begin{array}{r}87,11 \\
(87,77) \\
\end{array}$ & $\begin{array}{r}89,37 \\
(66,23) \\
\end{array}$ & 2,04 & 0,099 \\
\hline \multirow{3}{*}{ 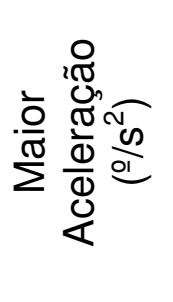 } & Ombro & $\begin{array}{c}2513,42 \\
(639,88)\end{array}$ & $\begin{array}{c}2572,54 \\
(559,92)\end{array}$ & $\begin{array}{c}2469,74 \\
(546,19)\end{array}$ & $\begin{array}{c}2441,71 \\
(497,59)\end{array}$ & $\begin{array}{c}2389,91 \\
(577,35)\end{array}$ & 1,26 & 0,294 \\
\hline & Cotovelo & $\begin{array}{l}7881,83 \\
(875,72)^{345}\end{array}$ & $\begin{array}{c}7837,22 \\
(794,77)\end{array}$ & $\begin{array}{l}7573,33 \\
(902,17)\end{array}$ & $\begin{array}{l}7239,08 \\
(970,88)\end{array}$ & $\begin{array}{l}7268,99 \\
(930,78)^{123}\end{array}$ & 19,84 & 0,0001 \\
\hline & Punho & $\begin{array}{c}1657,50 \\
(630,95) \\
\end{array}$ & $\begin{array}{c}1642,69 \\
(975,51) \\
\end{array}$ & $\begin{array}{c}1566,60 \\
(745,73)^{4} \\
\end{array}$ & $\begin{array}{c}1988,93 \\
(646,29)^{3} \\
\end{array}$ & $\begin{array}{c}1856,83 \\
(716,27) \\
\end{array}$ & 3,44 & 0,013 \\
\hline \multirow{3}{*}{  } & Ombro & $\begin{array}{c}1433,51 \\
(722,13)\end{array}$ & $\begin{array}{c}1559,56 \\
(909,39)\end{array}$ & $\begin{array}{c}1549,57 \\
(839,89)\end{array}$ & $\begin{array}{c}1678,31 \\
(887,22)\end{array}$ & $\begin{array}{c}1627,18 \\
(935,48)\end{array}$ & 2,05 & 0,098 \\
\hline & Cotovelo & $\begin{array}{c}1186,15 \\
(920,05)\end{array}$ & $\begin{array}{c}1154,26 \\
(988,17)\end{array}$ & $\begin{array}{c}1033,45 \\
(766,74)\end{array}$ & $\begin{array}{c}1229,71 \\
(930,66)\end{array}$ & $\begin{array}{c}940,31 \\
(893,49)\end{array}$ & 1,43 & 0,234 \\
\hline & Punho & $\begin{array}{l}-1401,67 \\
(1250,30)\end{array}$ & $\begin{array}{l}-1347,70 \\
(1163,40)\end{array}$ & $\begin{array}{c}-1664,60 \\
(1186,50)^{5}\end{array}$ & $\begin{array}{c}-1890,14 \\
(1029,16)^{12}\end{array}$ & $\begin{array}{l}-2166,20 \\
(1008,20)^{123}\end{array}$ & 7,77 & 0,0001 \\
\hline
\end{tabular}

Diferente de ${ }^{1} 100 \mathrm{~g},{ }^{2} 200 \mathrm{~g},{ }^{3} 300 \mathrm{~g},{ }^{4} 400 \mathrm{~g} \mathrm{e}{ }^{5} 500 \mathrm{~g}$. 
TABELA 27 - Média, DP (entre parênteses), $F$ e $p$ para as variáveis angulares espaciais de desempenho (articulações), em função da massa do disco.

\begin{tabular}{|c|c|c|c|c|c|c|c|c|}
\hline \multirow[b]{2}{*}{ Variável } & \multirow[b]{2}{*}{ Artic. } & \multicolumn{5}{|c|}{ Massa do disco (g) } & \multicolumn{2}{|c|}{ Estatística } \\
\hline & & 100 & 200 & 300 & 400 & 500 & $F_{1,15}$ & $p$ \\
\hline \multirow{3}{*}{  } & Ombro & $\begin{array}{l}0,151 \\
(0,025)\end{array}$ & $\begin{array}{c}0,148 \\
(0,023)^{45}\end{array}$ & $\begin{array}{c}0,153 \\
(0,020)\end{array}$ & $\begin{array}{l}0,162 \\
(0,032)^{2}\end{array}$ & $\begin{array}{l}0,162 \\
(0,024)^{2}\end{array}$ & 3,94 & 0,006 \\
\hline & Cotovelo & $\begin{array}{l}0,134 \\
(0,024)\end{array}$ & $\begin{array}{l}0,131 \\
(0,022)\end{array}$ & $\begin{array}{c}0,134 \\
(0,018)\end{array}$ & $\begin{array}{l}0,140 \\
(0,030)\end{array}$ & $\begin{array}{l}0,140 \\
(0,025)\end{array}$ & 1,98 & 0,108 \\
\hline & Punho & $\begin{array}{l}0,071 \\
(0,070)\end{array}$ & $\begin{array}{c}0,079 \\
(0,062)\end{array}$ & $\begin{array}{c}0,092 \\
(0,072)\end{array}$ & $\begin{array}{l}0,091 \\
(0,052)\end{array}$ & $\begin{array}{l}0,092 \\
(0,053)\end{array}$ & 0,64 & 0,632 \\
\hline \multirow{3}{*}{ 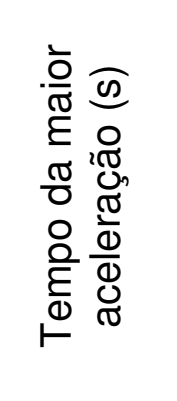 } & Ombro & $\begin{array}{c}0,100 \\
(0,032)\end{array}$ & $\begin{array}{c}0,097 \\
(0,032)\end{array}$ & $\begin{array}{c}0,103 \\
(0,030)\end{array}$ & $\begin{array}{l}0,112 \\
(0,039)^{2}\end{array}$ & $\begin{array}{l}0,117 \\
(0,043)^{2}\end{array}$ & 3,56 & 0,011 \\
\hline & Cotovelo & $\begin{array}{l}0,066 \\
(0,023)\end{array}$ & $\begin{array}{c}0,062 \\
(0,022)\end{array}$ & $\begin{array}{l}0,064 \\
(0,017)\end{array}$ & $\begin{array}{l}0,068 \\
(0,029)\end{array}$ & $\begin{array}{l}0,069 \\
(0,023)\end{array}$ & 0,90 & 0,467 \\
\hline & Punho & $\begin{array}{l}0,160 \\
(0,088)\end{array}$ & $\begin{array}{c}0,145 \\
(0,094)\end{array}$ & $\begin{array}{c}0,163 \\
(0,084)\end{array}$ & $\begin{array}{l}0,175 \\
(0,090)\end{array}$ & $\begin{array}{l}0,186 \\
(0,087)\end{array}$ & 0,94 & 0,446 \\
\hline \multirow{3}{*}{ 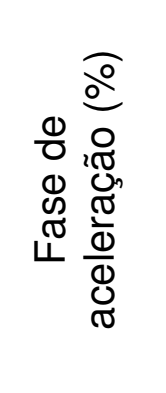 } & Ombro & $\begin{array}{c}70,17 \\
(7,13)\end{array}$ & $\begin{array}{c}68,84 \\
(10,11)\end{array}$ & $\begin{array}{c}66,85 \\
(10,55)\end{array}$ & $\begin{array}{c}67,08 \\
(12,14)\end{array}$ & $\begin{array}{c}67,81 \\
(9,51)\end{array}$ & 1,10 & 0,366 \\
\hline & Cotovelo & $\begin{array}{c}62,18 \\
(5,13)\end{array}$ & $\begin{array}{c}60,36 \\
(8,07)\end{array}$ & $\begin{array}{c}58,37 \\
(7,30)\end{array}$ & $\begin{array}{c}57,90 \\
(8,30)\end{array}$ & $\begin{array}{c}58,23 \\
(4,93)\end{array}$ & 2,85 & 0,031 \\
\hline & Punho & $\begin{array}{l}33,81 \\
(34,09)\end{array}$ & $\begin{array}{r}36,57 \\
(26,11)\end{array}$ & $\begin{array}{c}40,18 \\
(29,93)\end{array}$ & $\begin{array}{c}36,86 \\
(19,36)\end{array}$ & $\begin{array}{c}38,22 \\
(15,54)\end{array}$ & 0,240 & 0,914 \\
\hline \multirow{3}{*}{ 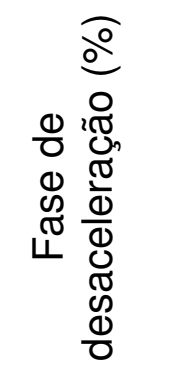 } & Ombro & $\begin{array}{c}29,83 \\
(7,13)\end{array}$ & $\begin{array}{c}31,16 \\
(10,11)\end{array}$ & $\begin{array}{c}33,15 \\
(10,55)\end{array}$ & $\begin{array}{c}32,92 \\
(12,14)\end{array}$ & $\begin{array}{c}32,19 \\
(9,51)\end{array}$ & 1,10 & 0,366 \\
\hline & Cotovelo & $\begin{array}{c}37,82 \\
(5,13)\end{array}$ & $\begin{array}{c}39,64 \\
(8,07)\end{array}$ & $\begin{array}{c}41,63 \\
(7,30)\end{array}$ & $\begin{array}{c}42,10 \\
(8,30)\end{array}$ & $\begin{array}{c}41,77 \\
(4,93)\end{array}$ & 2,85 & 0,031 \\
\hline & Punho & $\begin{array}{c}66,19 \\
(34,09)\end{array}$ & $\begin{array}{c}63,43 \\
(26,11)\end{array}$ & $\begin{array}{r}59,82 \\
(29,93)\end{array}$ & $\begin{array}{c}63,14 \\
(19,36)\end{array}$ & $\begin{array}{l}61,78 \\
(15,54)\end{array}$ & 0,240 & 0,914 \\
\hline
\end{tabular}

Diferente de $100 \mathrm{~g}^{2}{ }^{2} 200 \mathrm{~g},{ }^{3} 300 \mathrm{~g},{ }^{4} 400 \mathrm{~g} \mathrm{e}{ }^{5} 500 \mathrm{~g}$. 


\subsection{Discussão}

9.6.1 Variáveis lineares de resultado (disco) e de desempenho (manopla)

O aumento na massa do disco proporciona maior impacto entre a manopla e o disco. Desta forma, maior geração de força seria necessária para lançar o disco em direção ao alvo remoto com a mesma velocidade nas diferentes condições analisadas. Como a geração de força foi relacionada à maior variabilidade de resposta no movimento (Meyer et al., 1982; Schmidt et al., 1978, 1979), foi formulada a hipótese (H26) de que maiores erro e variabilidade seriam verificados nas condições com o aumento na massa dos discos. Entretanto, estudos que analisaram movimentos de toques recíprocos (semelhante à tarefa de Fitts; Adam et al., 1997; Biegstraaten et al., 2003), de rebatida (Caljow et al., 2005) e de saque no tênis (Elliott et al., 1989); sugeriram que o impacto pode atuar como força passiva para desacelerar o movimento. Tal estratégia permitiria maior geração de velocidade e de aceleração no movimento sem comprometer sua precisão. Assim, foi formulada a hipótese (H27) de que o aumento na massa do disco também permitiria maior geração de velocidade e de aceleração no movimento.

Maiores erro e variabilidade foram verificados em função do aumento na massa do disco, o que levou a aceitação da hipótese H26. Contudo, o acréscimo na massa do disco não proporcionou modificações na magnitude da aceleração, na magnitude da velocidade e na velocidade no instante de contato manopla-disco. Apenas foi verificado aumento na magnitude da desaceleração no instante de contato manopla-disco com o acréscimo na massa do disco. Por conseguinte, foi sugerido que a geração de aceleração/variabilidade no movimento pode ser compensada ao longo da cadeia cinemática, no qual a resposta do disco seria apenas influenciada pela aceleração/variabilidade no instante de contato manopladisco. Tais achados refutaram a hipótese $\mathrm{H} 27$ e foram explicados pela estratégia de preparação para o contato iminente adotada no controle do movimento.

O acréscimo na massa do disco demonstrou estratégias de controle diferenciadas daquelas sugeridas e observadas em outros estudos. Ao contrário da estratégia sugerida, através do aproveitamento das forças passivas para desacelerar 
o movimento (Adam et al., 1997; Biegstraaten et al., 2003; Caljow et al., 2005; Elliott et al., 1989; Guiard, 1997), o sistema demonstrou priorizar a preparação para o contato iminente da manopla com o disco. Esta preparação, ao invés de aumentar a velocidade e a aceleração, proporcionou um movimento com maiores magnitudes de desaceleração, no instante de contato manopla-disco, à medida que a massa do disco foi aumentada. Isto foi realizado por meio de maiores tempos de movimento e da maior diferença entre o tempo para o contato e o tempo em que ocorreu a maior velocidade, em função do acréscimo na massa do disco. Desta forma, ao invés do sistema priorizar a precisão, através da sincronização do maior valor de velocidade com o instante de contato manopla-disco (hipótese H28), foi verificada maior magnitude da desaceleração do movimento com o aumento na massa do disco. Por conseguinte, foi refutada a hipótese H28 que previa a estratégia de sincronizar 0 tempo da maior velocidade com o instante de contato manopla-disco, para que menores magnitudes de aceleração ocorressem no instante determinante do desempenho.

Outra estratégia que tem sido sugerida para a manutenção da precisão é o aumento na fase de desaceleração no movimento. Esta estratégia permitiria ao sistema melhor ajuste nas porções finais do movimento (Mackenzie et al., 1987; Teixeira, 2000; Zelaznik, 1993). Segundo Zelaznik (1993), esta regulação do instante de tempo em que as forças de aceleração e de desaceleração ocorrem seria o fator responsável pela relação inversa velocidade-precisão. Quando maior precisão fosse necessária a fase de desaceleração seria aumentada no movimento, ao passo que quando a demanda na geração de velocidade fosse maior no movimento sua fase de aceleração seria aumentada. Como a massa do disco demanda maior geração de força para lançar o disco em direção ao alvo remoto, e o impacto poderia atuar para auxiliar na desaceleração do movimento, foi formulada a hipótese (H29) de que haveria maior fase de aceleração com o aumento na massa do disco. Todavia, os resultados do presente estudo verificaram uma diminuição na fase de aceleração com aumento na fase de desaceleração, em função do acréscimo na massa do disco. Estes resultados refutaram a hipótese $\mathrm{H} 29$ e poderiam sugerir a utilização da estratégia de aumento na fase de desaceleração para aumentar a precisão no movimento. Todavia, mesmo com o aumento na fase de desaceleração, a menor 
precisão e a maior variabilidade encontradas pareceram estar mais relacionadas à idéia de que o sistema priorizou mais a preparação para o contato iminente com o disco do que a estratégia de controle da precisão. Os resultados da análise das ações angulares corroboraram esta explicação e auxiliaram a compreender as estratégias de controle adotadas no movimento, em decorrência da manipulação na massa do disco.

\subsubsection{Variáveis angulares de desempenho (articulações)}

Um fator que pode contribuir para o entendimento da estratégia de controle utilizada no movimento é a análise das ações de cada articulação que participa no movimento. Como o desempenho linear da manopla é resultado da interação das ações das articulações, também foram analisadas as variáveis angulares em função do aumento na massa do disco. Foram verificadas reduções na magnitude da velocidade e da aceleração no cotovelo, na velocidade no instante de contato para o cotovelo e o ombro, além de um aumento na magnitude da desaceleração do punho no instante de contato manopla-disco. Entretanto, não foi verificada modificação na fase de aceleração e de desaceleração das articulações com o aumento na massa do disco (hipótese H30). Estes resultados corroboram com a explicação de que o sistema priorizou a estratégia de enfatizar a preparação do movimento para o contato com o disco ao invés da precisão no movimento. Pois, era esperado que maiores velocidades e acelerações, por meio de maior fase de aceleração, fossem geradas com o aumento na massa do disco para direcioná-lo ao alvo remoto. Por conseguinte, foi refutada a hipótese H30 sugerindo maior fase de aceleração nas articulações (ombro, cotovelo e punho) com o aumento na massa do disco.

\subsection{Conclusão}

O aumento na massa do disco ocasionou em maior erro e variabilidade. Isto pareceu ter ocorrido em função da grande magnitude de desaceleração verificada no instante de contato manopla-disco. Aparentemente, o sistema priorizou 
a estratégia de preparação para o contato iminente da manopla com o disco, em função do aumento na massa do disco. Nesta preparação, houve maiores tempo de movimento e fase de desaceleração, além de menores velocidades no instante de contato para o cotovelo e o ombro, menor magnitude de velocidade e de aceleração no cotovelo, e maior magnitude de desaceleração no punho. 
Este estudo analisou as características cinemáticas de resultado (disco) e de desempenho (manopla e articulações), na tarefa de direcionar um disco a um alvo remoto através de um movimento de contato de potência com uma manopla, para entender as estratégias de controle utilizadas na regulação da relação inversa velocidade-precisão. A tarefa proposta foi analisada em função de diferentes fontes de restrição investigadas independentemente nos experimentos. Assim, cada experimento objetivou analisar o efeito de uma restrição, tal como distância (experimento I), velocidade (experimento II), precisão (tamanho do disco no experimento III, e tamanho do alvo remoto no experimento IV), inércia (massa da manopla no experimento $\mathrm{V}$ ) e impacto (massa do disco no experimento $\mathrm{VI}$ ).

A partir da análise dos resultados nos experimentos, diferentes estratégias de controle para a geração de velocidade e a manutenção da precisão foram sugeridas, em função das restrições utilizadas. Dois índices de dificuldade (ID' e ID") foram propostos e calculados para quantificar a restrição imposta sobre a tarefa e para tentar predizer algumas das variáveis temporais do movimento ( $T M, T_{c}$, e $T_{a}$ ). $A$ associação de alguns parâmetros da velocidade linear da manopla (velocidade média, maior velocidade e velocidade no contato manopla-disco) com a precisão e a variabilidade de resultado do movimento também foi realizada. Por último, foram analisadas as ações angulares das articulações do ombro, do cotovelo e do punho, como ferramenta de auxílio para compreender as estratégias de controle utilizadas na regulação do movimento no paradigma da relação inversa entre a velocidade e a precisão.

10.1 Estratégias de controle motor para regulação velocidade-precisão

As tarefas motoras mais complexas, tal como a tarefa motora utilizada no presente estudo, demonstram estratégias de controle da relação inversa velocidadeprecisão diferenciadas de tarefas mais simples (Chowdhary \& Challis, 2001; Elliott et al., 1989; Okazaki et al., 2006b; Teixeira, 1999). Enquanto que em tarefas motoras mais simples a regulação da velocidade e da precisão pode ser explicada 
unicamente por parâmetros graduados pela magnitude da velocidade ou da aceleração/força (Meyer et al., 1982, 1988; Schmidt et al., 1978, 1979), pela proporção entre as fases de aceleração e de desaceleração (Mackenzie et al., 1987; Van Muelen \& Gooskens, 1990; Zelaznik, 1993), pela capacidade limitada do sistema em processar informações (Fitts, 1954; Fitts \& Pettersen, 1964), pela utilização do feedback sensorial (Crossman \& Goodeve, 1963/1983; Meyer et al., 1982; Woodworth, 1899), ou simplesmente como uma característica particular e própria do sistema que emerge em resposta ao movimento (Plamondon, 1993, 1995a, 1995b; Plamondon \& Alimi, 1997), em tarefas motoras complexas, a regulação velocidadeprecisão pareceu ser realizada pela interação conjunta de diferentes estratégias de controle. Para explicar os resultados dos experimentos foram sugeridas as seguintes estratégias de controle motor: (a) regular os tempos dos maiores valores de velocidade em função do instante de contato manopla-disco, (b) manutenção na fase de aceleração e de desaceleração no movimento, (c) utilizar as forças de inércia para auxiliar na estabilização do movimento, (d) aproveitar as forças de impacto para desacelerar o movimento, e (e) a independência entre a regulação da velocidade e a restrição da precisão no movimento.

A estratégia de manipulação dos maiores valores de velocidade tem sido sugerida em diversas tarefas complexas que demandam de grande rapidez e precisão de desempenho, tais como arremesso no basquetebol (Okazaki, 2006; Okazaki \& Rodacki, 2005; Okazaki et al., 2006b), chute no futebol (Teixeira, 1999), saque no tênis (Elliott et al., 1989) e arremesso estilo beisebol (Teixeira, 2000). Nesta estratégia ocorre uma tentativa de sincronizar o tempo do maior valor de velocidade com o instante crítico/determinante do movimento (contato, rebatida, lançamento, impacto, etc.). A racionalidade para tal formulação está baseada no fato de que no instante em que ocorre a maior velocidade a aceleração é igual a zero. Como a aceleração tem sido diretamente associada à força, e esta última tem sido relacionada à maior variabilidade de resposta, menor variabilidade ocorreria nos instantes próximos ao maior valor de velocidade. Assim, diferente da proposição de Schmidt e colaboradores $(1978,1979)$ e de Meyer e colaboradores (1982, 1988), a variabilidade de resposta no movimento não seria resultante da magnitude gerada no impulso de força/aceleração, mas sim da magnitude gerada da força/aceleração no 
instante determinante do desempenho. Ou seja, tanto o parâmetro da magnitude do impulso, quanto sua regulação temporal, contribuiria concomitantemente no controle de um movimento rápido e preciso. Por meio desta estratégia de controle sugerida também é possível entender como muitos movimentos podem ser extremamente rápidos e precisos, ou lentos e imprecisos, contrariando o paradigma da relação inversa velocidade-precisão. Esta estratégia de controle foi utilizada para explicar os experimentos I, II, IV e V, que verificaram grandes magnitudes de aceleração no movimento, mas com magnitudes reduzidas no instante de contato manopla-disco e com a manutenção na precisão do movimento. Os experimentos III e VI também forneceram suporte para utilizar esta estratégia de controle para explicar os resultados, pois menor precisão foi verificada quando a sincronização entre os maiores valores de velocidade e o instante de contato não ocorreram propriamente, permitindo maiores magnitudes de aceleração (desaceleração) no movimento.

Outra estratégia de controle sugerida para os experimentos realizados foi a regulação entre a fase de aceleração e de desaceleração no movimento. Tem sido proposto que o aumento na fase de aceleração ocorre quando há maior exigência na geração de velocidade do movimento, enquanto maior fase de desaceleração é verificada quando o movimento demanda maior precisão (Teixeira, 2000; Van Muelen \& Gooskens, 1990; Zelaznik, 1993). Esta estratégia de controle é justificada pela maior possibilidade de utilização do feedback sensorial, que seria realizada principalmente na fase de desaceleração do movimento (Teixeira, 2000; Van Muelen \& Gooskens, 1990). Por conseguinte, a maior fase de aceleração para o desenvolvimento da velocidade resulta em menor possibilidade de ajustes na fase de desaceleração do movimento. Contudo, também foi sugerido que esta regulação temporal entre as fases de aceleração e de desaceleração, independentemente da informação do feedback, seria suficiente para regular a relação inversa entre a velocidade e a precisão no movimento (Zelaznik, 1993). Esta estratégia tem sido verificada em tarefas laboratoriais mais simples, analisando o paradigma da relação inversa velocidade-precisão (Mackenzie et al., 1987; Van Muelen \& Gooskens, 1990), e foi utilizada para auxiliar a explicar a manutenção da precisão nos experimentos II e V. Nestes dois experimentos não foram verificadas modificações na precisão e na variabilidade do movimento em função da manipulação da velocidade de movimento 
(experimento II) e da massa da manopla (experimento V), pois houve a manutenção nas proporções entre as fases de aceleração e de desaceleração no movimento. Todavia, os experimentos que manipularam a distância manopla-disco (experimento I) e o tamanho do alvo remoto (experimento IV) verificaram maiores fases de aceleração, mas sem detrimento na precisão do movimento. Por outro lado, a diminuição no tamanho do disco (experimento III) não apresentou modificação nas proporções das fases de aceleração no movimento, mas foi suficiente para reduzir a precisão no movimento. Enquanto, o aumento na massa do disco (experimento $\mathrm{VI}$ ) diminuiu a fase de aceleração, mas não proporcionou vantagens para a precisão do movimento (redução da precisão com o aumento da massa do disco). Por conseguinte, a estratégia de regulação das fases de aceleração e de desaceleração na tarefa analisada, por si só, não demonstrou ser suficiente para explicar a regulação entre a geração de velocidade e a manutenção da precisão na tarefa analisada.

O aproveitamento das forças de inércia também tem sido proposto para aumentar a estabilidade no sistema e, assim, facilitar a regulação da precisão em movimentos rápidos (Khan et al., 1999). Esta estratégia foi sugerida para auxiliar a explicar a manutenção na precisão do movimento, quando a massa da manopla foi aumentada (experimento V). Pois, quando a massa da manopla foi aumentada, houve menores velocidades e acelerações no movimento concomitantemente com a manutenção da precisão. Desta forma, mesmo que o aumento na massa da manopla demande maior geração de força, que poderia resultar em maior variabilidade e menor precisão, a força necessária para desviar a trajetória da manopla para produzir erros também aumentaria. Conseqüentemente, a demanda de força necessária para aumentar o erro no movimento em condições com maiores massas da manopla seria ainda maior que em condições com menores massas. Contudo, o aumento da massa do disco, proporcionando maior impacto manopla-disco, não demonstrou beneficiar a precisão do movimento como o aumento da massa da manopla.

Alguns estudos com tarefas motoras mais simples de tocar em alvos com uma ponteira (Adam et al., 1997; Biegstraaten et al., 2003; Guiard, 1997), e com tarefas motoras mais complexas como o saque no tênis (Elliott et al., 1989) e a 
rebatida (Caljow et al., 2005), têm sugerido que o impacto pode auxiliar na manutenção da precisão do movimento através de um mecanismo passivo de forças que atua para desacelerar o movimento. Esta estratégia permitiria maior fase de aceleração para o desenvolvimento da velocidade, pois as forças do impacto auxiliariam na desaceleração do mesmo. Os resultados do presente estudo, contudo, não corroboram integralmente esta proposição. Quando foi aumentada a massa do disco (experimento VI) para analisar o efeito do impacto sobre o movimento, foi verificada menor precisão e maior variabilidade. Este aumento no impacto levou o sistema a priorizar a estratégia de preparação para o contato iminente entre manopla e disco, ao invés enfatizar o controle da precisão. Ademais, foi verificada uma redução na fase de aceleração quando a massa do disco foi aumentada, ao invés de um aumento como a estratégia do proveito das forças de impacto propõe. Por conseguinte, foi sugerido que magnitudes mais baixas das forças de impacto poderiam auxiliar na estabilidade do movimento para a manutenção da precisão, enquanto o aumento das forças de impacto para grandes magnitudes teria efeito oposto, comprometendo a estabilidade e, conseqüentemente, a precisão.

As características particulares da tarefa utilizada, com a geração de velocidade ocorrendo predominantemente em uma dimensão espacial (eixo x) e a restrição da precisão em outra (eixo y) resultou em outra hipótese para explicar o controle do movimento, a independência entre o componente de velocidade e o de precisão do movimento. Esta hipótese foi fundamentada na premissa de que há uma especificidade (espacial) na qual as restrições ocorreram (dimensão do movimento: $\mathrm{x}$ e y). Desta forma, a restrição que ocorreria sobre a velocidade seria referente apenas à dimensão espacial em que ela foi desempenhada (eixo x, que delimitou a distância manopla-disco, ou a amplitude de movimento). Ao passo que, a restrição da precisão (eixo y) ocorreria em outra dimensão espacial perpendicular à dimensão em que a geração de velocidade foi realizada. Todavia, em situações nas quais as restrições da velocidade e da precisão ocorressem na mesma dimensão espacial, como no caso das tarefas mais simples unidimensionais analisadas no paradigma da relação inversa velocidade-precisão (cf. Fitts, 1954; Okazaki et al., 2008b; Pereira \& Okazaki, 2008), o aumento na geração de velocidade ocorreria em detrimento da precisão. Por outro lado, quando as dimensões espaciais das restrições fossem diferentes (como 
na tarefa analisada no presente estudo), os componentes de velocidade e de precisão poderiam ser regulados independentemente. Esta estratégia foi sugerida para auxiliar a explicar a manutenção da precisão no experimento I, e foi testada no experimento II através da manipulação da velocidade no movimento. Os resultados do experimento II, no entanto, refutaram a possibilidade desta estratégia de controle ter acontecido nos experimentos, pois a precisão do movimento foi mais associada à geração de velocidade no eixo x (manopla-disco) do que no eixo y. Além disso, o movimento linear da manopla foi resultado de ações rotacionais (angulares) das articulações que não permitiu a dissociação entre as dimensões do movimento. Ademais, caso esta estratégia de controle tivesse ocorrido no movimento, possivelmente a precisão do movimento não teria sido comprometida nos experimentos que manipularam o tamanho e a massa do disco. Por conseguinte, estratégias específicas, para cada tarefa ou restrição, pareceram ser utilizadas no controle da geração de velocidade e da manutenção da precisão no movimento analisado.

Em resumo, a manipulação da distância manopla-disco (experimento I) demonstrou utilizar estratégia de sincronizar os maiores valores de velocidade com o instante de contato manopla-disco, mesmo com a maior aceleração nas condições com menores distâncias que aparentemente foram compensadas pela menor restrição imposta pelo tamanho do alvo virtual (ângulo de aproximação: $\beta$ "). O aumento na velocidade de movimento (experimento II) foi compensado pela estratégia de garantir menores acelerações no instante de contato manopla-disco e pela estratégia da manutenção na proporção das fases de aceleração e de desaceleração no movimento. A redução no tamanho do disco (experimento III) levou à menor precisão, pois, mesmo com a manutenção nas proporções das fases de aceleração e de desaceleração no movimento, não houve uma sincronização adequada entre os maiores valores de velocidade e o instante de contato manopladisco. Por outro lado, a redução no tamanho do alvo remoto (experimento IV) não modificou a precisão do movimento, mesmo com a maior na fase de aceleração, pois o sistema utilizou a estratégia de sincronizar o tempo da menor aceleração com o instante determinante do desempenho. A utilização apropriada desta última estratégia de controle, aparentemente, também aconteceu quando a massa da 
manopla foi manipulada (experimento $\mathrm{V}$ ), proporcionando precisão de movimento juntamente com o aproveitamento da maior estabilidade resultante do acréscimo na massa da manopla. Todavia, o acréscimo na massa do disco (experimento VI) fez com que o sistema priorizasse a preparação para o contato iminente (manopla-disco) ao invés da manutenção na precisão do movimento. Ademais, quando a massa do disco diminuiu, houve maior fase de desaceleração, mas sem aumento ou manutenção na precisão do movimento. Estes resultados em conjunto sugerem que o controle na geração de velocidade e na manutenção da precisão pareceu estar mais relacionado à estratégia de controle da sincronização dos maiores valores de velocidade com o instante determinante do desempenho (contato manopla-disco). No entanto, não foi desconsiderada a possibilidade do sistema utilizar as estratégias da manutenção entre as fases de aceleração e de desaceleração, e da maior estabilidade de movimento proporcionada com o aumento na massa da manopla e com a diminuição na massa do disco. Assim, o sistema apresentou características flexíveis e dinâmicas, no qual uma ou mais estratégias de movimento foram utilizadas para atender às restrições específicas da tarefa ou da condição.

10.2 Análises de regressão linear: relação velocidade-precisão

No que diz respeito à quantificação da restrição imposta no movimento e de sua capacidade de predição das variáveis temporais no movimento, tem sido proposto o cálculo de um índice de dificuldade. Este índice de dificuldade tem sido utilizado para predizer o tempo de movimento, possuindo suporte em diversas tarefas e condições experimentais (cf. Elliott et al., 2004; Plamondon \& Alimi, 1997; Soukoreff \& Mackenzie, 2004). Por esta razão, dois índices de dificuldade (ID' e ID") foram propostos para determinar a quantidade de restrição imposta na tarefa e para tentar predizer as variáveis temporais do movimento ( $T M, T_{c}$ e $T_{a}$ ) quando foram manipulados a distância manopla-disco e os tamanhos do disco e do alvo remoto. $O$ ID' considerou o ângulo da margem de acerto, enquanto que o ID" utilizou o tamanho do alvo virtual (T) e a distância manopla-disco, ambos para determinar o índice de dificuldade da tarefa experimental analisada nos experimentos. Estes índices de dificuldade apresentaram coeficientes variando de ID' $=6,27$ e de ID" $=6,96$ até ID' = 
6,95 e ID" = 7,79 quando foi manipulada a distância manopla-disco; de ID' = 6,95 e de ID" = 7,79 até ID' = 8,10 e ID" = 8,94 quando foi manipulado o tamanho do disco; e, de ID' = 6,95 e de ID" = 7,79 até ID' = 9,27 e ID" = 10,12 quando foi manipulado o tamanho do alvo remoto. De forma geral, o aumento no índice de dificuldade demonstrou uma associação direta com o tempo de movimento (TM) e o tempo para o contato $\left(T_{c}\right)$, e uma relação inversa com o tempo após o contato $\left(T_{\mathrm{a}}\right)$. No entanto, apenas foram significantes as associações entre os índices de dificuldade e as variáveis temporais analisadas no experimento em que foram manipuladas as distâncias manopla-disco. Estes resultados estão de acordo com a explicação fornecida para os experimentos III e IV, na qual apenas a região central do disco atuou como fonte determinante na restrição do movimento, em função das duas fontes de restrição espacial (disco e o alvo remoto) e da estratégia de controle utilizada para atender o objetivo da tarefa (direcionar o disco para a região central do alvo remoto). Desta forma, a predição do desempenho, através de indicadores da restrição imposta pela tarefa (IDs), não foi robusta o suficiente para contemplar a tarefa motora proposta. Outros fatores também podem ter atuado como fonte de restrição no movimento, não permitindo a predição do desempenho apenas pelos IDs, tais como as estratégias de controle para a geração de velocidade e a manutenção da precisão, as forças de inércia e as forças de impacto. Foi sugerido que, em tarefas motoras complexas, a predição do desempenho estaria mais associada às estratégias de controle adotadas para a geração de velocidade e a manutenção da precisão do que às restrições espaciais quantificadas por meio dos IDs.

A relação velocidade-precisão também tem sido analisada a partir da manipulação da velocidade, ou do tempo de movimento, em função da quantificação da variabilidade da resposta através do erro espacial (Plata et al., 1985; Schmidt et al., 1978, 1979; Write \& Meyer, 1983; Zelaznik, 1993). Esta análise tem demonstrado uma relação linear entre a velocidade média do movimento e a variabilidade dos pontos finais do erro, quando o movimento é desempenhado em velocidades máximas. Contudo, no presente estudo (experimento II), a precisão (média do erro angular absoluto) e a variabilidade (desvio padrão do erro angular absoluto) também foram preditos por alguns parâmetros da velocidade no movimento desempenhada 
em níveis submáximos. Por exemplo, a velocidade média (eixo x e y), o maior valor de velocidade (eixo $\mathrm{x}$ e $\mathrm{y}$ ) e a velocidade no instante de contato (eixo $\mathrm{x}$ ), demonstraram uma relação inversa com a precisão e uma relação direta com a variabilidade. Todavia, não foi verificada associação significante da precisão com a velocidade média (eixo x e y), e com a velocidade no contato manopla-disco (eixo x e y), além da variabilidade com a velocidade no contato manopla-disco (eixo y). Estes resultados sugerem que, na tarefa analisada, a predição da precisão e da variabilidade de reposta pode ser realizada através de alguns parâmetros da velocidade do movimento, quando a mesma estratégia de controle for adotada para a regulação da velocidade e a manutenção da precisão no movimento.

\subsection{Desempenho das articulações no movimento}

A análise das ações angulares das articulações (ombro, cotovelo e punho) também auxiliou no entendimento das estratégias de controle utilizadas para a regulação na relação inversa entre a geração de velocidade e a manutenção na precisão do movimento. Pois, o comportamento linear da manopla foi resultado das ações angulares que demonstraram aspectos particulares do movimento que não puderam ser observados de forma global apenas com a análise do movimento da manopla. Apesar desta análise não ser normalmente verificada em estudos que investigaram o paradigma da relação inversa velocidade-precisão, o presente estudo explorou a análise das ações individuais das articulações em função das variáveis manipuladas em cada experimento. Cada experimento demonstrou modificações ímpares em função da restrição imposta sobre o sistema e da estratégia de controle adotada para a regulação na geração de velocidade e na manutenção na precisão.

O aumento na distância, no experimento I, levou a um maior ângulo das articulações no instante de contato manopla-disco (ombro, cotovelo e punho). Maior amplitude também foi verificada no cotovelo com o acréscimo na distância de movimento. Maior velocidade no instante de contato, maiores magnitude e fase de aceleração, também foram verificadas no ombro e no cotovelo com o aumento na distância manopla-disco. Porém, o acréscimo na distância levou a redução na velocidade do punho e na aceleração do cotovelo, no instante de contato. $\mathrm{O}$ aumento 
na distância também atrasou os tempos da maior velocidade nas articulações (ombro, cotovelo e punho). Também houve um atraso no tempo da maior aceleração no ombro e no cotovelo. No experimento II, o acréscimo na velocidade de movimento foi realizado através de maiores ângulo no instante de contato, magnitude de velocidade e aceleração (magnitude e no instante de contato) das articulações (ombro, cotovelo e punho). $\mathrm{O}$ aumento na velocidade de movimento também levou à maior velocidade e amplitude angular no ombro e no cotovelo. Contudo, a regulação no tempo dos maiores valores de velocidade e de aceleração permitiu a diminuição da magnitude destas variáveis no instante de contato manopla-disco. A fase de aceleração do movimento foi aumentada no ombro enquanto no punho foi verificado um aumento da fase de desaceleração, em função do acréscimo na velocidade de movimento. A redução no tamanho do disco, no experimento III, levou a menores ângulos no instante de contato manopla-disco (ombro e cotovelo), além de maior magnitude de aceleração no instante de contato no cotovelo. Todavia, não houve efeito do tamanho do disco sobre as variáveis temporais angulares das articulações. No experimento IV, a redução no tamanho do alvo remoto não demonstrou modificar a maioria das variáveis cinemáticas angulares analisadas. Apenas foi verificada maiores amplitude angular e aceleração no punho, com a redução do tamanho do alvo remoto. $\mathrm{O}$ aumento na massa da manopla, no experimento $\mathrm{V}$, aumentou $\mathrm{O}$ ângulo do cotovelo no instante de contato manopla-disco, e reduziu a maior velocidade (cotovelo e punho), a velocidade no instante de contato manopla-disco (cotovelo), a maior aceleração (cotovelo e punho), e a aceleração no contato (ombro e cotovelo). No experimento $\mathrm{VI}$, o acréscimo no peso do disco reduziu a velocidade e a aceleração no cotovelo, diminuiu a velocidade do cotovelo e do ombro no instante de contato manopla-disco, e aumentou a magnitude da desaceleração no instante de contato manopla-disco.

Em se tratando da participação das articulações na regulação do movimento, foi proposto (experimento I) que as articulações teriam papeis específicos no controle do movimento, no que diz respeito à regulação velocidadeprecisão. $\mathrm{Na}$ qual, ombro e cotovelo estariam mais associados com a geração de velocidade enquanto o punho estaria mais associado com os ajustes da precisão. Contudo, sem desconsiderar a participação do ombro e do cotovelo no auxílio da 
regulação da precisão e do punho na geração de velocidade, mas com uma contribuição reduzida. Esta proposição foi realizada com base na fase de aceleração verificada no ombro e no cotovelo (aproximadamente $60 \%$ do tempo de movimento) e na maior fase de desaceleração no punho (superior a $60 \%$ do tempo de movimento). Esta estrutura temporal das fases de aceleração e de desaceleração das articulações foi verificada, posteriormente, nos seis experimentos analisados. Desta forma, quando fosse aumentada a velocidade (experimento II) deveriam ser verificadas maiores fases de aceleração no ombro e no cotovelo com redução na fase de desaceleração do punho, enquanto o aumento na demanda da precisão (experimento III e IV) levaria a maior fase de desaceleração no punho com redução na fase de aceleração do ombro e do cotovelo. Todavia, tais previsões não foram verificadas nos experimentos, sugerindo a regulação conjunta das articulações em função da restrição imposta na tarefa/condição e da estratégia de controle adotada para a regulação velocidade-precisão. Tais resultados sugeriram que as articulações desempenharam o movimento através de uma única sinergia direcionada a responder aos objetivos e às restrições da tarefa, assim como às estratégias de controle adotadas. Desta forma, o movimento teria sido regulado de forma integral, não fracionando as ações especificamente para cada articulação. Tal estratégia permite vantagens em termos de redução na demanda de controle do movimento, pois uma quantidade reduzida de parâmetros de controle pode ser especificada para a ação, e possibilita maior flexibilidade para o sistema distribuir e corrigir a variabilidade (ou o erro) no movimento ao longo de toda a sinergia (cadeia cinemática). Conseqüentemente, diferentes combinações articulares podem garantir a mesma precisão de resposta e de desempenho (Doorenbosch et al., 1997; Helsen et al., 2000; Stelmach \& Diggles, 1982). 
Os modelos de controle motor que tentaram explicar a regulação inversa entre a velocidade e a precisão não demonstraram ser apropriados para explicar o comportamento da tarefa motora complexa utilizada no presente estudo. As diferentes restrições manipuladas nos experimentos demonstrou que o sistema foi capaz de utilizar mais de uma estratégia de regulação da velocidade-precisão. As seguintes estratégias de controle motor foram sugeridas para explicar os resultados nos experimentos: (a) sincronização entre o maior valor de velocidade com o instante determinante no desempenho (experimento I-VI), (b) manutenção da proporção entre as fases de aceleração e de desaceleração no movimento (experimento II, V), (c) aumento da inércia na estabilização do movimento (experimento $V$ ), (d) diminuição das forças de impacto para aumentar a estabilidade do movimento (experimento VI) e (e) o controle da geração de velocidade e da manutenção da precisão em dimensões independentes (sugerido no experimento I, mas refutado no experimento II).

Em tarefas motoras complexas, a predição do desempenho ( $T M, T_{c}$ e $T_{a}$ ) pareceu estar mais associada às estratégias de controle utilizadas no movimento do que às restrições espaciais quantificadas por meio dos IDs (distância manopla-disco, tamanho do disco e do alvo). Foi sugerido que o sistema adotou a estratégia de controlar o movimento através de uma sinergia que organizou a ação das articulações de forma a produzir um movimento com grande velocidade e precisão. Assim, as pequenas modificações nos parâmetros de controle de uma dada articulação poderiam ser compensadas pela ação das outras articulações, garantindo a precisão com diferentes combinações de movimento.

Em conjunto, esta série de experimentos demonstrou a característica dinâmica e flexível do sistema, frente às diferentes restrições impostas sobre 0 movimento, para a geração de velocidade e a regulação da precisão. 
11.2 Recomendações

Recomenda-se para futuros estudos a análise do paradigma da relação inversa velocidade-precisão através de mais tarefas motoras complexas, tais como lançamentos, arremessos, rebatidas, chutes, etc. Também, são sugeridos mais estudos que analisem as estratégias de controle propostas nos experimentos realizados no presente estudo para a regulação da relação velocidade-precisão. A análise do desempenho obtida através da ação das articulações que realizam o movimento também devem ser realizadas para melhor entendimento das estratégias de controle motor utilizadas na regulação velocidade-precisão. 


\section{REFERÊNCIAS}

ABEND, W.; BIZZI, E.; MORASSO, P. Human arm trajectory formation. Brain, v.105, p.331-348, 1982.

ACCOT, J. \& ZHAI, S. Refining Fitts' law models for bivariate Pointing. Letters Computer-Human Interaction, v.5, n.1, p.193-200, 2003.

ADAM, J.J. the effects of objectives and constraints on motor control strategy in reciprocal aiming movements. Journal of Motor Behavior, v.24, n.2, p.173-185, 1992.

ADAM, J.J.; LOON, E.M.; PAAS, F.G.W.C.; DROST, M.R.; DOGEN, M.M.J.; KODDE, R. Impact forces of one- and two-element target-aiming responses. Human Movement Science, v.16, p.369-377, 1997.

ADAM, J.J.; PASS, F.G.W.C.; WYSSEN, C.J.M.; SLINGERLAND, H.; BEKKERING, $\mathrm{H}$.; DROST, M. The control of two-element, reciprocal aiming movements: Evidence for chunking. Human Movement Science, v.14, p.1-11, 1995.

ALIMI, M.A.; PLAMONDON, R. Performance analysis of handwritten stroke generation models. Proceedings of the $3^{\text {rd }}$ International Workshop on Frontiers in Handwriting Recognition. Buffalo - NY: 1993a.

ALIMI, M.A.; PLAMONDON, R. Parameter analysis of handwriting stroke generation models. Proceedings of the $6^{\text {th }}$ International Conference on Handwriting Drawing Paris. France: 1993b.

ALIMI, M.A.; PLAMONDON, R. Analysis of the parameter dependence of handwriting generation models on movement characteristics. In: FAURE, C.; KEUSS, P.; LORETTE, G.; VINTER, A. (Ed.). Advances in handwriting and writing. Europa: 1994.

ANDERSON, D.I.; SIDAWAY, B. Coordination Changes Associated With Practice of a Soccer Kick. Research Quarterly for Exercise and Sport, v.65, n.2, p.93-99, 1994.

ANDRES, R.O.; HARTUNG, K.J. Prediction of head movement time using Fitts' law. Human Factors, v.31, n.6, p.703-713, 1989.

ANNETT, J.; GOLBY, C.W.; KAY, H. The measurement of elements in a assembly task: The information output of the human motor system. Quarterly Journal of Experimental Psychology, v.10, p.1-11, 1958. 
ARNAULT, L.Y. GREENSTEIN, J.S. An evaluation of display/control gain. Proceedings of the Human Factors Society - 31st Annual Meeting, p.437-441, 1987.

ATKESIN, C.G.; HOLLERBACK, J.M. Kinematic features of unrestrained vertical arm movements. Neuroscience, v.5, p.2318-2330, 1985.

BEGGS, W.D.A.; HOWARTH, C.I. Movement control in a repetitive motor task. Nature, v.225, p.752-753, 1970.

BEGGS, W.D.A.; HOWARTH, C.I. The accuracy of aiming at a target: Some further evidence for a theory of intermittent control. Acta Psychologica, v.36, p.171-177, 1972a.

BEGGS, W.D.A.; HOWARTH, C.I. The movement of the hand towards a target. The Quarterly Journal of Experimental Psychology, v.24, p.448-453, 1972b.

BIEGSTRAATEN, M.; SMEETS, J.B.J.; BRENNER, E. Impact Forces Cannot Explain the One-Target Advantage in Rapid Aimed Hand Movements. Human Movement Science, v.22, p.365-376, 2003.

BOOTSMA, R.J.; MOTTET, D. Dynamic of trajectory formation and speed/accuracy trade-offs. In: PLAMONDON, R.; ALIMI, A.M. Speed/Accuracy trade-offs in targetdirected movements. Behavioral and Brain Sciences, v.20, p.279-349, 1997.

BOOTSMA, R.J.; BOULARD, M.; FERNANDEZ, L.; MOTTET, D. Informational constraints in human precision aiming. Neuroscience Letters, v.333, p.141-145, 2002.

BOOTSMA, R.J.; FERNANDEZ, L.; MOTTET, D. Behind Fitts' Law: kinematic patterns in goal-directed movements. International Journal of Human-Computer Studies, v.61, p.811-821, 2004.

BORITZ, J.; BOOTH, K.S.; COWAN, W.B. Fitts' law studies of directional mouse movement. Proceedings of Graphics Interface '91. Toronto: Canadian Information Processing Society, pp. 216-223, 1991.

BRAVO, P.E.; LEGARE, M.; COOK, A.M.; HUSSEY, S.M. Application of Fitts' law to arm movements aimed at targets in people with cerebral palsy. In: PRESPERIN, J.J. (Ed.). Proceedings of the 13th Annual Conference on Rehabilitation Engineering Society of North America. Washington - DC, p. 213-214, 1990. 
BRINDLE, T.J.; UHL, T.; NITZ, A.J.; SHAPIRO, R. The influence of external loads on movement Precision during active shoulder internal rotation movements as measured by 3 indices of accuracy. Journal of Athletic Training, v.41, n.1, p.6066, 2006.

BROGMUS, G.E. Effects of age and sex on speed and accuracy of hand movement and the refinements they suggests for Fitts' law. Proceedings of the Human Factors Society - 35 ${ }^{\text {th }}$ Meeting, p.208-212, 1991.

BROOKS, V.B. Motor program revisited. In: TALBOTT, R.E. \& HUMPHREY, D.R. (Ed.). Posture and movement, Raven - NY, p.13-49, 1979.

BROWN, S.H.C.; COOK, J.D. Amplitude- and instruction-dependent modulation of movement-related electromyogram activity in humans. Journal of Physiology, v.316, p.97-107, 1981.

BUCK, L. Target location effects in tapping tasks. Acta Psychologica, v.62, p.1-13, 1986.

BURKE, R.E.; EDGERTON, V.R. Motor unit properties and selective involvement in movement. Exercise and Sports Sciences Review, v.3, p.31-69, 1975.

CALJOUW, S.R.; VAN DER KAMP, J.; SAVELSBERGH, G.J.P. Bi-phasic hitting with constraints on impact velocity and temporal precision. Human Movement Science, v.24, p.206-217, 2005.

CANNON, D.J.; LEIFER, L.J. Speed and accuracy for a telerobotic human/machine system: Experiments with a target-threshold control theory model for Fitts' law. IEEE Int. Conf. Systems, Man, and Cybernetics. Los Angeles - CA, p.677-679, 1990.

CARD, S.K.; ENGLISH, W.K.; BURR, B.J. Evaluation of mouse, rate-controlled isometric joystick, step keys, and text keys for text selection on a CRT. Ergonomics, v.21, p.601-613, 1978.

CARLTON, L.G. Control processes in the production of discrete aiming responses. Journal of Human Movement Studies, v.5, p.115-124, 1979.

CARLTON, L.G. Movement control characteristics of aiming responses. Ergonomics, v.23, p.1019-1032, 1980. 
CARLTON, L.G. Processing visual feedback information for movement control. Journal of Experimental Psychology: Human Perception and Performance, v.7, p.1019-1030, 1981a.

CARLTON, L.G. Visual information: The control of aiming movements. Quarterly Journal of Experimental Psychology, n.33A, p.87-93, 1981b.

CARLTON, L.G.; LIU, Y.T. Speed/accuracy relations: the kinetic-kinematic link and predictions for rapid timing tasks. In: PLAMONDON, R. \& ALIMI, A.M. Speed/Accuracy trade-offs in target-directed movements. Behavioral and Brain Sciences, v.20, p.279-349, 1997.

CARLTON, L. G.; NEWELL, K.M. Force variability and characteristics of force production. In: Newell, K.M. \& Corcos D.M. Variability and Motor Control. Chicago-llinois: Human Kinetics Publishers, 1993.

CHOW, J.; CARLTON, L.; LIM, Y.T.; CHAE, W.S.; SHIM, J.H.; KUENSTER, A.; KOKUBUN, K. Comparing the pre- and post-impact ball and racquet kinematics of elite tennis players' first and second serves: a preliminary study. Journal of Sports Sciences,v.21, n.7, p.529-537, 2003.

CHOWDHARY, A.G. \& CHALLIS, J.H. The biomechanics of an overarm throwing task: a simulation model examination of optimal timing of muscle actions. Journal of Theoretical Biology, v.211, p.39-53, 2001.

CHUA, R. \& ELLIOTT, D. Visual regulation of manual aiming. Human Movement Science, v.12, p.365-401, 1993.

CORCOS, D.M.; AGARWAL, G.C.; FLAHERTY, B.P.; GOTTLIEB, G.L. Organizing principles for single joint movements: 4. Implications for isometric contraction. Journal of Neurophysiology, v.64, p.1033-1042, 1990.

CORCOS, D.M.; GOTTLIEB, G.L.; AGARWAL, G.C. Accuracy constraints upon rapid elbow movements. Journal of Motor Behavior, v.20, p.255-272, 1988.

CROSSMAN, E.R.F.W. The speed and accuracy of simple hand movements. In: CROSSMAN, E.R.F.W.; SEYMOUR, W.D. (Ed). The Nature and Acquisition of Industrial Skills. Report to M.R.C. and D.S.I.R. Joint Committee on Individual Efficiency in Industry, 1957. 
CROSSMAN, E.R.F.W. The information-capacity of the human motor-system in pursuit tracking. Quarterly Journal of Experimental Psychology. v.12, p.1-16, 1960.

CROSSMAN, E.R.F.W. \& GOODEVE, J. Feedback control of hand-movement and Fitts' Law. Quarterly Journal of Experimental Psychology, v.35A, p.251-278, $1963 / 1983$.

DE JONG, W.P.; VAN GALEN, G.P. Are speed/accuracy trade-offs caused by neuromotor noise, or not? In: PLAMONDON, R.; ALIMI, A.M. Speed/Accuracy trade-offs in target-directed movements. Behavioral and Brain Sciences, v.20, p.279-349, 1997.

DESMURGET, M.; PRABLANC, C.; ROSSETTI, Y. Kinematic theory: From numerical fitting to data interpretation. In: PLAMONDON, R.; ALIMI, A.M. Speed/Accuracy trade-offs in target-directed movements. Behavioral and Brain Sciences, v.20, p.279-349, 1997.

DOORENBOSCH, C.A.M.; WELTER, T.G.; VAN INGEN SCHENAU, G.J. Intermuscular co-ordination during fast contact control leg task in man. Brain Research, v.751, p.239-246, 1997.

DRAPER, J.V.; HANDEL. S.; HOOD, C.C. Fitts' task by teleoperator: Movement time, velocity, and acceleration. Proceedings $34^{\text {th }}$ Annual Meeting of the Human Factos Society, Orlando - FL, 1990.

DRASCIC, D.; MILGRAM, P.; GRODSKI, J. Learning effects in telemanipulation with monoscopic versus stereoscopic remote viewing. Institute of Electrical and Electronics Engineers International Conference on Systems, Man, and Cybernetics, Cambridge-MA, 1989.

DRURY, C.G. Application of Fitts' law to foot-pedal design. Human Factors, v.17, n.4, p. 368-373, 1975.

DRURY, C.G.; HOFFMANN, E.R. A model for movement time on data-entry keyboards. Ergonomics, v.35, n.2, p.129-147, 1992.

ELLIOTT, D.; HELSEN, W.F.; CHUA, R. A Century Later: Woodworth's (1899) TwoComponent Model of Goal Directed Aiming. Psychological Bulletin, v.127, n.3, p.342-357, 2001. 
ELLIOTT, B.; MARSH, T.; OVERHEU, P.A biomechanical comparison of the multisegment and single unit topspin forehand drives in tennis. International Journal of Sport Biomechanics, v.5, p.350-364, 1989.

ELLIOTT, D.; TREMBLAY, L.; HANSEN, S.; MENDOZA, J. Learning to optimize speed, accuracy, and energy expenditure: a framework for understanding speedaccuracy relations in goal-directed aiming. Journal of Motor Behavior, v.36, n.3, p. 339-351, 2004.

EPPS, B.W. Comparison of six cursor control devices based on Fitts' law models. Proceedings of the Human Factors Society 30th Annual Meeting. Santa Monica CA: Human Factors Society, p.327-331, 1986.

FENN, W.O.; MARSH, B.O. Muscular force at different speeds of shortening. Journal of Physiology, v.85, p.277-297, 1935.

FERRELL, W.R. Remote manipulation with transmission delay. Institute of Electrical and Electronics Engineers Transactions on Human Factors in Electronics, p.2432, 1965.

FITTS, P. The information capacity of the human motor system in controlling the amplitude of movement. Journal of Experimental Psychology, v.47, n.6, p.381391, 1954.

FITTS, P.; PETERSON, J.R. Information capacity of discrete motor responses. Journal of Experimental Psychology, v.67, p.103-112, 1964.

FLOWERS, K.A. Handedness and controlled movements. British Journal of Psychology, v.66, n.1, p.39-52, 1975.

FLOWERS, K.A. Visual closeloop and openloop characteristics of voluntary movement in patients with Parkinsonism and intention tremor. Brain, v.99, p.269310, 1976.

FOWLER,B.; WHITE, P.L.; HOLNESS, D.E.; WRIGHT, G.R.; ACKLES, K.N. The effects of inert gas narcosis on the speed and accuracy of movement. Ergonomics, v.25, n.3, p.303-312, 1982.

GAN, K.C.; HOFFMANN, E.R. Geometrical conditions for ballistic and visually controlled movements. Ergonomics, v.31, n.5, p.829-839, 1988. 
GIAKAS, G.; BALTZOPOULOS, V. A Comparison of automatic filtering techniques applied to biomechanical walking data. Journal of Biomechanics, v.30, n.8, p.851855, 1997a.

GIAKAS, G.; BALTZOPOULOS, V. Optimal digital filtering requires a different cut-off frequency strategy for the determination of the higher derivatives. Journal of Biomechanics, v.30, n.8, p. 851-855, 1997b.

GIELEN, C.C.A.M.; OOSTEN, K.; VAN PULL TER GUNNE, F. Relation between EMG activation patterns and kinematic properties of aimed arm movements. Journal of Motor Behavior, v.17, p.421-442, 1985.

GILLAN, D.J.; HOLDEN, K.; ADAM, S.; RUDISILL, M.; MAGEE, L. How does Fitts' law fit pointing and dragging? Proceedings of Computer and Human Interactions, v.90, p.227-234, 1990.

GLENCROSS, D.J.; BARRETT, N. Discrete movements. In: HOLDING, D.H. (Ed.), Human skills: Studies in human performance, $2^{\mathrm{a}}$ ed., New York - NY: Wiley, p.334, 1989.

GOGGIN, N.L.; MEEUWSEN, H.J. Age Related Differences in the Control of Spatial Aiming Movements. Research Quarterly for Exercise and Sport, v.63, n.4, p.366$372,1992$.

GOLDMAN, S. Information theory. New York - NY: Prentice-Hall, 1953.

GOODMAN, S.R. Accuracy and variability of the movement in Fitts' and Schmidt's laws. In: PLAMONDON, R.; ALIMI, A.M. Speed/Accuracy trade-offs in targetdirected movements. Behavioral and Brain Sciences, v.20, p.279-349, 1997.

GOTTLIEB, G.L. Influence of strategy on muscle activity during impact movements. Journal of Motor Behavior, v.33, n.3, p. 235-242, 2001.

GOTTLIEB, G.L.; CORCOS, D.M.; AGARWAL, G.C. Strategies for the control of voluntary movements with one mechanical degree of freedom. Behavioral and Brain Sciences, v.12, p.421-442, 1985.

GROSSBERG, S. Neural models of reaching. In: PLAMONDON, R. \& ALIMI, A.M. Speed/Accuracy trade-offs in target-directed movements. Behavioral and Brain Sciences, v.20, p.279-349, 1997.

GUIARD, Y. Fitts' law in the discrete vs. cyclical paradigm. Human Movement Studies, v.16, p.97-131, 1997. 
HANCOCK, P.A.; VERWEY, W.B. Where in the world is the speed/accuracy tradeoff? In: PLAMONDON, R.; ALIMI, A.M. Speed/Accuracy trade-offs in targetdirected movements. Behavioral and Brain Sciences, v.20, p.279-349, 1997.

HANCOCK, W.M.; LANGOLF, G.; CLARK, D.O. Development of standard data for stereoscopic microscope work. AllE Transactions, v.5, n.2, p.113-118, 1973.

HARTZELL, E.J.; DUNBAR, S.; BEVERIDGE, R.; CORTILLA, R. Helicopter pilot response latency as a function of the spatial arrangement of instruments and controls. Proceedings of the $18^{\text {th }}$ Annual Conference of Manual Control. Dayton$\mathrm{OH}$, p.345-364, 1982.

HELSEN, W.F.; ELLIOTT, D.; STARKES, J.L.; RICKER, K.L. Coupling of eye, finger, elbow, and shoulder movements during manual aiming. Journal of Motor Behavior, v.32, n.3, 2000.

HERRMANN, U.; SOECHTING, J. Neuronal and muscular correlates consistent with Plamondon's theory: Velocity coding and temporal activation patterns. In: PLAMONDON, R.; ALIMI, A.M. Speed/Accuracy trade-offs in target-directed movements. Behavioral and Brain Sciences, v.20, p.279-349, 1997.

HEUER, H. What is Fitts' law about? In: PLAMONDON, R. \& ALIMI, A.M. Speed/Accuracy trade-offs in target-directed movements. Behavioral and Brain Sciences, v.20, p.279-349, 1997.

HILL, A.V. The heat of shortening and the dynamic constants of muscle. Proceedings of the Royal Society of London, v.126, 136-195, 1938.

HOFFMAN, E.R. Capture of moving targets: A modification of Fitts' Law. Ergonomics, v.34, n.2, p.211-212, 1991a.

HOFFMAN, E.R. A comparison of hand and foot movement times. Ergonomics. v.34, n.4, 397-406, 1991b.

HOFFMAN, E.R. Fitts' law with transmission delay. Ergonomics, v.35, n.1, p. 37-48, 1992.

HOFFMAN, E.R. \& SHEIKH, I.H. Finger width corrections in Fitts' law: implications for speed-accuracy research. Journal of Motor Behavior, v.23, n.4, p. 259-262, 1991. HOLLY, J.E. Individual data and clear assumptions about movement. In: PLAMONDON, R.; ALIMI, A.M. Speed/Accuracy trade-offs in target-directed movements. Behavioral and Brain Sciences, v.20, p.279-349, 1997. 
HOWARTH, C.I.; BEGGS, W.D.A.; BOWDEN, J.M. The relationship between speed and accuracy of movement aimed at a target. Acta Psychologica, v.35, p.207218, 1971.

JAFARI, M.; KONDRASKE, G.V. An acoustic investigation of the interactive dynamics of speech motor performance. Institute of Electrical and Electronics Engineers Engineering in Medicine and Biology Society $10^{\text {th }}$ Annual Conference. New Orleans - LA, v.4, p.1529-1530, 1988.

JAGACINSKI, R.J.; MOK, D.L. Fitts' law in two dimensions with hand and head movements. Journal of Motor Behavior, v.17, n.1, p. 77-95, 1985.

JAGACINSKI, R.J.; REPPERGER, D.W.; MORAN, M.S.; WARD, S.L.; GLASS, B. Fitts' law and the microstructure of rapid discrete movements. Journal of Experimental Psychology: Human Perception and Performance, v.6, n.2, p.309320, 1980a.

JAGACINSKI, R.J.; REPPERGER, D.W.; WARD, S.L.; MORAN, M.S. A test of Fitts' law with moving target. Human Factors, v.22, n.2, p.225-233, 1980b.

JAX, S.A.; ROSENBAUM, D.A.; VAUGHAN, J. Extending Fitts' law to manual obstacle avoidance. Experimental Brain Research, v.180, p.775-779, 2007.

JEANNEROD, M. The timing of natural prehension movements. Journal of Motor Behavior, v.16, p.235-254, 1984.

JONES, T. An empirical study of children's use of computer pointing devices. Journal of Educational Computing Research, v.7, n.1, p.61-176, 1991.

JOHNSGARD, T. Fitts' law with a virtual reality glove and a mouse: Effects of gain. Proceedings of the Graphics Interface Conference. Banff - Alberta - Canadá, p.8-15, 1994.

KANTOWITZ, B.H.; ELVERS, G.C. Fitts' law an isometric controller: Effects of order of control and control-display gain. Journal of Motor Behavior, v.20, n.1, p.53-66, 1988.

KEELE, S.W. Movement control in skilled motor performance. Psychological Bulletin, v.70, n.6, 1968.

KEELE, S.W. Attention and human performance. Pacific Palisades - CA: Goodyear Publishing, 1973. 
KEELE, S.W.; POSNER, M. Processing of Visual Feedback in Rapid Movements. Journal of Experimental Psychology, v.88, n.1, 1968.

KERR, R. Movement time in an underwater environment. Journal of Motor Behavior, v.5, n.3, p.175-178, 1973.

KERR, R. Diving, adaptation, and Fitts' law. Journal of Motor Behavior, v.10, n.4, p.255-260, 1078.

KERR, B.A.; LANGOLF, G.D. Speed of aiming movements. Quarterly Journal of Experimental Psychology, v.29, p.475-81, 1977.

KHAN, M.A.; GARRY, M.I.; FRANKS, I.M. The effect of target size and inertial load on the control of rapid aiming movements. Experimental Brain Research, v.124, p.151-159, 1999.

KLAPP, S.T. Feedback versus motor programming in the control of aimed movements. Journal of Experimental Psychology: Human Perception and Performance, v.104, p.147-153, 1975.

KNIGHT, A.A.; DARGNALL, P.R. Precision in movements. Ergonomics, v.10, n.3, p.321-330, 1967.

KVASETH, T.O. A model of linear arm movements with preview constraints. Ergonomics, v.18, n.5, p.529-538, 1975.

KVALSETH, T.O. Effects of marijuana on human reaction time and motor control. Perceptual and Motor Skills, v.45, p.935-939, 1977.

KVASETH, T.O. Quantitative models of motor responses subject to longitudinal, lateral and preview constraints. Human Factors, v.20, n.1, p.35-39, 1978.

KVALSTH, T.O. An alternative to Fitts' law. Bulletin of the Psychonomic Society, v.16, n.5, p.371-373, 1980.

KVALSETH, T.O. An experiment paradigm for analyzing human information processing during motor control tasks. Proceedings of the Human Factors Society - 25 ${ }^{\text {th }}$ Annual Meeting, p.581-585, 1981.

LANGOLF, G.D.; CHAFFIN, D.B.; FOULKE, J.A. An investigation of Fitts' Law using a wide range of movement amplitudes. Journal of Motor Behavior, v.8, p.113-128, 1976.

LANGOLF, G.; HANCOCK, W.M. Human performance times in microscopic work. AIEE Transactions, v.7, n.2, p.110-117, 1975. 
LESTIENNE, F. Effects of inertial load and velocity on the braking process of voluntary limb movements. Experimental Brain Research, v.53, p.407-418, 1979.

MACKENZIE, I.S. A note on the information-theoretic base for Fitts' law. Journal of Motor Behavior, v.21, n.3, p. 323-330, 1989.

MACKENZIE, I.S. Fitts' law as a research and design tool in human-computer Interaction. Human-Computer Interaction, v.7, p.91-139, 1992.

MACKENZIE, C.L.; MARTENIUK, R.G.; DUGAS, C.; LISKE, D.; EICKMEIER, B. Three-dimensional movement trajectories in Fitts' task: Implications for control. Quarterly Journal of Experimental Psychology, v.39A, p.629-647, 1987.

MARTENIUK, R.G.; MACKENZIE, C.L.; JEANNEROD, M.; ATHENES, S.; DUGAS, C. Constraints on human arm movement trajectories. Canadian Journal of Psychology, v.41, n.3, p.365-378, 1987.

MEGAW, E.D. Fitts' tapping revisited. Journal of Human Movement Studies, v.1, p.163-171, 1975.

MEYER, D.E.; SMITH, J.E.K.; WRIGHT, C.E. Models for the Speed and Accuracy of Aimed Movements. Psychological Review, v.89, n.5, 1982.

MEYER, D.E.; ABRAMS, R.A.; KORNBLUM, S.; WRIGHT, C.E.; SMITH, J.E.K. Optimality in human motor performance: Ideal control of rapid aimed movements. Psychological Review, v.95, n.3, p.340-370, 1988.

MILNER, G.A. What is information measurement? American Psychologist, v.8, p.3$11,1953$.

MILNER, T.E. Controlling velocity in rapid movements. Journal of Motor Behavior, v.18, n.2, 1986.

MILNER, T.E.; IJAZ, M.M. The effect of accuracy constraints on three-dimensional movement kinematics. Neuroscience, v.35, n.2, p.365-374, 1990.

MORASSO, P. Spatial control of arm movements. Experimental Brain Research, v.42, p.223-227, 1981.

MURATA, A.; IWASE, H. Extending Fitts' law to a three-dimensional pointing task. Human Movement Science, v.20, p.791-805, 2001.

MUSTARD, B.E.; LEE, R.G. Relationship between EMG patterns and kinematics properties for flexion movements at the human wrist. Journal of Neuroscience, v.5, p.2732-2743, 1987. 
NAGASAKI, H. Asymmetric velocity and acceleration profiles of human arm movements. Experimental Brain Research, v.74, p.319-326, 1989.

NEWELL, K.M. The speed-accuracy paradox in movement control: Errors of time and space. In: STELMACH G.E.; REQUIN, J. Tutorials in Motor Behavior. NorthHolland Publishing Company, p. 501-509, 1980.

NEWELL, K.M.; CARLTON, L.G.; CARLTON, M.J. The relationship of impulse to response timing error. Journal of Motor Behavior, v.14, n.01, p.24-45, 1982.

NEWMAN, D.J.; BUSSOLARI, S.R. Dual-task performance on an interactive human/computer space shuttle flight experiment. Biomedical Sciences, vol. 26, p.213-225, 1990.

OKAZAKI, V.H.A. O arremesso de jump no basquetebol de adultos e crianças em função do aumento na distância. Dissertação (Mestrado em Biomecânica) Universidade Federal do Paraná, Curitiba-PR, 220 f., 2006.

OKAZAKI, V.H.A.; RODACKI, A.L.F. Changes in basketball shooting coordination in children performing with diferent Balls. Fédération Internationale D'éducation Physique, v.75, n.2, p.368-371, 2005.

OKAZAKI, V.H.A.; OKAZAKI, F.H.A.; KOPP, N. Temporal organization of arm movements in accurate throws. Fédération Internationale D'éducation Physique, v.78, p.625-626, 2008a.

OKAZAKI, V.H.A.; OKAZAKI, F.H.A.; LIMA, E.S.; CAMINHA, L.Q.; TEIXEIRA, L.A. Modelo estocástico de sub-movimentos otimizados em movimentos com restrição espacial simulados em computador. Revista Brasileira de Biomecânica, v.9, n.16, p.18-26, 2008b.

OKAZAKI, V.H.A.; OLIVEIRA, G.O.; FERREIRA JÚNIOR, R.; RODACKI, A.L.F. Coordenação do arremesso de jump no basquetebol de crianças. Fédération Internationale D'éducation Physique, v.76, n.2, p. 523-526, 2006a.

OKAZAKI, V.H.A.; RODACKI, A.L.F.; DEZAN, V.H.; SARRAF, T.A. Coordenação do arremesso de jump no basquetebol de crianças e adultos. Revista Brasileira de Biomecânica, v.7, p.15-22, 2006b.

OKAZAKI, V.H.A.; RODACKI, A.L.F.; OKAZAKI, F.H.A. O efeito do aumento da distância na coordenação do arremesso de jump no basquetebol e a relação velocidade-precisão. Lecturas: Educación Física y Deportes, v.11, n.97, 2006c. 
OKAZAKI, V.H.A.; TEIXEIRA, L.A.; RODACKI, A.L.F. Tipo de filtro e cálculo das derivadas na análise cinemática. In: XII Congresso Brasileiro de Biomecânica, São Pedro-SP, p. 1-4, 2007a.

OKAZAKI, V.H.A.; TEIXEIRA, L.A.; RODACKI, A.L.F. Freqüência de amostragem e filtragem na cinemática. In: XII Congresso Brasileiro de Biomecânica, São PedroSP, p. 1-4, 2007b.

OKAZAKI, V.H.A.; TEIXEIRA, L.A.; RODACKI, A.L.F. Eficácia da análise residual para determinar a intensidade do filtro na cinemática. In: XII Congresso Brasileiro de Biomecânica, São Pedro-SP, p. 1-5, 2007c.

PATTERSON, R.P.; MORENO, M.I. Bicycle pedalling forces as a function of pedalling rate and Power output. Medicine and Science in Sports and Exercise, V.22, p.512-516, 1990.

PEREIRA, C.F.; OKAZAKI, V.H.A. Efeito da aprendizagem no controle de movimentos rápidos e precisos. In: Teixeira, L.A.; LIMA, A.C.; OKAZAKI, V.H.A.; LIMA, E.S. (Ed.) Especialização em Aprendizagem Motora. São Paulo-SP: Departamento de Biodinâmica do Movimento do Corpo Humano da Escola de Educação Física e Esporte da Universidade de São Paulo, vol. 1, p. 130-143, 2008.

PFANN, K.D.; CORCOS, D.M.; MOORE, C.G.; HASAN, Z. Circle-drawing movements at different speeds: role of inertial anisotropy. Journal of Neurophysiology, v.88, p.2399-2407, 2002.

PIERCE, J.R. Symbols, signals, and noise: The nature and process of communication. New York- NY: Harper, p.305, 1961.

PLAMONDON, R. On the origin of asymmetric bell-shape velocity profiles. In: REQUIN, J. \& STELMACH, G.E. (Ed.). Tutorials in Motor Neuroscience. Kluwer, 1991.

PLAMONDON, R. A theory of rapid movements. In: STELMACH, G.E.; REQUIN, J. (Ed.). Tutorials in Motor Behavior. Elsevier, 1992.

PLAMONDON, R. Looking at handwriting generation from a velocity control perspective. Acta Psychologica. v.82, p.89-101, 1993.

PLAMONDON, R. A kinematic theory of rapid human movements: 1. Movement representation and generation. Biological Cybernetics, v.72, p.295-307, 1995a. 
PLAMONDON, R. A kinematic theory of rapid human movements: 2. Movement time and control. Biological Cybernetics, v.72, p.309-320, 1995b.

PLAMONDON, R. \& ALIMI, A.M. Speed/Accuracy trade-offs in target-directed movements. Behavioral and Brain Sciences, v.20, p.279-349, 1997.

PLATA, A.E.; FRANKS, J.S.; ALLARD, R.; THOMAS, E. Speed-accuracy characteristics of saccadic eye movements. Journal of Motor Behavior, v.17, p.411-419, 1985.

POLIT, A.; BIZZI, E. Characteristics of motor programs underlying arm movements in monkeys. Journal of Neurphysiology. v.42, n.1, p.183-194, 1979.

PRABLANC, C.; MARTIN, O. Automatic control during hand reaching at undetected two-dimensional target displacements. Journal of Neurophysiology, v.67, p.455469, 1992.

PUTNAN, C.A. A segment interaction analysis of proximo-to-distal sequential segment motion patterns. Medicine and Science in Sports and Exercise, v.23, n.1, 130-144, 1991.

PUTNAN, C.A. Sequential motions of body segments in striking and throwing skills: descriptions and explanations. Journal of Biomechanics, v.26, p.125-135, 1993.

RADWIN, R.G.; VANDERHEIDEN, G.C.; LIN, M.L. A method for evaluating headcontrolled Computer input devices using Fitts' law. Human Factors, v.32, n.4, p.423-438, 1990.

RAOUF, A.; TSUI, J. A performance time as affected by choice uncertainty and index of difficulty. Proceedings of the Human Factors Society $22^{\text {nd }}$ Annual Meeting. Detroit - MI, 1978.

REPPERGER D.W.; REMIS S.J. Use of a multi-axis Fitts' law paradigm to characterize total body motion - A study in teleoperation. IEEE Int. Conf. Systems Engineering Pittsburg, Pennsylvania, pp.105-108, 1990.

ROSENBAUM, D.A.; KRIST, H. Antecedents of Action. In: HEUER, H. \& KEELE, S.W. Hand book of perception and action. Volume 2: Motor Skills. San DiegoCalifornia-EUA: Academic Press, 1996.

ROSENBAUM, D.A.; PATASHNIK, O. A mental clock-setting process revealed by reaction times. In: STELMACH, G.E. \& REQUIN, J. (Eds), Tutorials in Motor Behavior. Amsterdam: North-Holland, p.487-499, 1980. 
SALMONI, A.W. A descriptive analysis of children performing Fitts' reciprocal tapping task. Journal of Human Movement Studies. v.9, p.81-95, 1983.

SALMONI, A.W.; MCILWAIN, J.S. Fitts' reciprocal tapping task: a measure of motor capacity? Journal of Human Movement Studies. v.9, p.81-95, 1979.

SHANNON, C.E. A mathematical theory of communication. Bell System Technical Journal. v.27, p.623-656, 1948.

SCHMIDT, R.A. A schema theory of discrete motor skill learning. Psychological Review. v.82, p.225-60, 1975.

SCHMIDT, R.A. On the theoretical status of time in motor program representations. In: STELMACH, G.E.; REQUIN, J. (Eds.), Tutorials in motor behavior. Amsterdam: Elsevier-North Holland, 1980.

SCHMIDT, R.A.; McGOWN, C. Terminal accuracy of unexpectedly loaded rapid movements: Evidence for a mass-spring mechanism in programming. Journal of Motor Behavior, v.12, n.2, p.149-161, 1980.

SCHMIDT, R.A.; SHERWOOD, D.E.; ZELAZNIK, H.N.; LEIKING, B.J. Speedaccuracy trade-offs in motor behavior: Theories of impulse variability. In HEUER, H.; KLEINBEC, V. SCHMIDT, K.H. (Eds.), Motor behavior: Programming, control, and acquisition. Berlin: Springer-Verlag, p. 79-123, 1985.

SCHMIDT, R.A.; ZELAZNIK, H.N.; FRANK, J.S. Sources of inaccuracy in rapid movement. In: G.E. STELMACH (Ed.), Information processing in motor control and learning. New York, Academic Press, p.183-203, 1978.

SCHMIDT, R.A.; ZELAZNIK, H.; HAWKINS, B.; FRANK, J.S.; QUINN, J.T. Motoroutput variability: A theory for the accuracy of rapid motor acts. Psychological Review, v.86, n.5, p.415-451, 1979.

SHANNON, C.E. A mathematical theory of communication. Bell System Technical Journal, v.27, p.623-656, 1948.

SHANNON, C.E. The mathematical theory of communication. Urbana-Illinois: University of Illinois Press, 1949.

SHANNON, C.E.; WEAVER, W. The mathematical theory of communication. UrbanaIllinois: University of Illinois Press, p.148, 1963.

SHERIDAN, M.R. A reappraisal of Fitts' law. Journal of Motor Behavior, v.11, p.179$188,1979$. 
SHERIDAN, T.B.; FERRELL, W.R. Remote manipulative control with transmission delay. Institute of Electrical and Electronics Engineers Transactions on Human Factors in Electronics, p.25-29, 1963.

SHERWOOD, D.E.; SCHMIDT, R.A. The relationship between force and force variability in minimal and near-maximal static and dynamic contractions. Journal of Motor Behavior, v.12, p.75-89, 1980.

SHERWOOD, D.E.; SCHMIDT, R.A.; WALTER, C.B. The force / force - variability relationship under controlled temporal conditions. Journal of Motor Behavior, v.20, n.2, p.106-116, 1988.

SHINHAR D. Human control of robotic movement. IEEE Int. Conf. Systems, Man and Cybernetics, Atlanta-GE, p.76-79, 1986.

SHORT, M.W.; FISCHMAN, M.G.; WANG, Y.T. Cinematographical analysis of movement pathway constraints in rapid target-striking tasks. Journal of Motor Behavior, v.28, n.2, p.157-163, 1996.

SIDAWAY, B. Motor programming as a function of constraints on movement initiation. Journal of Motor Behavior, v.23, n.2, p.120-130, 1991.

SIDAWAY, B.; SEKIYA, H.; FAIRWEATHER, M. Movement variability as a function of accuracy demand in programmed serial aiming responses. Journal of Motor Behavior, v.27, n.1, p.67-76, 1995.

SMEETS, J.B.J.; ERKELENS, C.J.; DENIER VAN DER GON, J.J. Perturbation of fast goal-directed arm movements: different behavior of early and late EMG responses. Journal of Motor Behavior, v.27, n.1, p.77-88, 1995.

SMEETS, J.; FRENS, M.A.; BRENNER, E. Throwing Darths: Timing is not a Limiting Factor. Experimental Brain Research, v.144, p.268-274, 2002.

SMITS-ENGELSMAN, B.C.M.; SUGDEN, D.; DUYSENS, J. Developmental trends in speed accuracy trade-off in 6-10-year-old children performing rapid reciprocal and discrete aiming movements. Human Movement Science, v.25, p.37-49, 2006.

SMITS-ENGELSMAN, B.C.M.; VAN GALEN, G.P.; DUYSENS, J. The Breakdown of Fitts'Law in Rapid, Reciprocal Aiming Movements. Experimental Brain Research, v.145, n.2, p.222-230, 2002.

SOCHTING, J.F.; LAQUANITI, F. Invariant characteristics of a pointing movement in man. Journal of Neuroscience, v.1, n.7, p.710-720, 1981. 
SOUKOREFF, R.W. \& MACKENZIE, I.S. Towards a standard for pointing device evaluation, perspectives on 27 years of Fitts'law research in $\mathrm{HCl}$. International Journal of Human-Computer Studies, v.61, p.751-789, 2004.

SOUTHARD, D. Mass and Velocity: Control Parameters for Throwing Patterns. Research Quarterly for Exercise and Sport, v.69, n.4, p.355-367, 1998.

SPARROW, W.A. \& SPARROW, H.T. Trends in Motor Behavior Research: A Study Based on Citation Analysis. Journal of Human Movement Studies, v.21, p.183199, 1991.

SPITZ, G. Target acquisition performance using a head mounted cursor control device and a stylus with digitizing tablet. Proceedings of the Human Factors Society - 34th Annual Meeting, p.405-409, 1990.

STELMACH, G.E. \& DIGGGLES, V. Control Theories in Motor Behavior. Acta Psychologica, v.50, p.83-105, 1982.

SUGDEN, D.A. Movement speed in children. Journal of Motor Behavior, v.12, p.125132, 1980.

THOMAS, J.R.; NELSON, J.K.; SILVERMAN, S.J. Métodos de pesquisa em atividade física. São-Paulo - SP, Artmed: 2007.

THOMPSON, S.G.; McCONNELL, D.S.; SLOCUM, J.S.; BOHAN, M. Kinematic analysis of multiple constraints on a pointing task. Human Movement Science, v.26, p.11-26, 2007.

TEIXEIRA, L.A. Controle Motor. Barueri-SP: Manole, 375.

TEIXEIRA, L.A. Coordenação intersegmentar em arremessos com diferentes demandas de precisão. Revista Paulista de Educação Física, v.11, n.1, p.5-14, 1997.

TEIXEIRA, L.A. Kinematics of dicking as a function of different sources of constraint on accurancy. Perceptuals and Motor Skills, v.88, p.785-789, 1999.

TEIXEIRA, L.A. Sobre a generalidade de estratégias de controle sensório motor. Revista Paulista de Educação Física, v.3, p.89-96, 2000.

TRESILIAN, J.R.; LONERGAN, A. Intercepting a moving target: effects of temporal precision constraints and movement amplitude. Experimental Brain Research, v.142, p.193-207, 2002. 
UNO, Y.; KAWATO, M.R.; SUZUKI, R. Formation and control of optimal trajectory in human multijoint arm movement. Biological cybernetics, v.61, p.89-101, 1989.

VAN DEN TILLAAR, R.; ETTEMA, G. A comparison between novices and experts of the velocity-accuracy trade-off in overarm throwing. Perceptual and Motor Skills, v.103, p. 503-514, 2006.

VAN DER MEULEN, J.H; GOOSKENS, R.H.; DENIER VAN DER GON, J.J.; GEILEN, C.C.; WILHELM, K. Mechanisms underlying accuracy in fast goal-directed arm movements in man. Journal of Motor Behavior, v.22, n.1, p.67-84, 1990.

VAN GALEN, G.P. \& SCHOMAKER, L.R.B. Fitts' law as a low-pass filter effect of muscle stiffness. Human Movement Science, v. 11, p. 11-21, 1992.

VINCE, M.A. Corrective movements in a pursuit task. Quarterly Journal of Experimental Psychology, v.1, p.85-103, 1948.

WADMAN, W.J.; DENIER VAN DER GON, J.J.; GEUZE, R.H.; MOL, C.R. Control of fast goal-directed arm movements. Journal of Human Movement Studies, v.5, p.3-17, 1979.

WADE, M.G.; NEWELL, K.M.; WALLACE, S.A. Decision time and movement time as a function of response complexity in retarded persons. American Journal of Mental Deficiency, v.83, n.2, p.135-144, 1978.

WALLACE, S.A. An impulse-timing theory for reciprocal control of muscular activity in rapid, discrete movements. Journal of Motor Behavior, v.13, n.3, p.144-160, 1981.

WALLACE, S.A. \& NEWELL, K.M. Visual control of discrete aiming movements. Quarterly Journal of Experimental Psychology, v.35A, p.311-321, 1983.

WALLACE, S.A.; NEWELL, K.M.; WADE, M.G. Decision and response times as a function of movement difficulty in preschool children. Child Development, v.49, p.509-12, 1978.

WARE, C. \& MIKAELIAN, H.H. An evaluation of an eye tracker as a device for computer input. Proc. CHI+Gl'87 Conf. Human Factors in Computing Systems and Graphics Interface, New York-NY, p.183-188, 1987.

WELFORD, A.T. The measurement of sensory-motor performance: Survey and reappraisal of twelve years' progress. Ergonomics, v.3, p.189-230, 1960.

WELFORD, A.T. Fundamentals of skill. Methuen - London, 1968. 
WELFORD, A.T.; NORRIS, A.H.; SHOCK, N.W. Speed and accuracy of movement and their changes with age. Acta Psychologica, v.30, p.3-15, 1969.

WOODWORTH, R.S. The accuracy of voluntary movement. Psychological Review (Monograph Supplement), v.3, p.1-119, 1899.

WRIGHT, C.E.; MEYER, D.E. Conditions for a linear speed-accuracy trade-off in aimed movements. Quarterly Journal of Experimental Psychology, v.35A, p.279296, 1983.

YAO, W.X.; DESOLA, B.; ZUNKER, W. Spatial accuracy demand in aiming movements: Kinematic analysis of subtended angle and tolerance width. Perceptual and Motor Skills, v.104, p.611-620, 2007.

ZHAI, S.; KONG, J.; REN, X. Speed-Accuracy tradeoff in Fitts' law tasks: On the equivalency of actual and nominal pointing precision. International Journal of Human-Computer Studies, v.61, p.823-856, 2004.

ZELAZNIK, H.N. Necessary and sufficient conditions for the production of linear speed-accuracy trade-offs in aimed hand movements. In: NEWELL, K.M. \& CORCOS D.M. Variability and Motor Control. Chicago-llinois: Human Kinetics Publishers, 1993.

ZELAZNIK, H. N.; SHAPIRO, D. C.; MCCOLSKY, D. Effects of a secondary task on the accuracy of single aiming movements. Journal of Experimental Psychology: Human Perception and Performance, v.7, p.1007-1018, 1981.

ZELAZNIK, H.N.; SCHMIDT, R.A.; GIELEN, C.C.A.M. Kinematic properties of aimed hand movements. Journal of Motor Behavior, v.18, p.353-372, 1986. 
ANEXOS 


\title{
TERMO DE CONSENTIMENTO DE PARTICIPAÇÃO
}

\author{
Pesquisadores responsáveis: Luis Augusto Teixeira \\ Victor Hugo Alves Okazaki
}

Este é um convite especial para você participar voluntariamente do estudo "CONTROLE DE MOVIMENTOS RÁPIDOS E PRECISOS DIRECIONADOS A ALVOS DUPLOS". Por favor, leia com atenção as informações abaixo antes de dar seu consentimento para participar ou não do estudo. Qualquer dúvida sobre o estudo ou sobre este documento pergunte diretamente ao pesquisador Victor Hugo Alves Okazaki ou entre em contato através do telefone 92554433.

\section{- OBJETIVO DO ESTUDO}

Este projeto é dedicado ao estudo de ações motoras requisitando simultaneamente grande potência e precisão de movimento no contato com um alvo espacial (primário), que deverá ser projetado com velocidade em direção a um alvo remoto (secundário). O controle motor nessa tarefa será investigado por meio de movimentos planares de extensão do cotovelo do braço preferido sobre uma superfície plana. O estudo será conduzido ao longo de seis experimentos, analisando-se o efeito das seguintes variáveis sobre o desempenho motor: amplitude de movimento, velocidade de movimento, tamanho dos alvos primário e secundário, peso do sistema efetor (força inercial) e peso do alvo primário (impacto). O registro do desempenho será realizado por meio de filmagem. Em conjunto, os resultados desse projeto têm potencial de preencher uma lacuna importante no conhecimento sobre movimentos balísticos que também requerem precisão.

\section{- PROCEDIMENTOS}

Sobre a sua pele, a partir do processo de palpação, serão determinados alguns pontos anatômicos onde serão fixados pequenos marcadores auto-adesivos de $15 \mathrm{~mm}$ de diâmetro para análise do movimento. Você realizará um aquecimento e, posteriormente, será filmado realizando movimentos planares de extensão do cotovelo sobre uma superfície plana nas condições selecionadas pelo pesquisador (a sessão terá aproximadamente 30 minutos de duração).

OBS: Este procedimento não apresenta dor ou risco para sua saúde.

\section{- BENEFÍCIOS}

Os achados preliminares deste projeto possibilitarão analisar a maneira pela qual diferentes fatores associados à ação de contatar um alvo com alta velocidade modulam o seu controle. À medida que este é um tema original de pesquisa, fica aparente que estes resultados possuem grande potencial em contribuir substancialmente com o corpo de conhecimento sobre o controle de ações motoras balísticas.

Caso seja de interesse do participante acompanhar os resultados preliminares desta pesquisa, um relatório com os achados mais importantes poderá ser encaminhado ao participante. Assim, o participante deverá fornecer algum endereço eletrônico (e-mail) para que este relatório possa ser encaminhado. 


\section{- DESPESAS/ RESSARCIMENTO DE DESPESAS DO VOLUNTÁRIO}

Todos os sujeitos envolvidos nesta pesquisa são isentos de custos.

Para sua maior segurança, a USP possui assistência médica vinculada ao HU e HCFMUSP, no caso de eventuais danos a sua saúde decorrente da pesquisa.

- PARTICIPAÇÃO VOLUNTÁRIA

A sua participação neste estudo é voluntária e você terá plena e total liberdade para desistir do estudo a qualquer momento, sem que isso acarrete qualquer prejuízo para você.

\section{- GARANTIA DE SIGILO E PRIVACIDADE}

As informações relacionadas ao estudo são confidenciais e qualquer informação divulgada em relatório ou publicação será feita sob forma codificada, para que a confidencialidade seja mantida. O pesquisador garante que seu nome não será divulgado sob hipótese alguma.

\section{- ESCLARECIMENTO DE DÚVIDAS}

Você pode e deve fazer todas as perguntas que julgar necessárias antes de concordar na sua participação do estudo.

- PESQUISADORES RESPONSÁVEIS

Luis Augusto Teixeira

Victor Hugo Alves Okazaki (telefone para contato: $X X X X X X-X X X X)$ (telefone para contato: $X X X X X X-X X X X)$

Diante do exposto acima eu,

declaro que fui esclarecido sobre os objetivos, procedimentos e benefícios do presente estudo. Participo de livre e espontânea vontade do estudo em questão. Foime assegurado o direito de abandonar o estudo a qualquer momento, se eu assim o desejar. Declaro também não possuir nenhum grau de dependência profissional ou educacional com os pesquisadores envolvidos nesse projeto (ou seja, os pesquisadores desse projeto não podem me prejudicar de modo algum no trabalho ou nos estudos), não me sentindo pressionado de nenhum modo a participar dessa pesquisa.

São Paulo, de de 20

Responsável

$R G$
Pesquisador

$R G$ 
